UNIVERSIDADE DE SÃO PAULO
INSTITUTO DE GEOCIENCIAS

\title{
PALEOAUTOECOLOGIA DOS BIVALVES DO GRUPO PASSA DOIS (NEOPERMIANO), NO ESTADO DE SÃO PAULO: BIVALVES FÓSSEIS COMO INDICADORES DA DINÂMICA SEDIMENTAR
}

RENATO PIRANI GHILARDI

Orientador: Prof. Dr. Marcello Guimarães Simões

DISSERTAÇÃO DE MESTRADO

COMISSÃO JULGADORA

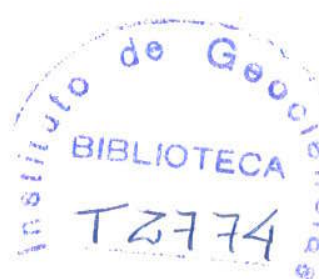

S. P.

Nome

Presidente: Prof. Dr. Marcello Guimarães Simões

Examinadores:

Dr. Fernando Cilento Fittipaldi

Prof. Dr. Setembrino Petri

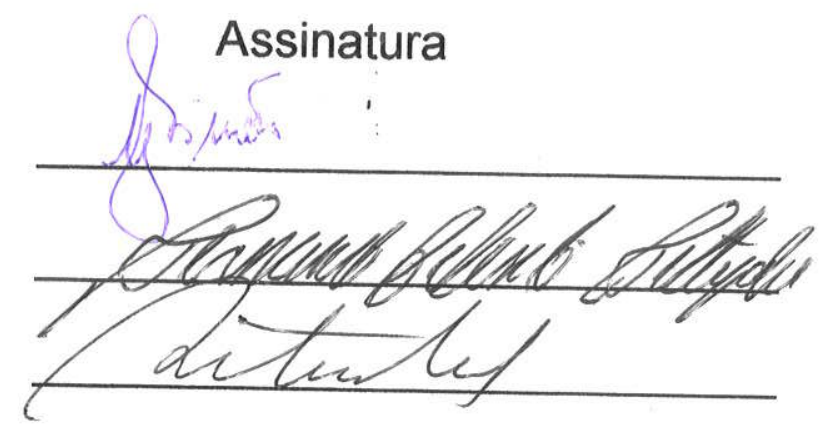




\section{UNIVERSIDADE DE SÃO PAULO INSTITUTO DE GEOCIÊNCIAS}

\section{PALEOAUTOECOLOGIA DOS BIVALVES DO GRUPO PASSA DOIS (NEOPERMIANO), NO ESTADO DE SÃO PAULO: BIVALVES FÓSSEIS COMO INDICADORES DA DINÂMICA SEDIMENTAR}

\section{RENATO PIRANI GHILARDI}

Orientador: Prof. Dr. MARCELLO GUIMARÃES SIMŐES

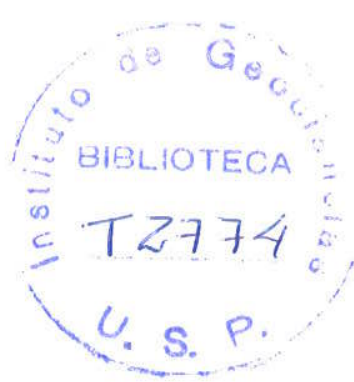

DISSERTAÇÃO DE MESTRADO

Programa de Pós-GraduaçÃo em Geologia Sedimentar

SÃO PAULO

1999

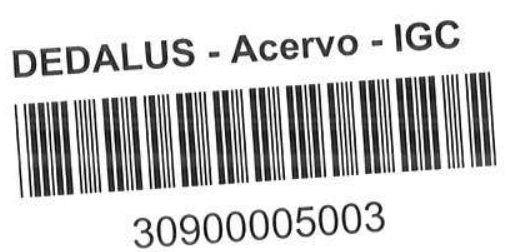


Felix qui potuit rerum cognoscere causas

Virgilio (Geórgicas II, 485) 
"The autecology of extinct organisms has been wrongfully neglected for the past few decades. Studies of ancient communities, macroevolution, and changes in diversity through time have stolen the spotlight and have led palaeontologists to think and practise as if autecological problems have been solved or can safely be avoided in more macroscopic reconstructions. Although synecolgical investigations have often had salutary influences on autecological research, many of the most basic aspects of autecological studies remain unexplored. Our ability to reconstruct ancient microenvironments is still often crude, though some success stories can be cited." (Levinton, 1984) 


\section{Índice Geral}

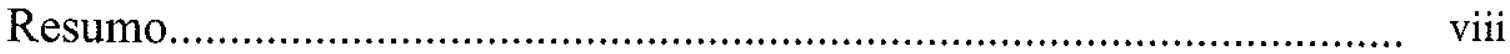

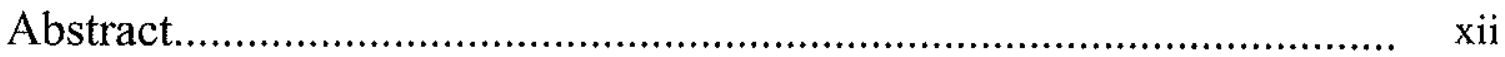

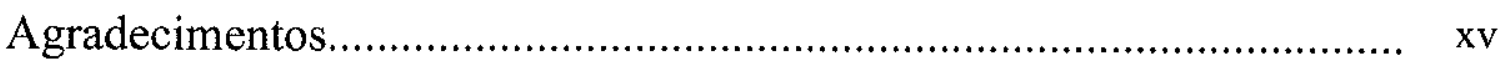

\section{Capítulo 1}

1. INTRODUÇÃO.

1.1 PROBLEMÁTICA ENVOLVIDA/JUSTIFICATIVA................................................................

1.2 OBJETIVOS

\section{Capítulo 2}

2. MATERIAIS.\& MËTODOS

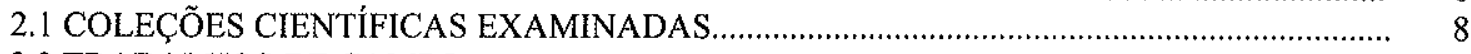

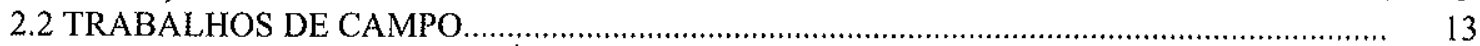

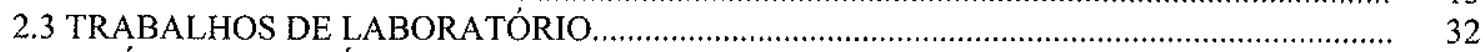

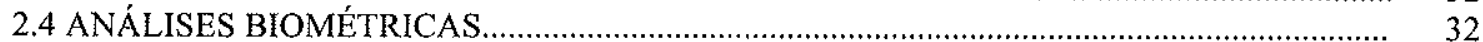

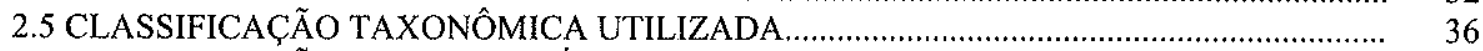

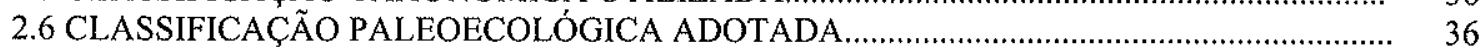

\section{Capítulo 3}

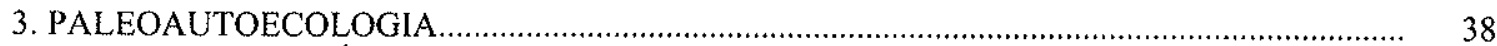

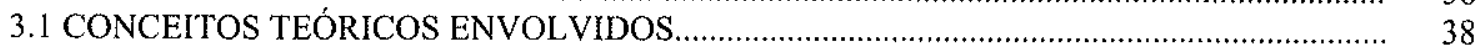

3.1.1 A Escola Americana (Paradigmática) .......................................................................... 39

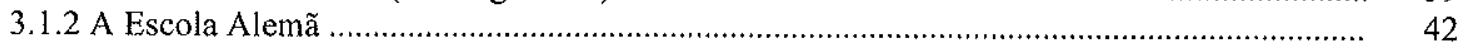

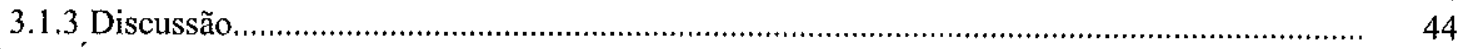

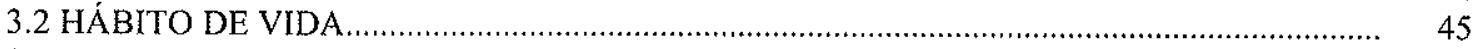

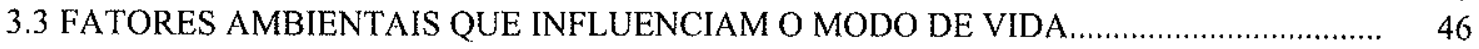

\section{Capítulo 4}

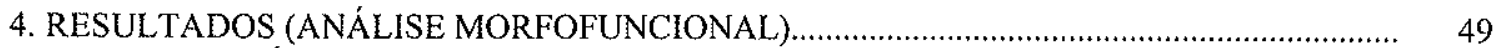

4.1 CARACTERÍSTICAS EXTERNAS DAS CONCHAS .................................................. 49

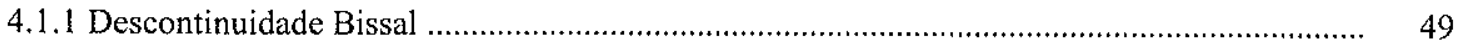

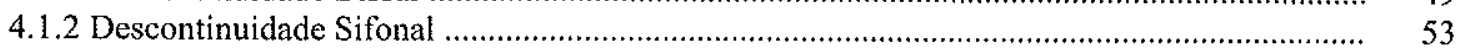

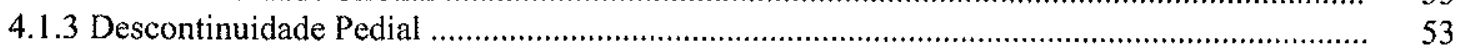

4.1.4 Forma da Concha (em seção) ................................................................................... 57

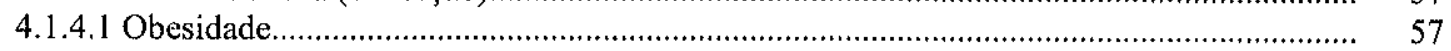

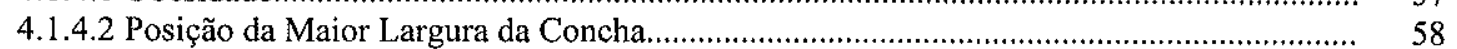

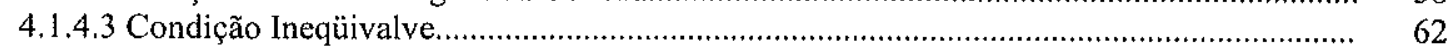

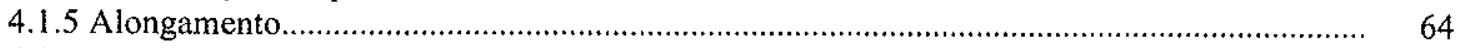

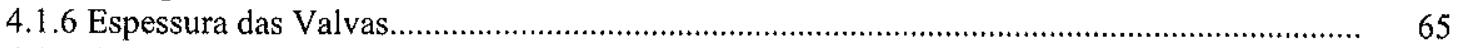

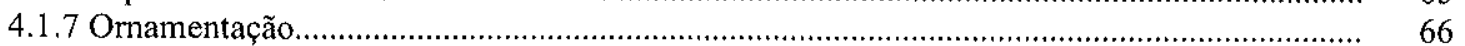




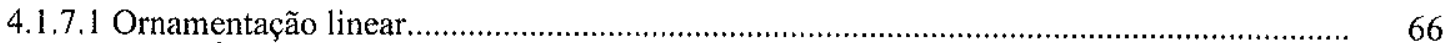

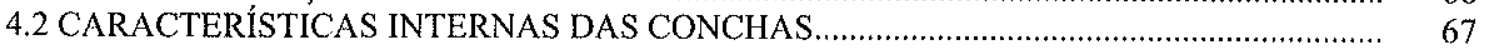

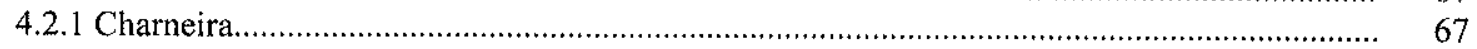

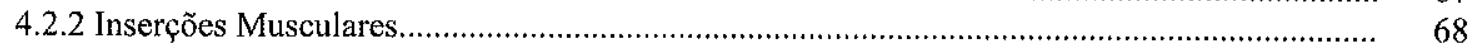

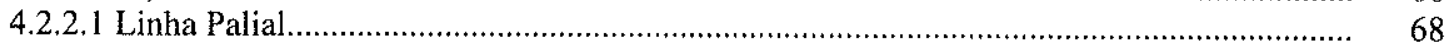

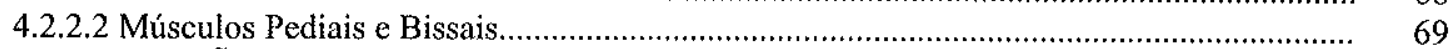

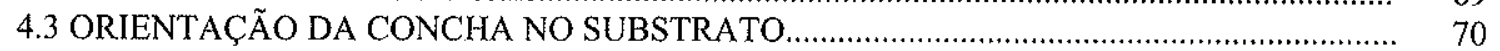

\section{Capítulo 5}

5. DISCUSSÃO

5.1 FORAM OS BIVALVES DAS FORMAÇÕES SERRA ALTA, TEREZINA E CORUMBATAÍ FORMAS DE ÁGUA DOCE?..

5.2 MODO DE VIDA (EPIFAUNA VERSUS INFAUNA) E O ESTRESSE AMBIENTAL

5.3 SUBSTRATO DE VIDA DOS BIVALVES DO GRUPO PASSA DOIS E OS LITÓTIPOS ONDE SÃO PRESERVADOS.

5.4 Anhembia froesi e Tambaquyra camargoi COMO BIVALVES PERMIANOS QUIMIOSSIMBIONTES...

\section{Capítulo 6}

6. BIVALVES FÓSSEIS COMO INDICADORES DA DINÂMICA SEDIMENTAR

6.1 PRINCÍPIOS GERAIS DA ANÁLISE TAFONÔMICA/ (PALEO)AUTOECOLÓGICA COMBINADA.

\section{Capítulo 7}

7. ANÁLISE PALEOSSINECOLÓGICA

\section{Capítulo 8}

8. CONCLUSÕES.

\section{Cápitulo 9}

9. BIBLIOGRAFIA

\section{Anexos}

TABELA DE MEDIDAS E ÍNDICES DOS BIVALVES DO GRUPO PASSA DOIS

UTILIZADOS NESSE ESTUDO 


\section{Índice de Figuras}

Figura 1- Mapa de localização dos afloramentos estudados, na região de Porangaba e Rio Claro, SP. Explicação no texto.

Figura 2- Vista geral do afloramento 2, Formação Serra Alta, município de Porangaba, SP. A seta indica o nível mais inferior com concreções.

Figura 3- Concreção carbonática, centimétrica, Formação Serra Alta, município de Porangaba, SP... 16

Figura 4- Seção colunar do afloramento 1, Formação Serra Alta, município de Porangaba, SP......... 17

Figura 5- Vista geral do afloramento 3, na pedreira do Calcário Vitte.

Figura 6- Afloramento 3, na pedreira do Calcário Vitte, Formação Corumbataí.....

Figura 7- Detalhe do contato entre as formações Irati e Corumbataí, mesma localidade acima.......

Figura 8- Provável local do antigo afloramento na rodovia Rio Claro-Ipeúna-Charqueada, Formação Corumbataí. Explicação no texto.

Figura 9- Seção colunar do afloramento 3, na pedreira do Calcário Vitte, município de Rio Claro, SP.

Figura 10- Mapa dos afloramentos fossilíferos da Formação Corumbataí, na região de Rio Claro, SP. (Simões, 1998).

Figura 11- Seção colunar do afloramento 4, Formação Corumbataí, no distrito de Ferraz, SP (Simões, 1998).

Figura 12- Seção colunar do afloramento 9, formações Corumbataí e Pirambóia, Rio Claro, SP.......

Figura 13- Detalhe dos siltitos argilosos da parte superior da Formação Corumbataí, na antiga estrada secundária que liga Tambaú a Santa Rosa do Viterbo, SP.

Figura 14- Seção colunar do afloramento 10, topo da Formação Corumbataí, Tambaú, SP. Modificado de Torello (1999).

Figura 15- Vista geral do afloramento 11, Formação Corumbataí, Tambaú, SP. Os três colaboradores demarcam os níveis fossilíferos

Figura 16- Vista geral do afloramento 12, Formação Corumbataí, município de Tambaú, SP

Figura 17- Seção colunar do afloramento 11, Formação Corumbataí, Tambaú, SP. Modificado de Torello (1999)

Figura 18- Seção colunar do afloramento 12, Formação Corumbataí, Tambaú, SP. Modificado de Torello (1999).

Figura 19- Principais medidas obtidas em conchas de bivalves [e.g., Pinzonella illusa (X 2,5)] e valores biométricos relacionáveis. Legenda: 1- Edmondia unioniformis (X 0,25- Carbonífero); 2 Sanguinolites discors (X 0,17- Carbonífero); 3 - Megadesmus globosus (X 0,15 - Permiano);4Triplicosta progressiva (X 0,30- Eoceno); 5- Promacrus nasutus (X 0,17- Carbonífero); 6- 
Crassiconcha stuckenbergi (X 0,23- Permiano); 7- Cadiomorpha oblonga (X 0,18-Carbonífero); 8- Machomya jurensis (X 0,17 -Jurássico) e 9- Chaenomya leavenworthensis (X 0,16Carbonífero)

Figura 20- Relevo hipotético demonstrando, por analogia, que as várias adaptações possíveis (B ou C), em que uma espécie pode suportar morfologicamente não coincidem, necessariamente com o "pico" adaptativo ótimo (A). Modificado de Signor III (1982).

Figura 21- Triângulo de Seilacher (1970), demonstrando os três vértices controladores da morfologia de um indivíduo

Figura 22- Poliedro teórico elaborado por Seilacher (1991)

Figura 23- Hábitos de vida em bivalves. Legenda: 1- Perfuradores (A-Pholas sp.) e aninhadores (B- Hiatella sp.); 2- Cimentados (A-Crassostrea sp.), natantes (B-Pecten $\mathrm{sp}$.) e fixados por bisso (C- Pinctada sp., D- Mytilus sp.); 3- Semi-infauna (A-Atrina sp.), Escavador raso (B-Astarte sp.); 4- Escavador profundo (A- Mya sp., C- Tellina sp.), escavador intermediário (B- Mercenaria sp.) e escavador raso (D- Cuspidaria sp.). Modificado de Stanley (1968).

Figura 24- Fatores ambientais controladores da morfologia de uma concha. Modificado de Stanley (1970).

Figura 25- Localização do Ponto M em bivalves. Modificado de Stanley (1970).

Figura 26- Esquema mostrando o provável ponto de protração do pé de Tambaquyra camargoi (A) e Anhembia froesi (B).

Figura 27- Esquema mostrando o provável ponto de protação do pé de Ferrazia cardinalis (A); Plesiocyprinella carinata (B); Casterella gratiosa (C); Terraiopsis aequilateralis (D); Pinzonella illusa (E); Roxoa corumbataiensis (F); Holdhausiella elongata (G); Favalia arcuata (H); Angatubia cowperesioides (I); Cowperesia anceps (J); Runnegariella fragilis (L) e, Othonella araguaiana (M). A concha de Itatamba paraima é morfologicamente semelhante a de Casterella gratiosa, não sendo ilustrada.

Figura 28- Esquema mostrando o provável ponto de protração do pé de Jacquesia brasiliensis (A); Pinzonella neotropica (B) e, Roxoa intricans $(\mathrm{C})$.

Figura 29- Representação do movimento de balanço em uma concha de forma esférica (A), concha discóide (B) e concha laminar (C). As setas indicam a resistência oferecida pelo substrato. Modificado de Stanley (1970)

Figura 30- Relação entre a forma tridimensional das conchas e a provável velocidade de escavação de: Tambaquyra camargoi (A); Anhembia froesi (B); Pinzonella illusa (C); Plesiocyprinella carinata (D); Casterella gratiosa (E) e, Ferrazia cardinalis (F). A linha pontilhada separa as regiões de escavação lenta (a esquerda) e rápida, segundo Stanley (1970)

Figura 31- Relação entre a forma tridimensional das conchas e a provável velocidade de escavação de: Terraia aequilateralis (A); Angatubia cowperesioides (B); Cowperesia anceps (C); Runnegariella fragilis (D); Favalia arcuata (E) e, Othonella araguaiana (F). A linha pontilhada separa as regiões de escavação lenta (a esquerda) e rápida, segundo Stanley (1970).

Figura 32 - Relação entre a forma tridimensional das conchas e da possível velocidade de escavação das conchas de: Holdhausiella elongata (A); Roxoa corumbataiensis (B); Pinzonella neotropica (C) e, Jacquesia brasiliensis (D)....

Figura 33- Valva direita de Pinzonella neotropica. A seta indica a depressão radial 
Figura 34- Valvas de Pinzonella neotropica articuladas fechadas. A seta indica a torção da parte ventral das valvas para a esquerda. Notar a forte condição ineqüivalve. Explicação: A- imagem normal das valvas articuladas de Pinzonella neotropica, B- imagem alterada do mesmo espécime para facilitar visualização da torção ventral das valvas.

Figura 35- Blocos diagramas com o provável substrato e posição de vida das conchas de ?Anthraconaia mezzalirai (1), Anhembia froesi (2), Maackia contorta (3), Tambaquyra camargoi (4) e Barbosaia angulata (5)....

Figura 36- Blocos diagramas com o provável substrato e posição de vida das conchas de Coxesia mezzalirai (1), Holdhausiella elongata (2), Favalia arcuata (3), Othonella araguaiana (4), Plesiocyprinella carinata (5), Angatubia cowperesioides (6), Cowperesia anceps (7), Pinzonella illusa (8), Ferrazia cardinalis (9), Casterella gratiosa (10), Itatamba paraima (11), Runnegariella fragilis (12), Terraiopsis aequilateralis (13) e Roxoa corumbataiensis (14).

Figura 37- Blocos diagramas com o provável substrato e posição de vida das conchas de Naiadopsis lamellosus (1), Jacquesia brasiliensis (2), Pinzonella neotropica (3) e Roxoa intricans (4).

Figura 38- Modo de vida dos bivalves do Grupo Passa Dois (exclusive Formação Rio do Rasto) (A), assembléia de Anhembia froesi (B), Pinzonella illusa (C) e Pinzonella neotropica (D).

Figura 39- Distribuição dos tamanhos máximos de conchas de algumas espécies de anomalodesmatas do Neopaleozóico da Bacia do Paraná. Notar o maior valor localizado no intervalo correspondente à assembléia de Anhembia froesi (formações Serra Alta e Corumbataí). Explicação: 1- Myonia tayoensis $(35 \mathrm{~mm}) ; 2-$ Myonia riograndensis $(20 \mathrm{~mm}) ; 3-$ Maackia iratiensis (10mm); 4- Tambaquyra camargoi $(100,1 \mathrm{~mm}) ; 5-$ Casterella gratiosa (43mm); 6- Ferrazia cardinalis $(32 \mathrm{~mm}) ; 7-$ Leinzia similis $(10 \mathrm{~mm})$ e, $8-$ Relogiicola delicata $(10 \mathrm{~mm})$. Fonte: Beurlen (1957b), Rocha-Campos (1970), Rohn (1988), Simões (1992) e este trabalho.

Figura 40- Distribuição vertical e horizontal de Anhembia froesi e Tambaquyra camargoi na Bacia do Paraná. Modificado de Rohn (1994).

Figura 41- Modo de ocorrência de conchas de bivalves marinhos, segundo o regime sedimentar e sua (paleo) autoecologia. Explicação: 1- contato água/sedimento; 2- antigo contato água/sedimento; 3- substrato rico em restos bioclásticos; 4- agradação de sedimento (deposição rápida); 5 agradação de sedimento (deposição lenta) e; 6- concha com encrustação ou bioerosão, na margem posterior. Exemplos relacionáveis ao quadro 10 .

Figura 42- Concentração fossilífera C (sensu Torello, 1999). Notar o aumento do grau de empacotamento dos bioclastos em direção ao topo e o contato basal erosivo. Espessura da concentração $4,5 \mathrm{~cm}$.......

Figura 43- Seqüência esquemática do processo de retroalimentação tafonômica e de preservação de animais em posição de vida da epifauna sobre uma concentração coquinóide, como a concentração tratada no item 6.2 .

Figura 44- Exemplar de Naiadopsis lamellosus em provável posição de vida. Valva direita silicificada de exemplar da mesma espécie (A), vista frontal de um exemplar da mesma espécie demonstrando achatamento dorso-ventral (B).....

Figura 45- Seção da concentração fossilífera C (sensu Torello, 1999), notar a presença de concha de Pinzonella neotropica articulada fechada (detalhe). Explicação no texto...... 
Figura 46- Processo de retroalimentação tafonômica decorrente de sucessivos eventos concentradores de material bioclástico em ambientes de planície de maré (litoral de Jeram, Malásia). Modificado de Seilacher (1985).

Figura 47- Seção composta do arenito bioclástico de Ferraz, mostrando seus contatos estratigráficos, bem como as feições tafonômicas e bioestratinômicas das 4 subunidades microestratigráficas reconhecidas, segundo Simões (1998) e Simões \& Kowalewski (1998a)

Figura 48- Fluxograma de trabalho e etapas na realização de uma análise paleoecológica levando em conta o estudo autoecológico e tafonômico de detalhe, como ponto de partida para a elaboração de hipóteses e reconstruções paleossinecológicas. 


\section{Índice de Quadros}

Quadro 1- Relação das espécies presentes nas três assembléias malacofaunísticas do Grupo Passa Dois, no Estado de São Paulo

Quadro 2-Características morfológicas dos bivalves da assembléia de Anhembia froesi. Fonte: Maranhão $(1986,1995)$ e Ghilardi \& Simões (1997). • Feição descrita originalmente neste estudo..

Quadro 3- Características morfológicas dos bivalves da assembléia de Pinzonella illusa. Fonte: Simões et al. (1997); Mello et al. (1998a) e Mello (1999).

Quadro 4- Características morfológicas dos bivalves da assembléia de Pinzonella neotropica. Fonte: Simões et al. (1997); Mello et al. (1998a) e Mello (1999).

Quadro 5-Termos descritivos para os valores das medidas dos caracteres morfológicos de conchas de bivalves. Modificado de Stanley, 1970.

Quadro 6- Modo de vida inferido para os bivalves da assembléia Anhembia froesi

Quadro 7- Modo de vida inferido para os bivalves da assembléia Pinzonella illusa.

Quadro 8- Modo de vida inferido para os bivalves da assembléia Pinzonella neotropica.....

Quadro 9- Principais feições observadas em bivalves dulcícolas e marinhos. Explicação: 1Cowperesia anceps (X 1,3); 2- Ferrazia cardinalis (X 0,60); 3- Bragraveia corrugata (X 0,61); 4Arconaia lanceolata $(\mathrm{X} 0,28) ; 5$ - Obliquaria reflexa $(\mathrm{X} 0,42) ; 6$ - Cristaria plicaria $(\mathrm{X} 0,22) ; 7$ Runnegariella fragilis (X 2,3); 8- Hyridella ambigua (X 0,44); 9- Arconaia lanceolata (X 0,27); 10- Pinzonella illusa (X 0,75); 11 - Pinzonella illusa (X 0,78).

Quadro 10- Possíveis informações (paleo)ambientais fornecidas pelo modo de vida e preservação de conchas de bivalves fósseis. As inferências não podem ser estabelecidas apenas com base em uma feição isoladamente; dados tafonômicos, sedimentológicos e estratigráficos devem ser empregados. Explicação no texto. 


\section{Resumo}

No presente estudo é realizada uma análise morfofuncional (paleoautoecológica) dos bivalves das formações Serra Alta, Terezina e Corumbataí, Grupo Passa Dois, Neopermiano, que ocorrem nas assembléias de Anhembia froesi, Pinzonella illusa e Pinzonella neotropica, no Estado de São Paulo. O estudo teve por objetivo a reconstrução do habito de vida destes invertebrados como ponto de partida para a discussão de aspectos paleoecológicos mais amplos. Na assembléia de Anhembia froesi (Formação Serra Alta e base da Formação Corumbataí), ocorrem bivalves escavadores rasos, lentos (Anhembia froesi, Tambaquyra camargoi, Mendesia piracicabensis, Maackia contorta), de semi-infauna (Barbosaia angulata) e epifauna (?Anthraconaia mezzaliral) bissadas. $\mathrm{Na}$ assembléia de Pinzonella illusa (formações Serra Alta e Corumbataí), com maior diversidade de guildas, predominam os bivalves escavadores rasos, lentos (Pinzonella illusa, Plesiocyprinella carinata, Ferrazia cardinalis, Terraiopsis aequilateralis e Othonella araguaiana), sendo encontrados, também, escavadores rasos, rápidos (Favalia arcuata, Holdhausiella elongata e Runnegariella fragilis) ou escavadores intermediários (Casterella gratiosa, Itatamba paraima). Evidências morfofuncionais (e.g., obesidade da concha) sugerem que estas espécies tiveram preferência por substrato arenoso, estável. Formas escavadoras intermediárias, rápidas (Cowperesia anceps, Angatubia cowperesioides), em substratos finos também ocorrem, sendo incomuns os escavadores profundos (Roxoa corumbataiensis) e de epifauna bissada (Coxesia mezzaliral). A assembléia de Pinzonella neotropica (formações Corumbataí e Terezina) inclui bivalves escavadores rasos, lentos, em substrato arenoso, estável (Pinzonella neotropica, Jacquesia brasiliensis), escavadores intermediários, rápidos, em substrato fino (Cowperesia anceps) e escavadores profundos, em substrato estável (Roxoa intricans). Além destes, bivalves da semi-infauna bissada (Naiadopsis lamellosus) são também freqüentes. 
A baixa proporção de bivalves da epifauna nas malacofaunas estudadas pode ser explicada pela interação de fatores, como a baixa disponibilidade de substratos grossos, duros; as condições de águas rasas, freqüentemente afetadas por tempestades e o alto grau de estresse ambiental (variação na salinidade) que marcam o intervalo estratigráfico de ocorrência dos bivalves.

Nenhuma das 25 espécies estudadas apresenta características anatômicas (e.g., claustrum, tubérculos, torção das valvas) ou feições tafonômicas (e.g., pontos de dissolução do umbo, fraturas regeneradas) tipicamente encontradas nas conchas dos bivalves dulcícolas. Por outro lado, feições morfológicas exclusivas de bivalves marinhos foram observadas em Ferrazia cardinalis (e.g, costelas radiais), Runnegariella fragilis (e.g., concha anteriormente expandida) e Cowperesia anceps (e.g., ornamentação concêntrica). Além disso, características bioestratinômicas típicas de conchas de bivalves marinhos ou de águas salobras, como predação por organismos durófagos foram verificadas em valvas de Plesiocyprinella carinata e, principalmente, de Pinzonella illusa. Os bivalves do Grupo Passa Dois (exclusive Formação Irati) não foram, portanto, organismos dulcícolas. Essa hipótese encontra respaldo também em análises cladísticas que mostram que a maior parte, se não todos os bivalves do intervalo estudado, são afins à famílias marinhas (e.g., Família Megadesmidae). Entretanto, precisa ficar claro que o teor preciso de salinidade do ambiente não pode ser determinado com base exclusivamente na análise paleoautoecológica.

Neste estudo, sugere-se, pela primeira vez, que Anhembia froesi e Tambaquyra camargoi (formações Serra Alta e Corumbataí) são excelentes candidatos permianos para figurarem no rol de bivalves quimiossimbiontes, como indicado pela presença de rostrum e gigantismo nas suas conchas e pelo fato de serem encontradas em sedimentos finos depositados abaixo ou junto ao nível de base das ondas de tempestades, em ambiente com teor variável de oxigênio, o que pode ser corroborado também por outras evidências estratigráficas e tafonômicas (e.g., presença de horizontes com nódulos fosfáticos nos sedimentos associados). 
No geral, os bivalves estudados ocorrem em concentrações fossilíferas internamente complexas, mormente representadas por tempestitos proximais (predominantes) e distais. Por exemplo, bivalves preservados em posição de vida são muito raramente encontrados nas concentrações fossilíferas examinadas. Geralmente, os bivalves escavadores rasos, de semi-infauna e epifauna, representam elementos parautóctones a alóctones nas acumulações esqueléticas, exibindo maior grau de mistura temporal e baixa resolução espacial (time-averaging), do que os bivalves escavadores profundos e intermediários. Isso se deve, possivelmente, a estratégia de vida mais exposta à ação de distúrbios físicos (e.g., correntes tracionais de fundo) exibida pelas formas de epifauna, semi-infauna e infauna rasa.

As características morfofuncionais e tafonômicas das conchas dos bivalves podem constituir, em conjunto, importantes ferramentas para a determinação da dinâmica sedimentar (e.g., taxa de sedimentação). Por exemplo, em uma concentração coquinóide (tempestito), encontrada no topo da Formação Corumbataí (assembléia de Pinzonella neotropica), há a presença de conchas articuladas fechadas de bivalves escavadores rasos (Pinzonella neotropica), intermediários (Cowperesia anceps) e de semi-infauna bissada (Naiadopsis lamellosus). Valvas desta última espécie ocorrem desarticuladas, fragmentadas e caoticamente distribuídas na matriz, contribuindo significativamente com a composição da acumulação esquelética. Entretanto, valvas articuladas e em posição de vida ocorrem também no topo da concentração, permitindo não apenas o reconhecimento do processo de retroalimentação tafonômica, como também a identificação de diferentes eventos de não deposição de sedimentos, seguidos de episódios de rápida deposição de finos, possivelmente associados às tempestades.

Todos os dados paleoautoecológicos e tafonômicos obtidos mostram, consistentemente, que reconstruções paleossinecológicas não podem ser estabelecidas sem o prévio conhecimento desses dados. Neste contexto, um protocolo contendo 7 etapas distintas (e.g., atividades preliminares como a delimitação do escopo de estudo e hipóteses, atividades de coleta, atividades de 
laboratório, análise qualitativa, análise quantitativa, interpretação dos dados e apresentação dos resultados) é sugerido, como ponto de partida para a análise e verificação mais rigorosa de hipóteses paleossinecológicas. 


\section{Abstract}

In this study a detailed paleoautoecological analysis of the Permian bivalves of Passa Dois Group (Serra Alta, Terezina and Corumbataí Formations), Paraná Basin, was carried out. Its main goal is the reconstruction of the mode of life of these bivalves as a starting point for broad paleoecological discussions. The Anhembia froesi assemblage (Serra Alta and Corumbataí Formations) is dominated by shallow and slow burrowing bivalves (Anhembia froesi, Tambaquyra camargoi, Mendesia piracicabensis, Maackia contorta). Semiinfaunal (Barbosaia angulata) and epifaunal, byssate (?Anthraconaia mezzalirai) bivalves are also common. On the other hand, a large number of shallow and slow burrowers (Pinzonella illusa, Plesiocyprinella carinata, Ferrazia cardinalis, Terraiopsis aequilateralis and Othonella araguaiana) dominate the Pinzonella illusa assemblage (Serra Alta and Corumbataí Formations). Rapid burrowers (shallow or intermediate) are, however, represented by the shallow burrowers Favalia arcuata, Holdhausiella elongata and Runnegariella fragilis, and the intermediate burrowers Cowperesia anceps, Angatubia cowperesioides, respectively. Slow, intermediate burrowers (Casterella gratiosa, Itatamba paraima) are less common, while deep burrowers (Roxoa corumbataiensis) and epifaunal byssate (Coxesia mezzaliral) bivalves are rare. Several lines of morphological evidence (e.g., shell morphology, obesity) strongly suggest that the shallow and deep burrowers as well as epifaunal byssate bivalves colonized stable (sandy) substrates. The same ecological guilds that are represented in this assemblage can be recognized in the Pinzonella neotropica assemblage (upper part of Corumbatai and Terezina Formations) such as: shallow and slow burrowers in soft and stable substrates (Pinzonella neotropica, Jacquesia brasiliensis); rapid and intermediate burrowers in soft bottoms (Cowperesia anceps); deep burrowers (Roxoa intricans) and endobyssate elements (Naiadopsis lamellosus) in soft, but bioclastic-rich sediments. All of them were suspension-feeding bivalves. 
The low percentage of epifaunal, byssate bivalves in these assemblages is noteworthy. An interplay of abiotic and biotic factors could explain this feature. For example, during the deposition of the Corumbataí and Terezina Formations, condition of shallow waters, with soft and unstable substrate, frequently affected by storm events prevailed.

Morphologic (e.g., claustrum, tubercles, valve torsion) and taphonomic features (e.g., dissolution pits, regenerated breakages) commonly observed in freshwater bivalves were not found in the studied species $(n=25)$. On the other hand, morphologic features typically observed in marine bivalves were noted in Ferrazia cardinalis (e.g, radial ribs), Runnegariella fragilis (e.g., anteriorly expanded shells) and Cowperesia anceps (e.g., concentric ornamentation). Additionally, some specimens of Plesiocyprinella carinata, and particularly Pinzonella illusa, show signs (drill holes) of drilling predation. Drilled bivalves are unknown among freshwater forms. The Passa Dois Group bivalves (not including the Irati Formation) were not freshwater bivalves, which is in accordance with recent cladistic analysis that indicates affinities with marine bivalve families. In addition, Anhembia froesi and Tambaquyra camargoi (Serra Alta and Corumbataí) are interpreted, for the first time, as chemosymbiotic bivalves. This is supported by the occurrence of a rostrum (Anhembia froesi) and the large body size of their shells. These bivalves are also found in fine, soft, oxygen deficient substrates, deposited below or near storm wave base.

The examined bivalves are often preserved in internally complex fossil concentrations (proximal and distal tempestites). In all of these bivalves in life position are rare. The occurrence of disharmonious time-averaging is remarkable, particularly among the epifaunal, semi-infaunal and shallow burrowers. This is because the shells of bivalves with exposed strategy are more prone to spatial and temporal mixing.

The paleoautoecologic and taphonomic analysis could be an important tool for the study of sedimentary dynamics (e,g., sedimentation rate). For example, life positioned specimens of Naiadopsis lamellosus with the comissure plane inclined about 45 degrees to the bedding plane occur on the top of a thin 
$(\sim 10 \mathrm{~cm})$ bioclastic-rich concentration, intercalated in siltstones. The underlying shell layer was buried to a depth of $\sim 1.6 \mathrm{~cm}$. Normally, the shells are buried up to their umbonal carena, the anterior margin (buried portion) of closed articulated shells being slightly compressed dorso-ventrally. The original substrate provided by the underlying accumulation, including a great amount of bioclasts and also some muddy parts, seems suitable for the settling of Naiadopsis lamellosus larvae. Still, the presence of disarticulated, complete or fragmented, and abraded or pristine shells of Naiadopsis lamellosus with different size classes suggests different episodes of substrate colonization and reworking, indicating the occurrence of different periods of extensive taphonomic feedback. Although preserved in life position taphonomic evidence indicates that the temporal resolution of these concentrations is variable, often preserving a time-averaged record of the benthic marine populations. In the case of Naiadopsis lamellosus, different periods of colonization and disruptment have contributed to the bioclast enrichment of the substrate, at different times, corroborating the idea that the genetic processes that are responsible for the origin of a particular concentration are less important for the time-averaging phenomenon than the presence of old shells or bioclasts in a given depositional system.

The obtained data have shown consistently that paleossynecological reconstruction that are not based on detailed paleoautoecologic and taphonomic studies are not justifiable. In this context, a seven step protocol is proposed as an alternative approach for a more accurate test of paleossynecological hypothese. 


\section{Agradecimentos}

Gostaria de expressar meus sinceros agradecimentos:

- Ao Professor Doutor Marcello Guimarães Simões que, além de me orientar construtivamente e me ensinar a viver e pensar academicamente, teve tempo de ser meu melhor amigo;

- À meu pai, João Batista Ghilardi, e minha mãe, Márcia Pirani Ghilardi, além de meus irmãos e parentes, por sempre me incentivar e ajudar nos momentos mais necessários;

- À minha razão (tanto de ser como de juízo), Renata Cecília Amaro, pelas correções de texto, fotos, discussões e, principalmente, pelo amor;

- Ao meu amigo Msc. Luiz Henrique Cruz de Mello pelos esporros nos momentos ideais e pela amizade, tenho certeza, eterna;

- À minha amiga Msc. Fernanda de Freitas Torello pela ajuda, sempre infindável, e pelo exemplo de comportamento;

- Ao Laboratório de Citogenética de Vertebrados, IB/USP, em especial à pessoa de Maria José de Jesus Silva, pela possibilidade de impressão deste documento em impressora a laser;

- Aos professores Denise Pereira de Arruda e José Maria Martes pelas revisões no texto e amizade;

- Aos professores doutores Michal Kowalewski e Antônio Carlos Marques (Tim) pelos trabalhos de campo e discussões construtivas;

- Aos colegas de laboratório Juliana de Moraes Leme, Sabrina Coelho Rodrigues, Juliana Nunes, Ana Paula Farro, Maria Fernanda Dutra, André Pietsch Lima, pelas discussões sempre construtivas e coletas de campo, e aos amigos Lígia Barrozo Simões, Alexandre Salles, Paulo Albuquerque, Maria José de Jesus Silva, Juliana Marge Pagnozzi, Katia Pellegrino, Carolina Bertolotto, Valéria Fagundes, Raquel Pena, Paulo Roberto Lopes e Alessandro por, imperceptivelmente mas constantemente, me ajudarem a ser feliz;

- Aos professores do DGSA/USP, especialmente Thomas Rich Fairchild, pelas correções de texto, e Luís Eduardo Anelli; 
- Aos professores do DZ/IBB/UNESP, especialmente Nelson Bernardi e Francisco de Assis Mello, pela minha formação;

- Aos funcionários do DGSA/USP, especialmente Ana Paula Cabanal Pentagna, Ivone Casseb e Luzia Sonia Candeo, pela ajuda;

- Aos funcionários do DZ/IB/UNESP, especialmente Ana Maria Fernandes, Maria Aparecida Nunes de Oliveira, Juliana Ramos, José Mário Pizani e Flávio da Silva, pela amizade e ajuda;

- Ao Departamento de Zoologia do Instituto de Biociências da UNESP/Botucatu por permitir o uso de suas instalações e recursos durante a realização deste trabalho;

- À Capes que financiou a confecção deste trabalho e à Fapesp (Proc. 94/5021-3 e 96/9708) pelos trabalhos de campo. 
INTRODUÇÃO 


\section{INTRODUÇÃO}

Paleoautoecologia pode ser definida como o estudo das interações entre uma espécie, com seu ambiente biótico e abiótico, envolvendo a reconstrução do antigo ambiente de vida do organismo e o entendimento de como a morfologia, comportamento e outros atributos de um animal extinto influenciaram em sua sobrevivência e reprodução, face ao ambiente reconstruído (Levinton, 1984). Em decorrência de sua natureza interdisciplinar, estudos paleoautoecológicos são complexos, envolvendo a caracterização do ambiente físico, do ambiente biótico e o entendimento do significado autoecológico de uma dada estrutura biológica e suas relações com o comportamento e fisiologia do animal em estudo.

Curiosamente, estudos autoecológicos, como os realizados por Stanley $(1970,1972) \mathrm{e}$ Kriz (1984) são raros e, juntamente com a análise tafonômica de detalhe, deveriam largamente preceder os estudos paleossinecológicos, que são os predominantes na literatura. Embora muitos paleontólogos de invertebrados que não estudam bivalves tenham feito suas críticas a aplicação dos critérios morfofuncionais estabelecidos por Stanley (1970), para o estudo da paleoautoecologia de bivalves fósseis (veja, por exemplo, Bassett \& Lawson, 1984), existe consenso de que este é justamente o grupo mais favorável para este tipo de abordagem dada sua abundância no registro geológico, nos ambientes aquáticos do Recente e pela íntima relação existente entre a forma da concha e o modo de vida do animal.

Uma compilação dos diversos artigos sobre morfologia funcional com diferentes grupos de organismos foi apresentado por Dodd \& Stanton (1981) e Pickerill \& Brenchley (1991). Embora vários autores tenham apresentado estudos autoecológicos rigorosos, com base em bivalves silurianos (Bambach, 1971; Kriz, 1984; Liljedahl, 1985; Sanchez, 1991), devonianos (Kotzian, 1995), jurássicos (Duff, 1975; Hallam, 1976; Fürsich, 1980, 1982; Fürsich \& Oschmann, 1986; Wignall, 1990) e cenozóicos (Stanley, 1970, 1972, 1975; Savazzi, 1990; Savazzi \& Peiyi, 1992), menos comuns são os trabalhos que tratam da autoecologia dos bivalves carboníferos e permianos (Runnegar, 1974, 1979; Ghilardi, 1995, 1996; Simões \& Anelli, 1995; Anelli et al., 1995, 1998; Simões \& Mello, 1996).

No contexto acima, seria oportuno, pois, um estudo dos bivalves do Grupo Passa Dois (Neopermiano), da Bacia do Paraná, considerando que as coquinas e arenitos bioclásticos, silicificados, formados por acúmulo denso de conchas de bivalves ("shell beds", sensu Kidwell, 1991), constituem uma das características paleontológicas e sedimentológicas mais 
notáveis das formações Terezina e Corumbataí, no Estado de São Paulo (Torello \& Simões, 1994; Simões et al., 1996a; Simões \& Kowalewski, 1998a; Torello, 1999). Estas concentrações de material bioclástico correspondem às clássicas assembléias de Anhembia froesi (Maranhão, 1986, 1995), Pinzonella illusa e Pinzonella neotropica (Mendes, 1952; Runnegar \& Newell, 1971), que ocorrem em sucessão estratigráfica na região de Rio Claro, SP (Rohn, 1994).

Estudos paleoecológicos (Simões \& Rocha-Campos, 1990a, 1990b, 1994; Simões, 1992; Anelli et al., 1998; Simões et al., 1998b), tafonômicos (Simões \& Rocha-Campos, 1992, 1993; Torello \& Simões, 1994; Simões, 1996, 1998; Simões et al., 1996a; Simões \& Kowalewski, 1998a, b; Torello, 1999), sedimentológicos e estratigráficos (Sousa, 1985; Lavina, 1991; Rohn, 1994; Rohn et al., 1995; Maranhão, 1995; Klein, 1997), têm demonstrado que as concentrações fossilíferas que contêm elementos da assembléia de Pinzonella illusa e Pinzonella neotropica são parautóctones a alóctones e geradas durante eventos de tempestades, em mar epicontinental, sob condições de águas relativamente rasas. Contudo, estudos tafonômicos e paleoecológicos detalhados referentes aos bivalves da assembléia de Anhembia froesi, nunca foram feitos, uma vez que o estudo de Maranhão (1986), de cunho eminentemente taxonômico, não abordou pormenorizadamente tais aspectos.

Embora o conhecimento taxonômico dos bivalves das assembléias de Anhembia froesi, Pinzonella illusa e Pinzonella neotropica possa ser considerado adequado para a presente análise (Simões et al., 1997; Mello et al., 1998b; Mello, 1999), não existem ainda estudos paleoautoecológicos detalhados empregando conceitos e critérios modernos (e.g., Stanley, 1970, 1972, 1981; Fürsich, 1976, 1980, 1994; Liljedahl, 1985; Fürsich \& Aberhan, 1990; Fürsich et al., 1991) para a interpretação da morfologia funcional e modo de vida destes invertebrados. Tais estudos são muito úteis para o entendimento das condições ambientais (e.g., tipo de substrato, energia do meio, batimetria) predominantes durante a história deposicional das formações Serra Alta, Corumbataí e Terezina, no Estado de São Paulo, sendo amplamente complementares aos de cunho sedimentológico e estratigráfico já disponíveis, conforme será ressaltado ao longo do presente documento. 


\subsection{Problemática envolvida}

Assim como os fatores bióticos, o meio físico no qual os organismos vivem exerce forte influência sobre sua distribuição geográfica (Thorson, 1966). No ambiente marinho, os principais parâmetros físicos são a luminosidade, temperatura, salinidade, taxas de sedimentação, energia do meio (e.g., correntes) e o tipo de substrato. Nos ambientes marinhos do Paleozóico, as tempestades parecem ter sido o agente mais efetivo, influenciando não apenas a distribuição, mas também o modo de vida dos organismos (Miller et al., 1988).

Conforme comenta Fürsich (1976), desses parâmetros apenas o substrato pode ser diretamente avaliado pelos paleoecologistas, embora inferências sobre as taxas de sedimentação, a energia do meio e a batimetria possam ser feitas indiretamente (Brett et al., 1993). O substrato é, por sua vez, caracterizado por uma série de parâmetros (e.g., aeração, estabilidade, grau de consolidação, tamanho das partículas, seleção dos grãos) dos quais apenas a granulometria e seleção podem ser diretamente estudados (Fürsich, 1976).

A influência do substrato na distribuição de invertebrados e das comunidades bentonicas nos ambientes marinhos do Recente foi demonstrada por Newell et al. (1959), Purdy (1964), Sanders (1958) e Stanley (1970), dentre outros. Entretanto, não são comuns os estudos similares para as comunidades de macroinvertebrados marinhos fósseis (e.g., Woober, 1968; Kauffman, 1969; Wright, 1973; Fürsich, 1976, 1977, 1980; Fürsich \& Werner, 1984). Esses, porém, são necessários para entendimento das relações entre os organismos e os diferentes tipos de substrato e as mudanças evolutivas e as sucessões faunísticas que ocorreram nos habitats marinhos do Fanerozóico (Fürsich, 1976).

A interpretação do modo de vida (paleoautoecologia) de bivalves fósseis baseia-se não apenas na análise da morfologia funcional, mas também na comparação do provável modo de vida das espécies fósseis com os hábitos de vida das espécies viventes, aparentadas (Anelli et al., 1998).

A literatura moderna a respeito da análise morfofuncional de conchas de bivalves marinhos oferece já um arcabouço conceitual e metodológico útil na reconstrução dos hábitos de vida das espécies fósseis, particularmente das formas escavadoras (e.g., Stanley, 1970, 1972, 1975, 1981; Fürsich, 1980; Liljedahl, 1985). Através da interpretação da anatomia funcional é possível obter-se informações importantes sobre os parâmetros físicos dos ambientes onde estes organismos viveram. Por exemplo, McAllester \& Rhoads (1967) constataram haver boa correlação entre a profundidade de escavação dos bivalves que 
colonizam os mares epicontinentais do Recente e a espessura da lâmina d'água. As formas escavadoras profundas estão, por exemplo, na sua grande maioria, restritas aos ambientes de águas rasas, pois necessitam escapar das rápidas flutuações dos parâmetros ambientais (e.g., temperatura) que ocorrem nestes habitats. Deste modo, haveria uma relação inversa entre a profundidade de escavação e a profundidade da água (McAllester \& Rhoads, 1967).

Por outro lado, Vermeij \& Dudley (1985) e Savazzi \& Peiyi (1992) notaram que as conchas dos bivalves dulcícolas, viventes ou fósseis, possuem adaptações morfológicas distintas das encontradas nos bivalves marinhos, em função de seu hábito de vida diferente. Portanto, com as devidas reservas, a análise da morfologia funcional pode fornecer informações adicionais sobre a salinidade da água (veja item 5.1).

As reconstruções dos hábitos de vida de bivalves escavadores marinhos fósseis derivadas da interpretação morfofuncional e sua comparação com exemplares fósseis das mesmas espécies, preservadas in situ, têm demonstrado que os resultados obtidos são congruentes (Fürsich, 1980), sendo, possivelmente, fidedignos. Anelli et al. (1998), por exemplo, notaram grande similaridade entre a posição de vida de anomalodesmatas do Neopaleozóico, inferida a partir da análise morfofuncional (Anelli, 1994) e a posição de vida de anomalodesmos preservados in situ, nos sedimentos das formações Piauí (Neocarbonífero) e Rio do Sul (Eopermiano). As maiores diferenças notadas estão relacionadas aos valores do ângulo do eixo longo da concha, em relação ao plano de acamamento, que é normalmente maior nas reconstruções fundamentadas na análise morfofuncional. Conclusão semelhante foi obtida também por Simões et al. (1998b) e Torello (1999) que examinaram invertebrados (e.g., braquiópodes, bivalves) preservados in situ em sedimentos da Formação Ponta Grossa (Devoniano) e da Formação Corumbataí (Neopermiano).

O estudo dos bivalves das assembléias de Anhembia froesi, Pinzonella illusa e Pinzonella neotropica, no contexto acima, pode, pois, fornecer subsídios de grande interesse sobre os processos sedimentares, as condições ambientais (e.g., tipo de substrato, energia do meio) e paleobatimétricas presentes nos habitats por eles colonizados.

As seguintes razões justificam a abordagem que será empregada neste estudo:

a- Os bivalves das assembléias de Anhembia froesi, Pinzonella illusa e Pinzonella neotropica são bem conhecidos do ponto de vista taxonômico e evolutivo (Simões et al., 1997; Mello et al., 1998b; Mello, 1999);

b - Existem já diversos estudos tafonômicos (Simões, 1992; Torello \& Simões, 1994; Simões, 1998; Simões et al., 1996a, 1998a, b, c; Simões \& Kowalewski, 1998a, b) 
sobre as concentrações fossilíferas contendo bivalves atribuídos as assembléias de Pinzonella illusa e Pinzonella neotropica. Esses estudos demonstraram que tais concentrações possuem gênese complexa, tendo sido geradas a partir de eventos de tempestade (Torello \& Simões, 1994; Simões, 1996, 1998; Simões et al., 1996a; Simões \& Kowalewski, 1998a, b). Elas são marcantemente parautóctones e parecem exibir um acentuado grau de mistura temporal ("time-averaging") e espacial ("spatial-averaging") (Simões, 1998; Simões \& Kowalewski, 1998a, b), isto é, mistura de elementos esqueléticos de populações ou comunidades não contemporâneas (Fürsich \& Aberhan, 1990) de áreas distitas. Portanto, as feições tafonômicas dessas concentrações fossilíferas, impõem sérias restrições aos estudos paleossinecológicos (vide item 6), mas não paleoautoecológicos (veja discussão em Simões, 1998; Simões \& Kowalewski, 1998a, b);

c- As conchas da assembléia de Pinzonella illusa e Pinzonella neotropica estão, muitas vezes, silicificadas e, portanto, bem preservadas, podendo facilmente serem extraídas da matriz, empregando-se métodos físicos e químicos (Simões, 1988; Simões \& Fittipaldi, 1992). Desta forma, o estudo das feições anatômicas externas e internas das conchas pode ser muito detalhado. O mesmo não é verdadeiro, entretanto, para os bivalves da assembléia de Anhembia froesi, que ocorrem, normalmente, na forma de moldes mal preservados (Maranhão, 1986). Recentemente, porém, Ghilardi \& Simões (1997) descreveram a musculatura de diversos elementos (e.g., Anhembia froesi, Holdhausiella almeidai, Barbosaia angulata e Mendesia piracicabensis) da assembléia de Anhembia froesi, demonstrando que, potencialmente, as feições internas de suas conchas podem ser também detalhadamente descritas e analisadas;

d- O Laboratório de Paleozoologia Evolutiva do Departamento de Zoologia, IB/UNESP-Botucatu e o Departamento de Geologia Sedimentar e Ambiental, IG/USP, possuem em suas coleções científicas aproximadamente 3000 exemplares, já preparados, de bivalves das assembléias de Pinzonella illusa e Pinzonella neotropica que foram examinados na elaboração do estudo paleoautoecológico preliminar de Ghilardi (1995). Adicionalmente, o Laboratório de Paleozoologia Evolutiva do Departamento de Zoologia, IB/UNESP-Botucatu, dispõe de um conjunto de amostras de blocos de arenitos bioclásticos e coquinas silicíficadas, das 
assembléias de Pinzonella illusa e Pinzonella neotropica provenientes de diversas localidades do Estado de São Paulo, que puderam ser examinadas e,

e- $\mathrm{O}$ exame da literatura prévia revela existirem ainda muitas controvérsias a respeito da história deposicional do intervalo estratigráfico onde os bivalves das assembléias de Anhembia froesi, Pinzonella illusa e Pinzonella neotropica ocorrem (veja Rohn, 1994) e dos ambientes onde os bivalves viveram (Simões \& Fittipaldi, 1987; Rohn, 1994; Simões et al., 1998b).

Em adição aos comentários acima, vale lembrar que paralelamente ao grande avanço obtido quanto a tafonômia e filogenia dos bivalves presentes nas assembléias de bivalves do Grupo Passa Dois, novos dados bioestratigráficos (e.g., Rohn, 1994; Maranhão, 1995) e a descoberta de mais de uma dezena de novos afloramentos (Ghilardi et al., 1997; Torello \& Simões, 1997; Mello et al., 1998a; Torello, 1999), abrangendo sedimentos das formações Serra Alta, Terezina e Corumbataí, vieram a contribuir para complementar o quadro evolutivo proposto por Simões (1992), o qual foi revisado e atualizado por Simões et al. (1998b). Verifica-se, deste modo, que os três pré-requisitos (e.g., estudos sedimentológicos/tafonômicos; bioestratigráficos e taxonômicos) citados por Fürsich (1977), como indispensáveis aos estudos paleoautoecológicos, estão disponíveis para os bivalves do Grupo Passa Dois, especialmente dos presentes nas formações Serra Alta, Terezina e Corumbataí.

\subsection{OBJETIVOS}

Tendo em vista os comentários acima, a presente dissertação tem como objetivos:

a- Estudo paleoautoecológico (morfofuncional) dos bivalves das assembléias de Anhembia froesi, Pinzonella illusa e Pinzonella neotropica, formações Serra Alta, Terezina e Corumbataí;

b- Análise das características paleoautoecológicas dos bivalves do Grupo Passa Dois (exclusive Formação Rio do Rasto) e sua comparação com as feições tafonômicas das concentrações fossilíferas examinadas;

c- Utilizar as características paleoautoecológicas das três assembléias examinadas na interpretação das condições ambientais (e.g., tipo de substrato, salinidade) vigentes no intervalo examinado (formações Serra Alta, Terezina e Corumbataí); 
d- Demonstrar a potencialidade dos bivalves fósseis, como indicadores da dinâmica sedimentar $\mathrm{e}$,

e- Propor uma nova metodologia para análises paleossinecológicas de assembléias de macroinvertebrados bentônicos, especialmente as dominadas por moluscos bivalves. 


\section{MATERIAIS \& MÉTODOS}




\section{MATERIAIS \& MÉTODOS}

\subsection{Coleções Científicas EXaminadas}

Para o presente estudo foram examinados cerca de 3000 exemplares de bivalves do Grupo Passa Dois (exclusive Formação Rio do Rasto), depositados em três coleções científicas: a- Coleção Científica do Laboratório de Paleozoologia Evolutiva do Instituto de Biociências da Universidade Estadual Paulista/UNESP, Campus de Botucatu; b- Coleção Científica do Instituto de Geociências da Universidade de São Paulo/USP, incluindo o material tipo estudado por Mendes (1944, 1952, 1963) e Runnegar \& Newell (1971) e, cColeção Científica do Instituto Geológico da Secretaria do Estado do Meio Ambiente de São Paulo (SMA), analisada por Mezzalira (1957) e Maranhão $(1986,1995)$.

No quadro 1, estão listados todos os táxons que compõem as assembléias examinadas. Os quadros 2, 3 e 4 sintetizam o conhecimento morfológico prévio das espécies envolvidas nesta análise. Depreende-se da análise dos quadros 2,3 e 4 que, do ponto de vista morfológico, os bivalves melhor conhecidos são os provenientes da assembléia de Pinzonella illusa, possivelmente porque com freqüência eles ocorrem com as conchas silicificadas e, portanto, em excelente estado de preservação (e.g., Mendes, 1952; Runnegar \& Newell, 1971; Simões \& Fittipaldi, 1987, 1992; Simões, 1992; Simões \& Anelli, 1995; Simões \& Mello, 1996). Não obstante porém, algumas espécies desta assembléia permaneciam, até o momento, no que diz respeito à sua morfologia interna, inadequadamente descritas (e.g., Holdhausiella elongata). Contrariamente, as espécies provenientes da assembléia de Anhembia froesi, que normalmente ocorrem na forma de moldes internos ou compostos, com forte compressão lateral, não eram bem conhecidos do ponto de vista de sua anatomia interna (Ghilardi \& Simões, 1997).

Conforme mostrado no quadro 2, foram identificadas e descritas algumas das feições musculares presentes em Anhembia froesi, Anhembia gigantea, Barbosaia angulata e Holdhausiella almeidai, todas da assembléia de Anhembia froesi (Ghilardi \& Simões, 1997). Das espécies morfologicamente pouco conhecidas da assembléia de Pinzonella ilusa, foram observadas e descritas as características internas de Holdhausiella elongata. Apesar de diversos moldes internos de Coxesia mezzalirai terem sido examinados, a presença de inserções musculares não foi constatada nesta espécie. 
Quadro 1- Relação das espécies presentes nas três assembléias malacofaunísticas do Grupo Passa Dois, no Estado de São Paulo.

\begin{tabular}{|c|c|}
\hline As & ção \\
\hline $\begin{array}{c}\text { Assembléia } \\
\text { Pinzonella neotropica } \\
\text { (formações Terezina e } \\
\text { Corumbataí) }\end{array}$ & $\begin{array}{l}\text { Casterella gratiosa Mendes, 1952; Ferrazia } \\
\text { cardinalis Reed, 1932; Jacquesia brasiliensis } \\
\text { (Reed), 1929; Holdhausiella elongata } \\
\text { (Holdhaus), 1918; Naiadopsis lamellosus } \\
\text { Mendes, 1952; Pinzonella neotropica (Reed), } \\
\text { 1928; Cowperesia anceps (Reed), 1935; Roxoa } \\
\text { intricans (Mendes), } 1944\end{array}$ \\
\hline $\begin{array}{c}\text { Assembléia } \\
\text { Pinzonella illusa } \\
\text { (formações Terezina e } \\
\text { Corumbatai) }\end{array}$ & 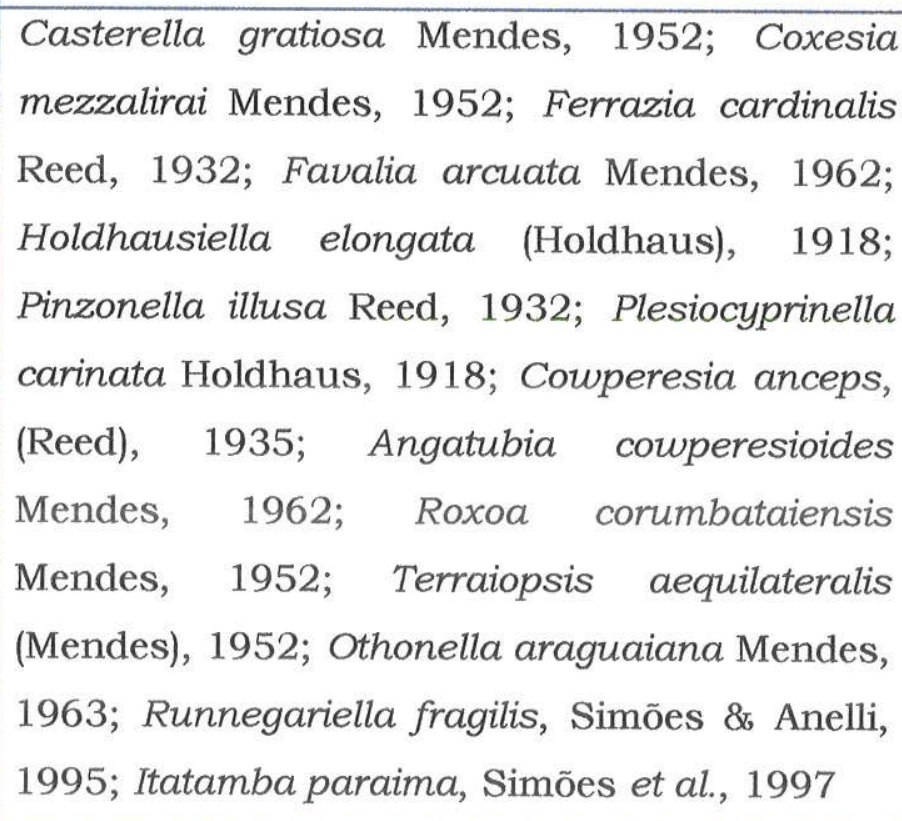 \\
\hline $\begin{array}{c}\text { Assembléia } \\
\text { Anhembia froesi } \\
\text { (formações Serra Alta e } \\
\text { Corumbataí) }\end{array}$ & $\begin{array}{lr}\text { ?Anthraconaia mezzalirai, Maranhão, } & \text { 1995; } \\
\text { Barbosaia angulata } & \text { Mendes, } \\
\text { Tambaquyra camargoi (Beurlen), } & \text { 1954b; } \\
\text { Ferrazia simplicicarinata, Maranhão, } & \text { 1986; } \\
\text { Holdhausiella almeidai Mendes, } & \text { 1952; } \\
\text { Anhembia froesi (Mendes), 1949; Pinzonella cf. } \\
\text { illusa Reed, 1932; Rioclaroa lefevrei Mezzalira, } \\
\text { 1957; Maackia contorta, Mendes, } 1954 ; \\
\text { Mendesia piracicabensis, Maranhão, } 1986\end{array}$ \\
\hline
\end{tabular}


Quadro 2-Características morfológicas dos bivalves da assembléia de Anhembia froesi. Fonte: Maranhão $(1986,1995)$ e Ghilardi \& Simões (1997). ๑ Feição descrita originalmente neste estudo.

\begin{tabular}{|c|c|c|c|c|c|c|c|c|c|c|c|}
\hline \multicolumn{11}{|c|}{ Características Morfológicas } & \\
\hline & \multicolumn{4}{|c|}{ Externas } & \multicolumn{7}{|c|}{ Internas } \\
\hline Espécie & $\begin{array}{l}\text { Descontinuidade } \\
\text { sifonal/pedial }\end{array}$ & $\begin{array}{l}\text { Carena } \\
\text { umbonal }\end{array}$ & Margem ventral & Ornamentação & $\begin{array}{l}\text { Tipo de linha } \\
\text { palial }\end{array}$ & Sinus palial & $\begin{array}{l}\text { Musculatura } \\
\text { do manto }\end{array}$ & $\begin{array}{l}\text { Inserções do adutor } \\
\text { (posterior/anterior) } \\
\text { e retrator }\end{array}$ & $\begin{array}{c}\text { Relação entre o } \\
\text { adutor } \\
\text { (posterior/anterior)/ } \\
\text { retrator } \\
\end{array}$ & $\begin{array}{l}\text { Margem } \\
\text { cardinal }\end{array}$ & $\begin{array}{c}\text { Dente } \\
\text { cardinal }\end{array}$ \\
\hline Anhembia froesi & Ausente & Presente & Lisa reta & Lisa & Estriada & Ausente & $\begin{array}{c}\text { Presente } \\
\text { (pontuações) }\end{array}$ & Bem definido $\odot$ & Fundido & $?$ & Triangular $\odot$ \\
\hline $\begin{array}{l}\text { ?Anthraconaia } \\
\text { mezzalirai }\end{array}$ & $?$ & Ausente & Lisa curvada & Lisa & $?$ & $?$ & $?$ & $?$ & $?$ & $?$ & $?$ \\
\hline $\begin{array}{c}\text { Barbosaia } \\
\text { angulata }\end{array}$ & $?$ & Presente & Lisa reta & Lisa & Lisa & Ausente & $?$ & Bem definido & Fundido & $?$ & $?$ \\
\hline $\begin{array}{l}\text { Maackia } \\
\text { contorta }\end{array}$ & $?$ & Carena dupla & Lisa reta & Lisa & $?$ & $?$ & $?$ & $?$ & $?$ & $?$ & $?$ \\
\hline $\begin{array}{c}\text { Mendesia } \\
\text { piracicabensis }\end{array}$ & $?$ & Presente & Lisa curvada & Lisa & Lisa & Ausente & $?$ & Bem definido & Fundido & $?$ & $?$ \\
\hline $\begin{array}{l}\text { Tambaquyra } \\
\text { camargoi }\end{array}$ & Ausente & Ausente & Lisa curvada & Nodular $\odot$ & Lisa $\odot$ & $?$ & Ausente $\odot$ & Bem definido $\odot$ & Fundido $\odot$ & $\begin{array}{c}\text { Espessa, } \\
\text { formando } \\
\text { estrutura } \\
\text { odontóide @ }\end{array}$ & Ausente $\odot$ \\
\hline
\end{tabular}


Quadro 3- Características morfológicas dos bivalves da assembléia de Pinzonella illusa. Fonte: Simões et al. (1997); Mello et al. (1998a) e Mello (1999).

\begin{tabular}{|c|c|c|c|c|c|c|c|c|c|c|c|}
\hline \multicolumn{12}{|c|}{$\begin{array}{l}\text { Características Morfológicas } \\
\end{array}$} \\
\hline & \multicolumn{4}{|c|}{ Externas } & \multicolumn{7}{|c|}{ Internas } \\
\hline Espécie & $\begin{array}{c}\text { Descontinuidade } \\
\text { sifonal/pedial }\end{array}$ & Carena umbonal & Margem ventral & Ornamentação & Tipo de linha palial & Sinus palial & $\begin{array}{l}\text { Musculatura do } \\
\text { manto }\end{array}$ & $\begin{array}{l}\text { Inserç̃es do adutor } \\
\text { (posterior/anterior) } \mathrm{e} \\
\text { retrator }\end{array}$ & $\begin{array}{l}\text { Relação entre o adutor } \\
\text { (posterior/anterior)/ } \\
\text { retrator }\end{array}$ & Margem cardinal & Dente cardinal \\
\hline $\begin{array}{c}\text { Angatubia } \\
\text { cowperesioides }\end{array}$ & Pequena sifonal & Ausente & Lisa, curva & Lisa & $?$ & $?$ & $?$ & $?$ & $?$ & $\begin{array}{l}\text { Espessa, formando } \\
\text { estrutura semelhante } \\
\text { a dente }\end{array}$ & Triangular \\
\hline Casterella gratiosa & Pequena sifonal & Ausente & Lisa, curva & Lisa & Lisa & $\begin{array}{l}\text { Pequeno } \\
\text { sinus }\end{array}$ & Ausente & Desconhecido & Não fundidos & Pouco espessa & Ausente \\
\hline Cowperesia anceps & Pequena sifonal & Presente & Lisa, curva & Concêntrica & Lisa & Pequeno sinus & Ausente & $\begin{array}{l}\text { Bem definido, } \\
\text { profundamente } \\
\text { impresso }\end{array}$ & Não fundidos & $\begin{array}{l}\text { Espessa formando } \\
\text { estruutura sementhante } \\
\text { a dente }\end{array}$ & Triangular \\
\hline Coxesia mezzaliraia & Pequena bissal & Ausente & Lisa, reta & Lisa & $?$ & Ausente & Ausente & Desconhecido & $?$ & Pouco espessa & Ausente \\
\hline Favalia arcuata & Ausente & Presente & Lisa, curva & Lisa & Lisa & Ausente & Ausente & Bem definido & Não fundidos & Pouco espessa & Triangular \\
\hline Ferrazia cardinalis & Ausente & Presente & Lisa, curva & Radial & Lisa & Ausente & Ausente & $\begin{array}{c}\text { Bem definido, } \\
\text { profundamente } \\
\text { impresso }\end{array}$ & Não fundidos & Pouco espessa & $\begin{array}{l}\text { Triangular com face } \\
\text { côncava }\end{array}$ \\
\hline $\begin{array}{c}\begin{array}{c}\text { Holdhausiella } \\
\text { elongata }\end{array} \\
\end{array}$ & Ausente & Presente & Lisa, reta & Lisa & Lisa & Ausente & Ausente & $\begin{array}{c}\text { Bem definido, } \\
\text { profundamente } \\
\text { impresso }\end{array}$ & Não fundidos & Pouco espessa & Triangular \\
\hline Itatamba paraima & Pequena sifonal & Ausente & Lisa, curva & Lisa & Lisa & Deconhecido & Ausente & Bem impresso & Não fundidos & Pouco espessa & Ausente \\
\hline $\begin{array}{c}\text { Othonella } \\
\text { araguaiana }\end{array}$ & Ausente & Presente & Lisa, curva & Ausente & $?$ & $?$ & $?$ & Bem definido & Fundido & Espessa & Triangular \\
\hline Pinzonella illusa & Ausente & Presente & Lisa, curva & Lisa & Lisa & Ausente & Ausente & $\begin{array}{c}\text { Bem definido, } \\
\text { profundamente } \\
\text { impresso }\end{array}$ & Não fundidos & Pouco espessa & Triangular \\
\hline $\begin{array}{l}\text { Plesiocyprinellia } \\
\text { carinata }\end{array}$ & Pequena sifonal & Presente & Lisa, curva & Lisa & Lisa & Ausente & Ausente & $\begin{array}{l}\text { Bem definido, } \\
\text { profundamente } \\
\text { impresso }\end{array}$ & Não fundid̄os & Pouco espessa & $\begin{array}{l}\text { Triangular com face } \\
\text { côncava }\end{array}$ \\
\hline $\begin{array}{c}\text { Roxoa } \\
\text { corumbataiensis }\end{array}$ & $\begin{array}{l}\text { Pequena sifonal e } \\
\text { grande pedial }\end{array}$ & Ausente & Lisa, reta & Lisa & Lisa & Sinus pronunciado & Ausente & $?$ & Não fundidos & Pouco espessa & Ausente \\
\hline Runnegariella fragilis & Ausente & Presente & Lisa, curva & Concêntrica & Digitada & Ausente & Ausente & $?$ & Fundidos & $\begin{array}{l}\text { Espessa, formando } \\
\text { estrutura odontóide }\end{array}$ & Triangular \\
\hline $\begin{array}{c}\text { Terraiopsis } \\
\text { aequilateralis }\end{array}$ & Ausente & Presente & Lisa, curva & Lisa & Lisa & Ausente & Ausente & $\begin{array}{c}\text { Bem definido, } \\
\text { profundamente } \\
\text { impresso }\end{array}$ & Não fundidos & Pouco espessa & Triangular \\
\hline
\end{tabular}


Quadro 4- Características morfológicas dos bivalves da assembléia de Pinzonella neotropica. Fonte: Simões et al. (1997); Mello et al. (1998a) e Mello (1999).

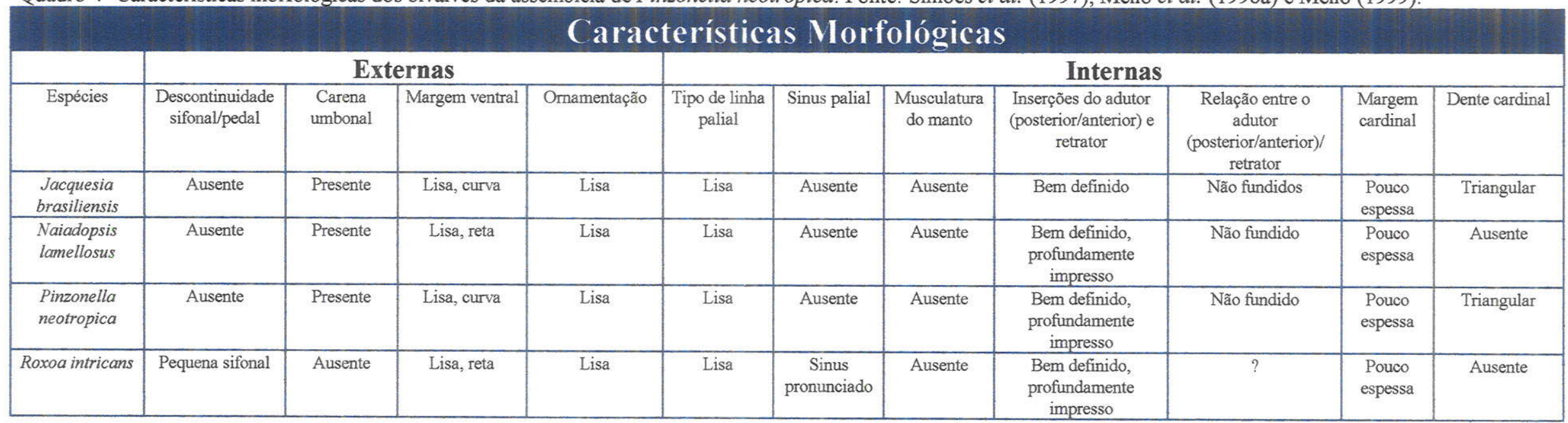


Embora em muitas das ocorrências fossilíferas da assembléia de Pinzonella neotropica as conchas estejam silicificadas e densamente concentradas, formando coquinas (Simões, 1996; Simões et al., 1996a), algumas das espécies encontradas estão bem preservadas (e.g., Cowperesia anceps, Jacquesia brasiliensis, Pinzonella neotropica). No entanto, outras espécies (e.g., Naiadopsis lamellosus), até o início do presente estudo, permaneciam também inadequadamente descritas, já que suas inserções musculares e a charneira não eram bem conhecidas. Este problema pode ser solucionado a partir da recente descoberta, na região de Tambaú, SP, de conchas bem preservadas de Naiadopsis lamellosus (Torello \& Simões, 1997; Torello, 1999), possibilitando a análise detalhada de sua morfologia interna e, deste modo, uma interpretação mais segura de seu modo de vida.

\subsection{Trabalhos de Campo}

Maranhão (1986) revisou os bivalves da assembléia de Anhembia froesi, no Estado de São Paulo, tendo demonstrado que esta assembléia era mais diversificada do que o suposto anteriormente. A autora não pode, contudo, contribuir de maneira decisiva para o conhecimento da morfologia interna das conchas desta assembléia, em razão da qualidade de preservação do material estudado. Maranhão (1986) estudou quatro localidades, muitas das quais já mencionadas por Mezzalira (1957). São as seguintes localidades citadas por Maranhão (1986): a- km 11 da Rodovia Rio Claro-Piracicaba (SP-127), Rio Claro; b- rodovia Rio Claro-Ipeúna-Charqueada, a cerca de $200 \mathrm{~m}$ antes da margem esquerda do Rio da Cabeça, Rio Claro; c- km 163 da rodovia Washington Luís (SP-310), Cordeirópolis e, d- km 7 da antiga rodovia Rio Claro-Piracicaba, Rio Claro.

Desde que estas localidades poderiam constituir locais apropriados para coleta adicional de bivalves da assembléia de Anhembia froesi, diversos trabalhos de campo foram realizados no sentido de relocalizá-los. Durante os trabalhos de campo verificou-se, no entanto, que os quatro afloramentos descritos, estudados por Maranhão (1986) não mais existiam, em função do pronunciado intemperismo dos sedimentos ou devido a sua destruição por obras de cunho civil ou atividade agrícola (e.g., pequenas mudanças do curso da estrada, utilização de máquinas agrícolas para preparo de solo e plantio de cana-de-açúcar). 
A fim de solucionar estas questões foram realizados trabalhos de campo em outras áreas de afloramentos do Grupo Passa Dois (formações Serra Alta, Terezina e Corumbataí), no Estado de São Paulo. Para organizar o trabalho de coleta, a faixa de afloramentos do Grupo Passa Dois, segundo o IPT (1981), foi subdividida em três grandes áreas: a- porção sudoeste (município de Angatuba), b- porção centro-sul (municípios de Porangaba e Bofete) e, cporção nordeste (municípios de Rio Claro, Piracicaba e Tambaú), As concentrações fossilíferas da região de Angatuba, face a má qualidade das exposições e ao profundo intemperismo dos sedimentos, pouco contribuiram com novos exemplares bem preservados. Entretanto, nos afloramentos da porção centro-sul (formações Serra Alta e Terezina) e da porção nordeste (Formação Corumbatai) foram descobertas diversas novas ocorrências, contendo bivalves bem preservados das assembléias de Anhembia froesi, Pinzonella illusa e Pinzonella neotropica (veja Ghilardi et al., 1997; Mello et al., 1998b; Torello, 1999).

Foram os seguintes os afloramentos examinados, aqui informalmente designados por números:

\section{A- Região Centro-Sul}

Afloramentos 1 e 2, situados, respectivamente nos quilômetros 160,5 e 161,5 da Rodovia Castello Branco (SP-280), no sentido capital-interior (figs. 1 e 2).

Nestes afloramentos estão expostos os sedimentos da base da Formação Serra Alta (Sousa, 1985; Maranhão, 1995), representados por espessa sucessão de siltitos e argilitos maciços ou com laminação plano-paralela, com intercalações de arenitos e calcários, com acamamento ondulado ou irregular e finas intercalações de folhelhos (Sousa, 1985; Maranhão, 1986, 1995; Simões \& Rohn, 1996; Torello et al., 1997). Estes sedimentos são cortados por diques clásticos de arenito muito fino (Sousa, 1985). Concreções calcárias, epigenéticas, lenticulares, centimétricas à métricas (fig. 3), de calcita micrítica (Sousa, 1985), paralelas ao plano de acamamento são comuns (figs. 2 e 4). No caso do afloramento 1 chama a atenção o fato de as conchas estarem preservadas no interior destas concreções (Mello et al., 1998a). 


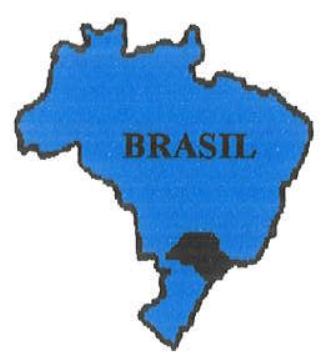

(3) Afloramentos fossiliferos
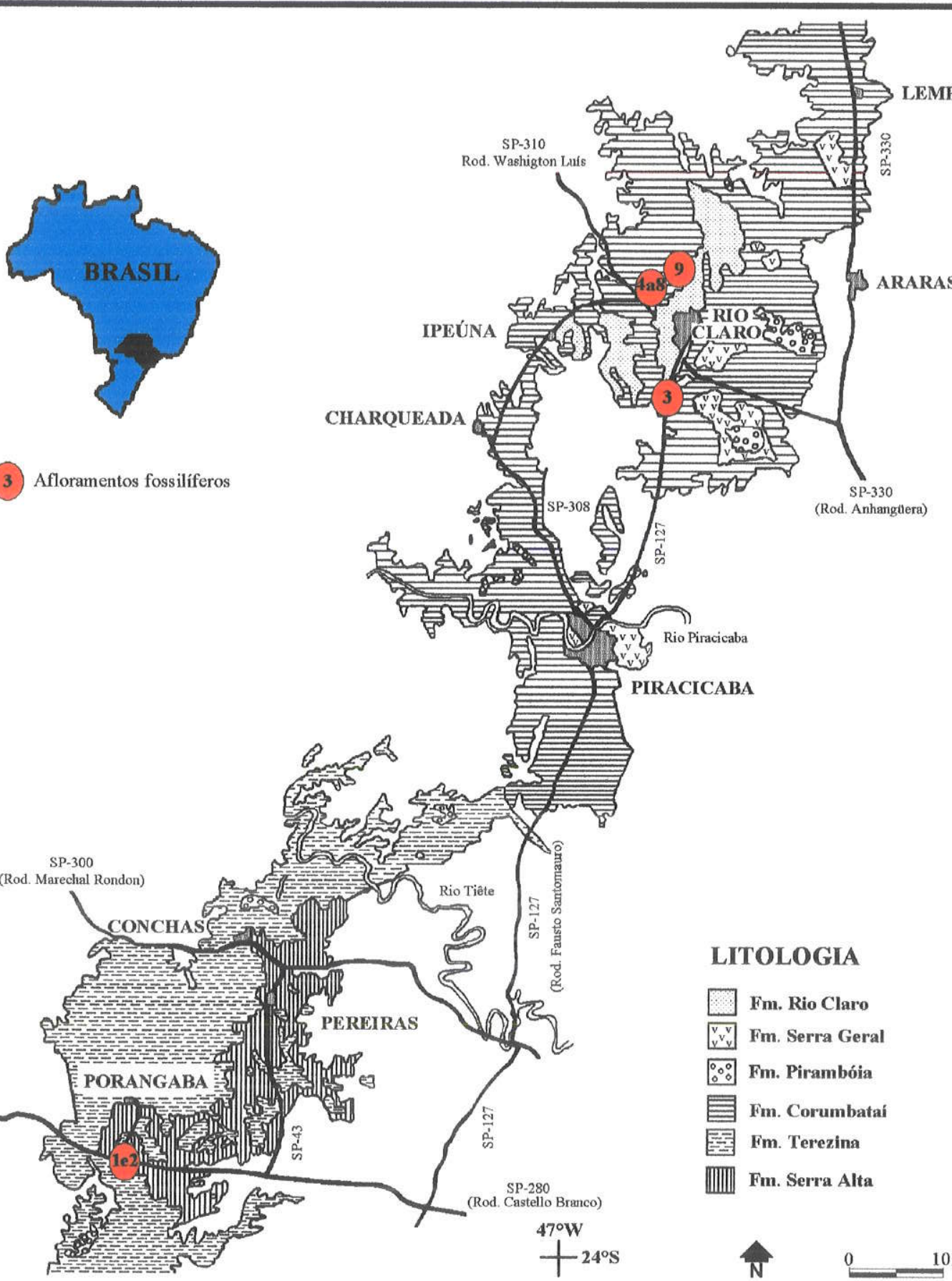

\section{LITOLOGIA}

Fm. Rio Claro

viv. Serra Geral

$\because \%$ Fm. Pirambóia

Fm. Corumbataí

Fm. Terezina

Fm. Serra Alta

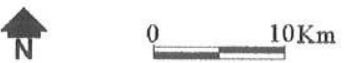

Figura 1- Mapa de localização dos afloramentos estudados, na região de Porangaba e Rio Claro, SP. Explicação no texto. 


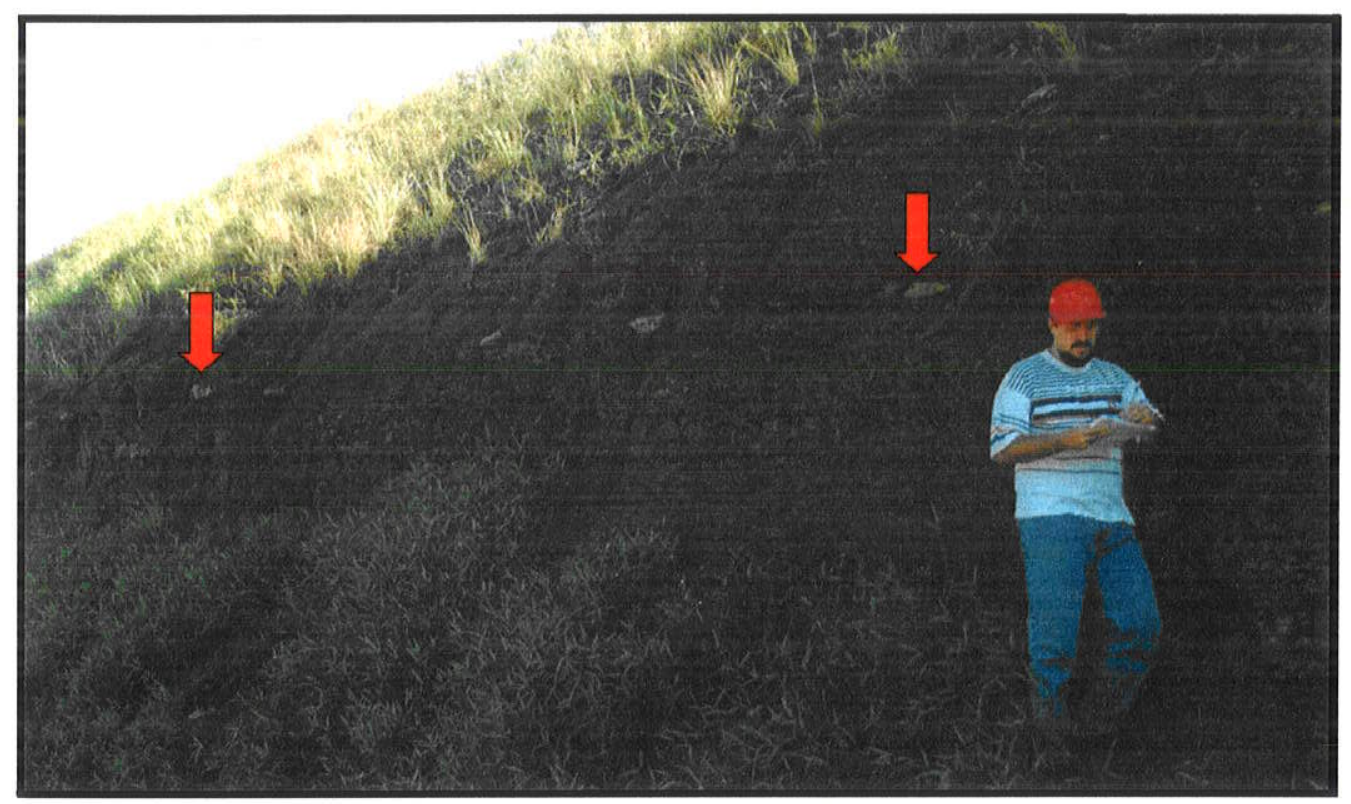

Figura 2- Vista geral do afloramento 2, Formação Serra Alta, município de Porangaba, SP. A seta indica o nível mais inferior com concreções.

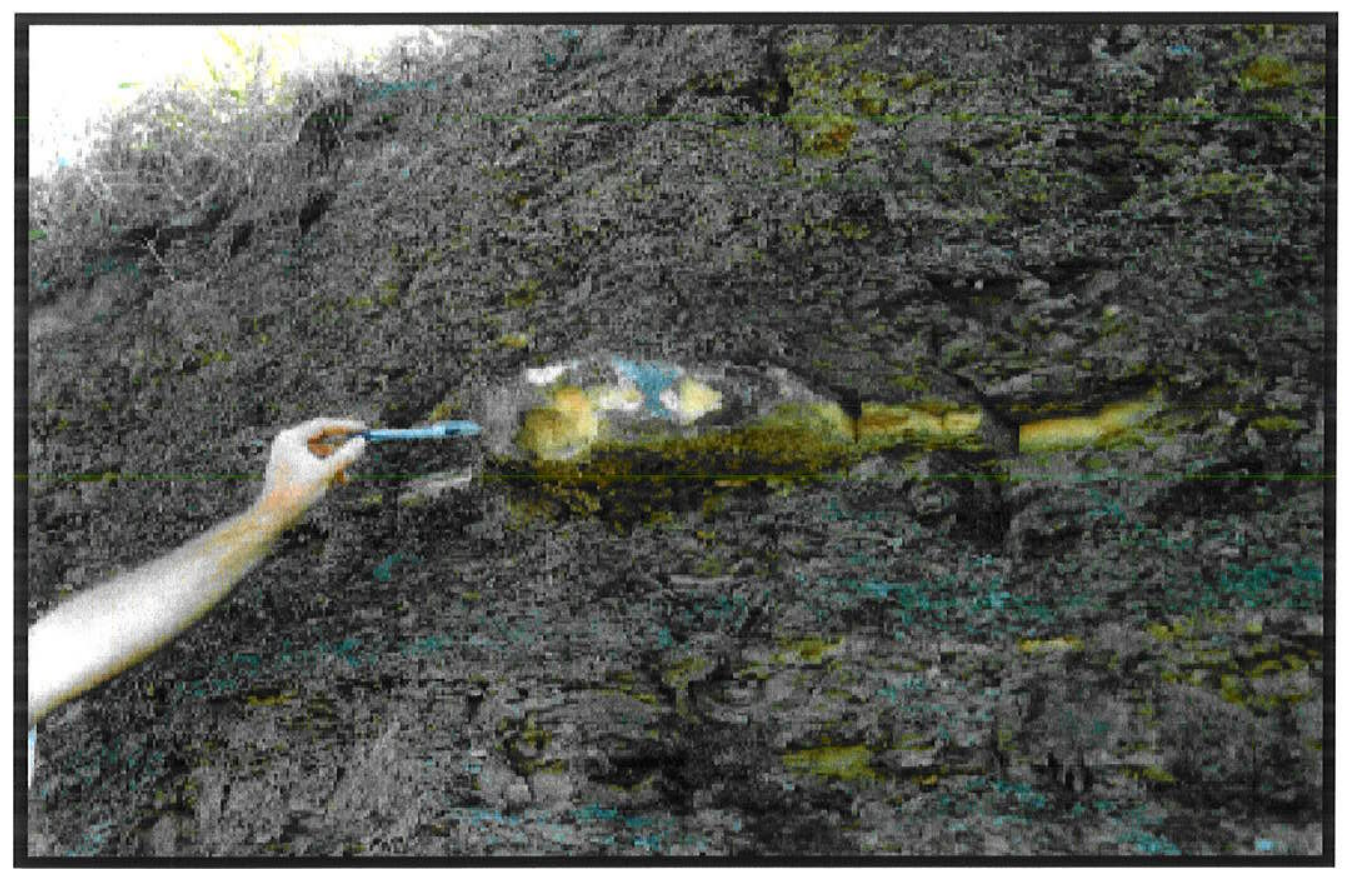

Figura 3- Concreção carbonática, centimétrica, Formação Serra Alta, município de Porangaba, SP. 


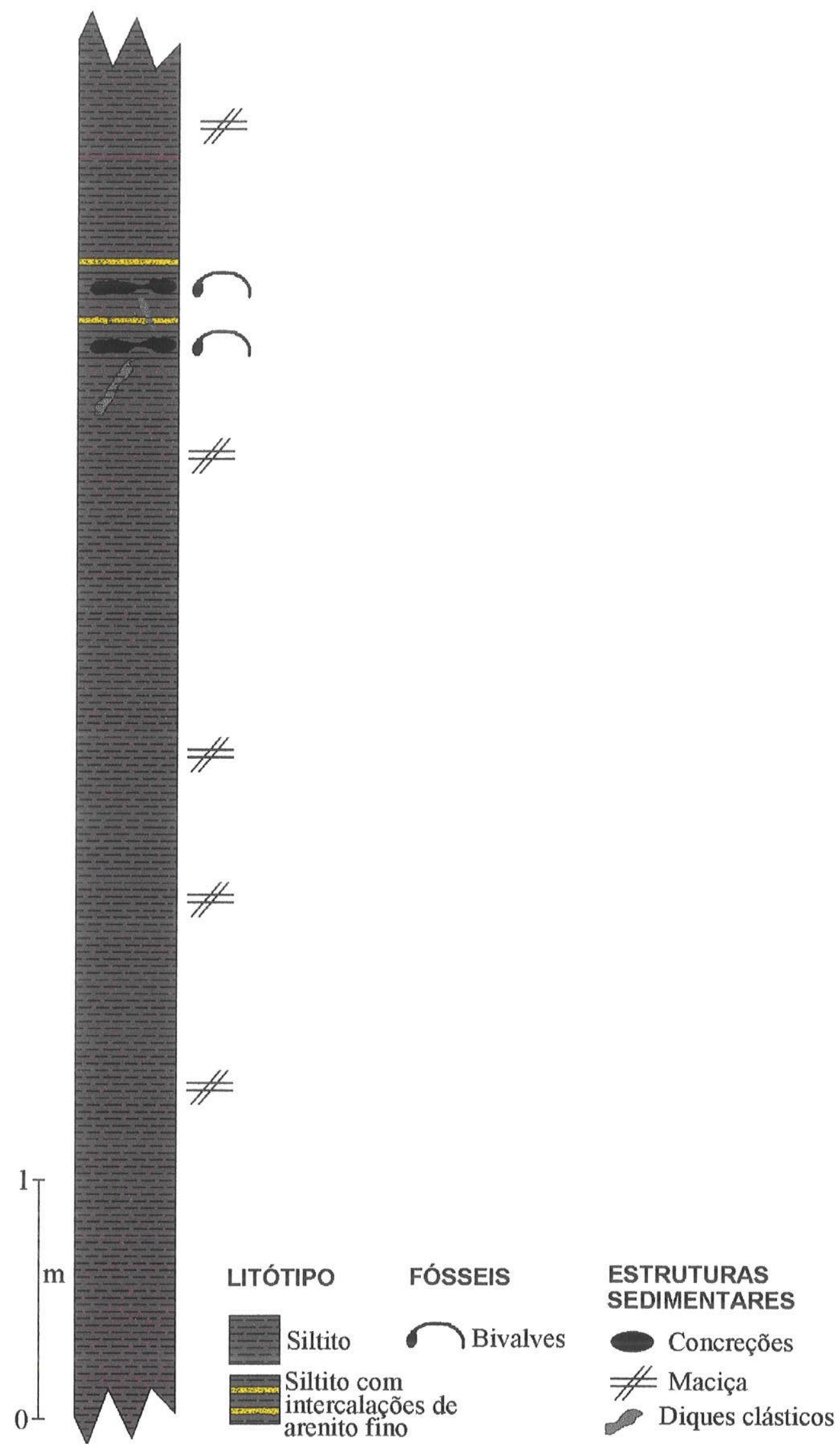

Figura 4- Seção colunar do afloramento 1, Formação Serra Alta, município de Porangaba, SP. 


\section{B- Região Nordeste}

Afloramento 3, aproximadamente no quilometro 10,5 da rodovia Fausto Santomauro, no sentido Rio Claro-Piracicaba (fig. 1), na pedreira do Calcário Vitte. Nesta localidade os sedimentos da base da Formação Corumbataí constituem a parte superior da pedreira de extração de calcário do Membro Assistência da Formação Irati (figs. 1 e 5). A ocorrência de bivalves nesta seção não é desconhecida na literatura geológica (Maranhão, 1986), mas esta localidade dista cerca de $500 \mathrm{~m}$ da estudada por essa autora.

Neste afloramento, os bivalves ocorrem cerca de 5,08 $\mathrm{m}$ acima do contato com a Formação Irati (fig. 6), considerando-se a última intercalação de folhelhos pirobetuminosos (fig. 7). Estes são transicionalmente sucedidos pelos argilitos arroxeados, maciços ou com incipiente laminação plano-paralela, com fratura conchoidal e raras intercalações de arenitos finos, com base erosiva, que caracterizam a Formação Corumbataí nesta área (fig. 9). As conchas estão representadas por moldes internos e externos, dispersas nos sedimentos e normalmente distribuídas concordantemente ao plano de acamamento, com a convexidade voltada para cima, embora conchas dispostas obliquamente sejam comuns. Predominam as conchas desarticuladas, especialmente as valvas esquerdas, as quais associam-se a raras conchas articuladas abertas. No geral, os bioclastos apresentam tamanho variando entre 15 a $30 \mathrm{~mm}$. As seguintes espécies foram verificadas neste afloramento: Tambaquyra camargoi, Mendesia piracicabensis, Maackia contorta, ?Anthraconaia mezzalirai, Holdhausiella almeidai e Barbosaia angulata.

A descoberta desta ocorrência revestiu-se de grande importância uma vez que foi possível determinar, pela primeira vez, com precisão, o posicionamento estratigráfico dos bivalves da assembléia de Anhembia froesi, em relação à base da Formação Irati, o que era anteriormente apenas inferido a partir de dados de superfície, cujos sedimentos estão profundamente intemperizados (Maranhão, 1995) (fig. 8). 


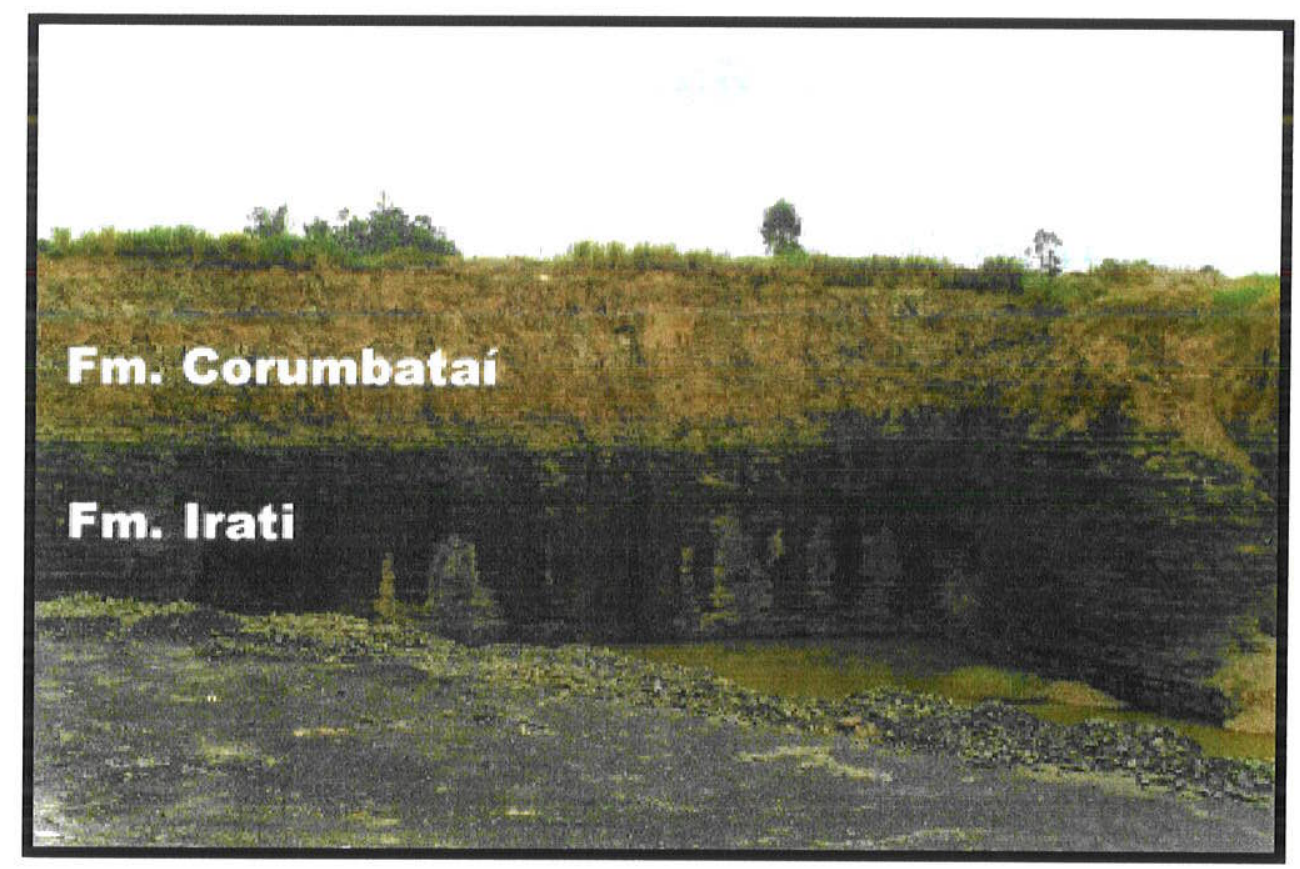

Figura 5- Vista geral do afloramento 3, na pedreira do Calcário Vitte.

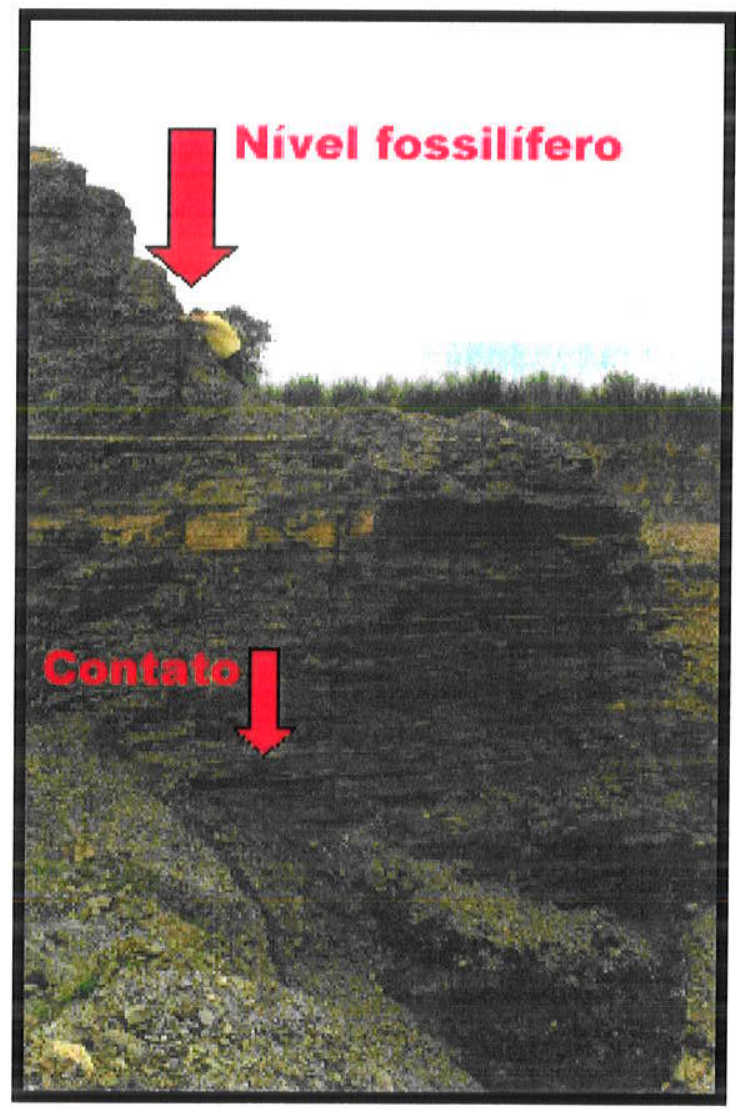

Figura 6- Afloramento 3, na pedreira do Calcário Vitte, Formação Corumbataí. 


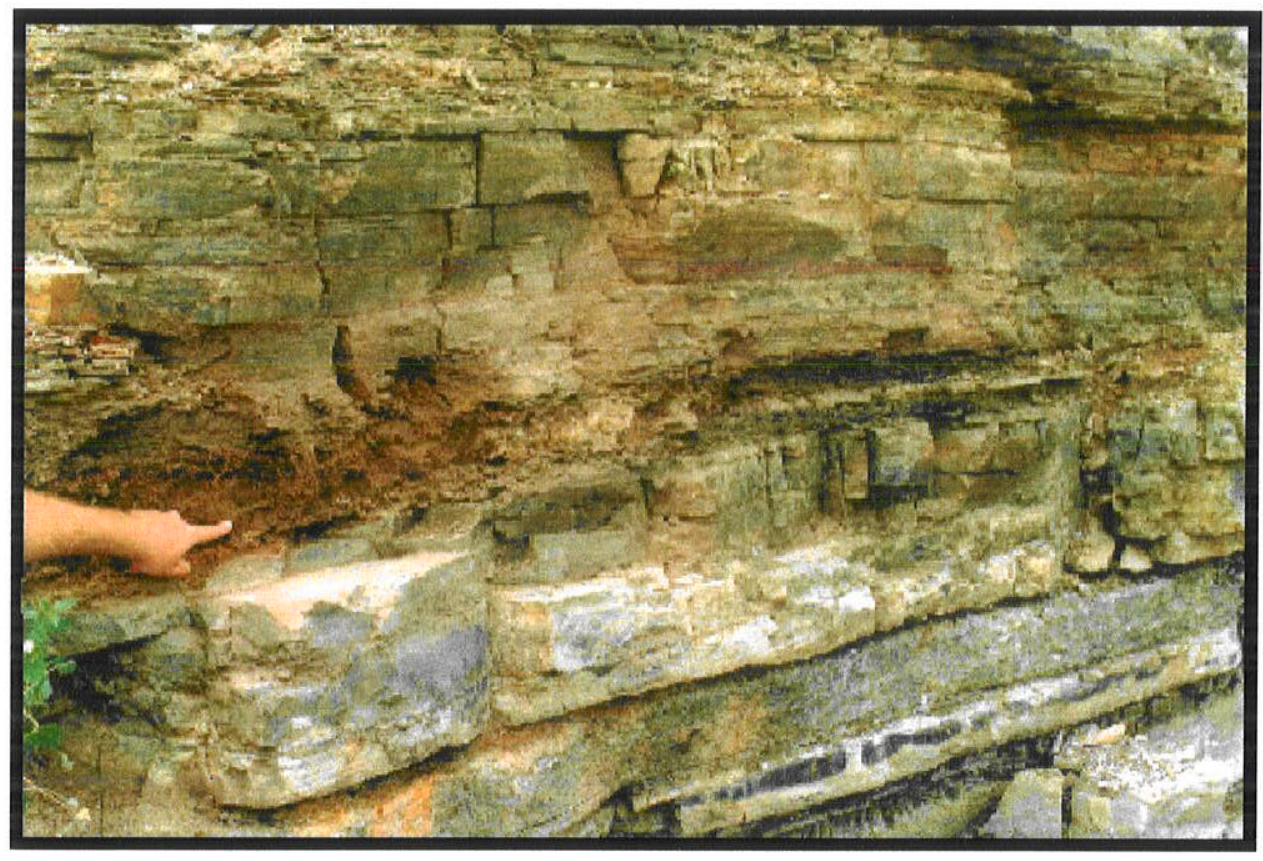

Figura 7- Detalhe do contato entre as formações Irati e Corumbataí, mesma localidade acima.

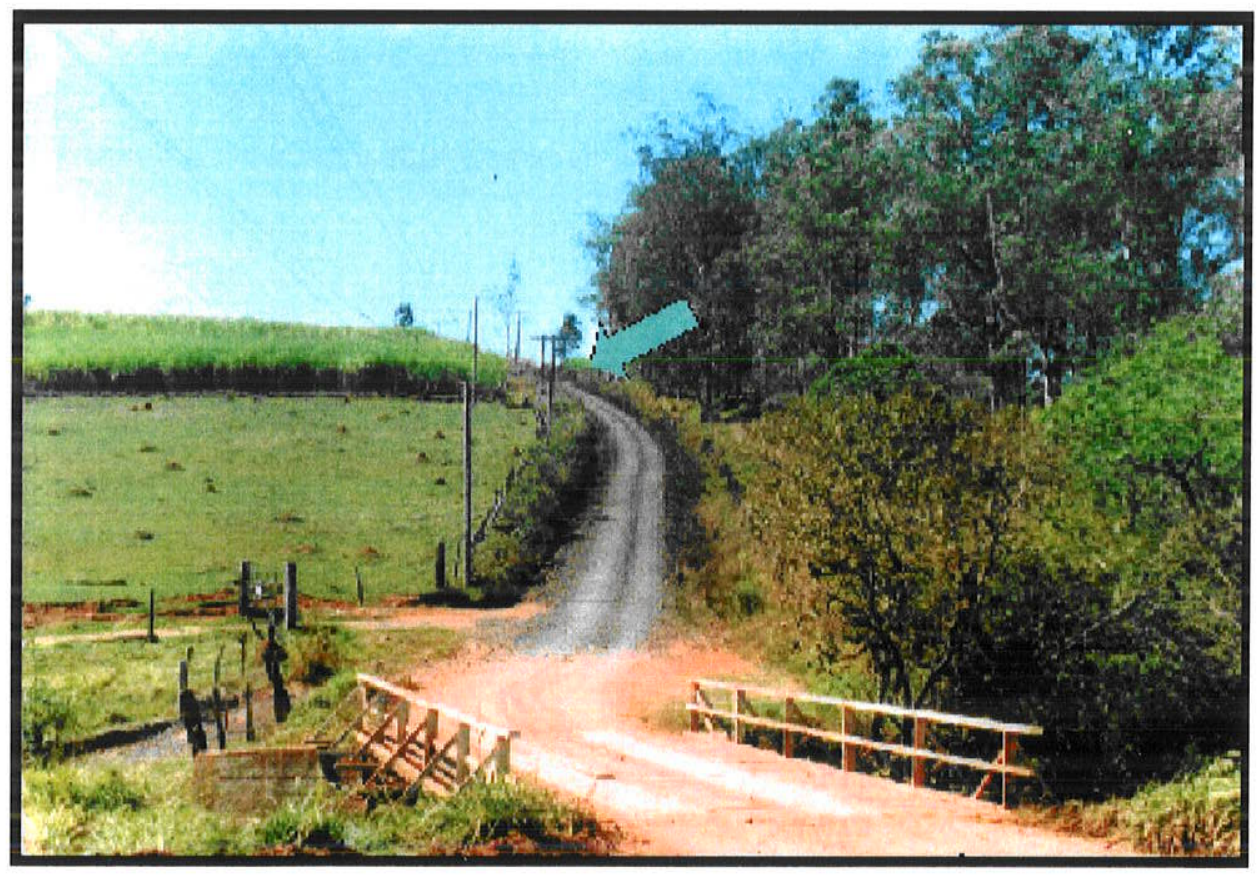

Figura 8- Provável local do antigo afloramento na rodovia Rio Claro-IpeúnaCharqueada, Formação Corumbataí. Explicação no texto. 


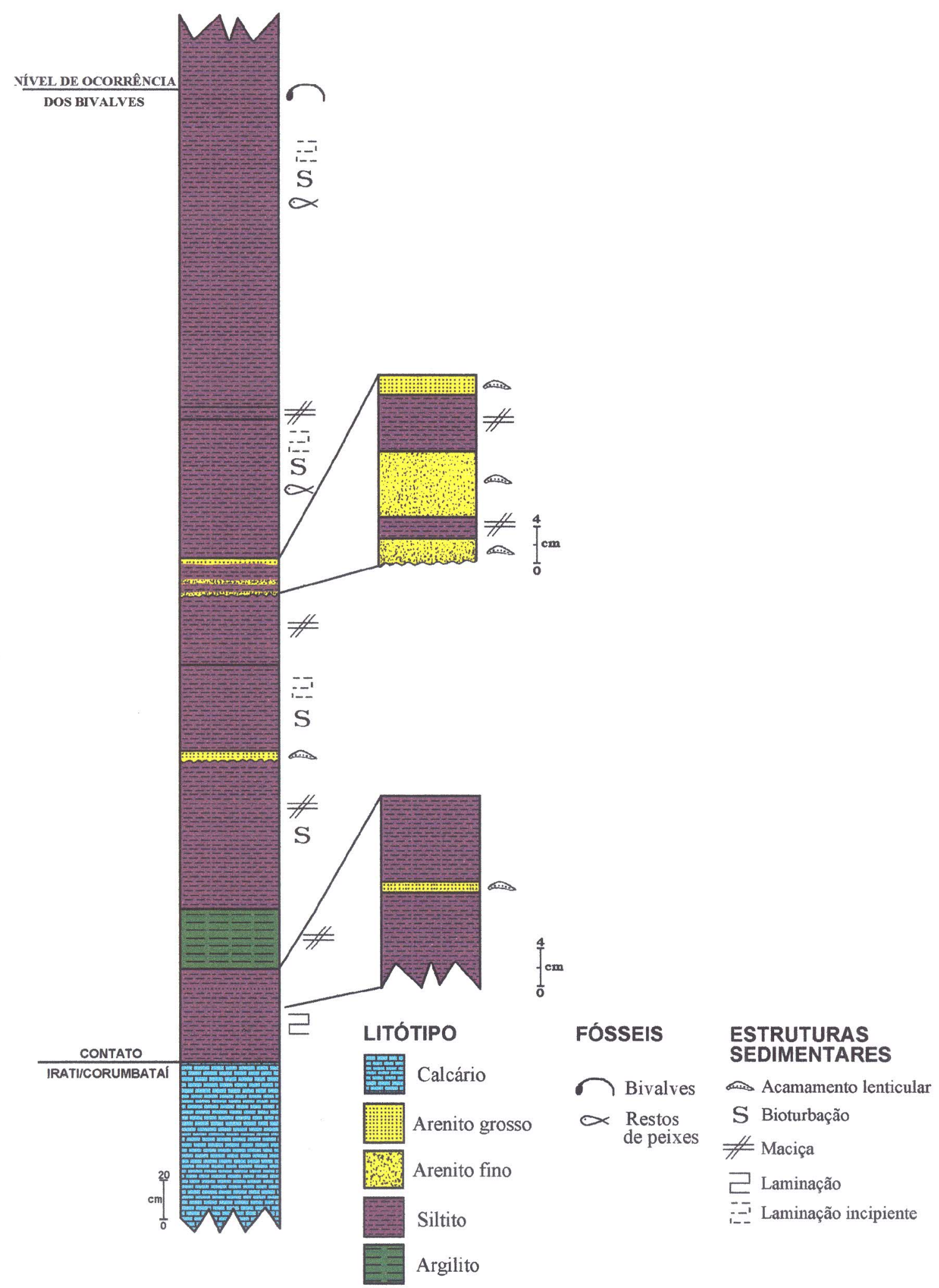

Figura 9- Seção colunar do afloramento 3, na pedreira do Calcário Vitte, município de Rio Claro, SP. 
Afloramento 4, situado cerca de 1,5 km antes da antiga estação de Ferraz, no distrito homônimo do município de Rio Claro, na estrada que liga Ajapi a Ferraz (fig. 10). Neste afloramento, as conchas encontram-se dispersas em arenito fino, silicificado (Mendes, 1952; Simões, 1990; Simões et al., 1994; Torello \& Simões, 1994; Simões \& Kowalewski, 1998a), com cerca de 30 a $50 \mathrm{~cm}$ de espessura. O contato basal do arenito, com os siltitos arroxeados com marcas onduladas e acamamento "flaser" é brusco e erosivo (fig. 11). Este afloramento forneceu a maior parte dos bivalves estudados, incluindo as seguintes espécies: Pinzonella illusa, Terraiopsis aequilateralis, Plesiocyprinella carinata, Casterella gratiosa, Cowperesia anceps, Holdhausiella elongata, Roxoa corumbataiensis, Favalia arcuata, Coxesia mezzalirai e Ferrazia cardinalis.

Já os afloramentos 5, 6, 7 e 8 estão localizados na Rua 6, no sentido da Fazenda Santa'anna de Urucaia, município de Rio Claro (fig. 10). Nestes locais afloram arenitos finos, com aproximadamente 30 a $50 \mathrm{~cm}$ de espessura semelhantes aos do afloramento de AjapiFerraz (veja também Ragonha, 1980). Os arenitos contêm conchas das seguintes espécies: Casterella gratiosa, Holdhausiella elongata, Plesiocyprinella carinata, Favalia arcuata, Terraiopsis aequilateralis, Pinzonella illusa e Ferrazia cardinalis.

O afloramento 9, está situado ao longo do leito abandonado da FEPASA (Ferrovia Paulista S.A.), a cerca de $700 \mathrm{~m}$ ao sul da sub-estação de Camaquã no município de Rio Claro, SP (fig. 1). Neste local, aflora a chamada coquina de Camaquã (Ragonha, 1984; Simões et al., 1996a) que intercala-se junto ao topo de um pacote de aproximadamente $8 \mathrm{~m}$ de siltito avermelhado e arroxeado, com marcas onduladas, lentes milimétricas de arenito fino e estruturas "flaser", correspondente à parte superior da Formação Corumbataí (fig. 12) (Simões et al., 1996a). A coquina, formada por bivalves densamente empacotados e caoticamente distribuído na matriz, estende-se lateralmente por cerca de $100 \mathrm{~m}$, tendo $11 \mathrm{~cm}$ de espessura máxima. 
R. P. Ghilardi 1999, Paleoautoecologia dos bivalves do Grupo Passa Dois (Neopermiano), no Estado de São Paulo: bivalves fósseis como indicadores da dinâmica sedimentar.

23

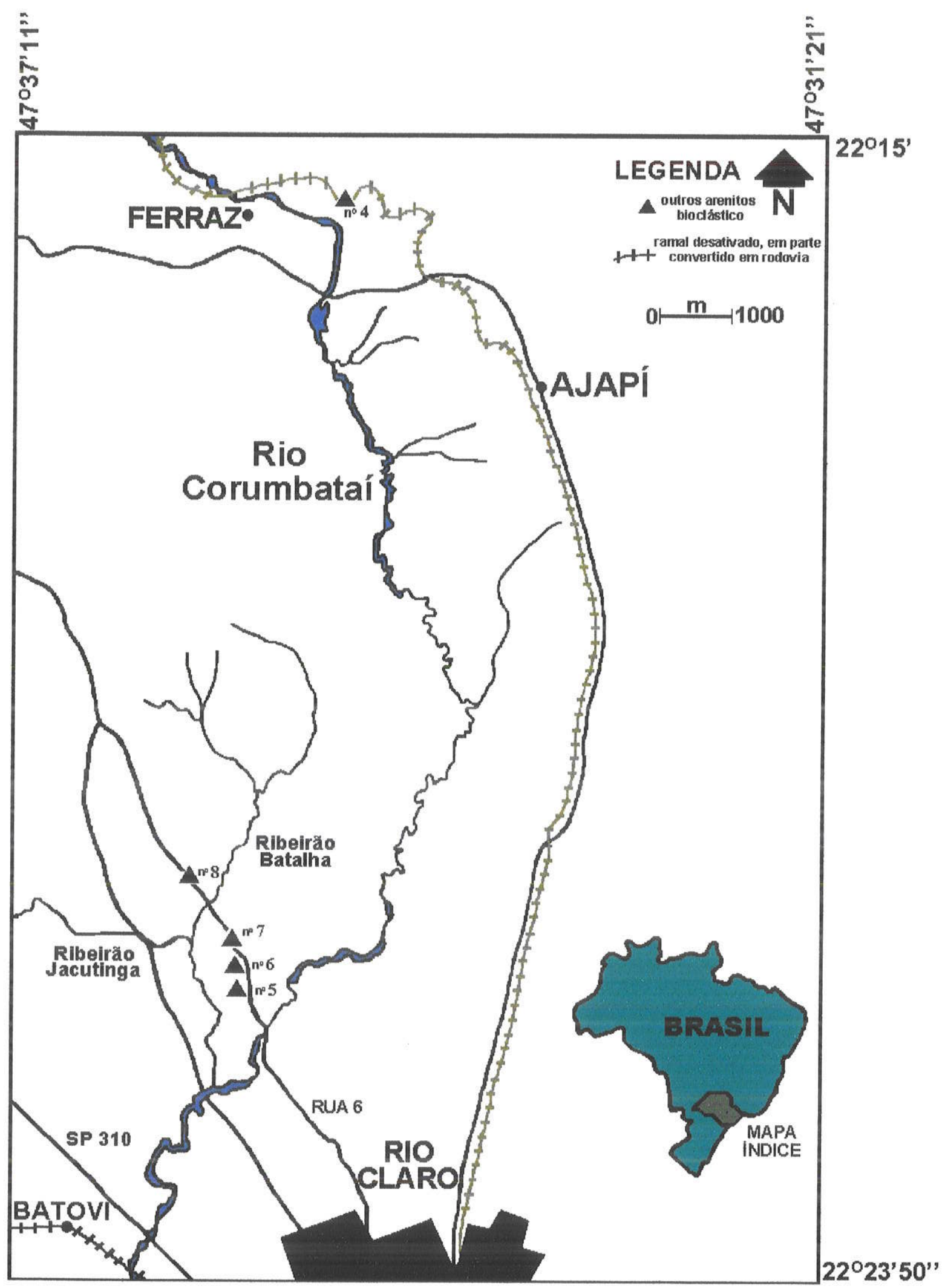

Figura 10- Mapa dos afloramentos fossilíferos da Formação Corumbataí, na região de Rio Claro, SP.

(Simões, 1998). 


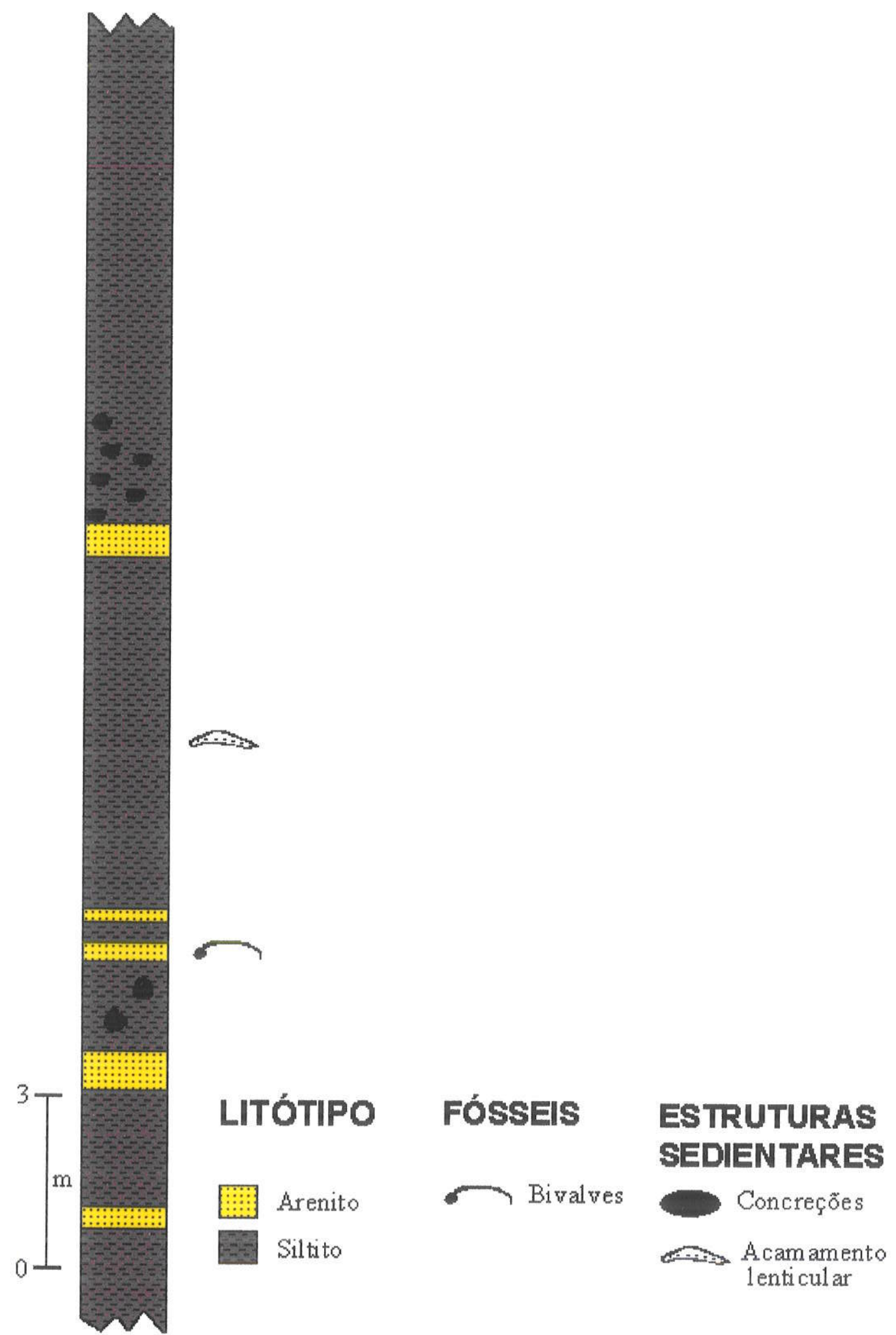

Figura 11- Seção colunar do afloramento 4, Formação Corumbataí, no distrito de Ferraz, SP (Simões, 1998). 


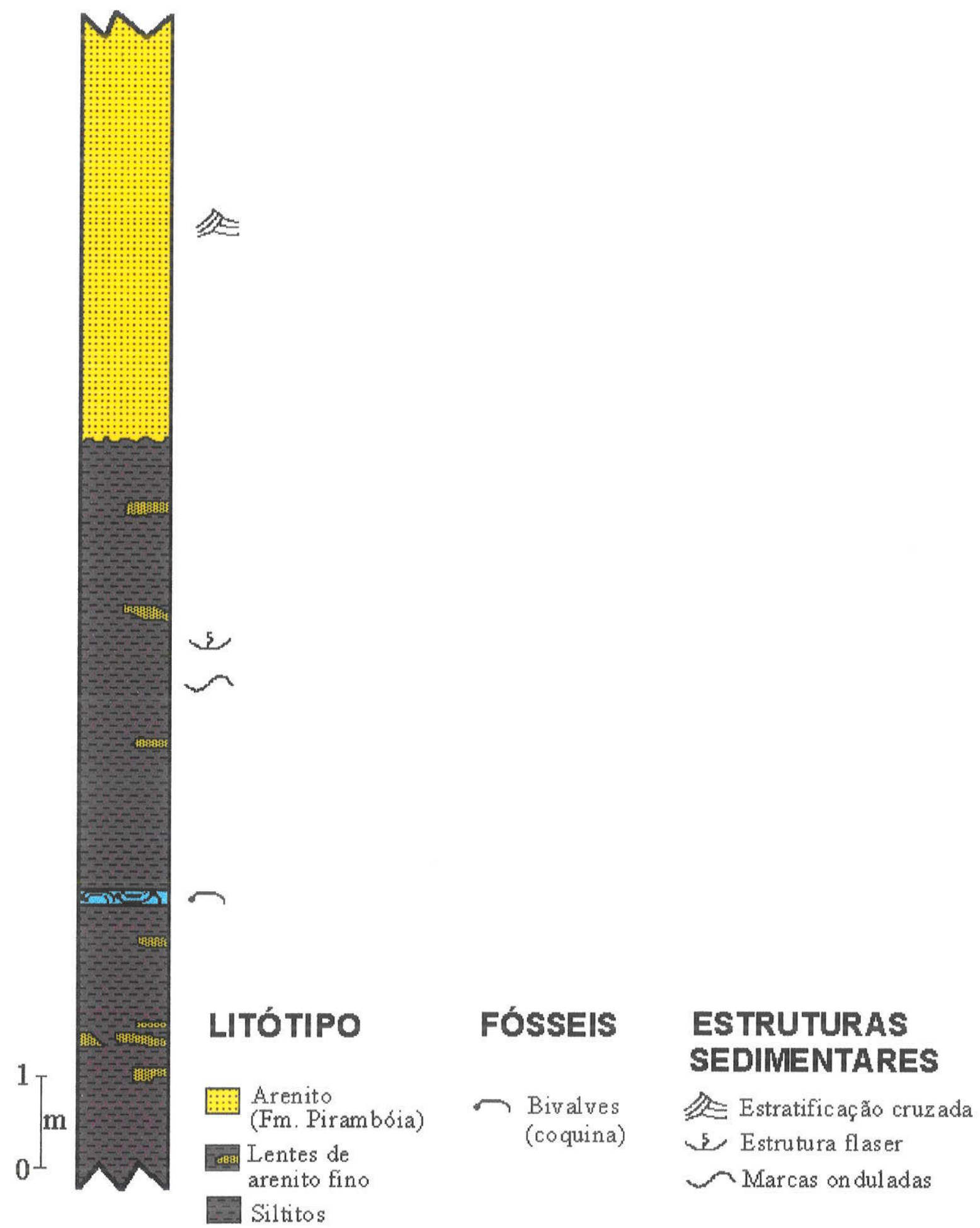

Figura 12- Seção colunar do afloramento 9, formações Corumbataí e Pirambóia, Rio Claro, SP. 
Já no município de Tambaú, encontram-se os afloramentos 10,11 e 12, situados a aproximadamente $5,2 \mathrm{~km}$ do rio Tambaú, a partir da cidade homônima, na antiga estrada secundária que liga Tambaú a Santa Rosa do Viterbo (Torello \& Simões, 1997; Torello, 1999).

O afloramento 10 , situa-se à margem direita da estrada cerca de $2 \mathrm{~km}$ após o entroncamento para a Fazenda São Roque (21 $1^{\circ} 39^{\prime} 58^{\prime \prime} \mathrm{S}$ e $47^{\circ} 14^{\prime} 86^{\prime \prime W}$ ) (fig. 13). A seção é formada, de um modo geral, por 90,02 m espessura de sedimentos atribuíveis à Formação Corumbataí. A 47,5 m da base, ocorre um pacote de arenito muito fino/siltito, com $2 \mathrm{~m}$ de espessura, que contém gretas de contração, marcas onduladas e estrutura ondulada ("wavy"). Acima ocorre um pacote de siltito e argilito, com gretas de contração, sucedido por uma intercalação de siltito bioturbado, com $10 \mathrm{~cm}$ de espessura, contendo bivalves fósseis. As conchas estão preferencialmente concentradas no topo da camada de siltito, com a convexidade das conchas preferencialmente voltadas para baixo. Ocorrem tanto conchas articuladas (85\%) como desarticuladas (Torello, 1999). O restante da seção é formado por pacotes métricos de arenito e siltito (fig. 14) (Torello, 1999).

O afloramento número 11 , situa-se nas terras de propriedade do Sítio São João do Capão Redondo, na margem esquerda da estrada secundária que liga Tambaú à Santa Rosa do Viterbo (21 $1^{\circ} 39^{\prime} 36^{\prime \prime S}$ e $47^{\circ} 15^{\prime} 32^{\prime \prime W}$ ) (fig. 15). Na base do afloramento ocorre um pacote de arenito fino a muito fino, maciço, com aproximadamente $3,2 \mathrm{~m}$ de espessura, os quais são sucedidos por siltito esverdeado, com fratura conchoidal. Acima deste, aflora um pacote de arenito fino/siltito, com cerca de $50 \mathrm{~cm}$ de espessura, arroxeado, com estrutura ondulada ("wavy"). Estes são sucedidos por uma camada de siltito argiloso, com $10 \mathrm{~cm}$ de espessura, contendo conchas de bivalves (Torello, 1999) (fig. 17). Os fósseis são representados por conchas desarticuladas (97\%), principalmente valvas esquerdas, dispersas caoticamente na matriz e paralelas ao plano de acamamento. 


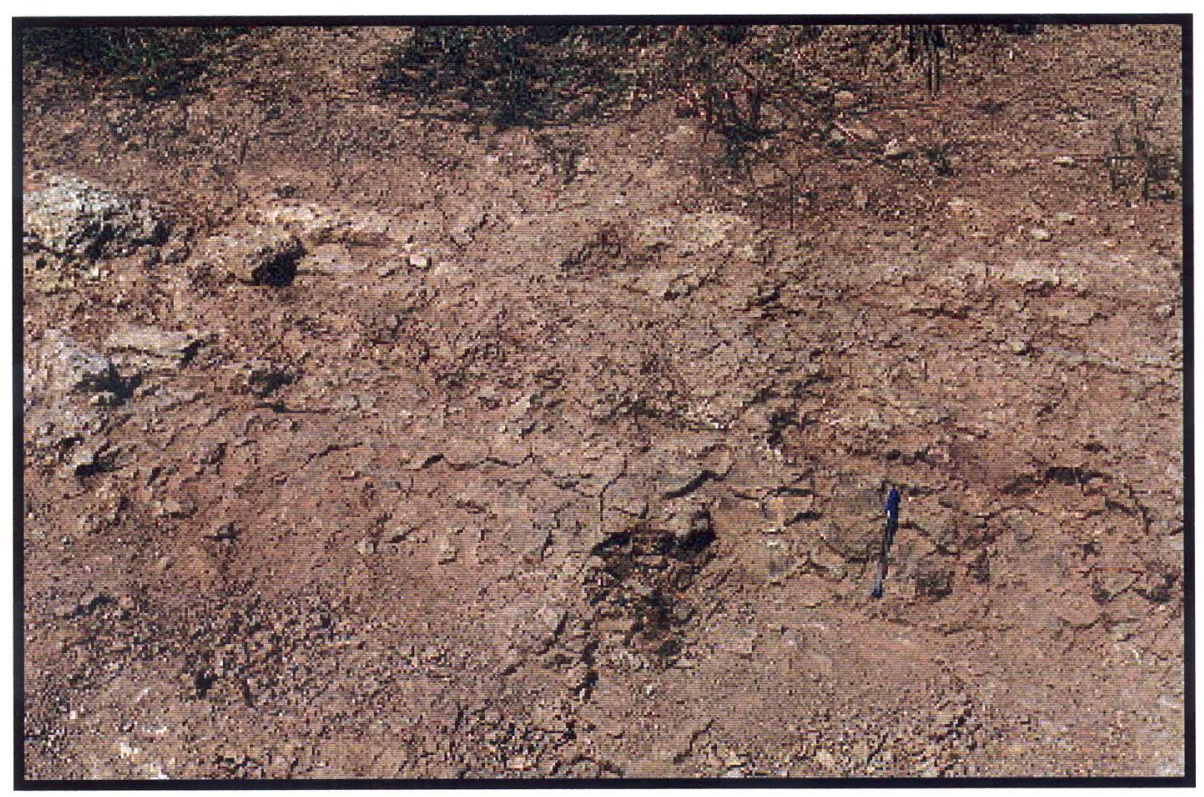

Figura 13- Detalhe dos siltitos argilosos da parte superior da Formação Corumbataí, na antiga estrada secundária que liga Tambaú a Santa Rosa do Viterbo, SP.

O afloramento 12, situa-se nas terras da Fazenda São Roque, à direita da bifurcação da estrada secundária que liga Tambaú a Santa Rosa do Viterbo (2138'76"S e 47¹4'15"W) (fig. 16), sendo representado por $1,5 \mathrm{~m}$ de espessura de arenito muito fino/siltito, arroxeado, bioturbado, maciço a incipientemente laminado. Sobrepõe-se uma camada de $1,10 \mathrm{~m}$ de espessura de argilito esverdeado com laminação onduladada, lentes de siltito ou arenito muito fino, também apresentando laminação ondulada (Torello, 1999). Acima destes, há um pacote de $1,5 \mathrm{~m}$ de espessura de arenito fino avermelhado, silicificado com marcas onduladas e gretas de contração centimétricas. Cerca de 1 metro acima, ocorre uma camada de siltito ou argilito avermelhado, creme quando intemperizado, maciço ou incipientemente laminado, com fratura conchoidal, apresentando gretas de contração centimétricas. Sobre o siltito assenta-se uma camada de arenito fino, creme, maciço, com bivalves (Pinzonella neotropica, Cowperesia anceps). O topo da seção é composto por arenito fino a médio, maciço, com $10 \mathrm{~cm}$ de espessura sendo brusco o contato basal com o siltito subjacente. No arenito há a presença freqüente de conchas de bivalves e ostracodes, caoticamente distribuídas na matriz (fig. 18). 


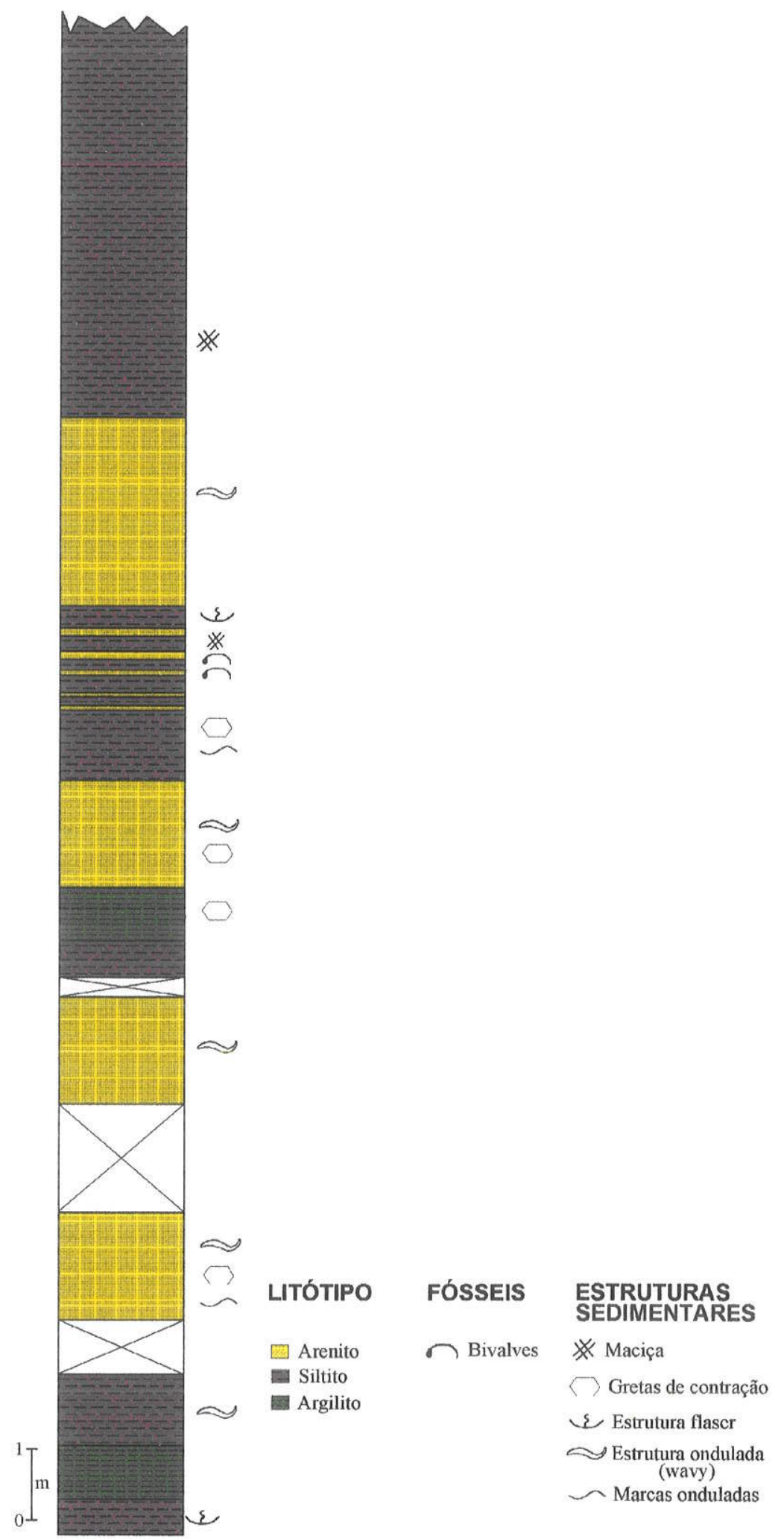

Figura 14- Seção colunar do afloramento 10, topo da Formação Corumbataí, Tambaú, SP. Modificado de Torello (1999). 


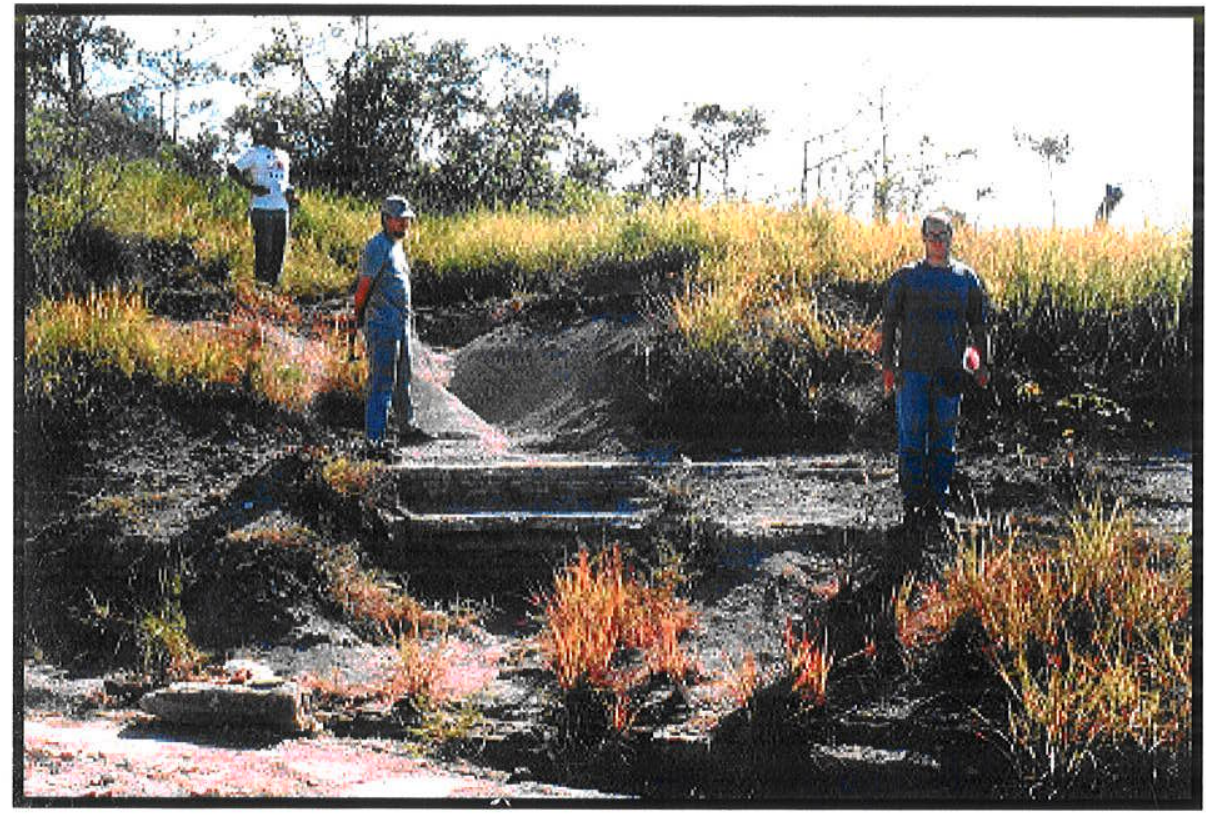

Figura 15- Vista geral do afloramento 11, Formação Corumbataí, Tambaú, SP. Os três colaboradores demarcam os níveis fossilíferos.

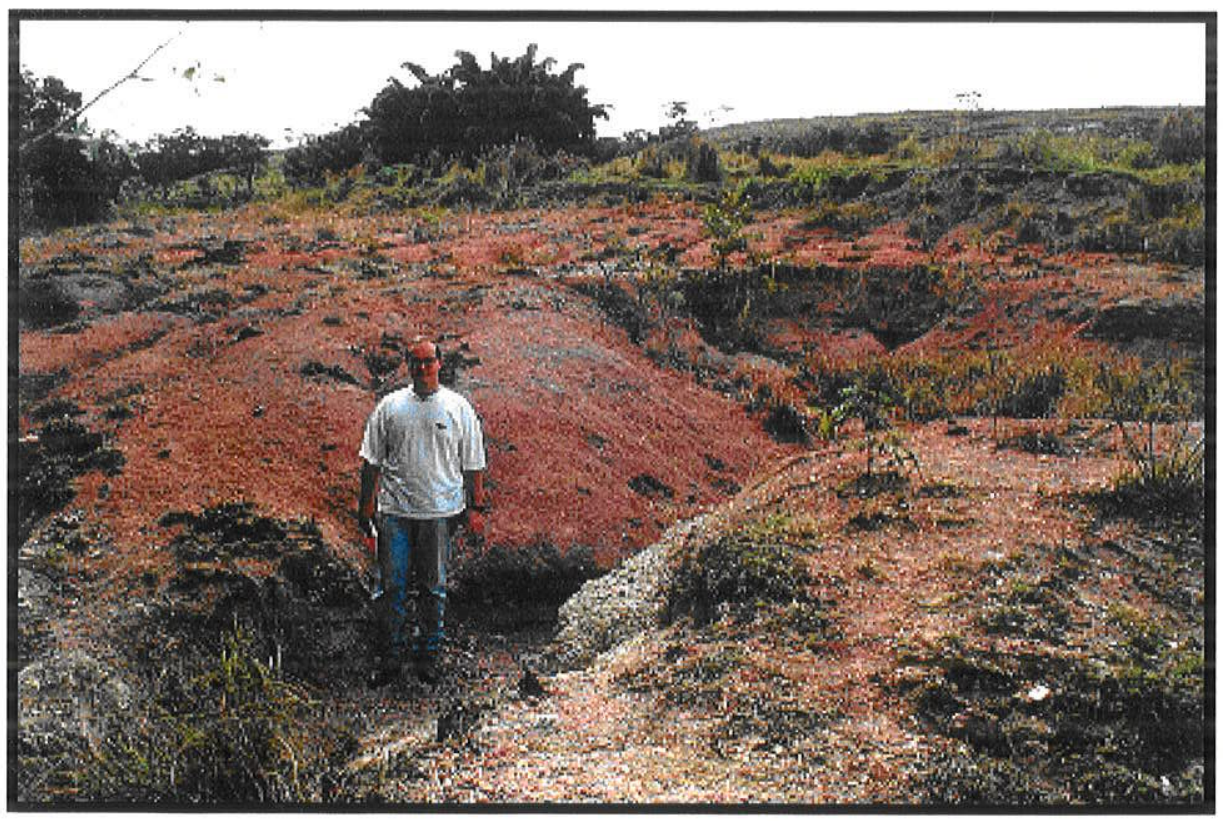

Figura 16- Vista geral do afloramento 12, Formação Corumbataí, município de Tambaú, SP. 


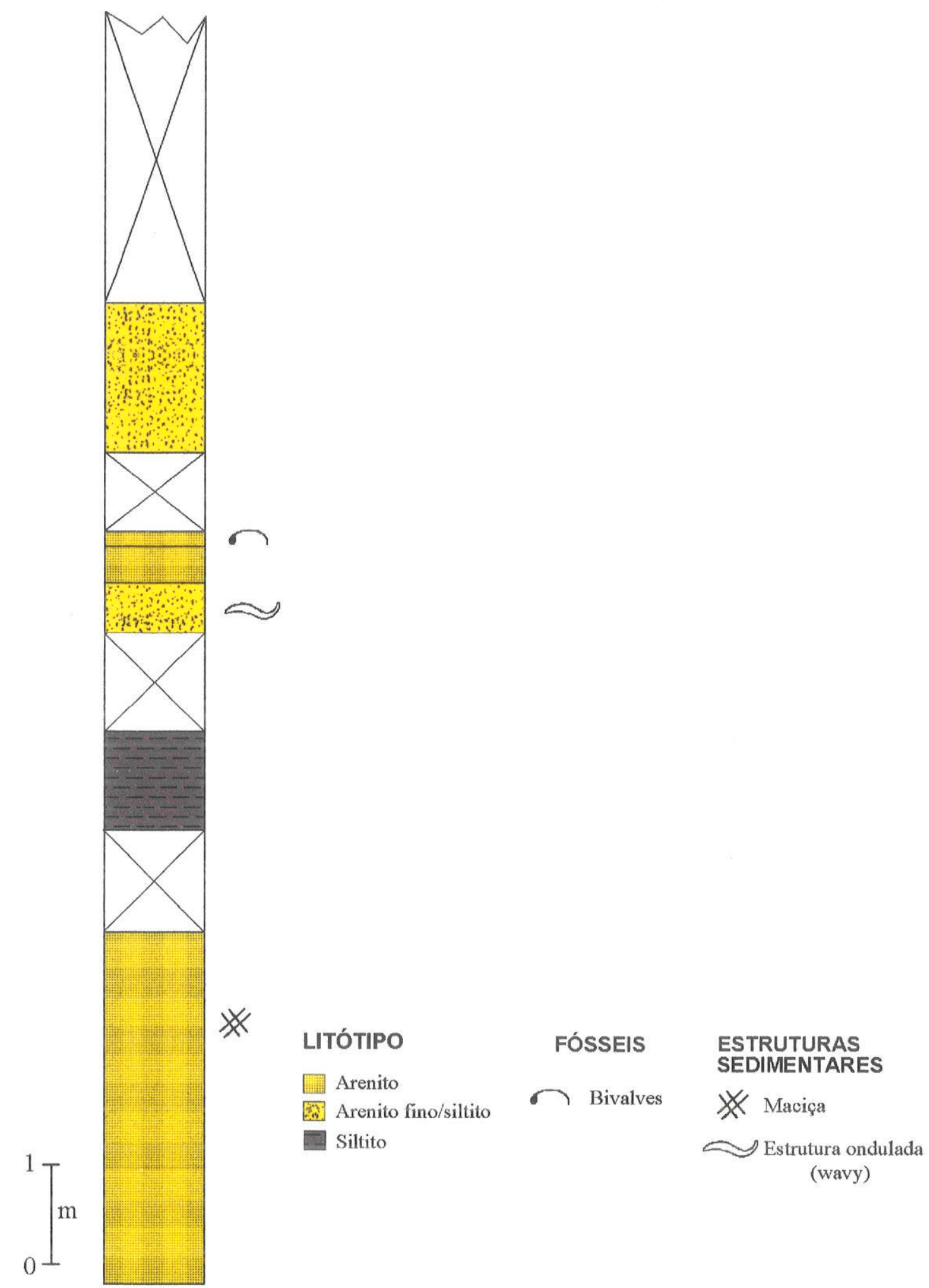

Figura 17- Seção colunar do afloramento 11, Formação Corumbataí, Tambaú, SP. Modificado de Torello (1999). 


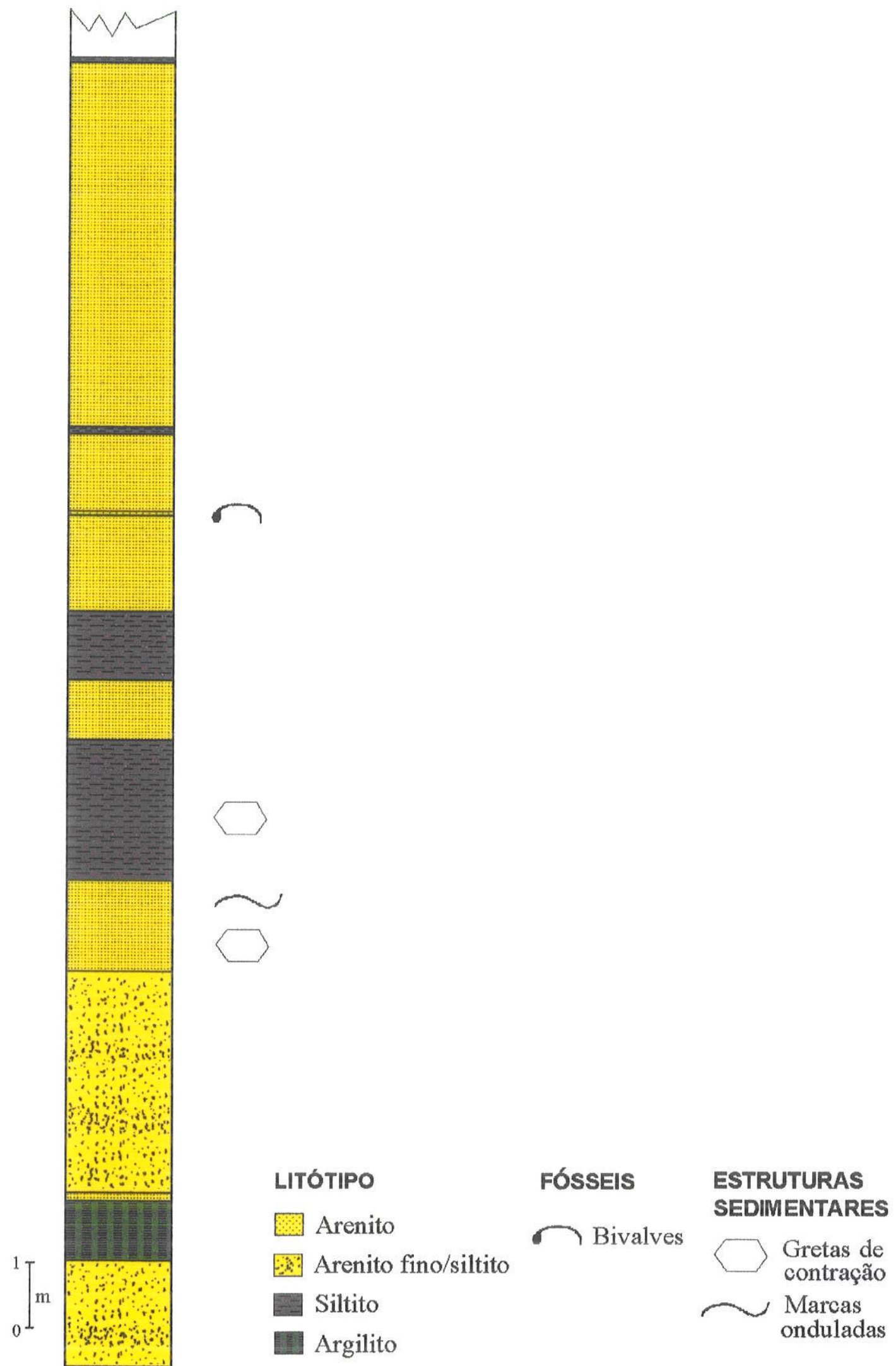

Figura 18- Seção colunar do afloramento 12, Formação Corumbataí, Tambaú, SP. Modificado de Torello (1999). 


\subsection{Trabalhos DE LABORATóRIO}

Os espécimes depositados nas coleções científicas examinadas encontravam-se, na sua grande maioria, já preparados e, em muitos casos, extraídos da matriz sedimentar. Em decorrência disto, os trabalhos de laboratório envolveram, na maioria das vezes, a confecção de moldes de látex, com a finalidade de possibilitar um exame mais acurado das feições morfológicas internas, especialmente da musculatura das conchas examinadas. Os trabalhos envolveram ainda a aplicação de magnésio metálico, fotografia e desenho das conchas estudadas. As técnicas envolvidas nesta etapa do trabalho estão amplamente descritas na literatura (Rocha-Campos, 1969; Mendes, 1988; Simões, 1992; Anelli, 1994) e são usuais ao tipo de estudo proposto. Por este motivo, elas não serão descritas neste documento.

\subsection{ANÁLISES BIOMÉTRICAS}

As análises biométricas foram realizadas através da metodologia proposta por Stanley $(1970,1972)$. Entretanto, deve ser ressaltado que sua aplicação depende do estado de preservação e da qualidade do material fossilífero. Em outras palavras, a análise biométrica é de difícil aplicação em conchas fósseis preservadas na forma de moldes com pronunciado achatamento lateral ou antero-posterior, como as encontradas na assembléia de Anhembia froesi. Entretanto, quando os moldes internos não apresentam esta feição, a aplicação da metodologia proposta por Stanley $(1970,1972)$ fornece importantes dados paleoautoecológicos (e.g., Rocha-Campos \& Simões, 1993; Anelli et al., 1998). Contrariamente, em conchas silicificadas, como as encontradas nas assembléias de Pinzonella illusa e Pinzonella neotropica, a utilização dos valores biométricos propostos por Stanley (1970) é de fácil aplicação.

Estes valores são obtidos a partir da biometria da concha dos bivalves que é estabelecida através das seguintes medidas: a- comprimento (C), que é definido como a máxima dimensão da concha paralela ao seu eixo antero-posterior, determinando o maior eixo da concha; b- altura (A), que é definida como o maior eixo perpendicular da concha; c- largura (L), que é definida como a máxima dimensão das duas valvas, perpendicular ao plano de comissura. Nas espécies assimétricas, entretanto, esta medida é definida como a máxima 
dimensão das duas valvas, tangencial à superfície do plano de comissura; d- comprimento anterior (CA), delimitado pela margem anterior até uma linha paralela a sua altura e que passa através da projeção do bico e, e- espessura de cada valva (fig. 19).

Utilizando os valores biométricos estabelecidos por Stanley (1970), alguns caracteres morfológicos podem ser inferidos, tais como: a- alongamento (C/A), que é a razão entre o comprimento e a altura da concha; b- obesidade (A/L), que é a razão entre a altura e a largura da concha; c- alongamento anterior $(\mathrm{CA} / \mathrm{C})$, que é a razão entre o comprimento anterior e o comprimento da concha e, d-tamanho, que é o comprimento da concha (fig. 19).

O quadro 5, lista os termos descritivos empregados na análise morfofuncional de conchas de bivalves (Stanley, 1970), assim como os índices a eles relacionados. 




Figura 19- Principais medidas obtidas em conchas de bivalves [e.g., Pinzonella illusa $(\mathrm{X} 2,5)]$ e valores biométricos relacionáveis. Legenda: 1- Edmondia unioniformis (X 0,25Carbonifero); 2 - Sanguinolites discors (X 0,17- Carbonifero); 3 - Megadesmus globosus (X 0,15 - Permiano); 4- Triplicosta progressiva (X 0,30- Eoceno); 5 Promacrus nasutus (X 0,17-Carbonífero); 6-Crassiconcha stuckenbergi (X 0,23-Permiano); 7-Cadiomorpha oblonga (X 0,18-Carbonifero); 8-Machomya
jurensis (X 0,17-Jurássico) e 9-Chaenomya leavenworthensis (X 0,16-Carbonifero). 
Quadro 5-Termos descritivos para os valores das medidas dos caracteres morfológicos de conchas de bivalves. Modificado de Stanley, 1970.

\begin{tabular}{|c|c|}
\hline Termo descritivo & $\begin{array}{l}\text { Valor do } \\
\text { Caráter }\end{array}$ \\
\hline Tamanho (Comprimento) & \\
\hline Muito pequeno & $\leq 1.5 \mathrm{~cm}$ \\
\hline Pequeno & $1.6-3.5 \mathrm{~cm}$ \\
\hline Moderadamente pequeno & $3.6-5.0 \mathrm{~cm}$ \\
\hline Moderadamente grande & $5.1-7.0 \mathrm{~cm}$ \\
\hline Grande & $7.1-10 \mathrm{~cm}$ \\
\hline Muito grande & $\geq 10.1 \mathrm{~cm}$ \\
\hline Alongamento (C/A) & \\
\hline Não alongada & $\leq 1.19$ \\
\hline Moderadamente alongada & $1.20-1.39$ \\
\hline Alongada & $1.40-1.59$ \\
\hline Muito alongada & $\geq 1.60$ \\
\hline Obesidade $(\mathrm{A} / \mathrm{L})$ & \\
\hline Fortemente inflada & $\leq 1.29$ \\
\hline Inflada & $1.30-1.49$ \\
\hline Moderadamente inflada & $1.50-1.69$ \\
\hline Comprimida & $1.70-1.99$ \\
\hline Muito comprimida & $\geq 2.00$ \\
\hline Alongamento Anterior (CA/C) & \\
\hline Parte anterior expandida & $0.51-0.60$ \\
\hline $\begin{array}{l}\text { Parte anterior fortemente } \\
\text { expandida }\end{array}$ & $\geq 0.61$ \\
\hline
\end{tabular}




\subsection{ClassificaÇÃo TaXonômiCa UTILIZAda}

Nos últimos setenta anos, vários esquemas de classificação foram propostos, para os bivalves do Grupo Passa Dois (veja síntese em Simões \& Fittipaldi, 1987, 1988, 1992). Destes, destacam-se os de Mendes (1952) e o de Runnegar \& Newell (1971), bem como as propostas de Maranhão (1986) e Rohn (1988). Até meados da década de 90, não havia, entretanto, consenso na literatura quanto ao número de gêneros e posição sistemática de muitos táxons. Porém, análises cladísticas mais recentes (Simões et al., 1997; Mello et al., 1998b; Mello, 1999), sugerem que a fauna de bivalves do Grupo Passa Dois é constituída pelos seguintes táxons: Angatubia cowperesioides, Anhembia froesi, Casterella gratiosa, Cowperesia anceps, Favalia arcuata, Ferrazia cardinalis, Holdhausiella elongata, Itatamba paraima, Jacquesia brasiliensis, Naiadopsis lamellosus, Othonella araguaiana, Plesiocyprinella carinata, Pinzonella illusa, Pinzonella neotropica, Roxoa corumbataiensis, Roxoa intricans. Runnegariella fragilis, Tambaquyra camargoi e Terraiopsis aequilateralis. Além destes, são considerados válidos também: ?Anthraconaia mezzalirai, Barbosaia angulata, Maackia contorta, Mendesia piracicabensis e Coxesia mezzalirai. Em adição, as espécies Ferrazia simplicicarinata, Holdhausiella almeidai e Rioclaroa lefevrei (assembléia de Anhembia froesi) não foram incluídas na presente análise devido ao pequeno número de espécimes disponíveis para estudo e pelo precário estado de preservação destes.

\subsection{ClassificaÇão Paleoecológica Adotada}

Uma ampla revisão da literatura mostra que existem basicamente três esquemas de classificação paleoautoecológicos (morfofuncionais), para os bivalves paleozóicos (Stanley, 1970, 1972; Liljedahl, 1985). O esquema de Liljedahl (1985) trata do modo de vida de bivalves eopaleozóicos, onde estes organismos não foram os elementos dominantes nas paleocomunidades. Os bivalves do Eopaleozóico parecem exibir, portanto, um número mais restrito de modos de vida do que os chamados bivalves da fauna moderna, característicos das comunidades bentônicas, a partir do Mesozóico (Brenchley \& Harper, 1998). 
Já o esquema de Stanley (1970), dá maior ênfase aos bivalves escavadores, particularmente mesozóicos e cenozóicos. Desde que as assembléias de bivalves do Grupo Passa Dois são dominados por formas escavadoras, especialmente anomalodesmatas (Runnegar \& Newell, 1971; Simões, 1992; Simões et al., 1998b, Mello, 1999), grupo de bivalves paleozóicos providos de sifões (Stanley, 1968), a classificação de Stanley (1970), acrescida da nomenclatura proposta por Runnegar (1974), parece ser a mais adequada ao presente estudo. 


\section{PALEOAUTOECOLOGIA}




\section{PALEOAUTOECOLOGIA}

\subsection{CONCEITOS TEÓRICOS ENVOLVIDOS}

A principal questão que norteia os estudos de Morfologia Funcional pode ser enquadrada na seguinte pergunta: "Qual a finalidade de determinado órgão?" Em outras palavras, a morfologia funcional visa a reconstrução operacional de uma dada estrutura em estudo. Para a aplicabilidade deste conceito é importante não perder de vista a noção de que a estrutura analisada é, ou foi, parte de um organismo, incluindo outras estruturas que se interagem entre si fisiologica e anatomicamente. Não se pode tratar, portanto, a estrutura em uma visão atomística, ou seja, independente e não relacionável com outras (Dudlemeijer, 1968). De fato, conforme destaca Stasek (1963), em sua "teoria das entidades independentes", freqüentemente o manto/concha e as partes moles dos bivalves são consideradas como entidades separadas, esquecendo-se que ambos têm uma história evolutiva e uma adaptabilidade conquistadas em conjunto, referentes a um determinado meio ambiente.

Para a reconstrução de funções e leis biológicas das estruturas dos organismos fósseis utilizam-se três passos metodológicos (Reif, 1983), abaixo descritos:

a- comparação com órgãos e estruturas de animais viventes. Neste caso, o estudo da morfologia funcional em fósseis é fundamentado em um princípio comparativo que estabelece que a função de determinada estrutura atual é, provavelmente, a mesma desde o início de seu registro. É claro que esta relação é fortalecida quanto maior for a proximidade filogenética dos animais analisados ou, nos casos onde as estruturas são homólogas ou homeomórficas. Os casos de homoplasia (e.g., convergência, paralelismo e reversão, sensu Amorim, 1997) não devem ser descartados, pois também refletem uma mesma função para uma estrutura análoga ou homóloga, apesar de serem de difícil diagnóstico em espécies fósseis (Thomas, 1979; Reif, 1983; Fisher, 1985, Amorim, 1997). Uma homoplasia não é, freqüentemente, o resultado de uma imposição funcional e adaptativa (solução ótima), mas é preferencialmente o resultado de uma imposição estrutural/morfogenética (única solução possível) (Reif et al, 1985);

b- análises de fácies sedimentares para o entendimento do paleoambiente $\mathrm{e}$ paleoecologia e, 
c- inferências sobre funções e leis biológicas das estruturas dos fósseis, provenientes das relações de parentesco, e que podem apenas serem testadas pela análise estrutural do fóssil (paradigma).

A despeito das limitações acima, combinando a análise tafonômica, a análise morfofuncional e a análise estratigráfica/sedimentológica diversos dados abióticos e bióticos sobre o ambiente no qual um dado grupo fóssil viveu podem ser extraídos e interpretados. Tendo em vista tais questões, o presente estudo está fundamentado nessas premissas, já que são inviáveis os estudos ontogenéticos e/ou comportamentais.

Segundo Reif (1983) e Reif et al. (1985), as principais aplicações da morfologia funcional são: a- auxiliar na reconstrução anatômica dos organismos; b- reconstruir a derivação filogenética dos órgãos; c- ajudar na análise filogenética; d- auxiliar na reconstrução de comportamento e, e- apoiar as reconstruções da estrutura das paleocomunidades. Uma análise criteriosa da literatura disponível sobre o assunto mostra, entretanto, que não existe consenso quanto às metodologias utilizadas na análise morfofuncional, provocando rupturas filosóficas que deram origem a duas escolas de estudo (e.g.; escola americana, escola alemã), ainda com discordâncias internas. O texto a seguir, apresenta uma síntese do pensamento destas duas escolas.

\subsubsection{A Escola Americana (Paradigmática)}

Para esta escola toda estrutura poderá preencher uma determinada função, com máxima eficiência, levando-se em consideração as limitações impostas pela natureza dos materiais (Rudwick, 1964a; Paul, 1975). O método de análise de morfologia funcional chamado paradigmático (ou mecanicista) teve suas diretrizes básicas propostas por Rudwick (1961, 1964a), tendo como exemplos a morfologia funcional de braquiópodes paleozóicos e mesozóicos. Carter (1967a) estendeu a metodologia a todos os grupos de animais e estabeleceu quatro procedimentos lógicos para a elaboração de um paradigma: a percepção, a estrutura estudada é examinada e comparada com a de táxons filogeneticamente próximos, viventes ou fósseis, ou com estruturas de táxons não correlatos. Neste passo, é comum a determinação de mais de uma função plausível para a estrutura em análise; b- especificação, 
testar as funções determinadas em relação às diferentes especificações idealizadas para cada estrutura, levando-se em consideração a natureza dos materiais. Um paradigma, neste ponto, é estabelecido para cada função postulada; c- avaliação, comparação de cada estrutura observada com o paradigma de sua função, avaliando a eficiência na qual a estrutura preenche a função e, d- interpretação, escolha do paradigma mais aplicável para a estrutura analisada a qual ela mais se aproxima. Apesar dos cuidados e critérios envolvidos nesta análise, a fase de interpretação é a que apresenta um maior grau de subjetividade.

Em decorrência disto, vários autores passaram a colocar em dúvida a validade da análise paradigmática. Grant (1972) argumenta, por exemplo, que o método paradigmático falhava por não ser um método sistemático, mas apenas "um ponto de vista", e por proporcionar, a diferentes pesquisadores, a elaboração de diferentes paradigmas, para a mesma função. De fato, Rudwick (1964b) e Carter (1967a), elaboraram diferentes paradigmas para o plano de comissura em zigue-zague e formadores de costelas em braquiópodes e bivalves. Rudwick (1964b) propôs que as costelas aumentariam a resistência da concha tanto de bivalves, como de braquiópodes. Carter (1967a), por outro lado, propôs a não aplicabilidade funcional para as costelas de bivalves.

Grant (1972) argumentou, também, que o método paradigmático é muito mecanicista, por não considerar um fóssil como um organismo vivo, sendo limitado não apenas pela natureza dos materiais, mas também pelo regime energético e a origem evolutiva do fóssil. Múltiplas soluções funcionais para uma mesma estrutura paradigmática ou várias estruturas paradigmáticas para uma dada função são situações não previstas pela análise e que ocorrem com freqüência nos organismos. Além desses fatores, mecanismos epigenéticos (i.e., mecanismos não relacionados a ação primária do gene) e energéticos são limitantes à adaptação ótima que um organismo pođe sofrer não sendo também discernido pelo método paradigmático (fig. 20).

A visão hiperselecionista dos paradigmáticos, em considerar uma função errada se esta não se aproxima da teoria otimizada, reforça o caráter do método em considerar toda estrutura uma adaptação, ou seja: a análise não está relacionada com a origem da estrutura, mas apenas em quão adaptada ela está a uma determinada função. 


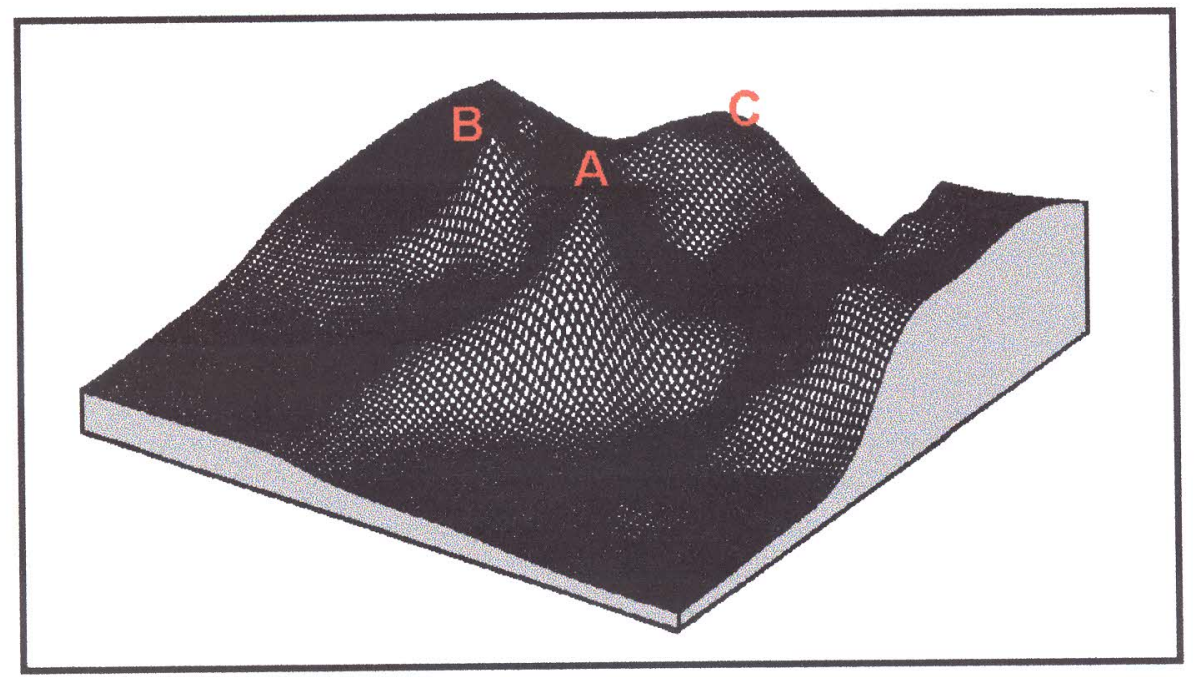

Figura 20- Relevo hipotético demonstrando, por analogia, que as várias adaptações possíveis (B ou C), em que uma espécie pode suportar morfologicamente não coincidem, necessariamente com o "pico" adaptativo ótimo (A). Modificado de Signor III (1982).

Tais fatores conduziram a se considerar que o teste de hipótese funcional paradigmático não é confiável, por não ser um teste rigoroso. Adicionalmente, o método não pode ser interpretado como biologicamente verdadeiro, uma vez que ele não demonstra uma relação linear entre a similaridade morfológica e a eficiência no desempenho de uma função, além de não demonstrar também uma correlação entre adaptabilidade e eficiência (Signor III, 1982). O método paradigmático defende somente a similaridade morfológica, como critério de teste e não pode ser considerado como produtor de resultados válidos (Signor III, 1982). É importante lembrar que evolução por seleção natural não prediz a elaboração de uma forma ótima pois, a princípio, os organismos devem ser "apenas capazes" de transmitir a seus descendentes suas características genéticas, permitindo sua sobrevivência (Fisher, 1985). 


\subsubsection{A Escola Alemã}

Seilacher (1970) propôs um novo arcabouço conceitual, em relação aos fatores controladores da morfologia dos organismos. Contrariando a visão paradigmática, de que toda estrutura estava adaptada morfologicamente, Seilacher (1970) estabeleceu que cada estrutura é controlada por fatores históricos-filogenéticos, fatores funcionais e fatores estruturais, o que originou o clássico triângulo de Seilacher (1970, 1991, 1998) (fig. 21).

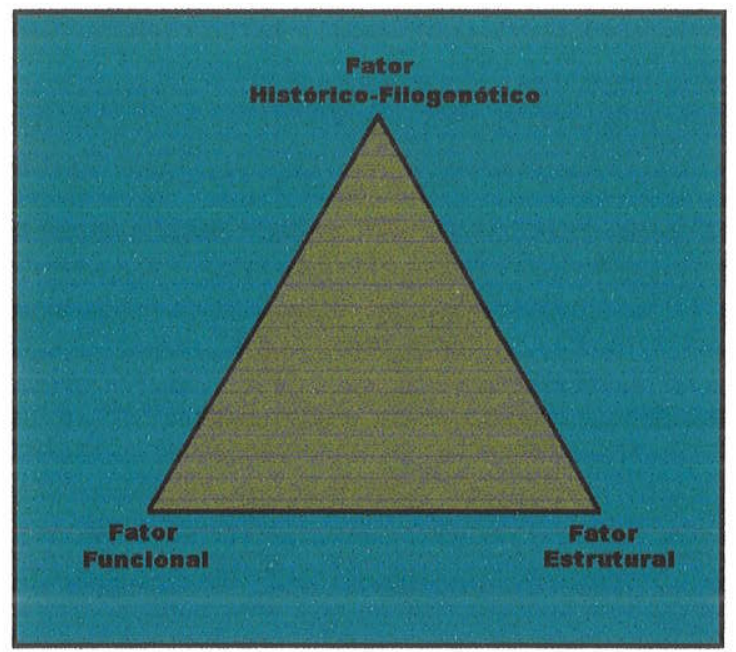

Figura 21- Triângulo de Seilacher (1970), demonstrando os três vértices controladores da morfologia de um indivíduo.

O fator histórico-filogenético faz referência às características próprias dos grupos animais (e.g., simetria radial em Echinodermata) e que podem ser interpretadas como um legado filogenético. Este fator está muito relacionado ao conceito do plano básico, isto é: o plano básico de um táxon de elevado grau hierárquico (e.g., Filo e Classe) que limita as adaptações possíveis, durante a evolução. Geneticamente, são aqueles aspectos da morfologia que não são assunto de variabilidade genética significante (Raup, 1972).

Por outro lado, o fator funcional refere-se às estruturas adaptadas direta $\mathrm{e}$ imediatamente através de seleção natural (Raup, 1972). Este fator é influenciado pela morfologia funcional, sendo o fator que mais se aproxima do paradigma de Rudwick (1964a).

Já o fator estrutural está associado aos elementos estruturais não adaptacionais e de baixo significado taxonômico (Seilacher, 1970), isto é, refere-se a variedade de características morfológicas que são fortemente influenciadas, tanto pela inevitabilidade física, dada pelas 
limitações próprias dos materiais, bem como pelo sistema de crescimento que, apesar de necessário ao organismo, produz algumas estruturas, como produtos não necessários. Os exemplos de caracteres não adaptativos e de caracteres onde, primariamente, sua função era diferente da utilizada (caracteres exaptativos, sensu Gould \& Vbra, 1982) são vários na literatura [e.g., padrão de coloração de bivalves e estruturas de ornamentação do tipo divaricada em moluscos (Seilacher, 1972); penas no processo evolutivo de aves e mimetismo da genitália de hienas (Gould \& Vbra, 1982)].

Raup (1972) introduziu mais dois fatores aos anteriormente utilizados por Seilacher (1970), denominados Fator Efeito Chance e Fator Ecofenotípico. O primeiro, diz respeito a probabilidade de uma estrutura existir ou não e, o segundo, considera os efeitos físicos e químicos que o meio ambiente tem sobre um genótipo, produzindo vários fenótipos. Este segundo fator, afetaria apenas alguns organismos de uma população que seriam as variedades estruturais que um táxon apresenta. Entretanto, Thomas (1979) argumenta que os fatores de elemento chance podem ser encontrados nos três fatores de Seilacher (1970) e que o efeito ecofenotípico estaria incluso no fator funcional, se for considerado que uma adaptação estrutural está regida, em parte, por fatores externos ambientais. Apesar destes comentários, Seilacher (1991) adicionou o fator ecofenotípico ao triângulo, construindo assim um poliedro teórico (fig. 22).

Realmente, os fatores sugeridos por Raup (1972) podem ser adicionados aos anteriormente estabelecidos por Seilacher (1970), sem que haja um comprometimento da análise morfofuncional, como um todo. É interessante notar que os vértices do triângulo de Seilacher (1970) não são os únicos pontos onde uma estrutura funcional pode se posicionar. Nas linhas que ligam os vértices podem ser encontradas estruturas onde os fatores atuaram equilibradamente para sua formação (e.g., câmaras de ar de cefalópodes entre o fator histórico-filogenético e o fator funcional). De fato, os três vértices de Seilacher (1970) refletem uma evolução biológica de uma dada estrutura, pois um fator funcional de um táxon extinto pode ser um fator histórico-filogenético de um grupo de táxons viventes derivados. 


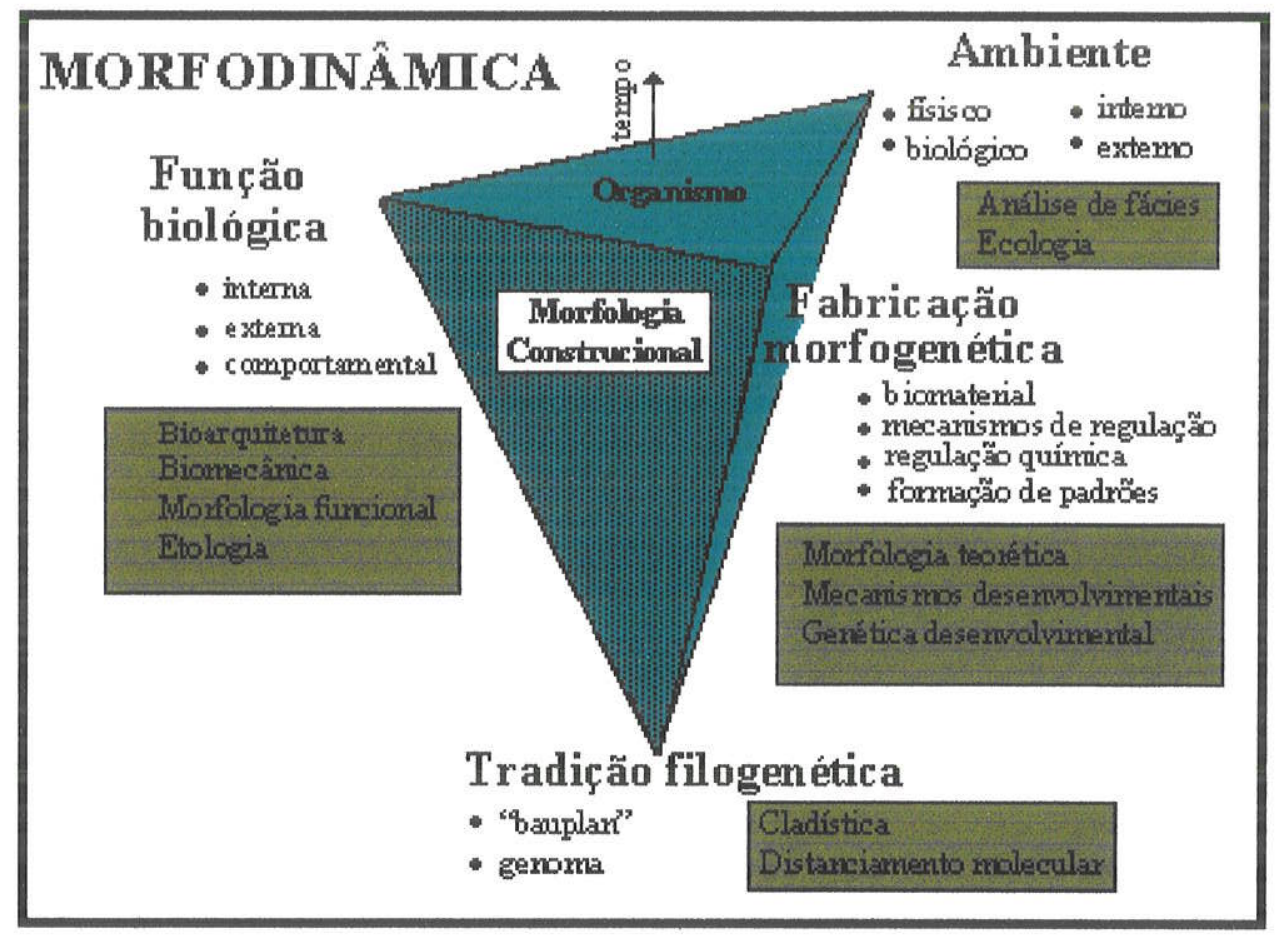

Figura 22- Poliedro teórico elaborado por Seilacher (1991).

\subsubsection{DISCUSSÃo}

É nítido que tanto a análise paradigmática, como a análise funcional de Seilacher (1970), têm um cerne comum. A análise de Seilacher (1970) é apenas mais abrangente do que a paradigmática. Ambas, entretanto, demonstram que a morfologia construcional/funcional é caracterizada por complexas relações entre fatores que controlam a forma e, que muitos aspectos dessa forma, são originados da interação desses processos, os quais estão ligados em níveis diferentes.

No estudo de fósseis, devido aos fatores de preservação, o uso do triângulo de Seilacher (1970) é de difícil aplicação, na sua totalidade. A análise da morfologia funcional em fósseis é realizada por modelos físicos, modelos simbólicos (teoréticos), modelos dinâmicos, modelos estatísticos, modelos determinísticos e modelos estocásticos (Raup, 1972), todos eles direcionados ao vértice funcional do triângulo de Seilacher (1970). Representam, desse modo, basicamente, o paradigma de Rudwick (1964a). Neste trabalho, a maior parte da análise morfológica foi realizada com o intuito de se estabelecer qual é a função de um dado órgão, caracterizando, portanto, uma análise tipicamente morfofuncional. 
A análise morfológica que leva em consideração o modo como um determinado órgão trabalha, bem como os processos físicos e químicos atuantes naquele órgão, além do entendimento da forma e a ação do orgão, denomina-se, como já visto, morfologia construcional e será abordada, quando necessária e possível, em alguns tópicos deste documento.

\subsection{HÁBITO DE VIDA}

Através da análise de uma série de características morfológicas, em conjunto com os dados biométricos, a morfologia funcional possibilita a interpretação do provável hábito de vida de um dado organismo. Assim sendo, deste ponto em diante, serão abordadas as principais características relacionadas aos hábitos de vida dos bivalves, principalmente dos que vivem fixados ao fundo através de bisso ou são escavadores, por serem representantes dos dois grandes grupos ecológicos que estão presentes na malacofauna do Grupo Passa Dois (Neopermiano) da Bacia do Paraná (Simões, 1992; Rohn, 1994; Maranhão, 1995, Simões et $a l ., 1998 b)$. Contudo, ainda existe uma grande variedade de hábitos de vida dentro da Classe Bivalvia, os quais serão devidamente abordados quando for conveniente.

O hábito de vida dos bivalves pode ser dividido em três grandes categorias (Stanley, 1970) abaixo descritas:

1) Posição de vida, de acordo com a posição no substrato, os bivalves podem ser de epifauna ou infauna. Entretanto, Runnegar (1974) acrescentou um modo de vida intermediário, denominado semi-infauna;

2) Modo de locomoção e fixação, esta característica possibilita a divisão dos bivalves em 7 grandes grupos ecológicos: a- Fixados por bisso, estão presos ao substrato por intermédio de um filamento córneo produzido pela glândula bissal; b- Cimentados, estão fixados a substratos duros por secreções produzidas pela própria concha; c- Reclinados, recostam-se ao substrato, sem capacidade de fixação; d- Natantes, se movem livremente pela lâmina d'água por propulsão própria; e- Escavadores, penetram no substrato por intermédio do pé e movimentos de balanço da concha associados, assumindo esta posição como a posição de vida; f- Perfuradores, aqueles que ocupam permanente ou temporariamente uma cavidade 
produzida em substrato duro e, g- Aninhadores, ocupam cavidades pré-existentes não possuindo capacidade de perfuração (fig. 23).

3) Mecanismos de Alimentação, os bivalves podem ser classificados em dois grupos principais, de acordo com os mecanismos empregados na obtenção de alimento: aSuspensívoros, obtêm alimento das partículas em suspensão na água, as quais são inaladas pelo sifão e conduzidas às brânquias e, b- Detritívoros, capturam o alimento, no sedimento, por meio da probóscide coletora (palpo labial). Este é constituído de matéria orgânica em decomposição, depositada no sedimento.

\subsection{FATORES AMBIENTAIS QUE INFLUENCIAM O MODO DE VIDA}

Os bivalves, como todos os organismos vivos, estão sujeitos às variações ambientais físicas, químicas e bióticas, as quais determinam a sua distribuição e o seu modo de vida. Segundo Stanley (1970), os principais fatores ambientais que controlam a morfologia de uma concha são o suprimento de alimento, o caráter do substrato e a movimentação das águas (fig. 24). O tipo de suprimento alimentar está relacionado com os mecanismos de alimentação acima mencionados. A princípio, o tipo de suprimento alimentar está diretamente associado ao caráter do substrato e à movimentação das águas.

Conforme destaca Davis (1925) e Sanders (1956), bivalves suspensívoros estão associados a sedimentos de granulometria mais grossa, em locais de águas agitadas pois, nestas condições, as partículas finas estarão em suspensão. Em contraposição, bivalves detritívoros estão associados a sedimentos mais finos, ricos em matéria orgânica, em decomposição.

No Recente, bivalves detritívoros estão restritos às espécies das Superfamílias Nuculacea e Tellinacea. Entretanto, alguns bivalves detritívoros nudibrânquios conseguem alterar seu mecanismo de alimentação, de acordo com as alterações sofridas na velocidade das águas (Reid \& Reid, 1969; Ólafsson, 1986; Levinton, 1991). Porém, essa alteração comportamental é apenas observada no sentido de bivalves detritívoros para suspensívoros, sendo que o inverso não ocorre. 

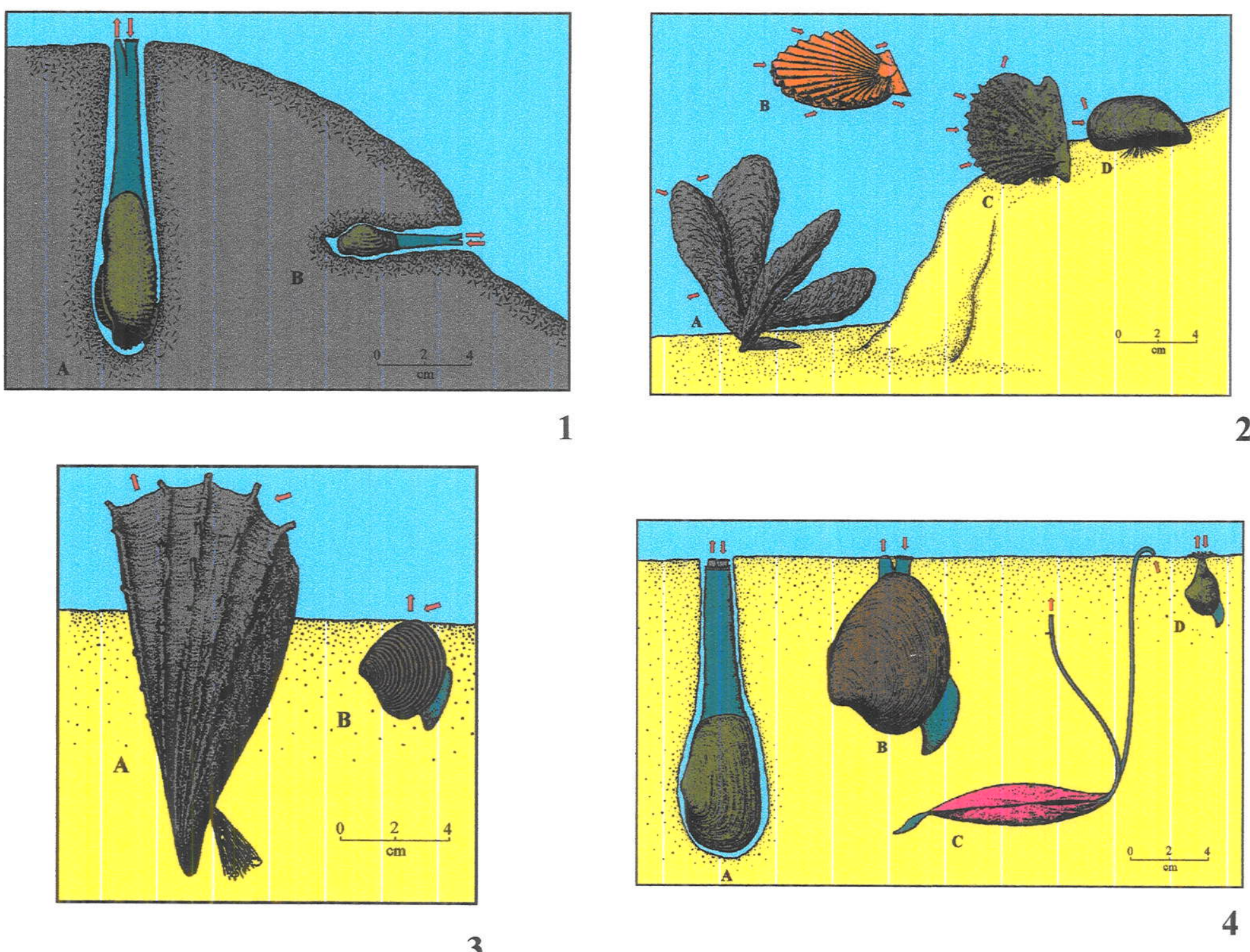

3

Figura 23- Hábitos de vida em bivalves. Legenda: 1- Perfuradores (A- Pholas sp.) e aninhadores (B- Hiatella sp.); 2- Cimentados (ACrassostrea sp.), natantes (B-Pecten sp.) e fixados por bisso (C- Pinctada sp., D- Mytilus sp.); 3- Semi-infauna (A-Atrina sp.), Escavador raso (B-Astarte sp.); 4- Escavador profundo (A-Mya sp., C- Tellina sp.), escavador intermediário (B- Mercenaria sp.) e escavador raso (DCuspidaria sp.). Modificado de Stanley (1968). 
A espessura da lamina d'água é outro fator ambiental que pode influenciar na morfologia de uma concha. A variação da granulometria dos sedimentos encontrados em diferentes profundidades, a variação de pressão e a variação de temperatura e luminosidade são características à profundidade da água (Brett et al., 1993).

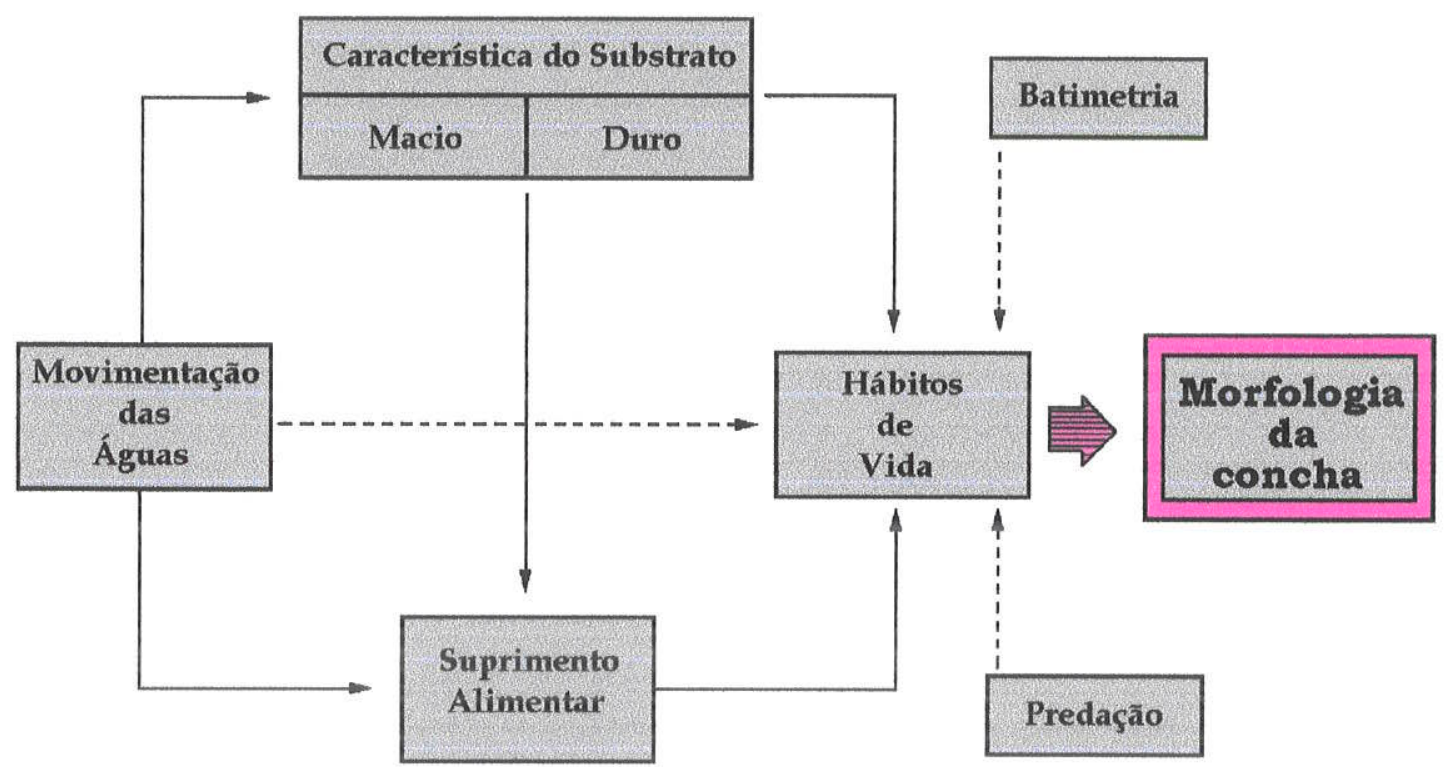

Figura 24- Fatores ambientais controladores da morfologia de uma concha. Modificado de Stanley (1970). 


\section{RESULTADOS}




\section{RESUltados (ANÁlise MoRfofuncional)}

A análise morfofuncional realizada envolveu tanto o estudo das características anatômicas externas das conchas, bem como, quando possível, as feições internas. A análise também abrangeu, no caso das espécies escavadoras, o estudo da orientação das conchas no substrato.

\subsection{CARACTERÍSTICAS EXTERNAS DAS CONCHAS}

Diversas são as características externas das conchas dos bivalves que estão relacionadas ao hábito de vida. Dentre estas, destacam-se, segundo Stanley (1970), a presença de descontinuidades comissurais ("gapes"), a forma da concha, a espessura e a ornamentação, dentre outras. Tais características serão descritas a seguir. Nos quadros 6,7 e 8 , estão sintetizados os dados morfofuncionais obtidos.

\subsubsection{DESCONTINUIDADE BisSAL}

Descontinuidade bissal é uma característica que está presente em formas da epifauna, sendo que por esta estrutura se dá a saída dos filamentos de fixação (bisso) da concha, no substrato. Devido as conchas dos bivalves da assembléia de Anhembia froesi serem preservadas na forma de moldes, na sua grande maioria, o reconhecimento de descontinuidade sifonal nestes organismos, se presente, é extremamente difícil. Dentre os bivalves analisados, apenas Coxesia mezzalirai (assembléia de Pinzonella illusa) apresenta abertura bissal detectável. 
Quadro 6- Modo de vida inferido para os bivalves da assembléia Anhembia froesi.

\begin{tabular}{|c|c|c|c|c|c|}
\hline Espécie & Modo de & Provável & Provável & Litótipo & Evidências \\
\hline & vida & $\begin{array}{l}\text { velocidade de } \\
\text { escavacño }\end{array}$ & $\begin{array}{l}\text { substrato de } \\
\text { vida }\end{array}$ & encontrado & \\
\hline $\begin{array}{c}\text { ?Anthraconaia } \\
\text { mezzalirai }\end{array}$ & Epifauna & - & $\begin{array}{c}\text { Substrato estável, } \\
\text { bioclástico }\end{array}$ & Siltito & $\begin{array}{l}\text { Porção anterior } \\
\text { reduzida; margem } \\
\text { ventral achatada; } \\
\text { provável condição } \\
\text { anisomiária. }\end{array}$ \\
\hline Barbosaia angulata & Semi-infauna & $?$ & $\begin{array}{l}\text { Substrato estável, } \\
\text { provavelmente } \\
\text { bioclástico }\end{array}$ & Siltito & $\begin{array}{c}\text { Forma não truncada } \\
\text { anteriormente; } \\
\text { maior largura } \\
\text { ventral; pequena } \\
\text { redução anterior; } \\
\text { condição } \\
\text { anisomiária. }\end{array}$ \\
\hline Anhembia froesi & Infauna rasa & Lenta & $\begin{array}{l}\text { Silte a arenito } \\
\text { muito fino }\end{array}$ & $\begin{array}{l}\text { Siltito e arenito } \\
\text { muito fino }\end{array}$ & $\begin{array}{c}\text { Concha fortemente } \\
\text { comprimida e } \\
\text { laminar; maior } \\
\text { largura meso- } \\
\text { posterior; linha } \\
\text { palial } \\
\text { integropaliada. }\end{array}$ \\
\hline Maackia contorta & Infauna rasa & $?$ & Silte & Siltito & $\begin{array}{l}\text { Maior largura meso- } \\
\text { posterior; condição } \\
\text { isomiária; linha } \\
\text { palial } \\
\text { integropaliada. }\end{array}$ \\
\hline $\begin{array}{c}\text { Mendesia } \\
\text { piracicabensis }\end{array}$ & Infauna rasa & $?$ & Silte & Siltito & $\begin{array}{l}\text { Maior largura meso- } \\
\text { posterior; condição } \\
\text { isomiária; linha } \\
\text { palial } \\
\text { integropaliada. }\end{array}$ \\
\hline $\begin{array}{c}\text { Tambaquyra } \\
\text { camargoi }\end{array}$ & Infauna rasa & Lenta & $\begin{array}{l}\text { Silte a arenito } \\
\text { muito fino }\end{array}$ & $\begin{array}{l}\text { Siltito e arenito } \\
\text { muito fino }\end{array}$ & $\begin{array}{l}\text { Concha inflada e } \\
\text { esférica; maior } \\
\text { largura meso- } \\
\text { posterior; } \\
\text { ornamentação } \\
\text { concêntrica. }\end{array}$ \\
\hline
\end{tabular}


Quadro 7- Modo de vida inferido para os bivalves da assembléia Pinzonella illusa.

\begin{tabular}{|c|c|c|c|c|c|}
\hline Espécie & Modo de & Provável & Provável & Litótipo & Morfologia \\
\hline & vida & velocidade de & substrato de & encontrado & \\
\hline & & escavação & vida & & \\
\hline Coxesia mezzalirai & Epifauna & - & $\begin{array}{l}\text { Substrato estável, } \\
\text { grosso, bioclástico }\end{array}$ & Arenito & $\begin{array}{l}\text { Abertura bissal; maior } \\
\text { largura ventral; redução da } \\
\text { porção anterior; provavel } \\
\text { condição anisomiária. }\end{array}$ \\
\hline Favalia arcuata & Infauna rasa & Rápida & Areia & $\begin{array}{l}\text { Arenito e calcário } \\
\text { oolítico }\end{array}$ & $\begin{array}{l}\text { Concha lateralmente } \\
\text { comprimida e laminar; } \\
\text { maior largura meso- } \\
\text { posterior. }\end{array}$ \\
\hline Ferrazia cardinalis & Infauna rasa & Lenta & Areia & $\begin{array}{l}\text { Arenito, siltito, } \\
\text { calcário oolítico e } \\
\text { coquina }\end{array}$ & $\begin{array}{l}\text { Concha inflada e esférica; } \\
\text { maior largura meso- } \\
\text { posterior; ornamentação } \\
\text { radial; linha palial } \\
\text { integropaliada. }\end{array}$ \\
\hline Holdhausiella elongata & Infauna rasa & Lenta & Areia & $\begin{array}{l}\text { Arenito, coquina e } \\
\text { siltito }\end{array}$ & $\begin{array}{l}\text { Concha lateralmente } \\
\text { comprimida e laminar; } \\
\text { maior largura meso- } \\
\text { posterior. }\end{array}$ \\
\hline Othonella araguaiana & Infauna rasa & Rápida & Areia & $\begin{array}{l}\text { Arenito, coquina e } \\
\text { calcário oolítico }\end{array}$ & $\begin{array}{l}\text { Concha moderadamente } \\
\text { inflada e discóide; maior } \\
\text { largura meso-posterior. }\end{array}$ \\
\hline Pinzonella illusa & Infauna rasa & Lenta & Areia & $\begin{array}{l}\text { Arenito, siltito, } \\
\text { coquina e calcário } \\
\text { oolítico }\end{array}$ & $\begin{array}{l}\text { Concha moderadamente } \\
\text { inflada e esférica; maior } \\
\text { largura meso-posterior; linha } \\
\text { palial integropaliada. }\end{array}$ \\
\hline Plesiocyprinella carinata & Infauna rasa & Lenta & Areia & Arenito e coquina & $\begin{array}{l}\text { Concha inflada e esférica; } \\
\text { maior largura meso- } \\
\text { posterior; linha palial } \\
\text { integropaliada. }\end{array}$ \\
\hline Runnegariella fragilis & Infauna rasa & Rápida & Areia & Calcário & $\begin{array}{c}\text { Concha lateralmente } \\
\text { comprimida; maior largura } \\
\text { meso-posterior; } \\
\text { ornamentação concêntrica } \\
\text { simétrica em seção; valva } \\
\text { pouco espessa, linha palial } \\
\text { integropaliada. } \\
\end{array}$ \\
\hline Terraiopsis aequilateralis & Infauna rasa & Lenta & Areia & $\begin{array}{l}\text { Arenito, coquina e } \\
\text { calcário oolitico }\end{array}$ & $\begin{array}{l}\text { Concha inflada e esférica; } \\
\text { maior largura meso- } \\
\text { posterior; linha palial } \\
\text { integropaliada. }\end{array}$ \\
\hline Angatubia cowperesioides & $\begin{array}{c}\text { Infauna } \\
\text { intermediária }\end{array}$ & Rápida & Areia? & $\begin{array}{l}\text { Arenito e calcário } \\
\text { oolítico }\end{array}$ & $\begin{array}{c}\text { Concha lateralmente } \\
\text { comprimida e discóide; } \\
\text { porção posterior } \\
\text { desenvolvida; valva pouco } \\
\text { espessa. }\end{array}$ \\
\hline Casterella gratiosa & $\begin{array}{c}\text { Infauna } \\
\text { intermediária }\end{array}$ & Lenta & Areia & Arenito & $\begin{array}{l}\text { Concha esférica; abertura } \\
\text { sifonal pequena; inflada; } \\
\text { maior largura meso- } \\
\text { posterior; pequeno sinus } \\
\text { palial. } \\
\end{array}$ \\
\hline Cowperesia anceps & $\begin{array}{c}\text { Infauna } \\
\text { intermediária }\end{array}$ & Rápida & Silte/Argila & Arenito e siltito & $\begin{array}{l}\text { Concha lateralmente } \\
\text { comprimida e discóide; } \\
\text { abertura sifonal pequena; } \\
\text { maior largura meso- } \\
\text { posterior; pequeno sinus } \\
\text { palial; valva pouco espessa; } \\
\text { ornamentação concêntrica } \\
\text { simétrica em seção. } \\
\end{array}$ \\
\hline Itatamba paraima & $\begin{array}{c}\text { Infauna } \\
\text { intermediária }\end{array}$ & Lenta & Areia & Calcário oolítico & $\begin{array}{c}\text { Inflada; abertura sifonal } \\
\text { pequena; maior largura } \\
\text { meso-posterior; pequano } \\
\text { sinus palial. }\end{array}$ \\
\hline Roxoa corumbataiensis & Infauna profunda & Lenta & Areia & Arenito & $\begin{array}{l}\text { Concha cilíndrica; abertura } \\
\text { pedial; abertura sifonal; } \\
\text { maior largura meso- } \\
\text { posterior; charneira } \\
\text { edentelosa; provável sinus } \\
\text { palial. } \\
\end{array}$ \\
\hline
\end{tabular}


Quadro 8- Modo de vida inferido para os bivalves da assembléia Pinzonella neotropica.

\begin{tabular}{|c|c|c|c|c|c|}
\hline Espécie & $\begin{array}{l}\text { Modo de } \\
\text { vida }\end{array}$ & $\begin{array}{l}\text { Provável } \\
\text { velocidade de } \\
\text { escavacão }\end{array}$ & $\begin{array}{c}\text { Provável } \\
\text { substrato de } \\
\text { vida }\end{array}$ & $\begin{array}{c}\text { Litótipo } \\
\text { encontrado }\end{array}$ & Morfologia \\
\hline $\begin{array}{l}\text { Naiadopsis } \\
\text { lamellosus }\end{array}$ & Semi-infauna & - & $\begin{array}{c}\text { Substrato } \\
\text { parcialmente } \\
\text { consolidado, rico } \\
\text { em bioclastos }\end{array}$ & $\begin{array}{c}\text { Coquina, às } \\
\text { vezes, associada } \\
\text { a lamitos com } \\
\text { partículas } \\
\text { bioclásticas }\end{array}$ & $\begin{array}{c}\text { Forma não } \\
\text { truncada } \\
\text { anteriormente; } \\
\text { maior largura } \\
\text { ventral; pequena } \\
\text { redução anterior; } \\
\text { condição } \\
\text { anisomiária. }\end{array}$ \\
\hline $\begin{array}{l}\text { Jacquesia } \\
\text { brasiliensis }\end{array}$ & Infauna rasa & Lenta & Areia & $\begin{array}{c}\text { Coquina e } \\
\text { calcário oolítico }\end{array}$ & $\begin{array}{l}\text { Concha inflada e } \\
\text { esférica; maior } \\
\text { largura meso- } \\
\text { posterior. }\end{array}$ \\
\hline $\begin{array}{l}\text { Pinzonella } \\
\text { neotropica }\end{array}$ & Infauna rasa & Lenta & Areia & $\begin{array}{c}\text { Coquina e } \\
\text { calcário oolítico }\end{array}$ & $\begin{array}{l}\text { Concha inflada e } \\
\text { esférica; maior } \\
\text { largura meso- } \\
\text { posterior; linha } \\
\text { palial } \\
\text { integropaliada. }\end{array}$ \\
\hline Roxoa intricans & $\begin{array}{l}\text { Infauna } \\
\text { profunda }\end{array}$ & Lenta & Areia & Coquina & $\begin{array}{c}\text { Concha } \\
\text { cilíndrica; } \\
\text { pequena } \\
\text { descontinuidade } \\
\text { sifonal; charneira } \\
\text { edentelosa; maior } \\
\text { largura meso- } \\
\text { posterior; sinus } \\
\text { palial. }\end{array}$ \\
\hline
\end{tabular}




\subsubsection{DESCONTINUIDADE SIFONAL}

Estrutura característica de formas escavadoras profundas com conchas elípticas, apresentando íntima relação entre o tamanho da abertura e o comprimento do sifão, o que, por sua vez, reflete a profundidade de escavação do bivalve (Stanley, 1970, 1972; Runnegar, 1974; Kondo, 1987). Na assembléia de Pinzonella illusa, as espécies Cowperesia anceps, Casterella gratiosa e Itatamba paraima apresentam uma pequena abertura sifonal, indicando a presença de um sifão curto, refletindo um hábito de vida escavador intermediário para estas espécies. Já Roxoa corumbataiensis e Roxoa intricans (assembléias de Pinzonella illusa e Pinzonella neotropica, respectivamente) também apresentam descontinuidade sifonal bem desenvolvida, indicando hábito escavador profundo, o que coadunaria com o sinus palial profundo de Roxoa intricans (Mendes, 1952; Runnegar \& Newell, 1971).

\subsubsection{Descontinuidade Pedial}

Característica de formas com hábito escavador, permitindo a rápida projeção do pé em direção ao substrato (Stanley, 1970), existindo relação direta entre o tamanho da abertura e o tamanho do pé (Yonge, 1957; Runnegar, 1966; Stanley, 1970). A abertura pedial ainda está relacionada com a posição de vida do animal. Os bivalves escavadores profundos quando exumados não têm, em sua maioria, a capacidade de re-escavação (Stanley, 1970; Kondo, 1987, 1989; Kondo \& Stace, 1995). Desta forma, a ancoragem das conchas no substrato é realizada por um pé grande e vigoroso que diminui a possibilidade de exumação. Conseqüentemente, as conchas escavadoras profundas possuem uma grande descontinuidade pedial. Das 25 espécies analisadas, apenas Roxoa corumbataiensis (assembléia de Pinzonella illusa) apresenta uma pronunciada descontinuidade pedial, sugerindo hábito escavador profundo, conforme já indicado também pela presença de descontinuidade sifonal.

$O$ ato de escavação merece uma discussão, um pouco mais aprofundada. $O$ ato de escavação de bivalves já foi pormenorizadamente descrito por vários autores (e.g., Trueman et al., 1966; Ansell \& Trueman, 1967; Nair \& Ansell, 1968) e, basicamente, consiste em seis fases coordenadas entre si (Rocha-Campos \& Simões, 1993): a- protração do pé pela contração dos músculos protratores pediais; $b$ - exploração do ambiente pelo pé, agora fora da concha, e enterramento da concha no substrato circunjacente; c- fechamento das valvas pela 
contração dos músculos adutores; d- o substrato ao redor é fluidificado pela água que é expulsa da cavidade do manto; e- a ancoragem do pé no substrato pela sua dilatação, resultando do aumento da quantidade de sangue levado para o hemocelo e, f- além destes movimentos, muitos bivalves ao se enterrarem sacodem a concha ("rocking-movement" ou movimento de balanço), pois os retratores pediais anteriores retraem-se antes dos músculos retratores pediais posteriores.

A protração do pé dá-se pela descontinuidade pedial ou pelo ponto de máxima abertura ventral do animal (Stanley, 1970). Em bivalves fósseis da Formação Corumbataí onde a descontinuidade pedial não está presente (e.g., Plesiocyprinella carinata, Casterella gratiosa, Ferrazia cardinalis, Holdhausiella elongata, Favalia arcuata, Cowperesia anceps, Angatubia cowperesioides, Itatamba paraima, Pinzonella illusa e Terraiopsis aequilateralis) o ponto de emergência do pé que irá iniciar os movimentos descritos acima, pode ser determinado conhecendo-se o eixo da charneira, que situa-se na porção anterior das ninfas ligamentares e o ponto junto à margem ventral mais afastado deste eixo (Stanley, 1970). Este ponto de máxima separação das valvas é denominado de ponto " $\mathrm{M}$ " e, comumente, posicionase no centro do segmento convexo da margem anterior da concha (Stanley, 1970) (fig. 25).

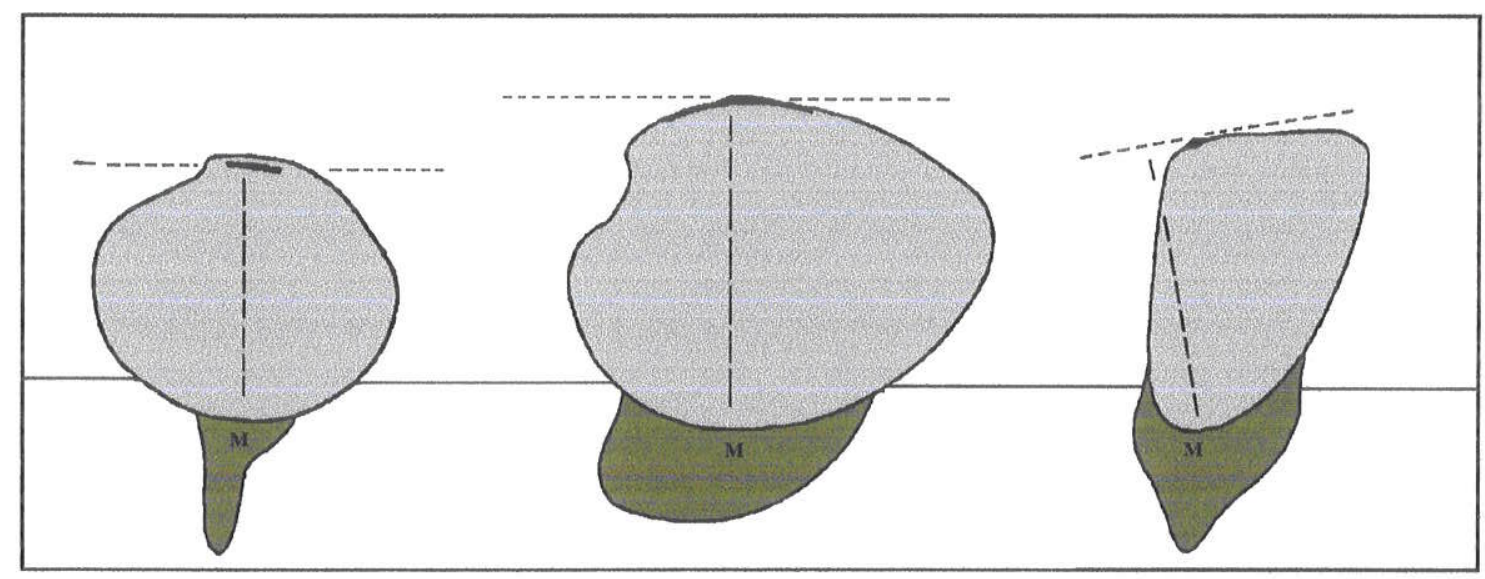

Figura 25- Localização do Ponto M em bivalves. Modificado de Stanley (1970).

Parte das espécies da assembléia de Anhembia froesi (e.g., Tambaquyra camargoi, Anhembia froesi), possivelmente, iniciava a escavação com o eixo da charneira aproximadamente horizontal, em relação ao substrato (fig. 26). Esta é uma característica comum aos bivalves que não possuem descontinuidade pedial (Stanley, 1970; Thomas, 1975). 


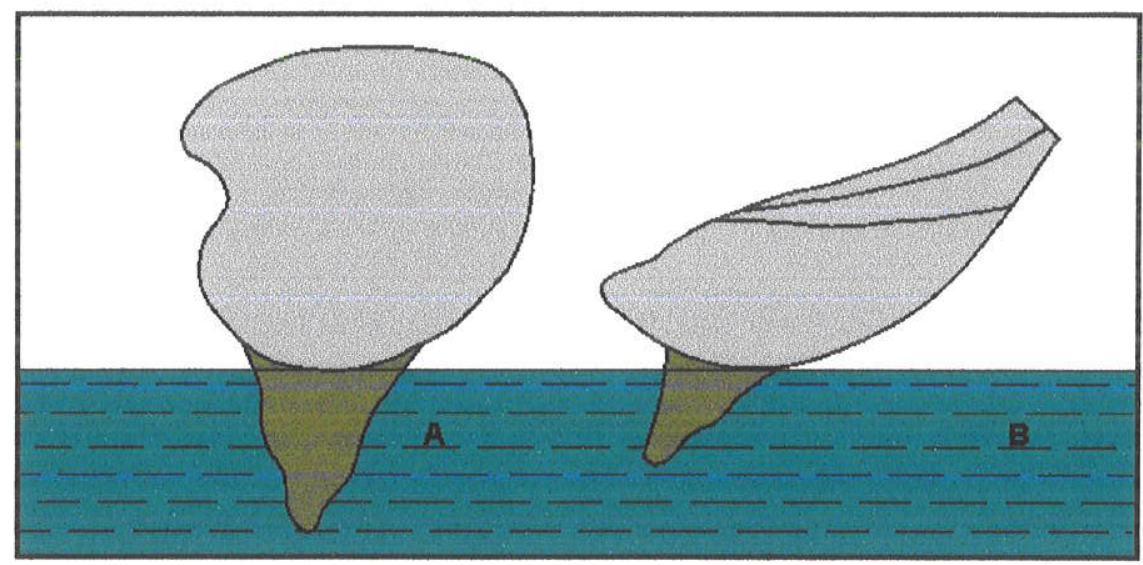

Figura 26- Esquema mostrando o provável ponto de protração do pé de Tambaquyra camargoi (A) e Anhembia froesi (B).

É importante lembrar aqui que condição semelhante deveria ser apresentada, também, por Casterella gratiosa, Plesiocyprinella carinata, Cowperesia anceps, Angatubia cowperesioides, Holdhausiella elongata, Favalia arcuata, Runnegariella fragilis, Itatamba paraima (assembléia Pinzonella illusa) e, Pinzonella neotropica e Jacquesia brasiliensis (assembléia Pinzonella neotropica) que, similarmente a outros anomalodesmatas, deveria apresentar margem do manto fundida, não sendo provável a protração ventral deste órgão. Por sua vez, Roxoa corumbataiensis, provavelmente penetrava o substrato com o eixo da charneira ligeiramente vertical, tendo em vista a presença de fenda pedial bem marcada (figs. 27 e 28$)$.

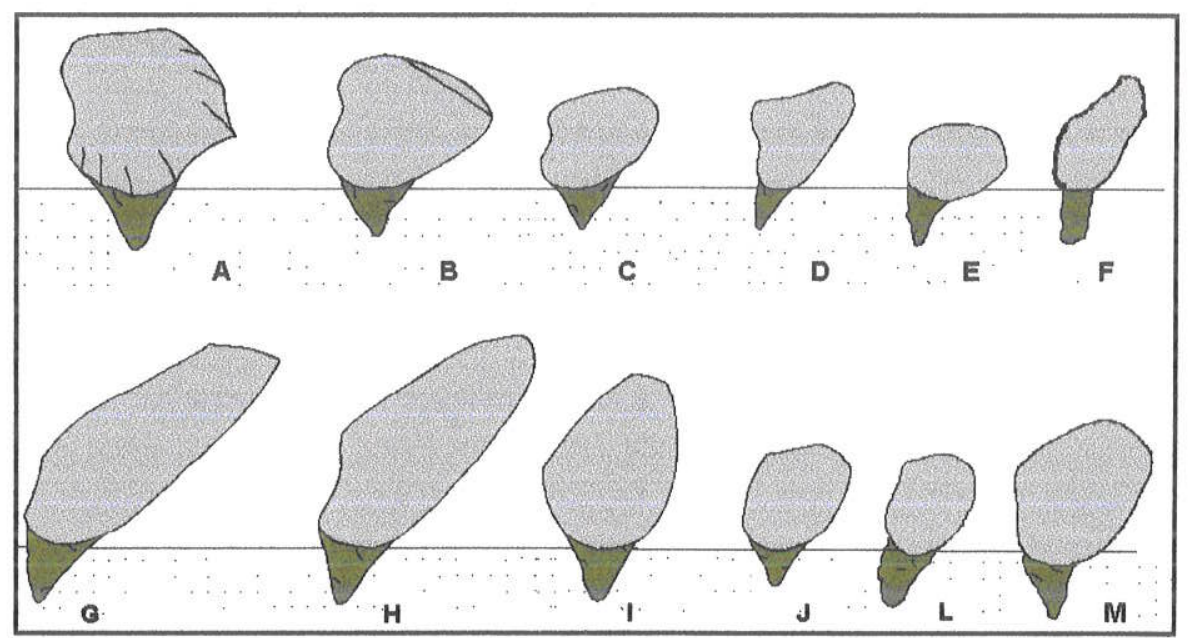

Figura 27- Esquema mostrando o provável ponto de protação do pé de Ferrazia cardinalis (A); Plesiocyprinella carinata (B); Casterella gratiosa (C); Terraiopsis aequilateralis (D); Pinzonella illusa (E); Roxoa corumbataiensis (F); Holdhausiella elongata (G); Favalia arcuata (H); Angatubia cowperesioides (I); Cowperesia anceps (J); Runnegariella fragilis (L) e, Othonella araguaiana (M). A concha de Itatamba paraima é morfologicamente semelhante a de Casterella gratiosa, não sendo ilustrada. 


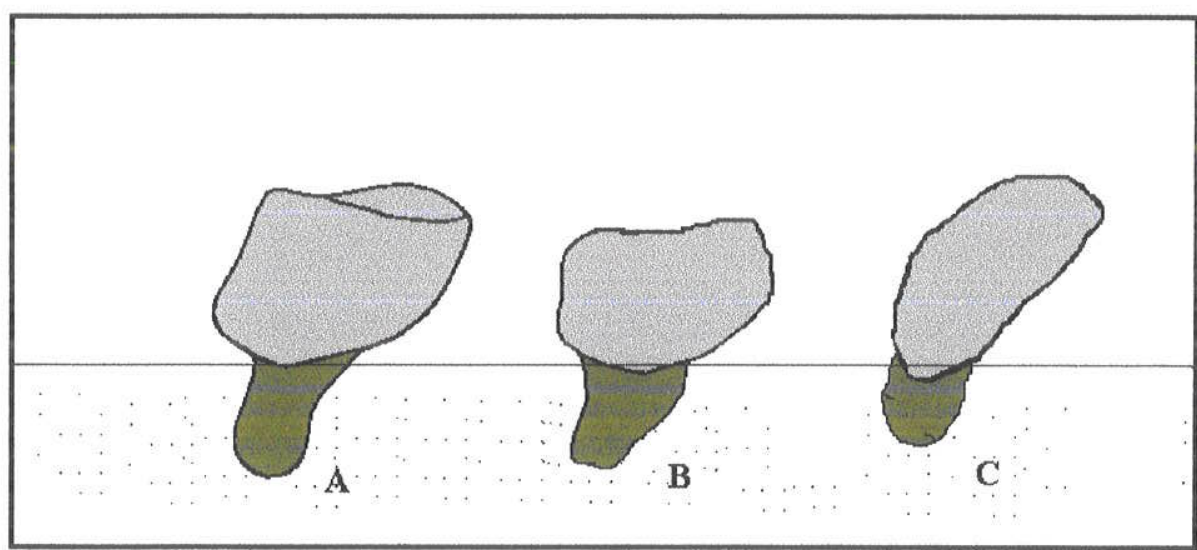

Figura 28- Esquema mostrando o provável ponto de protração do pé de Jacquesia brasiliensis (A); Pinzonella neotropica (B) e, Roxoa intricans (C).

O movimento de balanço realizado pelas conchas durante a escavação, devido a retração diferencial dos músculos retratores pediais anteriores e posteriores, pode variar de $0^{\circ}$ a $45^{\circ}$. Thomas (1975) notou que conchas alongadas ou anteriormente alongadas não apresentavam um considerável movimento de balanço. Em contraposição, bivalves que apresentam conchas esféricas ou circulares demonstram um apreciável movimento de balanço. Este fato torna-se compreensível dada a analogia entre a porção anterior e ventral de uma concha esférica, com uma lâmina encurvada. O movimento de balanço realizado pelas conchas esféricas é traduzido numa maior angulação, aumentando a capacidade e velocidade de escavação dos bivalves que apresentam esta característica (fig. 29).

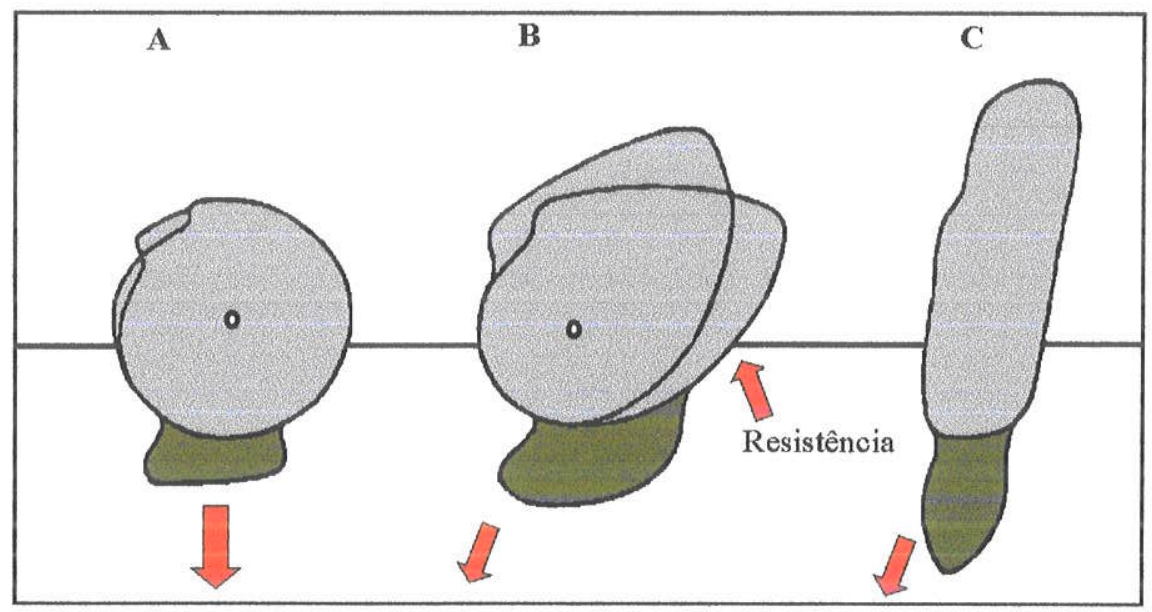

Figura 29- Representação do movimento de balanço em uma concha de forma esférica (A), concha discóide (B) e concha laminar (C). As setas indicam a resistência oferecida pelo substrato. Modificado de Stanley (1970). 
Segundo o raciocínio acima elaborado, as conchas de Tambaquyra camargoi (assembléia Anhembia froesi), Plesiocyprinella carinata, Ferrazia cardinalis e Pinzonella illusa (assembléia de Pinzonella illusa) e Pinzonella neotropica (assembléia Pinzonella neotropica) deveriam apresentar um considerável movimento de balanço durante a escavação, uma vez que todas as espécies possuem forma esférica.

\subsubsection{Forma da CONCHA (EM SEÇÃo)}

\subsubsection{OBESIDADE}

A obesidade da concha de um dado bivalve é obtida através da relação entre sua altura e largura (veja o item 2.4). Esta característica relaciona-se com a velocidade de escavação do organismo, sendo que em um animal com baixo índice de obesidade (índice menor que 1,49; concha inflada), a escavação é lenta. Por outro lado, um animal com alto índice de obesidade (índice maior que 1,70; concha lateralmente comprimida) apresenta uma hidrodinâmica mais favorável à escavação rápida. Segundo Stanley (1970), uma concha obesa está geralmente associada a uma escavação rasa em um substrato com granulometria areia (maior que $2 \mathrm{~mm}$ ). Ainda segundo este autor, são raros os bivalves com valores de obesidade inferiores a 1,50 e que são escavadores rápidos. Entretanto, a velocidade de escavação, em valor absoluto, não pode ser obtida, uma vez que o volume total de um bivalve influencia o tempo final de escavação. Assim os valores para os termos descritivos da velocidade de escavação, são obtidos através do índice dado pela divisão da raiz cúbica da massa do animal, em gramas, pelo tempo de escavação médio observado in vivo que, no caso dos fósseis analisados, não é passível de ser analisado. Por exemplo, Stanley (1970) considerou bivalves de escavação rápida aqueles com índice maior que 2 e bivalves escavadores lentos aqueles com índice menor que 0,5 .

Os bivalves da assembléia de Anhembia froesi não podem ter sua velocidade de escavação inferida devido ao fato de ocorrerem, predominantemente, na forma de moldes lateralmente deformados, o que inviabiliza a análise quantitativa. As únicas espécies que puderam ser mensuradas foram Tambaquyra camargoi e Anhembia froesi (fig. 30) que ocorrem com as conchas não deformadas, no interior de concreções, no afloramento 1 . Os dados indicam que Anhembia froesi possuía uma concha lateralmente comprimida [valor médio de obesidade (v.m.o.) $=2,2]$, de forma laminar, sugerindo uma velocidade de 
escavação rápida. Tambaquyra camargoi, por sua vez, possuía concha inflada e esférica (v.m.o.=1,52). Estas características, associadas à grande dimensão destas conchas, sugerem uma provável velocidade de escavação lenta.

$\mathrm{Na}$ assembléia de Pinzonella illusa, as espécies Terraiopsis aequilateralis (v.m.o.= 1,42), Plesiocyprinella carinata (v.m.o.=1,38), Ferrazia cardinalis (v.m.o.= 1,0), Itatamba paraima (v.m.o. $=1,29)$ e Casterella gratiosa (v.m.o.=1,39) apresentam-se como infladas e, portanto, possivelmente com baixa velocidade de escavação. Pinzonella illusa tem concha moderadamente inflada (v.m.o.= 1,54$)$ o que indicaria uma maior velocidade de escavação. Holdhausiella elongata (v.m.o.= 1,73), Othonella araguaiana (v.m.o.=2,66), Runnegariella fragilis (v.m.o.= 2,8), Favalia arcuata (v.m.o.= 2,3) e Cowperesia anceps (v.m.o.=2,21) foram possivelmente espécies com alta velocidade de escavação já que os índices obtidos encontram-se dentro do campo dos lateralmente comprimidos. Roxoa corumbataiensis, porém, possui concha moderadamente inflada (v.m.o.= 1,6), mas cilíndrica, o que indicaria um hábito lento de escavação (figs. 30, 31 e 32).

$\mathrm{Na}$ assembléia de Pinzonella neotropica, as conchas de Jacquesia brasiliensis (v.m.o. $=1,02)$ e Pinzonella neotropica (v.m.o.= 1,22) são fortemente infladas e, também, deveriam apresentar baixa velocidade de escavação (fig. 32, C e D).

\subsubsection{Posição da MAIOR LARGuRA da CONCHA}

A maior largura das conchas dos bivalves pode estar situada em diferentes posições na valva (e.g., anterior, posterior), refletindo modos de vida distintos. Quando a maior largura está presente na porção posterior ou dorsal, normalmente o organismo apresenta hábito escavador. Por outro lado, quando situada na porção ventral o organismo provavelmente é de epifauna, associado a substrato duro ou de semi-infauna. Isto se deve, pois, a maior largura ventral deslocar para baixo o centro de gravidade da concha, conferindo-lhe maior estabilidade (Stanley, 1970; Stanley, 1972; Brandshaw \& McCartan, 1991). Contudo, observa-se que as formas de semi-infauna apresentam a maior largura da concha numa porção mais mediana, quando comparadas às de epifauna (Brandshaw \& McCartan, 1991). 


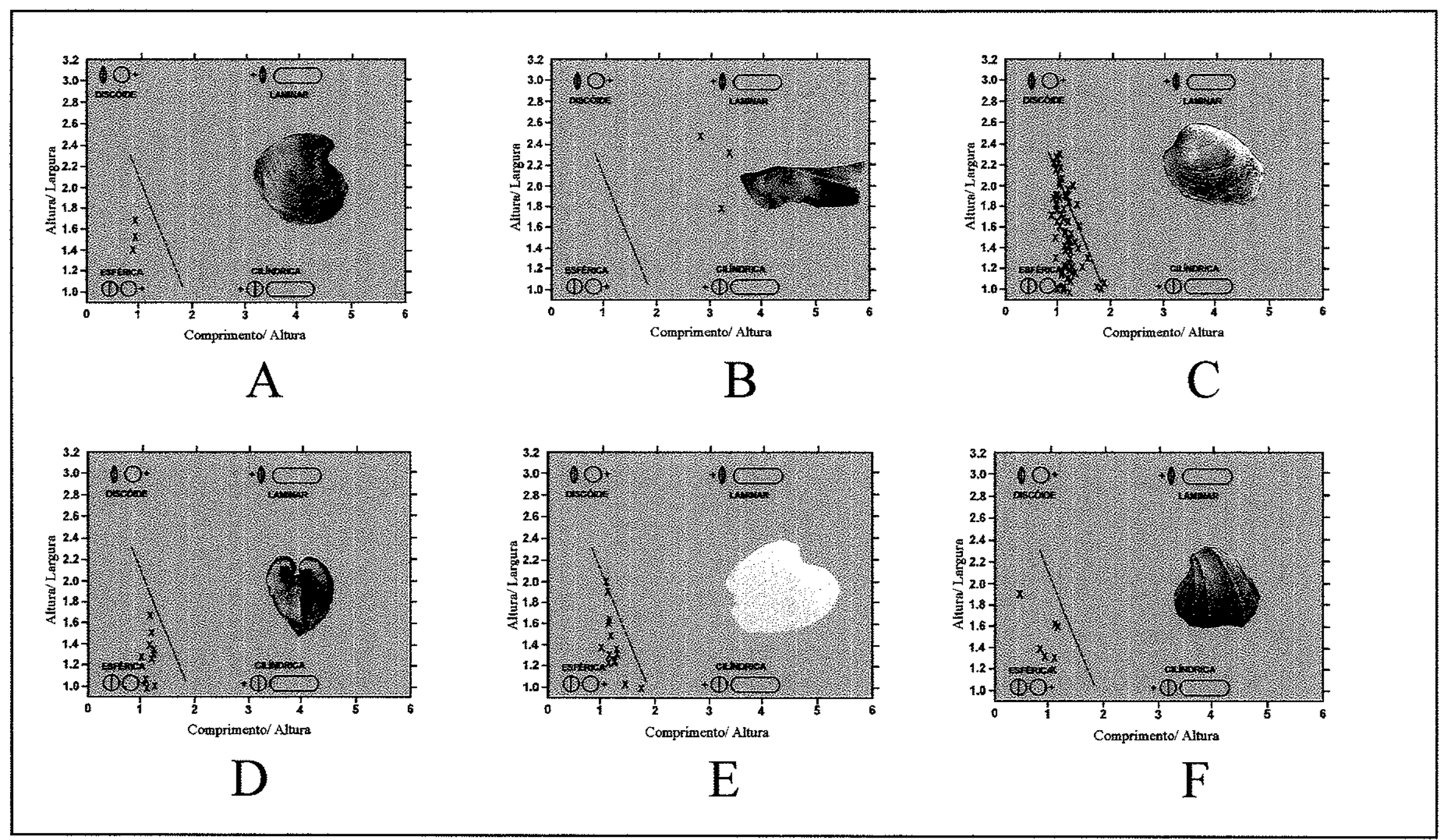

Figura 30- Relação entre a forma tridimensional das conchas e a provável velocidade de escavação de: Tambaquyra camargoi (A); Anhembia froesi (B); Pinzonella illusa (C); Plesiocyprinella carinata (D); Casterella gratiosa (E) e, Ferrazia cardinalis (F). A linha pontilhada separa as regiões de escavação lenta (a esquerda) e rápida, segundo Stanley (1970). 


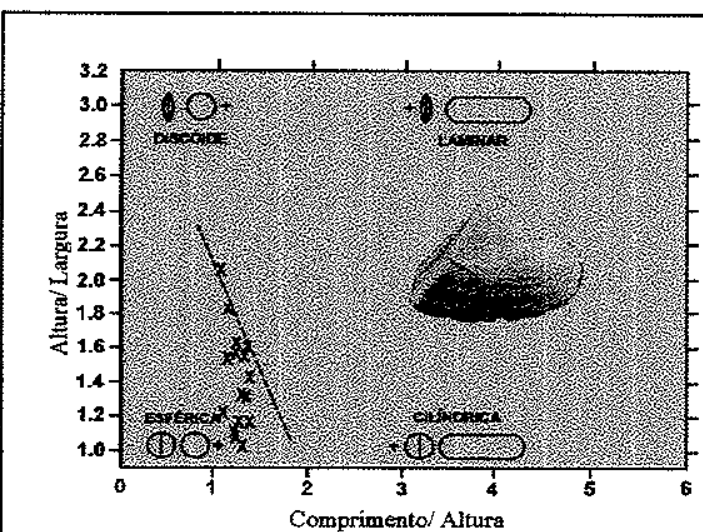

A

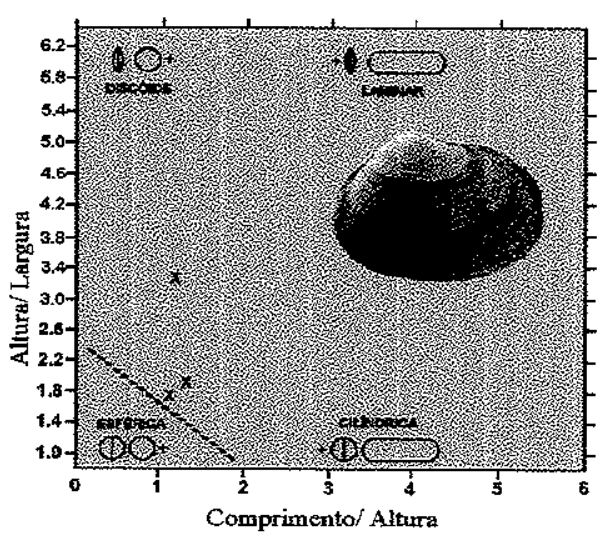

D

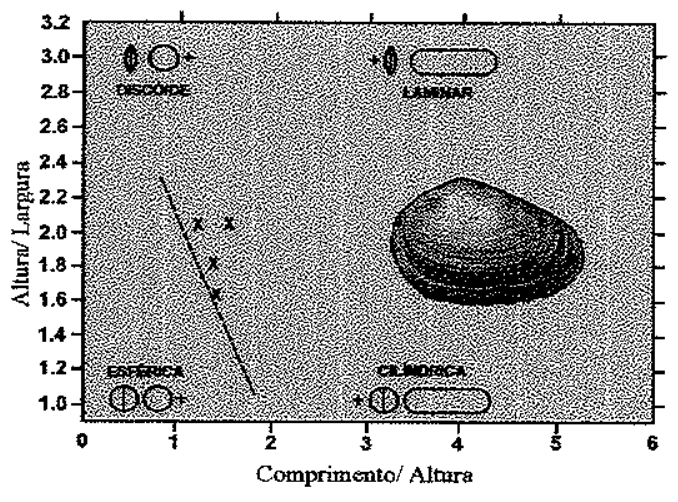

B

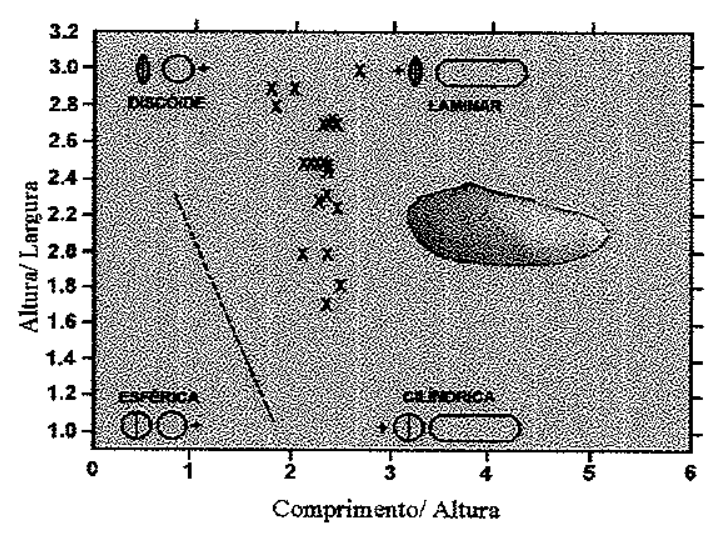

E

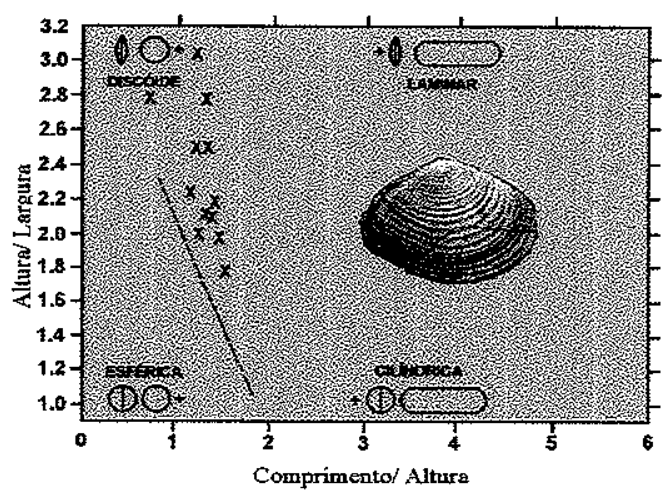

C

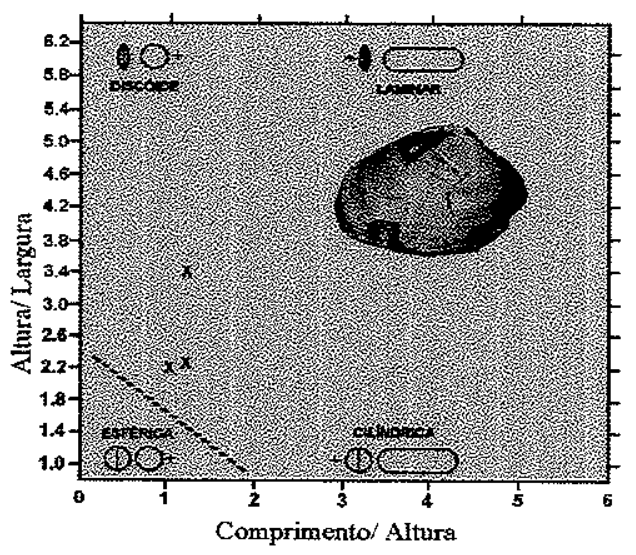

F

Figura 31 - Relação entre a forma tridimensional das conchas e a provável velocidade de escavação de: Terraia aequilateralis (A); Angatubia cowperesioides (B); Cowperesia anceps (C); Runnegariella fragilis (D); Favalia arcuata (E) e, Othonella araguaiana (F). A linha pontilhada separa as regiões de escavação lenta (a esquerda) e rápida, segundo Stanley (1970). 


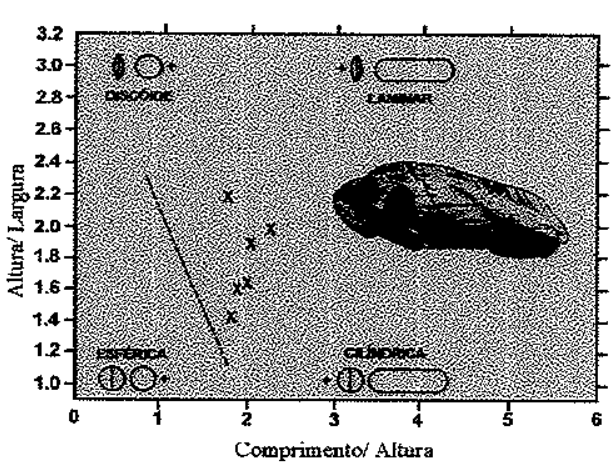

A

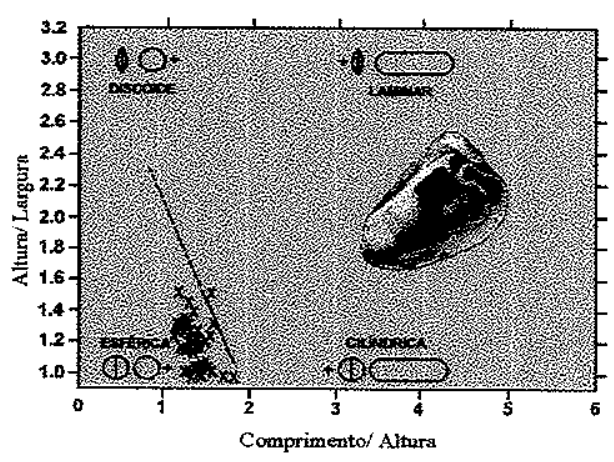

C

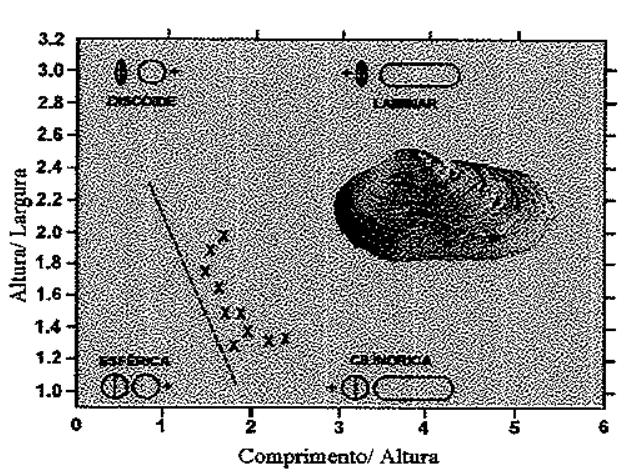

B

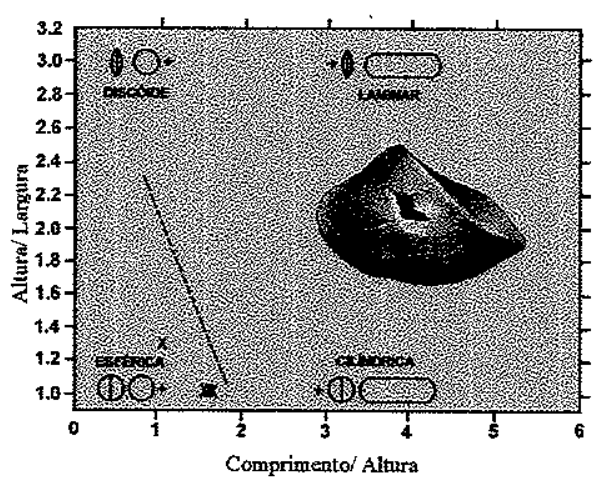

D

Figura 32 - Relação entre a forma tridimensional das conchas e da possível velocidade de escavação das conchas de: Holdhausiella elongata (A); Roxoa corumbataiensis (B); Pinzonella neotropica (C) e, Jacquesia brasiliensis (D). 
$\mathrm{Na}$ assembléia de Anhembia froesi, todos os bivalves apresentam maior largura da concha na região meso-posterior, assim como a maioria dos bivalves da assembléia de Pinzonella illusa. Entretanto, Coxesia mezzalirai apresenta a maior largura na porção ventral, mais uma vez sugerindo tratar-se de uma espécie de epifauna (veja item 5.2). Os bivalves da assembléia de Pinzonella neotropica, por sua vez, apresentam também a maior largura da concha na região meso-posterior. A exceção é Naiadopsis lamellosus, cuja concha possui a maior largura na região ventral. Tal feição favoreceria, possivelmente, sua estabilidade no substrato, sendo característica das formas da semi-infauna (Stanley, 1972; Brandshaw \& McCartan, 1991).

\subsubsection{CONDIÇÃO INEQÜIVALVE}

A presença de valvas com forma e tamanho diferentes, em um mesmo indivíduo, é uma característica conspícua de determinados bivalves. Em organismos de epifauna, tal característica está relacionada com uma maior estabilidade da concha no substrato, conferida, sobretudo, pelo achatamento lateral da valva que permanece em contato com o substrato (Stanley, 1970, 1972; Kotzian, 1995).

A despeito disto, bivalves do Grupo Passa Dois com possível hábito de epifauna (Coxesia mezzalirai) e semi-infauna (Naiadopsis lamellosus e Barbosaia angulata), não apresentam conchas com valvas ineqüivalves. Tal fato sugere, fortemente, que a posição de vida era com o plano sagital vertical, em relação ao substrato (veja também, Stanley, 1972). A concha de Pinzonella neotropica, entretanto, apresenta forte condição ineqüivalve. No geral, a valva esquerda apresenta-se cerca de uma vez e meia maior que a valva direita, possuindo uma depressão suave (depressão radial) que delimita a porção anterior e posterior da concha (fig. 33). Além disso, a porção posterior do animal apresenta um crescimento diferenciado entre a valva esquerda e direita, produzindo um recobrimento posterior da valva esquerda por sobre a direita, ocasionando uma "dobra" no plano de comissura (fig. 34). 


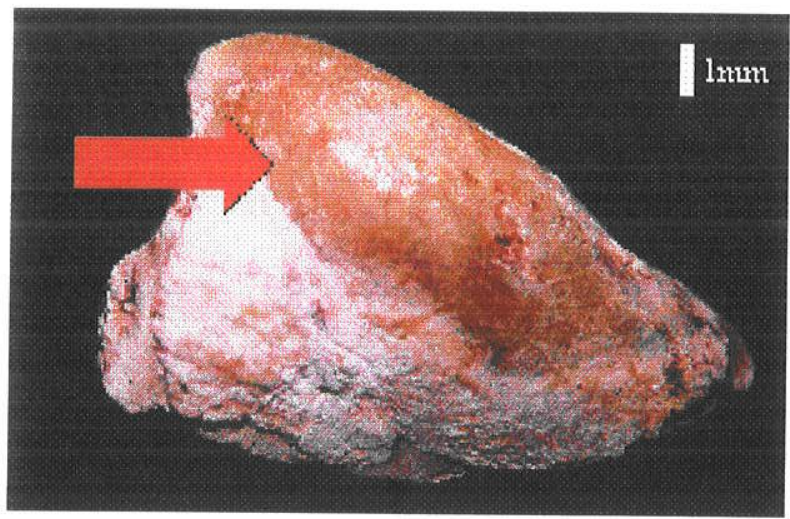

Figura 33- Valva direita de Pinzonella neotropica. A seta indica a depressão radial.

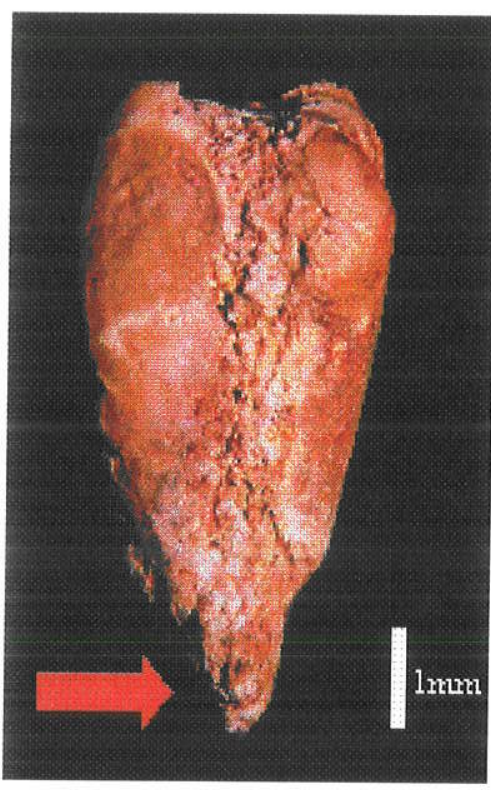

A

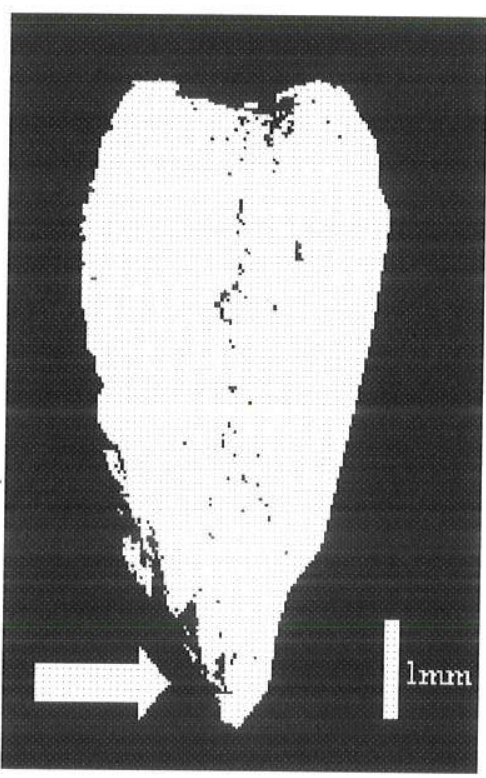

B

Figura 34- Valvas de Pinzonella neotropica articuladas fechadas. A seta indica a torção da parte ventral das valvas para a esquerda. Notar a forte condição ineqüivalve. Explicação: A- imagem normal das valvas articuladas de Pinzonella neotropica, B- imagem alterada do mesmo espécime para facilitar visualização da torção ventral das valvas. 


\subsubsection{Alongamento}

As dimensões da porção anterior e posterior das conchas relacionam-se com os modos de vida adotados pelos bivalves. A presença de uma porção anterior reduzida revela uma condição anisomiária (diferenças de tamanho entre musculatura anterior e posterior). Esta é uma característica de formas de epifauna, que apresentam notável redução dos músculos adutores e retratores anteriores. Tal feição pode ser empregada na diferenciação de formas de epifauna e semi-infauna bissada, pois, nesta última, a redução da porção anterior não é tão pronunciada (Stanley, 1970, 1972). Entre as formas escavadoras, existem conchas com a porção anterior ampla, abrigando um pé grande, que está associado com a rápida escavação (Stanley, 1970) ou, ainda, conchas com a porção anterior triangular, que facilita a penetração no substrato, proporcionando também uma rápida escavação (Stanley, 1972).

Entre os bivalves da assembléia de Anhembia froesi, as espécies Barbosaia angulata e ?Anthraconaia mezzalirai apresentam porção anterior da concha reduzida $(\mathrm{CA} / \mathrm{C}=0,23 \mathrm{e}$ 0,12 , respectivamente), corroborando a interpretação de um hábito de vida de semi-infauna $\mathrm{e}$ epifauna, respectivamente, conforme já sugerido por outras feições morfológicas.

$\mathrm{Na}$ assembléia de Pinzonella illusa, a espécie Coxesia mezzalirai apresenta concha com forte redução da porção anterior, sendo que sua forma mitilóide reforça a idéia de que fosse um representante da epifauna. Por sua vez, a concha de Runnegariella fragilis é a única, dentre as analisadas que possui a porção anterior expandida $(\mathrm{CA} / \mathrm{C}=0,56$, em média). Este fato sugere presença de um pé grande e vigoroso associado à escavação (Simões \& Anelli, 1995). Além disso, a forma laminar de sua porção anterior (estampa II, fig. 3) proporcionaria, a esta espécie, um menor movimento de balanço, durante o ato de escavação.

$\mathrm{Na}$ assembléia de Pinzonella neotropica, a espécie Naiadopsis lamellosus apresenta também porção anterior reduzida, mas em menor proporção do que em Coxesia mezzalirai. Tal fato condiz com o provável hábito de vida da semi-infauna, de vez que os representantes desta guilda apresentam, geralmente, uma posição anterior não tão reduzida quando comparados aos animais da epifauna (Stanley, 1970; Ghilardi, 1995).

Por outro lado, a presença de uma porção posterior desenvolvida está relacionada ao desenvolvimento dos sifões. Esta característica é típica de bivalves escavadores intermediários e profundos. Dentre os bivalves estudados, Angatubia cowperesioides, Holdhausiella elongata e Roxoa corumbataiensis (assembléia Pinzonella illusa) e Roxoa intricans (assembléia Pinzonella neotropica) possuem conchas posteriormente alongadas. 
Conforme já mencionado, Roxoa corumbataiensis e Roxoa intricans foram, possivelmente, formas escavadoras profundas, enquanto que Holdhausiella elongata foi escavadora rasa, já que não possui sinus palial. Angatubia cowperesioides foi, provavelmente, uma forma escavadora intermediária, mas esta interpretação não é destituída de dúvida, pois sua musculatura não é conhecida.

\subsubsection{ESPESSURA DAS VALVAS}

A espessura das valvas é dada pelo índice de espessura (Stanley, 1970), que é a razão entre o volume da concha e o volume da massa visceral interna do bivalve. Já que a medida do volume interno é prejudicada por fatores de preservação, nos bivalves fósseis ela é uma medida indireta.

Bivalves com valvas espessas são, geralmente, atribuídos à infauna rasa, estando desta forma protegidos da predação e da abrasão causada pela constante exumação, tendo em vista que eles vivem em um ambiente de alta energia. Por sua vez, conchas pouco espessas associam-se à formas escavadoras profundas. Além disso, há uma relação entre a granulometria do substrato e a espessura da concha, estando as conchas pouco espessas associadas a substratos finos, o que lhes confere maior flutuabilidade neste meio (Stanley, 1970).

Tambaquyra camargoi e Anhembia froesi (assembléia de Anhembia froesi) apresentam conchas espessas apesar de terem possivelmente vivido em substrato fino (arenito muito fino, siltito). Esta característica pode ser compreendida, considerando-se outras funções adaptativas (e.g., quimiossimbiose), discutidas no item 5.4 .

Runnegariella fragilis, Cowperesia anceps e Angatubia cowperesioides apresentam conchas menos espessas do que o restante da fauna de bivalves da assembléia de Pinzonella illusa, possivelmente como uma adaptação à vida em substrato mais siltico/argiloso. Por outro lado, Naiadopsis lamellosus apresenta concha mais espessa do que o restante dos bivalves da assembléia de Pinzonella neotropica. Esta característica, possivelmente, está associada ao hábito de semi-infauna, cuja porção exposta da concha está mais propensa ao ataque de predadores, à bioerosão e às injúrias provocadas pelo choque de partículas clásticas ou não. 


\subsubsection{ORNAMENTAÇÃo}

\subsubsection{ORNAMENTAÇÃO LINEAR}

Compreende linhas concêntricas e radiais com diferentes graus de pronunciamento. Carter (1967b) sugere cautela nas interpretações morfofuncionais, em relação à ornamentação, com especial atenção aos casos em que ela é pouco estudada nos animais marinhos viventes. Entretanto, organismos com forte ornamentação são geralmente esféricos e apresentam um hábito de vida escavador raso e lento (Stanley, 1970; 1981; Savazzi, 1982; Seilacher, 1984). Os diferentes tipos de ornamentação presentes na superfície externa das conchas dos bivalves compreendem uma das adaptações mais importantes para o hábito escavador, particularmente para as formas escavadoras rasas (Stanley, 1969, 1970, 1972, 1975, 1981; Seilacher, 1972, 1973; Savazzi, 1982 e Marsh, 1984). O caráter concêntrico da ornamentação está relacionado a dois aspectos principais: a- quando a ornamentação é assimétrica, em seção, há um aumento na velocidade de escavação, sendo característica própria de escavadores rasos e rápidos (Stanley, 1969, 1970, 1975, 1981), facilitando a penetração no substrato, por comprimir o sedimento ao seu redor e, b- a ornamentação é simétrica, em seção, que auxilia na sustentação e flutuação ("buyoance") em substrato fluidizado. Tal ornamentação não permite que o bivalve afunde, atuando como âncora. Esta ornamentação auxilia também no processo de prevenção da exumação por correntes tracionais de fundo, sendo, portanto, a ornamentação funcionalmente mais estabilizadora, do que locomotora.

A presença de uma ornamentação radial consiste em um auxílio ao ato de escavação, pois produz um serrilhado na margem ventral, que facilita a penetração da concha no substrato. Já as formas sem ornamentação (somente linhas de crescimento levemente marcadas) apresentam velocidade de escavação muito maior, quando comparadas às formas com ornamentação ou rugosidades pronunciadas (Stanley, 1970, 1975, 1977, 1981).

$\mathrm{Na}$ assembléia de Anhembia froesi, a espécie Tambaquyra camargoi apresenta uma ornamentação concêntrica, mas não fortemente impressa (estampa I, fig. 12). A ornamentação é simétrica, podendo, deste modo, auxiliar o animal a "flutuar" em substrato lamoso.

A maioria das conchas dos bivalves da assembléia de Pinzonella illusa (Pinzonella illusa, Casterella gratiosa, Holdhausiella elongata, Favalia arcuata, Runnegariella fragilis, Othonella araguaiana, e Plesiocyprinella carinata) possui linhas de crescimento tenuemente 
marcadas, conferindo-lhes um aspecto quase liso, principalmente na porção posterior da valva. É curioso observar que tal ornamentação ocorre, preferencialmente, nas formas infladas, o que poderia auxiliar no ato de escavação. O mesmo é válido para as espécies que são exclusivas da assembléia de Pinzonella neotropica (e.g., Jacquesia brasiliensis, Pinzonella neotropica e Roxoa intricans).

As conchas de Cowperesia anceps, entretanto, apresentam ornamentação concêntrica (estampa III, fig. 2) o que coaduna com um hábito escavador rápido, indicado por outras feições morfológicas (e.g., forma discóide, índice de obesidade). Sugere, ainda, um hábito de vida em sedimento argiloso ou síltico, também apontado por outras evidências morfológicas.

Por fim, a concha de Ferrazia cardinalis é singular dentre todas as paleozóicas, dada a presença de ornamentação radial (estampa II, fig. 10). Como resultado, sua margem ventral é serrilhada, o que facilita o ato de escavação (Stanley, 1970).

\subsection{CARACTERÍSTICAS INTERNAS DAS CONCHAS}

Da mesma forma que as feições externas, as características internas das conchas permitem a identificação de muitos aspectos relacionados ao hábito de vida dos bivalves, dentre estes, destacam-se as feições da charneira e as inserções musculares, a seguir descritas.

\subsubsection{Charneira}

A charneira dos bivalves apresenta uma grande diversidade, com relação ao número e a forma de seus componentes (dentes e fossetas). Entretanto, dois grupos principais podem ser reconhecidos: charneiras edentelosas, são encontradas na maioria dos bivalves escavadores profundos, pois a ausência dos dentes e fossetas facilita o movimento das valvas no eixo dorso-ventral, durante os movimentos sifonais e pediais (Stanley, 1970) e, charneira com dentes e fossetas que é geralmente limitada às espécies escavadoras rasas, sendo que a presença destes elementos facilita o rápido movimento das valvas ao longo do plano de comissura (Stanley, 1970).

Na assembléia de Anhembia froesi, a espécie Tambaquyra camargoi é edentelosa apresentando, apenas, uma projeção odontóide em sua charneira. Entretanto, as características 
morfológicas associadas, como a forma da concha e obesidade, sugerem hábito escavador raso.

Todos os bivalves escavadores rasos das assembléias de Pinzonella illusa e Pinzonella neotropica possuem dentes na charneira. Contrariamente, as formas escavadoras profundas (Roxoa corumbataiensis e Roxoa intricans) possuem charneira edentelosa, o que coaduna com outras evidências morfológicas. Dentre as formas escavadoras intermediárias, Casterella gratiosa não possui dentes na charneira

\subsubsection{INSERÇões MuSCULARES}

\subsubsection{Linha PALIAL}

Esta feição é resultante da inserção da margem do manto na concha e geralmente apresenta-se de duas maneiras principais: ou integropaliada, onde há ausência de sinus palial, indicando a ausência de sifão ou presença de sifão curto, sendo esta característica típica de organismos escavadores rasos, ou linha palial sinuspaliada, o sinus palial pode apresentar certa variação na sua profundidade, estando esta característica relacionada ao tamanho do sifão e, portanto, pode ser atribuída a um hábito escavador raso, intermediário ou profundo, de acordo com suas dimensões (Stanley, 1970; Runnegar, 1974; Kondo, 1987; Watters, 1993).

Apesar de Runnegar (1974) considerar um bivalve escavador profundo como o que possui pronunciado sinus palial, neste trabalho, considera-se escavador profundo o bivalve cuja porção posterior da concha enterrada está a cerca de $3 \mathrm{~cm}$ da interface água/sedimento (Stanley, 1970).

Na assembléia de Anhembia froesi, por exemplo, as espécies Mendesia piracicabensis e Anhembia froesi possuem linha palial integropaliada, sugerindo hábito escavador raso. A linha palial de Tambaquyra camargoi não é conhecida mas, entretanto, outras características morfológicas, como a obesidade, forma da concha e ausência de descontinuidade sifonal, sugerem um hábito escavador raso e, provavelmente, linha palial integropaliada.

A maior parte das espécies estudadas da assembléia de Pinzonella illusa (e.g., Plesiocyprinella carinata, Ferrazia cardinalis, Runnegariella fragilis, Pinzonella illusa e Terraiopsis aequilateralis), possui linha palial integropaliada, evidenciando a ausência de longos sifões. De fato, suas conchas são relativamente curtas ou anteriormente alongadas, sem 
fendas comissurais. Adicionalmente, apesar do fato da morfologia interna de Favalia arcuata, Othonella araguaiana e Holdhausiella elongata não ser bem conhecida é provável que tais espécies não possuíssem longos sifôes devido a ausência de descontinuidade sifonal em suas conchas. Todas estas espécies deveriam ser, portanto, escavadoras rasas. As espécies Casterella gratiosa, Itatamba paraima e Cowperesia anceps apresentam um pequeno sinus palial, refletindo um hábito de vida escavador intermediário. Roxoa corumbataiensis, por sua vez, não possui morfologia interna conhecida mas, devido a presença de uma descontinuidade sifonal bem marcada, é provável que possuísse longos sifões, indicando um hábito escavador profundo.

$\mathrm{Na}$ assembléia de Pinzonella neotropica, as espécies Pinzonella neotropica e Jacquesia brasiliensis apresentam linha palial integropaliada, sugerindo hábito escavador raso. Roxoa intricans, porém, possuí um sinus palial pronunciado que, associado a presença de descontinuidade sifonal e forma da concha cilíndrica, indicam um hábito escavador profundo.

\subsubsection{Músculos PediaIs e Bissais}

Muitas informações podem ser obtidas através do estudo de algumas características da musculatura pedial e bissal dos bivalves. $O$ músculo bissal, quando presente, indica que o organismo possui um modo de vida de epifauna ou semi-infauna. Conforme já comentado, organismos de epifauna apresentam uma pronunciada condição anisomiária da musculatura pedial, sendo as inserções musculares anteriores bem menores do que as posteriores. Esta é uma diferença importante com relação aos organismos de semi-infauna, que apresentam concha com um menor grau desta condição. Em formas de infauna, pode ocorrer uma pequena variação de tamanho entre os músculos pediais anteriores e posteriores, sendo, contudo, aceita como isomiária. Outra feição a ser considerada diz respeito ao grau de impressão da musculatura na concha, podendo esta ser leve ou profundamente impressa. Uma impressão muscular profunda é, geralmente, atribuída a um hábito escavador raso, ativo.

Alguns bivalves da assembléia Anhembia froesi (e.g., Tambaquyra camargoi, Mendesia piracicabensis) apresentam inserção muscular isomiária fortemente impressa, sugerindo hábito escavador (estampa I, fig. 5 e 10). Anhembia froesi possui musculatura pedial bem marcada, podendo indicar escavação ativa. Curiosamente, entretanto, este animal parece ter vivido em substrato raramente afetado por correntes tracionais de fundo. Por outro 
lado, Barbosaia angulata possui musculatura anisomiária, porém não pronunciada (estampa I, fig. 2), indicando um hábito de semi-infauna.

Alguns bivalves pertencentes à assembléia de Pinzonella illusa (Casterella gratiosa, Itatamba paraima, Plesiocyprinella carinata, Ferrazia cardinalis, Pinzonella illusa e Terraiopsis aequilateralis) possuem as inserções dos músculos adutores e protratores fortemente impressas, revelando um hábito escavador ativo. Por outro lado, Pinzonella neotropica e Jacquesia brasiliensis foram escavadoras ativas pois, como as formas ecologicamente similares da assembléia de Pinzonella illusa, estas possuem conchas onde as inserções dos músculos pediais estão fortemente impressas.

Por sua vez, Coxesia mezzalirai não possui inserções musculares conhecidas, mas a porção anterior da concha fortemente reduzida sugere uma condição anisomiária. O mesmo é válido para Naiadopsis lamellosus (assembléia de Pinzonella neotropica).

\subsection{ORIENTAÇÃO DA CONCHA NO SUBSTRATO}

Segundo Stanley $(1970)$ e Kondo $(1997,1998)$, a posição de vida de um bivalve é aquela na qual o animal se alimenta, após o ato de escavação. Esta é a melhor definição para posição de vida pois, para os bivalves da infauna, a obtenção de água para respiração e alimentação é o principal fator limitante de sua distribuição (Stanley, 1985). Em muitos casos a posição de vida de um bivalve pode ser diretamente analisada no registro fossilifero, nos casos em que estão preservados in situ (Stanley, 1970; Bambach, 1971; Fürsich, 1980; Kondo, 1990; Simões \& Rocha-Campos, 1994; Kondo \& Stace, 1995; Anelli et al, 1998; Farro, 1998). Entretanto, se as condições tafonômicas não propiciarem a preservação in situ do bivalve, a posição de vida pode ser inferida indiretamente, de acordo com algumas de suas características morfológicas (e.g., forma da concha).

A representação da provável orientação no substrato das conchas das espécies estudadas é mostrada nas figuras 35 a 37. Sua determinação levou em consideração as características morfofuncionais anteriormente discutidas, uma vez que, com exceção de Naiadopsis lamellosus (assembléia de Pinzonella neotropica) não são conhecidos bivalves preservados em posição de vida nas concentrações fossilíferas examinadas. 


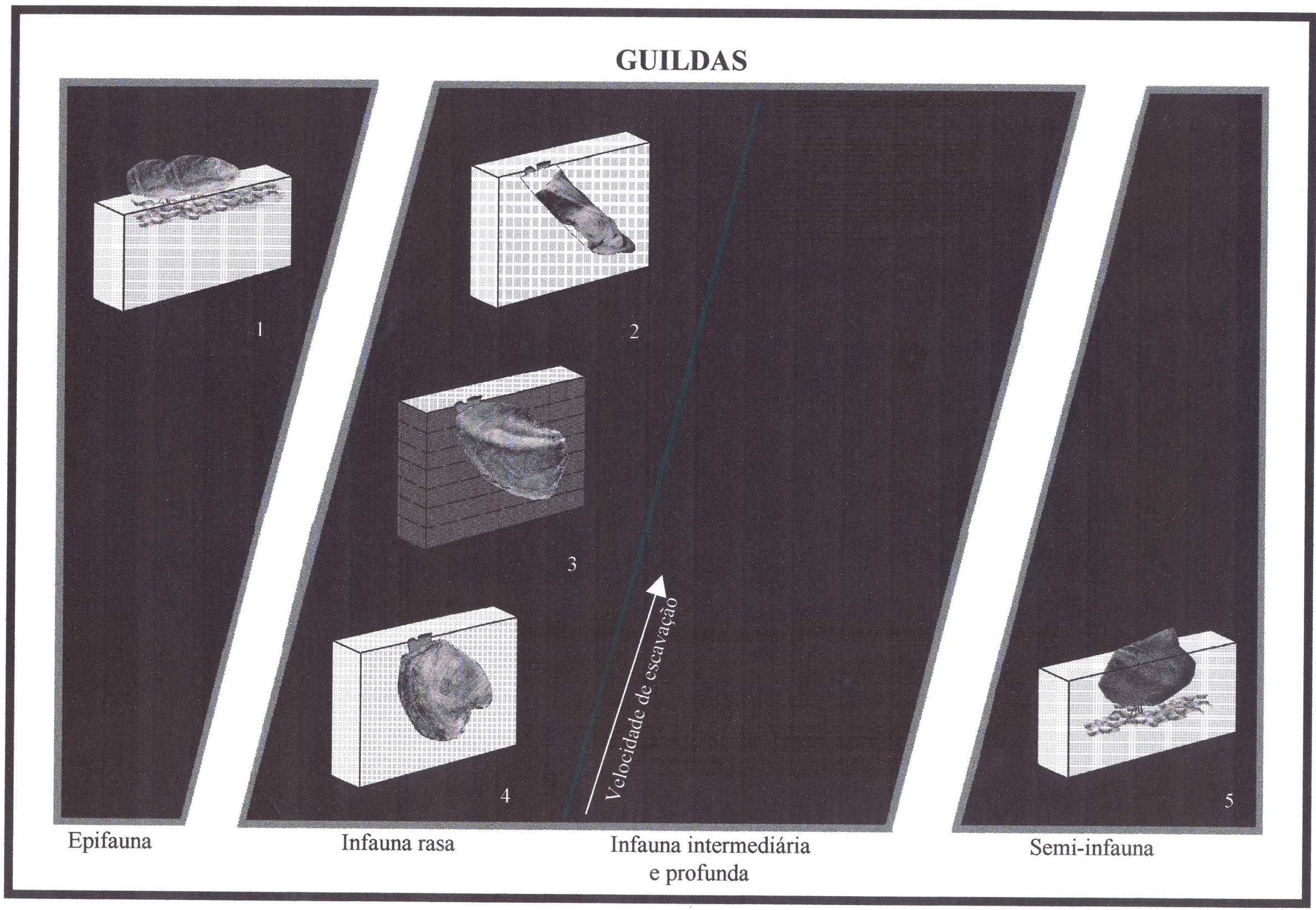

Figura 35- Blocos diagramas com o provável substrato e posição de vida das conchas de ?Anthraconaia mezzalirai (1), Anhembia froesi (2), Maackia contorta (3), Tambaquyra camargoi (4) e Barbosaia angulata (5). 


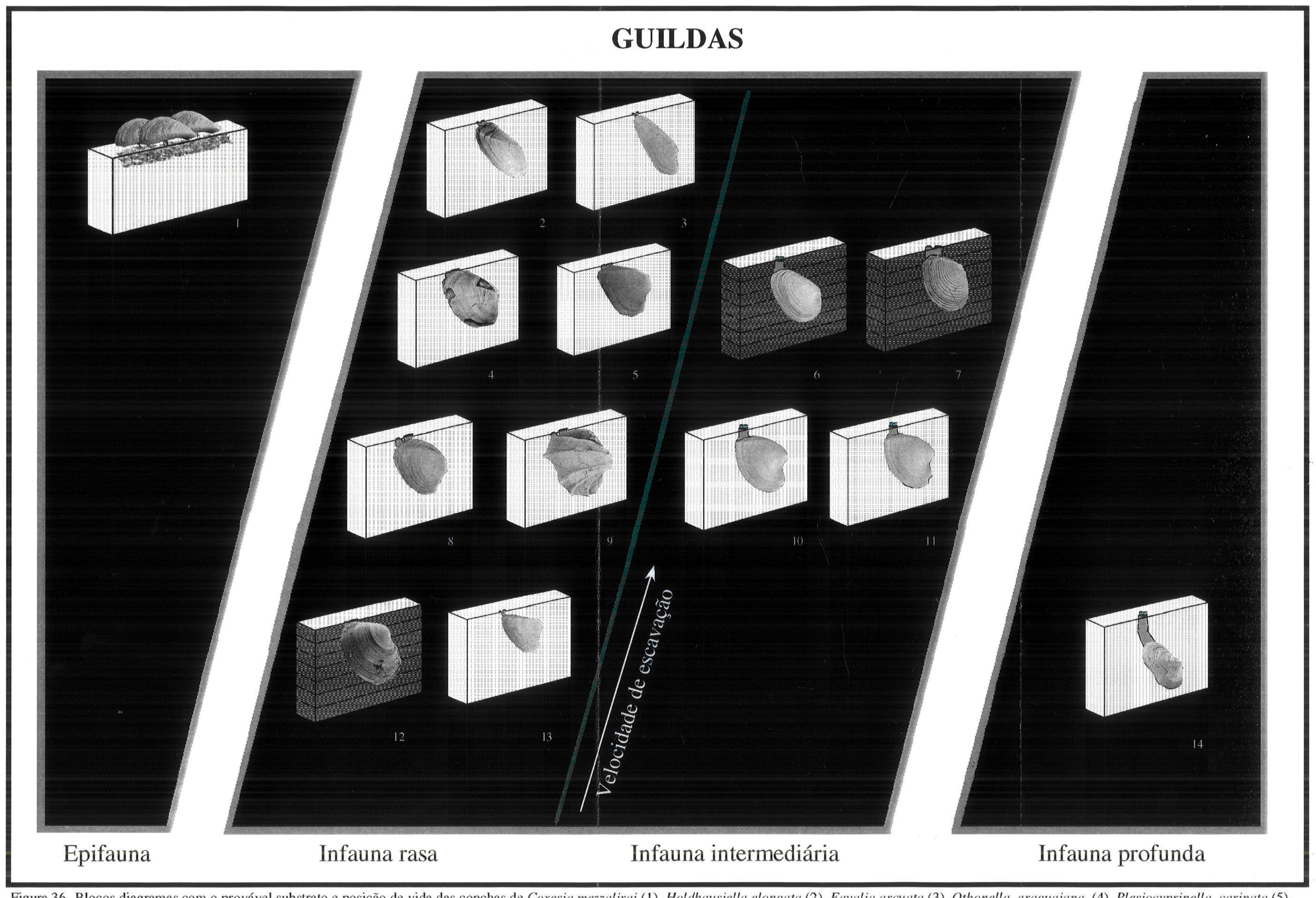

Figura 36- Blocos diagramas com o provável substrato e posição de vida das conchas de Coxesia mezzalirai (1), Holdhausiella elongata (2), Favalia arcuata (3), Othonella araguaiana (4), Plesiocyprinella carinata (5), Angatubia cowperesioides (6), Cowperesia anceps (7), Pinzonella illusa (8), Ferrazia cardinalis (9), Casterella gratiosa (10), Itatamba paraima (11), Runnegariella fragilis (12), Terraiopsis aequilateralis (13) e Roxoa corumbataiensis (14). 


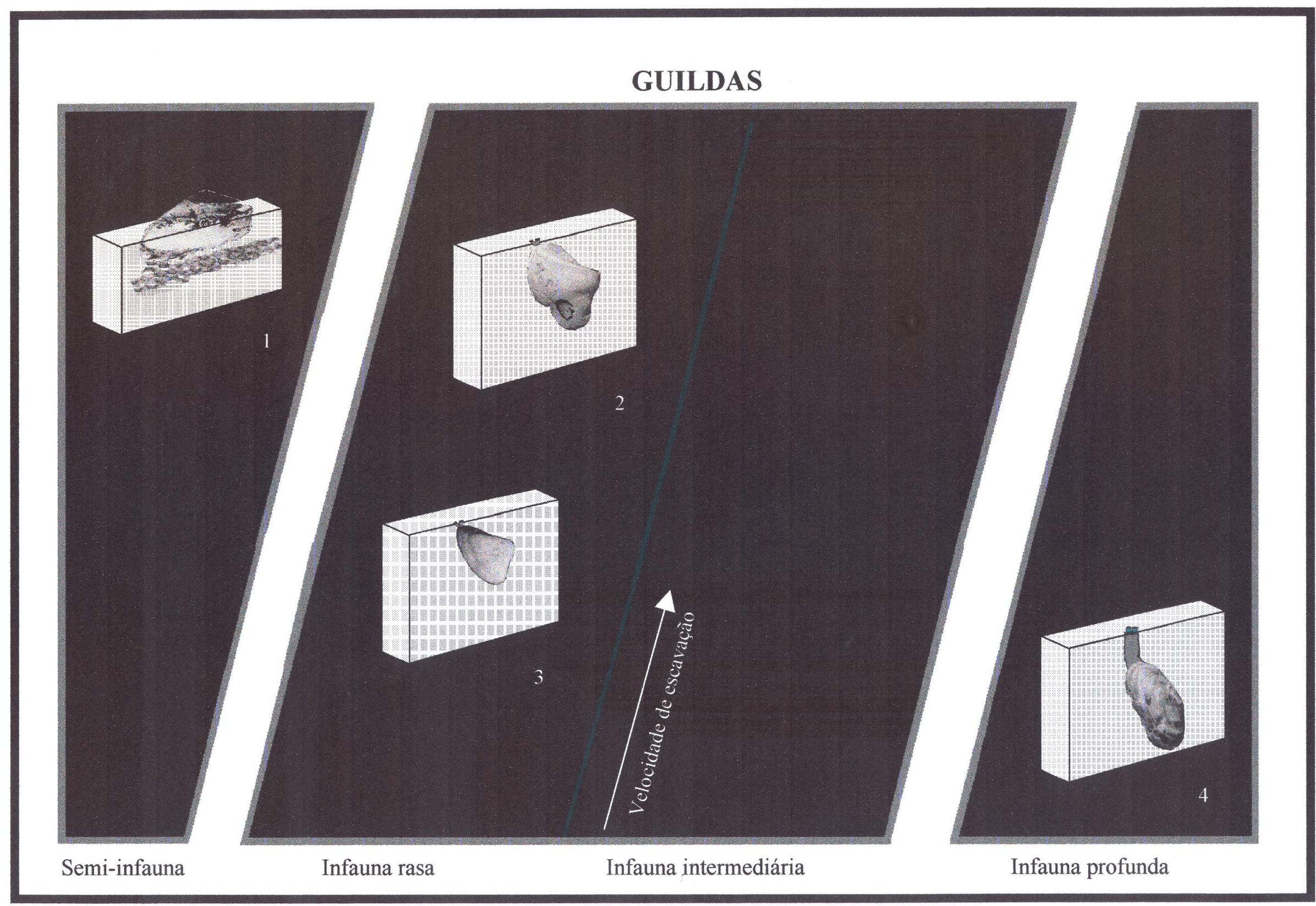

Figura 37- Blocos diagramas com o provável substrato e posição de vida das conchas de Naiadopsis lamellosus (1), Jacquesia brasiliensis (2), Pinzonella neotropica (3) e Roxoa intricans (4). 
DISCUSSÃO 


\section{DISCUSSÃO}

Conforme mencionado anteriormente, neste capítulo serão discutidas algumas das implicações da análise paleoautoecológica realizada, a qual fornece subsídios adicionais para resolução de problemas paleoautoecológicos que ainda persistem, especialmente no que tange à: a- possibilidade dos bivalves das assembléias de Anhembia froesi, Pinzonella illusa e Pinzonella neotropica terem sido elementos dulcícolas (Herbst et al., 1987); b- a questão do amplo predomínio das formas de infauna nas malacofaunas do Grupo Passa Dois (e.g., Runnegar \& Newell, 1971; Simões, 1992; Rohn, 1994; Simões et al., 1998b); c- as relações entre o modo de vida dos táxons estudados e os tipos de substratos originalmente colonizados e os litótipos onde eles são encontrados e, d- a possibilidade de alguns elementos da assembléia de Anhembia froesi (e.g., Tambaquyra camargoi e Anhembia froesi) terem sido bivalves quimiossimbiontes.

\subsection{FORAM OS BIVALVES DAS FORMAÇÕES SERRA ALTA, TEREZINA E CORUMBATAÍ FORMAS DE ÁGUA DOCE?}

A questão acima constituiu, por muito tempo, o cerne da discussão entre os paleontólogos que examinaram a malacofauna do Grupo Passa Dois. Uma ampla revisão histórica destas discussões, no período de 1918 a 1971, foi apresentada por Simões \& Fittipaldi (1987), sendo que em Rohn (1994) há uma discussão mais atualizada deste problema. No geral, pode-se dizer que a tentativa de interpretação do hábitat (marinho versus dulcícola) destes animais, com base puramente na análise paleontológica envolvia um grave pensamento circular, ou seja: os táxons do Grupo Passa Dois eram reconhecidamente endêmicos (veja Mendes, 1952), cujas relações de parentesco eram mal conhecidas (Mendes, 1967). Portanto, não eram conhecidas as formas aparentadas, nem, conseqüentemente, seus hábitos de vida. Deste modo, não era possível atribuí-los a um ambiente específico. Em outras palavras, a relação de parentesco era quem fornecia as bases para a interpretação ambiental.

Uma pequena mudança neste tipo de pensamento ocorreu quando Runegar \& Newell (1971) demonstraram que a maior parte dos bivalves do Grupo Passa Dois poderia ser atribuídas à famílias marinhas, de ampla distribuição no Neopaleozóico. Fundamentados nos dados paleontológicos, estratigráficos, sedimentológicos e isotópicos então disponíveis, os 
autores interpretaram a fauna como tipicamente salobra, idéia longamente defendida por Beurlen (1957a).

Mais recentemente, com a ampliação dos estudos paleontológicos e estratigráficos do Grupo Passa Dois, (Sousa, 1985; Rohn, 1988, 1994; Lavina, 1991; Maranhão, 1995; Simões et al., 1997) foi observado que o contexto paleoambiental era mais complexo do que suposto anteriormente, tendo prevalecido durante a deposição das formações Serra Alta, Terezina e Corumbataí, condições de salinidade variável (veja discussão em Suguio et al., 1974; Sousa, 1985; Sohn \& Rocha-Campos, 1990; Rohn, 1994; Maranhão, 1995; Matos, 1995), regressão marinha e clima, no geral, quente, configurando uma situação de alto estresse ambiental (veja discussão em Simões, 1992; Simões et al., 1998b). Curiosamente, entretanto, Herbst et al. (1987) interpretaram a malacofauna como tipicamente de água doce, fundamentados nas ocorrências de carófitas. Carófitas, entretanto, são representadas no registro paleontológico, normalmente, por restos transportados e retrabalhados e não indicam, necessariamente, ambiente dulcícola (Fürsich, 1994). De fato, conforme destaca Rohn (1994), é notável que as carófitas não foram observadas ainda nos sedimentos do Grupo Passa Dois depositadas sob condições tipicamente límnicas.

Se por um lado, não há a possibilidade de ser demonstrado que as malacofaunas aqui estudadas foram tipicamente marinhas, particularmente porque a ocorrência de formas exclusivas deste ambiente não são conhecidas, por outro, sabe-se hoje que eles, seguramente, pertencem à famílias marinhas do Neopaleozóico (Simões et al., 1997; Mello, 1999). Adicionalmente, deve ser lembrado que tanto os bivalves marinhos, como os de água doce, possuem feições morfológicas e tafonômicas (quadro 9) que thes são exclusivas (veja Fürsich, 1994, para uma discussão recente). Tais feições fornecem, portanto, evidências adicionais para a discussão acima.

Entre os malacólogos, os bivalves de água doce nunca receberam a atenção dispensada às formas marinhas. No que se refere a morfologia funcional, isto se deve, aparentemente, às poucas adaptações exclusivas que os grupos dulcícolas apresentam, assim como seus padrões evolutivos pouco complexos (Savazzi \& Peiyi, 1992). Entretanto, muitos bivalves de água doce apresentam características morfológicas únicas, demonstrando um alto grau de plasticidade morfológica que pode ser identificado no registro fossilífero (quadro 9). É interessante notar que as características exclusivas de bivalves marinhos, que são raras ou ausentes nos bivalves de água doce, em relação aos bivalves marinhos, são também raros ou 
Quadro 9- Principais feições observadas em bivalves dulcícolas e marinhos. Explicação: 1- Cowperesia anceps (X 1,3); 2- Ferrazia cardinalis (X 0,60); 3-Bragraveia corrugata (X 0,61); 4-Arconaia lanceolata (X 0,28); 5- Obliquaria reflexa (X 0,42); 6- Cristaria plicaria (X 0,22); 7 Runnegariella fragilis (X 2,3); 8- Hyridella ambigua (X 0,44); 9-Arconaia lanceolata (X 0,27); 10- Pinzonella illusa (X 0,75); 11- Pinzonella illusa (X 0,78).

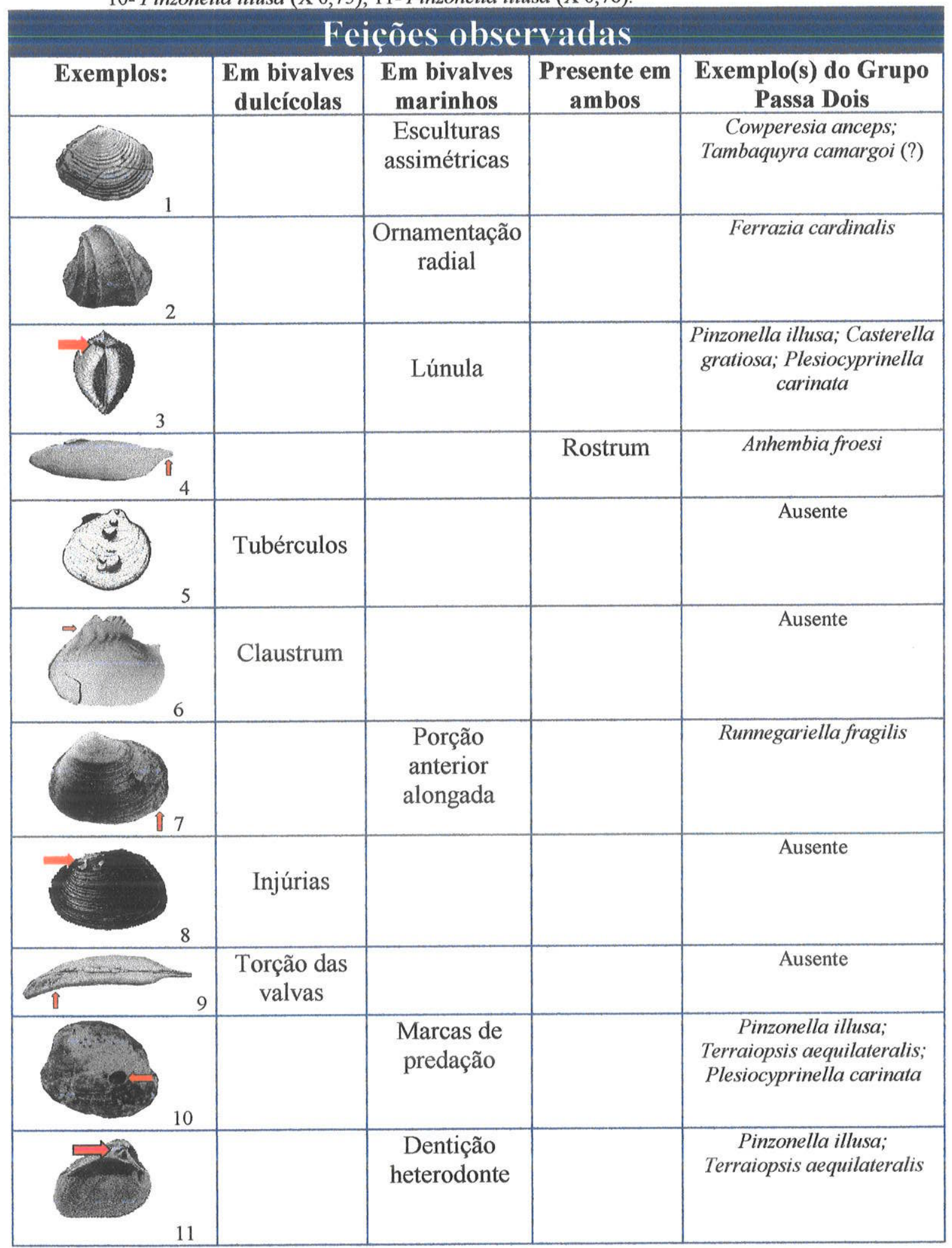


ausentes em táxons dulcícolas que pertenciam a grupos marinhos e que, secundariamente, invadiram o ambiente de água doce (e.g., Superfamília Cardiacea e famílias Arcidae e Donacidae) (Vermeij \& Dudley, 1985).

A princípio, as adaptações apresentadas por bivalves dulcícolas viventes estão relacionadas ao baixo grau de predação a que estão expostos e às correntes tracionais de fundo, que movimentam as partículas do substrato e transportam clastos de granulometria maior do que areia grossa, que podem proporcionar injúrias às valvas, quando exumadas e/ou roladas pelo leito do rio (Vermeij \& Dudley, 1985; Savazzi \& Peiyi, 1992). Nos bivalves norte-americanos da Superfamília Unionacea, por exemplo, são freqüentemente encontradas nas valvas pequenas depressões e rachaduras, não letais, restauradas. Tais estruturas decorrem do choque contra as valvas de sedimentos transportados por rolamento no leito do rio. Aparentemente este processo causa injúrias ao manto, na região interna da concha, porém, devido a provável tolerância a danos ao tecido mole, as estruturas restauradas são características exclusivas dos bivalves de água doce (Vermeij \& Dudley, 1985). Nenhuma das espécies aqui analisadas apresenta sinais de injúria e desgastes na região umbonal. Em adição, pontos de dissolução, comuns nas formas de água doce, não foram notados nos espécimes estudados

Algumas poucas características, por outro lado, estão relacionadas a adaptações por quimiossimbiose, assunto que será retomado mais adiante. Assim, todas as características adaptacionais mostradas aqui são nitidamente causadas por agentes não biológicos de seleção natural, como o tipo de fundo e transporte, que, em bivalves de água doce, são mais contundentes do que agentes biológicos, como a predação e a competição (Vermeij \& Dudley, 1985).

Bivalves dulcícolas viventes demonstram uma menor velocidade de escavação em relação aos bivalves marinhos, uma vez que no ambiente fluvial a dinâmica sedimentar (freqüência entre os eventos de erosão versus soterramento) é distinta da observada no ambiente marinho raso (acima do nível de base de ondas de tempestades) (Savazzi \& Peiyi, 1992). Tal fato é morfologicamente evidenciado pela expansão da porção anterior das conchas, assim como pela ausência de esculturas oblíquas e assimétricas em seção, na parte externa da valva. Por exemplo, bivalves que possuem porção anterior expandida comumente apresentam pé grande e vigoroso, utilizado para escavar rapidamente o substrato inconsolidado e constantemente retrabalhado por ondas e correntes, como é o caso de Runnegariella fragilis da assembléia de Pinzonella illusa (Simões \& Anelli, 1995). 
As esculturas oblíquas assimétricas em seção, por sua vez, também têm como função aumentar a velocidade de escavação, sendo particularmente importantes nos bivalves que colonizam habitats onde a exumação por correntes ou ondas é freqüente. Do mesmo modo, a lúnula, proporciona aos bivalves marinhos um aumento na velocidade de escavação, não tendo, entretanto, função definida nas conchas dos poucos bivalves dulcícolas (Vermeij \& Dudley, 1985) que possuem tal feição (Stanley, 1975). Segundo esse autor, a lúnula aumenta a velocidade de escavação, particularmente nas formas que exibem um pronunciado movimento de balanço. Dentre as espécies analisadas, Pinzonella illusa, Plesiocyprinella carinata, Ferrazia cardinalis e Casterella gratiosa possuem lúnula bem desenvolvida.

Esculturas simétricas em seção, tais como aquelas descritas por Stanley (1981), que conferem estabilidade aos bivalves que colonizam substratos freqüentemente afetados por correntes tracionais de fundo, são raras entre os bivalves de água doce. Cowperesia anceps e Angatubia cowperesioides, por exemplo, apresentam esse tipo de ornamentação. A ornamentação radial, por outro lado, tem como função principal aumentar a velocidade de escavação e não é encontrada em nenhum bivalve dulcícola. Das formas analisadas, Ferrazia cardinalis apresenta como autapomorfia (Simões et al., 1997) costelas radiais que variam, em número, de cinco a sete (Runnegar \& Newell, 1971). Por outro lado, os tubérculos e os nós são esculturas comuns nos bivalves da Família Unionidae da América do Norte, sendo exclusivos dos bivalves dulcícolas. Estas estruturas têm como função a ancoragem e estabilização dos bivalves (Vermeij \& Dudley, 1985; Gray, 1988), estando ausente nas espécies estudadas.

Uma maior estabilidade pode ser também proporcionada com a torção das valvas que, além disso, separa as correntes dos sifões inalante e exalante. Essa é uma feição típica dos Unionidae (Savazzi \& Peiyi, 1992), estando presente também em algumas famílias marinhas, tais como, Arcidae (McGhee, 1978; Savazzi, 1981), Bakevelliidae (Savazzi, 1984a), Mytilidae (Savazzi, 1984b, 1989), Colpomyidae (Liljedahl, 1994), Modiomorphidae (Johnston, 1993) e Sinodoridae (Johnston \& Zhang, 1998). Essa feição não foi observada nos bivalves analisados.

Os bivalves de água doce freqüentemente não apresentam dentição heterodonte, sendo a charneira mais espessa que a dos bivalves marinhos (Vermeij \& Dudley, 1985). Da malacofauna do Grupo Passa Dois, tanto Pinzonella illusa, como Terraiopsis aequilateralis apresentam dentição heterodonte, característica dos Veneroida. Já Plesiocyprinella carinata, Ferrazia cardinalis e Cowperesia anceps possuem um dente megadesmídeo na charneira da valva direita, semelhante ao dente cardinal dos heterodontes (Runnegar, 1967). 
O claustrum que é uma extensão dorsal pós umbonal das margens da concha sobre a linha da charneira é outra estrutura exclusiva de bivalves dulcícolas (Vermeij \& Dudley, 1985; Savazzi \& Peiyi, 1992). Sua função é aumentar a rigidez da charneira e proporcionar um impulso adicional de abertura das valvas contra a pressão do sedimento que circunda o animal (Savazzi \& Peiyi, 1992).

Diversos autores têm sugerido que os bivalves de água doce sofreram, ao longo de sua história evolutiva, "menor pressão" quanto a predação, do que os marinhos (e.g., Stanley, 1968, 1970, 1972; Vermeij, 1977, 1987). Conseqüentemente, nas conchas dos bivalves de água doce há uma maior incidência de aberturas (descontinuidades) anteriores e posteriores. Alguns autores como Stanley (1977) e Vermeij (1983), demonstraram que a incidência de predação entre os bivalves paleozóicos foi muito reduzida. Desse modo, alguns bivalves do Paleozóico seriam morfologica, mas não taxonomicamente, semelhantes aos bivalves viventes de água doce (Vermeij \& Dudley, 1985). Este fato, poderia inclusive explicar a semelhança morfológica entre bivalves atribuídos, com dúvidas, ao gênero Anthraconaia (?Anthraconaia mezzalirai) e os bivalves viventes e fósseis deste gênero, que vivem ou viveram sob condições de água doce. Este é o único bivalve do Grupo Passa Dois (formações Serra Alta, Terezina e Corumbataí) que seria morfologicamente semelhante à formas de água doce. A presença de homoplasia não pode ser aqui descartada.

Kowalewski et al. (no prelo) descreveram, recentemente, as primeiras conchas de bivalves permianos predados por organismos durófagos. Dentre essas, pelo menos, quatro pertencem a gêneros do Grupo Passa Dois (Casterella, Plesiocyprinella, Pinzonella, Terraiopsis). Predação por organismos durófagos não está presente em bivalves de água doce (Kowalewski \& Bambach, 1998).

As adaptações de bivalves dulcícolas para quimiossimbiose, nem sempre são de fácil reconhecimento, tanto nos animais viventes, como nos fósseis. Por exemplo, Solenaia oleivora possuí um pé de coloração amarela sulfúrica e vive em regiões anóxicas de rios e lagos sugerindo quimossimbiose. Entretanto, tal feição não se preserva no registro fossilifero. Em alguns casos, porém, certas estruturas podem ser consideradas como "bombas" de água intersticial anóxica, para as brânquias do bivalve. Por exemplo, o bivalve pleistocênico Arconaia lanceolata provavelmente usava seu rostrum, com tal função (Savazzi \& Peiyi, 1992). Tanto o rostrum, como quimossimbiose tem sido, entretanto, identificados em bivalves marinhos (Seilacher, 1984; Johnston \& Colom, 1998), sendo uma adaptação para vida em substratos finos, pobres em oxigênio (Kauffman, 1988; MacLeod \& Hoppe, 1992). 
Em resumo, portanto, não existem evidências morfológicas que indicam que os bivalves das assembléias de Anhembia froesi, Pinzonella illusa, e Pinzonella neotropica foram dulcícolas. Em adição, recentes estudos cladísticos (Simões et al., 1997; Mello et al., 1998b; Mello, 1999) mostram que os bivalves do Grupo Passa Dois (exclusive Formação Rio do Rasto) são aparentados às formas marinhas, o que estaria de acordo com os modelos evolutivos propostos por Beurlen (1957a), Runnegar \& Newell (1971); Simões (1992) e Simões et al. (1998b). Deve ser destacado, entretanto, que com base apenas na morfologia funcional não há como inferir o teor de salinidade do meio onde viveram os bivalves estudados, que deve ter sido altamente variável (veja discussão em Rohn, 1994). 


\subsection{Modo DE VIDA (EPIfaUna VERSUS INFAUNA) E O ESTRESSE AMBIENTAL}

Simões (1992) foi o primeiro autor a notar uma diminuição drástica no número de formas da epifauna e um aumento nas formas da infauna ao longo do registro Neopaleozóico (Grupos Tubarão e Passa Dois) da Bacia do Paraná. De fato, as malacofaunas das assembléias de Pinzonella illusa e Pinzonella neotropica, apresentam bivalves "ecologicamente" mais "mesozóicos" do que "paleozóicos", conferindo um aspecto "moderno" (coquinóide) e não "arcaico" (sensu Kidwell \& Brenchley, 1994) às acumulações esqueléticas onde são preservados. Tal feição é ressaltada pela alta proporção de formas escavadoras, com sifão fundido, possivelmente do tipo C de Yonge (1957). Conforme demonstrado por Mello (1999), a semelhança mostrada pelos bivalves escavadores do Grupo Passa Dois e formas mesozóicas é, em parte, devida a homoplasia heterócrona. Portanto, esta semelhança não pode ser utilizada, como argumento para a atribuição de uma idade triássica para a malacofauna (assembléias de Anhembia froesi, Pinzonella illusa e Pinzonella neotropica) do Grupo Passa Dois. Curiosamente, este fato tem sido observado também para outras malacofaunas permianas que, tafonomicamente, se assemelham mais às concentrações fossilíferas jurássicas (e.g., assinaturas tafonômicas, espessura, grau de empacotamento e geometria tridimensional), do que paleozóicas (Kidwell \& Brenchley, 1996), tendo em vista as mudanças na bioclasticidade que ocorreram neste intervalo, devido ao declínio dos braquiópodes e expansão dos bivalves escavadores.

Tendo em vista o contexto acima, seria extremamente oportuno discutir aqui, quais as possíveis causas para o predomínio das formas da infauna e suas implicações na análise ambiental do intervalo compreendido pelas formações Serra Alta, Corumbataí e Terezina.

Yonge (1962) propõe que os bivalves da epifauna são neotênicos, ou seja, retêm em sua fase adulta a característica bissal presente na fase larval. Yonge (1953), por sua vez, sugere que a atrofia do músculo adutor anterior foi uma adaptação à necessidade dos bivalves da epifauna terem sua parte posterior erguidas, para que os sifões inalante e exalante não fossem obstruídos, devido ao hábito gregário. No entanto, Stasek (1966) prefere atribuir a condição anisomiária a uma necessidade de elevação da parte posterior, sendo uma adaptação para facilitar a captura de alimento, em águas tropicais, mais pobres em recursos alimentares. Provavelmente, a proposta de Yonge (1953) é a mais provável já que para aumentar a captura 
de alimento, os bivalves provavelmente seguiriam outros rumos evolutivos, como o aumento das suas brânquias (Stanley, 1970).

Já os bivalves da semi-infauna podem também apresentar bisso, que proporciona fixação ao substrato. Sua característica principal é, entretanto, manter a parte anterior da concha no interior do substrato. Diferem eles dos bivalves da epifauna por possuírem uma condição anisomiária não tão marcante e por terem a parte mais larga da concha na região central, sendo que sua forma não é truncada anteriormente.

A presença de formas de epifauna e de semi-infauna bissadas é relativamente baixa no registro fossilifero do Grupo Passa Dois (Simões, 1992; Simões et al., 1998b) (fig. 38). Barbosaia angulata é, aparentemente, a única forma de semi-infauna presente na assembléia de Anhembia froesi. O mesmo é válido para Naiadopsis lamellosus da assembléia de Pinzonella neotropica (Ghilardi et al., 1995; Torello, 1999).

Esta interpretação, entretanto, não é desprovida de dúvida, uma vez que a forte condição ineqüivalve notada nas conchas de Pinzonella neotropica não é comum entre as formas escavadoras.

Stanley (1970) aponta que bivalves de epifauna, cujo plano de comissura está posicionado horizontalmente, em relação ao substrato, apresentam como característica mais importante e, mais inerente, a condição ineqüivalve. Uma das valvas estaria, deste modo, em maior contato com o substrato e tenderia, portanto, a apresentar características para a fixação e a estabilização do animal (veja, também, Kotzian, 1995). A valva oposta, por sua vez, apresentaria características contra injúrias causadas pelo ambiente, ao qual estaria exposta. Entretanto, a condição ineqüivalve, geralmente, está associada a uma ou mais características, tais como: a- alongamento de uma das aurícolas anteriores; $b$ - alongamento posterior da linha da charneira; c- presença de um sinus lateral na parte dorso-central da valva, que permanece em contato com o substrato; d- achatamento de uma das valvas em contato com o substrato e, e- redução da porção anterior da concha (Kaufmann, 1969; Stanley, 1970). Exceção feita a porção anterior reduzida (CA entre 0,11 e 0,29), nenhuma das conchas articuladas fechadas de Pinzonella neotropica apresenta tais características.

Quatro hipóteses poderiam ser sugeridas para explicar a posição de vida de Pinzonella neotropica, ou seja: a- animal de semi-infauna bissada, apoiado sobre a valva direita; banimal de epifauna bissada, apoiado sobre sua valva esquerda; c- animal reclinado e, danimal de infauna, ineqüivalve. 


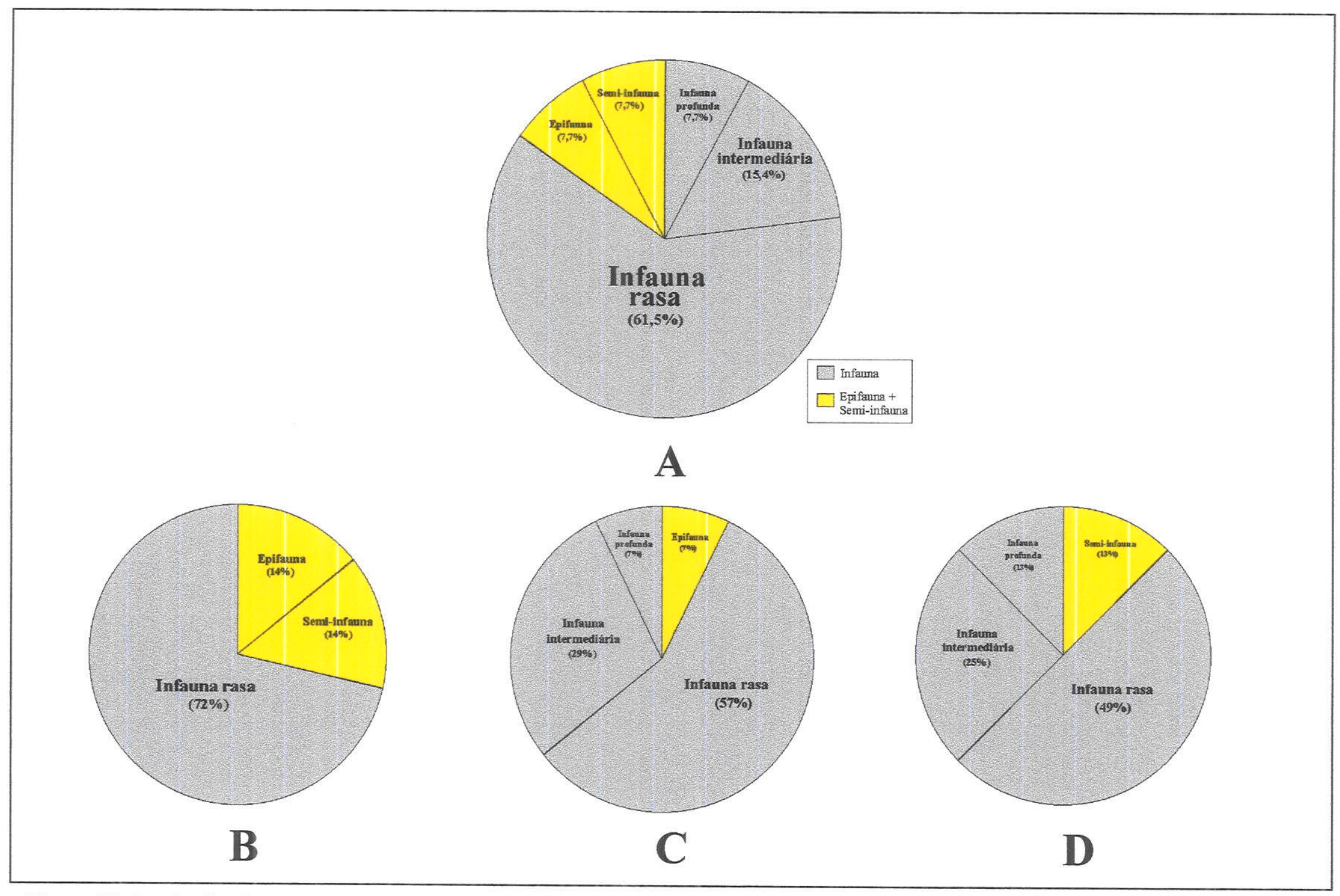

Figura 38- Modo de vida dos bivalves do Grupo Passa Dois (exclusive Formação Rio do Rasto) (A), assembléia de Anhembia froesi (B), Pinzonella illusa (C) e Pinzonella neotropica (D). 
Considerando a primeira hipótese, os exemplares DZP-2493 e DZP-2517 representariam animais em posição de vida. A depressão radial presente na valva esquerda separaria uma pequena porção da parte antero-ventral da concha que permaneceria abaixo do sedimento. Isto proporcionaria uma melhor ancoragem à concha que teria a porção anterior da valva esquerda e o umbo da valva direita, como dois pontos de apoio no interior no substrato. Entretanto, duas características refutam esta hipótese. A valva direita, na qual o bivalve se apoiaria é convexa, diferentemente da valva plana que os bivalves que possuem este hábito de vida apresentam. Além disto, a "dobra" da margem posterior que a concha apresenta, levaria a um colapso do sistema sifonal, pois os sifões estariam sendo conduzidos ao interior do substrato e não à interface água/sedimento.

Existe a possibilidade de que Pinzonella neotropica fosse um animal de epifauna bissada apoiado sobre sua valva esquerda. Neste caso, os exemplares DZP-2495 e DZP-2625 estariam in situ. Uma vez que a abertura sifonal está ausente, a depressão radial da valva esquerda funcionaria como fulcro de ancoragem, entre o umbo esquerdo e a porção ventral da valva esquerda, sobre o sedimento. Porém, a falta de uma abertura dorso-central da valva esquerda por onde passariam os filamentos do bisso e o fato da valva esquerda ser convexa e não plana, dificultam a interpretação acima. Contudo, a principal característica que inviabiliza as duas hipóteses anteriores é a ausência de uma abertura bissal, bem pronunciada. Esta estrutura pode ser reduzida, entretanto, se o animal em questão for uma forma reclinada, permanecendo sobre ou parcialmente coberto pelo substrato sem qualquer método de estabilização (Stanley, 1970). Apesar de serem raras no Recente, Stanley (1970) afirma que no passado geológico tais formas foram muito comuns. Uma vez que todos os bivalves com hábito similar permanecem deitados sobre uma das valvas, a maioria apresenta concha com forte condição ineqüivalve.

A principal característica das conchas desses animais, entretanto, é a diferença na convexidade da concha de apoio, que serve para elevar a comissura acima do substrato e impedir que o sedimento adentre nos sifões. Apesar destas duas características se enquadrarem em Pinzonella neotropica, a valva superior dos animais reclinados são achatadas para atuarem como escora às valvas inferiores. Nenhuma das valvas de Pinzonella neotropica (direita ou esquerda) é achatada invalidando a hipótese de que fossem reclinantes.

Duas superfamílias de bivalves do Recente (Tellinacea e Pandoracea), entretanto, apresentam espécies escavadoras com conchas ineqüivalves. Os animais têm um plano de 
comissura inclinado cerca de $30^{\circ}$ a $40^{\circ}$, em relação ao substrato, não permanecendo, portanto, numa posição vertical. Holme (1961) explica que nesta posição, as espécies detritívoras de Tellinacea obtêm uma melhor movimentação no interior do sedimento, na procura por alimento. Porém, esta posição não é favorável aos animais suspensívoros, dada a dificuldade de posicionar os sifões para fora do sedimento.

Stanley (1970) notou que nos animais viventes que possuem conchas ineqüivalves e são da infauna, há um crescimento diferenciado da valva de maior apoio no substrato. Isto faz com que os sifões sejam erguidos por sobre o substrato. Ainda, o posicionamento quase horizontal das conchas, em relação ao plano de acamamento do sedimento, evitaria a movimentação tanto para cima como para baixo, mantendo o animal em posição constante no sedimento. Aparentemente, esse foi o modo de vida de Pinzonella neotropica, jazendo no substrato com a valva esquerda mais inferiormente do que a direita, já que a "dobra" da porção posterior da valva é para a direita. Desse modo, portanto, Pinzonella neotropica foi um bivalve de infauna rasa com o plano de comissura horizontal, em relação ao substrato. As valvas articuladas fechadas de Pinzonella neotropica, encontradas em arenito, no afloramento 10, não estariam, deste modo, preservadas em posição de vida (veja também Torello, 1999).

Finalmente, ?Anthraconaia mezzalirai (assembléia Anhembia froesi) juntamente com Coxesia mezzalirai (assembléia de Pinzonella illusa) são as únicas formas de bivalves da epifauna encontradas no registro fossilifero do Grupo Passa Dois (Simões \& Costa, 1992).

Aparentemente, três fatores inter-relacionados poderiam ter contribuído para o amplo predomínio das formas de infauna na malacofauna do Grupo Passa Dois, a seguir descritos: aausência de substratos duros, estáveis, favoráveis à colonização pelas formas da epifauna; b- o alto grau de estresse ambiental vigente no intervalo estratigráfico compreendido pelas formações Serra Alta, Terezina e Corumbataí (e.g., Runnegar \& Newel, 1971; Simões,1992; Rohn, 1994) e, c- as condições batimétricas, predominantemente de águas rasas, durante os "tempos" Terezina/Corumbataí.

Diversos autores, dentre os quais Miller et al. (1988), notaram que o desenvolvimento de epifauna bissada, nos mares epicontinentais, caracterizados por predomínio de sedimentação siliciclástica fina, que é um bom corolário para o registro Permiano da Bacia do Paraná, está associado a períodos de baixa taxa de sedimentação ou de não deposição de sedimentos. Prolongados períodos de seleção dos sedimentos finos seriam responsáveis por um aumento proporcional de restos bioclásticos, disponíveis no substrato, condição necessária 
para fixação das larvas dos bivalves da epifauna. Tais períodos estariam relacionados a repetidos eventos de tempestade (Miller et al., 1988; Simões et al., no prelo), processo básico para o início do fenômeno acima (Miller et al., 1988), isto é, colonização pelos bivalves dos substratos mais ricos em restos bioclásticos (retroalimentação tafonômica) (Kidwell \& Jablonski, 1983).

As acumulações esqueléticas preservadas na Formação Serra Alta e na base da Formação Corumbataí mostram bioclastos freqüentemente dispersos na matriz, portanto, com baixo grau de empacotamento. Por outro lado, as acumulações esqueléticas encontradas na parte média e superior das formações Terezina e Corumbataí, comumente em arenitos bioclásticos ou coquinas, têm um potencial relativamente reduzido para preservar o processo de retroalimentação tafonômica, porque batimetricamente foram geradas entre o nível de base das ondas normais e o nível de base das ondas de tempestade (Simões et al., 1996a; Simões \& Kowalewski, 1998a; Torello, 1999). Deste modo, tais concentrações estariam, de maneira mais constante, sujeitas aos processos de retrabalhamento (Torello, 1999). Realmente, no material examinado, são raras as ocorrências de animais da epifauna ou semi-infauna preservados em posição de vida, como os discutidos por Kondo \& Kikuchi (1995), Simões et al. (1998a, b) e Torello (1999).

Outros fatores tafonômicos são também importantes, uma vez que as conchas dos bivalves da epifauna são desarticuladas, mesmo na ausência de correntes tracionais de fundo (Kondo, 1997). Assim sendo, a preservação de conchas articuladas de Coxesia mezzalirai (Torello \& Simões, 1994) em arenitos bioclásticos (Formação Corumbataí) sugere que estas provavelmente colonizaram este substrato, cuja granulometria e alta proporção de bioclastos seriam favoráveis às formas da epifauna bissada (Stanley, 1972; Kondo \& Kikuchi, 1995). Entretanto, tais intercalações de arenitos são raras nas formações Terezina e Corumbataí (Sousa, 1985; Rohn, 1994). Assim, o predomínio de sedimentação fina (silte/argila) durante a deposição destas unidades litoestratigráficas, não favoreceria o amplo desenvolvimento de comunidades dominadas por formas da epifauna bissada.

Adicionalmente, deve ser destacado que a baixa proporção de formas de epifauna e semi-infauna não é incomum no registro fossilífero de mares epicontinentais, sendo observada, por exemplo, nas seqüências regressivas do Cretáceo da América do Norte (Kauffman, 1977; Elder, 1989). Isto ocorre porque os bivalves da epifauna estão mais expostos fisicamente à ação do estresse ambiental do que os da infauna (Kauffman, 1977; 
Elder, 1989; Simões \& Rocha-Campos, 1990a, b), pois o sedimento que recobre as conchas atua como uma camada protetora às mudanças bruscas do meio ambiente, particularmente nos habitats de águas rasas (Simões, 1992). As condições de águas rasas reinantes durante a deposição da Formação Corumbataí (Sousa, 1985; Rohn, 1994) poderiam ser, de certo modo, inóspitas (e.g., remobilização por ondas e correntes, variação brusca na temperatura e salinidade) aos animais de epifauna, não favorecendo seu amplo desenvolvimento.

É curioso observar que, se de um lado as formas da epifauna foram raras durante os tempos Serra Alta, Terezina e Corumbataí, o mesmo não ocorre com as formas da infauna, largamente dominada pelos megadesmídeos (Runegar \& Newell, 1971; Simões et al. , 1997; Mello et al., 1998b; Mello, 1999). Uma interessante questão, portanto, emerge, ou seja: quais os fatores responsáveis por esse fenômeno?

De acordo com o atual conhecimento taxonômico (Mello, 1999) e paleoecológico dos bivalves do Grupo Passa Dois, três gêneros (Casterella, Itatamba, Cowperesia) dos quinze pertencentes à subfamília Plesiocyprinellinae (Simões et al., 1997) são escavadores intermediários, e um gênero escavador profundo (Roxoa). Essa não é uma feição comum porque o hábito escavador dos bivalves se desenvolveu extensivamente, apenas a partir do Mesozóico (Stanley, 1969), provavelmente como uma proteção aos distúrbios físicos (Stanley, 1969; Kondo, 1987) ou a predação (Carter, 1968; Stanley, 1969, Vermeij \& Dudley, 1985).

Obviamente, não pode ser assumido que as afirmações acima são inteiramente verdadeiras para toda a Classe Bivalvia, porque, em princípio, a polarização de caracteres é geralmente inconsistente (e.g., rearranjos Robertsonianas ou dominância hierárquica alélica, sensu Kitching, 1992), uma vez que são ignoradas as reversões, que são tão comuns no processo evolutivo (veja, por exemplo, Simões et al., 1997, para reversão na charneira e no modo de vida de megadesmídeos). Entretanto, se for considerado que esses dois fenômenos foram importantes na história evolutiva dos bivalves da Subfamília Plesiocyprinellinae, que agentes físicos e biológicos teriam sido decisivos na evolução do hábito escavador?

Evidências sedimentológicas, estratigráficas (Lavina, 1991; Rohn, 1994; Holz, 1997, 1998) e tafonômicas (Torello \& Simões, 1994; Simões et al., 1996a; Simões \& Kowalewski, 1998a) e, também o cenário paleogeográfico da Bacia do Paraná (mar epicontinental, sob regressão e gradual confinamento no final do Permiano, Simões et al., 1998b), durante o Neopaleozóico, indicam, no seu conjunto, que eventos de tempestade induzidos climática 
(Lavina et al., 1991) ou tectonicamente (Riccomini, 1995), poderiam ter influência sob a história evolutiva dos Plesiocyprinellinae. Conforme sugerido por Miller et al. (1988) e Speyer \& Brett (1991), eventos de tempestade foram os mais importantes agentes físicos, na evolução das comunidades de invertebrados bentônicos do Paleozóico. Já foi mencionado aqui, por diversas vezes, que a deposição dos sedimentos do Grupo Passa Dois ocorreu sob condições de águas rasas, afetadas por episódios de tempestade (Lavina, 1991; Rohn, 1994; Simões, 1998; Simões et al., 1998a, b, c).

De acordo com Kondo (1987), na média, ao longo do registro geológico, a erosão causada por tempestades é da ordem de 15 a $20 \mathrm{~cm}$ da camada superficial do substrato. Informações tafonômicas de detalhe, mostram que bivalves anomalodesmos escavadores profundos, em posição de vida e com o tubo do sifão preservado (Simões \& Rocha-Campos, 1994; Anelli et al., 1998; Farro, 1998), estariam enterrados no substrato a mais de $3 \mathrm{~cm}$ de profundidade. Deste modo, tais bivalves estariam sujeitos ao retrabalhamento dos sedimentos, sendo que a ocorrência de conchas escavadoras profundas (e.g., Roxoa), fora da posição de vida, comprova tal afirmação. Assim sendo, os efeitos da erosão do substrato e retrabalhamento, podem ter sido significantes no desenvolvimento da estratégia de escavação entre os Plesiocyprinellinae (veja Kondo, 1987, para exemplo cenozóico similar).

Do mesmo modo, a predação não pode ser descartada como importante agente na evolução do hábito escavador entre os Plesiocyprinellinae. Embora sinais de predação estejam aparentemente ausentes nas conchas dos megadesmídeos que estão preservadas no Grupo Tubarão, recentemente Simões \& Kowalewski (1998b) e Kowalewski et al. (no prelo), com base no material descoberto por Torello \& Simões (1994), registraram cerca de 20 conchas de megadesmídeos com sinais de predação, particularmente nas espécies escavadoras rasas (e.g., Plesiocyprinella carinata) e intermediárias (e.g., Casterella gratiosa). Tais conchas possuem orifícios subcirculares, provavelmente produzidos por animais carnívoros, perfuradores, de origem desconhecida (Simões \& Kowalewski, 1998b; Kowalewski \& Bambach, 1998; Kowalewski et al., no prelo). Além de ser uma das mais antigas ocorrências de predação em bivalves paleozóicos (Simões \& Kowalewski, 1998b), esta ocorrência mostra que a evolução do hábito escavador em Megadesmidae não pode ser explicada apenas por um único tipo de evidência. 


\subsection{Substrato de Vida dos Bivalves do Grupo Passa dois e os LITótiripos ONDE SÃo PRESERVADOS}

As concentrações fossilíferas onde são encontrados os bivalves das assembléias de Anhembia froesi, Pinzonella illusa e Pinzonella neotropica são, do ponto de vista tafonômico, marcantemente parautóctones a alóctones (Torello \& Simões, 1994; Simões, 1996; Simões et al., 1996a; Ghilardi et al., 1997; Mello et al., 1998a). É importante destacar aqui que os termos autóctone, parautóctone e alóctone, estão sendo empregados na concepção de Kidwell et al. (1986). Uma vez que ainda não foram encontrados bivalves em posição de vida nas concentrações fossilíferas do Grupo Passa Dois (exceto Naiadopsis lamellosus) (Simões et al., 1998a, b; Torello, 1999), suas relações com o substrato de vida são determinadas através de métodos indiretos de observação (análise autoecológica e tafonômica).

As conchas da assembléia de Anhembia froesi, que ocorrem preferencialmente desarticuladas e dispersas caoticamente na matriz sedimentar, parecem representar elementos parautóctones nos sedimentos das formações Serra Alta e Corumbataí (Torello, 1999). As conchas de Tambaquyra camargoi e Anhembia froesi são infladas e encontradas, na maioria das vezes, articuladas abertas e fechadas, sugerindo uma condição parautóctone. Entretanto, Barbosaia angulata por ser um organismo de semiinfauna e necessitar de um substrato estável para fixação do bisso, seria uma forma parautóctone a alóctone. A possibilidade de Barbosaia angulata utilizar conchas de outros organismos para sua fixação, sob condições de substrato fino (síltico/argiloso) não é descartada, uma vez que exemplares articulados abertos e, portanto, pouco transportados ou expostos na interface água/sedimento (Kidwell \& Bosence, 1991) são encontrados nos lâmitos das formações Serra Alta e Corumbataí (Ghilardi et al., 1997; Torello, 1999).

Stanley (1970) e Watters (1993) demonstram que bivalves escavadores profundos em substrato estável apresentam conchas tubulares (para minimizar o comprimento do sifão), aberturas comissurais bem desenvolvidas (para facilitar a rápida extensão e contração dos sifões e do pé), valvas finas (metabolicamente vantajosas) e charneira edentelosa (para maior facilidade dos movimentos de balanço das valvas). Roxoa corumbataiensis (assembléia de Pinzonella illusa) e Roxoa intricans (assembléia de Pinzonella neotropica) apresentam todas estas características. Curiosamente, Roxoa corumbataiensis é encontrada com a concha articulada fechada ou aberta, 
horizontalmente em relação ao plano de acamamento, nas concentrações preservadas nos arenitos bioclásticos da parte média da Formação Corumbataí, porém não em posição de vida (Torello \& Simões, 1994; Simões \& Kowalewski, 1998a, b). De fato, estes arenitos correspondem a tempestitos proximais, registrando diversos episódios de erosão e rápida deposição dos sedimentos (Simões, 1998; Simões \& Kowalewski, 1998a, b; Torello, 1999). Durante os eventos de erosão do fundo haveria reorientação dos animais e dos bioclastos já incorporados ao substrato (Torello \& Simões, 1994). Entretanto, o fato de Roxoa corumbataiensis ser encontrada com a concha articulada, sugere que essa não foi muito transportada, permanecendo por um curto intervalo de tempo (e.g., semanas, veja Schäffer, 1972) na interface água/sedimento. Porém, uma vez que estas conchas são escavadoras profundas e não estão preservadas em posição de vida elas foram, certamente, exumadas ou reorientadas no interior do substrato.

Por outro lado, Roxoa intricans, cuja semelhança morfológica com Roxoa corumbataiensis sugere modo de vida similar, em substrato arenoso, é exclusivamente encontrada nas concentrações do tipo coquina, na parte superior das formações Terezina e Corumbataí (Mendes, 1952; Simões et al., 1996a). Tais coquinas representam, também, tempestitos proximais, gerados por fluxos de tempestades (Simões et al., 1996a), indicando, claramente, que estes organismos são elementos alóctones nestas acumulações. Conforme demonstrado por Kidwell \& Jablonski (1983), por exemplo, substratos ricos em restos esqueléticos são desfavoráveis aos animais da infauna, uma vez que estes contribuem para uma maior estabilidade, dificultando ou mesmo impedindo o ato de escavação das formas de infauna.

As formas escavadoras rasas e intermediárias que vivem em substrato arenoso estável, de outro lado, apresentam conchas com valvas espessas e com o centro de gravidade na porção mediana da concha (Stanley, 1970) sendo, na maioria das vezes, formas alongadas (Alexander, 1993). As conchas de Pinzonella illusa, Plesiocyprinella carinata, Ferrazia cardinalis, Casterella gratiosa, Othonella araguaiana, Terraiopsis aequilateralis, Holdhausiella elongata, Favalia arcuata, Itatamba paraima e Runnegariella fragilis (assembléia Pinzonella illusa) e Pinzonella neotropica e Jacquesia brasiliensis (assembléia Pinzonella neotropica) apresentam estas características. É interessante observar que as conchas de Pinzonella illusa, Plesiocyprinella carinata, Terraiopsis aequilateralis e Casterella gratiosa são, freqüentemente, encontradas articuladas abertas ou fechadas nos arenitos da parte média da Formação Corumbataí. Em alguns exemplares de Pinzonella illusa e Plesiocyprinella 
carinata, por exemplo, os ligamentos estão preservados, sugerindo o soterramento de animais ainda vivos (Fürsich \& Oschmann, 1993; Simões \& Kowalewski, 1998a). Desse modo, os arenitos finos poderiam ter constituído, em parte, o substrato de vida de Pinzonella illusa, Ferrazia cardinalis, Plesiocyprinella carinata, Terraiopsis aequilateralis e Casterella gratiosa. Entretanto, Pinzonella illusa, Plesiocyprinella carinata, Itatamba paraima, Favalia arcuata, Holdhausiella elongata e Terraiopsis aequilateralis são também encontradas em coquinas (Mendes, 1963; Simões et al., 1994) e calcários oolíticos (Mendes, 1962; Rohn, 1994), que certamente não constituíram seu substrato de vida. De fato, segundo Rohn (1994), tanto as conchas, como os oóides que compõem os calcários oolíticos, foram retrabalhados de seu ambiente de origem, possivelmente por processos de alta energia (tempestades).

O substrato de arenito fino bem selecionado (Ragonha, 1980), hoje materializado pelos arenitos bioclásticos da porção inferior/média da Formação Corumbataí (Mendes, 1952; Landim, 1970; Torello \& Simões, 1994; Simões \& Kowalewski 1998a, b), poderia ser ocupado também por Coxesia mezzalirai. Entretanto, suas conchas ocorrem em pequeno número e desarticuladas, além de não apresentarem sinais de bioerosão, incrustação e corrosão, indicando um baixo grau de exposição na interface água/sedimento (Torello \& Simões, 1994). Não há registro, ainda, de pequenos agregados de conchas ("clusters"), colonizando o substrato constituído por conchas previamente desarticuladas. Desta forma, as conchas de Coxesia mezzalirai são interpretadas como elementos parautóctones a alóctones nestes arenitos finos, embora, de acordo com Simões \& Kowalewski (1998a), há a possibilidade delas representarem mudanças nas características do substrato (retroalimentação tafonômica), uma vez que Torello \& Simões (1994) descrevem conchas articuladas no afloramento entre os km 18 e 19 da antiga ferrovia Rio Claro-Analandia, entre Ajapi e Ferraz.

Contrariamente, bivalves que vivem em sedimento argiloso a síltico, inconsolidado, tendem a ter o tamanho reduzido e valvas finas, para evitar o enterramento no substrato diminuindo seu peso. Em alguns casos, esses invertebrados também apresentam concha com ornamentação concêntrica em seção, para proporcionar flutuabilidade (Stanley, 1970). As conchas de Cowperesia anceps, Runnegariella fragilis e Angatubia cowperesioides possuem estas características e, aparentemente, viviam neste tipo de substrato. Porém, conforme já mencionado, Cowperesia anceps é freqüentemente registrada nos arenitos bioclásticos, onde, via de regra, ocorre desarticulada. Assim sendo, Cowperesia anceps é possivelmente, um elemento alóctone 
nestas acumulações, tendo sido exumadas e transportadas dos locais de substrato síltico argiloso, onde viviam. Já Angatubia cowperesioides, que deve ter tido hábito similar ao de Cowperesia anceps, é encontrada em calcários oolíticos, onde as conchas estão concentradas num único plano de acamamento, constituindo porções coquinóides (Mendes, 1962). Tal substrato é incompatível com o modo de vida inferido para essa espécie.

Por sua vez, Runnegariella fragilis ocorre em calcários altamente bioturbados (Rocha-Campos et al., 1990; Simões \& Anelli, 1995). Suas conchas estão normalmente articuladas (veja Simões \& Anelli, 1995, fig. 3) e há a presença de, ao menos, um exemplar aparentemente em posição de vida (Simões, 1999, informação pessoal). A maioria das formas articuladas, entretanto, está distribuída caoticamente na matriz, o que poderia ter sido, em parte, produzido pela bioturbação. Runnegariella fragilis seria, portanto, um elemento autóctone a parautóctone na concentração fossilífera onde é registrada.

Naiadopsis lamellosus também é uma forma de semi-infauna bissada (Ghilardi et al., 1995), freqüentemente encontrada nas coquinas da parte superior da Formação Corumbataí. Curiosamente, entretanto, exemplares dessa espécie foram encontrados em posição de vida no topo da coquina da assembléia de Pinzonella neotropica, no nordeste do Estado de São Paulo, sugerindo que este tipo de sedimento constituiu o seu substrato de vida (Torello, 1999). Entretanto, as conchas de Pinzonella neotropica que são encontradas em associação com Naiadopsis lamellosus nas concentrações coquinóides, representam elementos retrabalhados de seu substrato de vida (Simões, 1996; Simões et al. 1996a). Torello (1999), porém, reportou a ocorrência de conchas articuladas fechadas e abertas de Pinzonella neotropica em arenito fino da parte superior da Formação Corumbataí, na região de Tambaú, SP. Esta ocorrência reveste-se de grande importância, pois pela primeira vez foram encontradas conchas de Pinzonella neotropica pouco transportadas, provavelmente preservadas no sedimento de vida, corroborando as observações de Simões et al. (1996a). 


\subsection{ANHEMBIA FROESI E TAMBAQUYRA CAMARGOI COMO BIVALVES PERMIANOS QUIMIOSSIMBIONTES}

Quimiossimbiose é a relação entre bactérias quimiotróficas e um hospedeiro onde as bactérias utilizam sulfido ( $\mathrm{HS}^{-}$) e oxigênio para obtenção de energia por processos químicos (Reid \& Brand, 1986). Felbeck et al. (1981) foram os primeiros pesquisadores a relacionarem uma condição de quimiossimbiose entre animais marinhos viventes, em profundidade e bactérias. Posteriormente, foi verificado que diversos grupos de invertebrados marinhos, tais como as poliquetas, oligoquetas, nemátodos e moluscos (Vetter et al., 1991) apresentam esta estratégia alimentar. Seilacher (1989) sugeriu, inclusive, que alguns dos animais da fauna de Ediacara (Vendiano) foram quimiossimbiontes. Dentre os bivalves, Solemya velum foi a primeira espécie a ser adicionada ao grupo de animais quimiossimbiontes (Cavanaugh, 1983).

Quimiossimbiose parece ter surgido independentemente em diversos grupos de bivalves escavadores, não aparentados (Wignall, 1994), sendo reconhecida nos protobrânquios, filibrânquios e lamelibrânquios (Soutward, 1986). Dentre estes, as famílias Lucinidae e Thyasiridae contém o maior número de táxons quimiossimbiontes (Reid \& Brand, 1986). Porém, nos últimos anos, essa condição foi verificada em diversos grupos de bivalves paleozóicos, mesozóicos e cenozóicos, incluindo, dentre outros: Inoceramidae (Eopermiano - Neocretáceo; Kauffman, 1988; MacLeod \& Hoppe, 1992; Johnston \& Collom, 1998), Solemyidae (Recente; Reid \& Bernard, 1980; Felbeck, 1983) e Unionidae (Pleistoceno - Recente; Seilacher, 1990; Savazzi \& Peiyi, 1992).

A simbiose consiste no controle feito pelo bivalve da disponibilidade de oxigênio e sulfido para a bactéria. No caso dos bivalves serem os hospedeiros, as bactérias estão localizadas nas brânquias. O bivalve recebe como troca a desintoxicação do sulfido e translocação de carboídratos e aminoácidos, como produtos do metabolismo das bactérias (Reid \& Brand, 1986). No Recente, os bivalves que apresentam esta associação vivem numa profundidade entre 30 a $60 \mathrm{~m}$. As bactérias são mais efetivas onde seu combustível (HS`) está disponível proximamente, como no caso de lamas anóxicas e bacias estagnadas (Seilacher, 1990).

Grossman (1993) e Wignall (1994), entretanto, consideram improvável a presença destes animais na facies de folhelhos negros, anóxicos. Porém, Kauffmann (1988) e MacLeod \& Hoppe (1992) sugerem que a estratégia quimiossimbiótica foi amplamente desenvolvida 
nos bivalves que colonizaram tal facies sedimentar. Para Wignall (1994) o metano e o HS` são altamente tóxicos e, por este motivo, os organismos quimiossimbiontes necessitam de um sistema de desintoxicação que requer amplo suprimento de oxigênio. Deste modo, esses invertebrados seriam encontrados nos locais onde a lâmina d'água pobre em oxigênio está situada próxima ao substrato. De qualquer modo, entretanto, Wignall (1990) e Nobuhara \& Tanaka (1993), reportaram a ocorrência de bivalves quimiossimbiontes em camadas anóxicas do substrato.

Seilacher (1990) apresentou um estudo rigoroso das características morfológicas e fisiológicas que estariam relacionadas aos bivalves associados a bactérias quimiotróficas viventes e os possíveis candidatos no registro fossilífero, que provavelmente mantiveram também uma relação quimiossimbiótica. Para os bivalves, quimiossimbiose requer primeiramente adaptações fisiológicas, como proteção do hospedeiro contra sulfido tóxico, que pode deixar secundariamente a morfologia da concha alterada. Entretanto, estas alterações por serem secundárias, não são relacionáveis entre si. No registro fossilífero, homoplasia e controle de facies, são os principais critérios para a constatação de organismos quimiossimbióticos (Wignall, 1994; Seilacher, 1998; Johnston \& Collom, 1998).

As características morfológicas das conchas dos bivalves associados a bactérias quimiotróficas são (Seilacher, 1990): a- presença de uma extensão anterior denominada rostrum, que tem como função bombear a água intersticial anóxica para as brânquias; btorção das valvas para posicionar os sifões próximo da lâmina d'água mais oxigenada; cperióstraco espesso como proteção contra a corrosão da concha por $\mathrm{H}_{2} \mathrm{~S}$; d- microestrutura porosa da concha para diminuir o peso, facultando vida em substratos argilosos anóxicos e, ecostelas proeminentes para abrigar as bactérias quimiotróficas. Vale destacar que estas adaptações podem ser encontradas unitariamente ou em conjunto, num dado bivalve. De fato, para Seilacher (1998) homoplasia seria o principal critério para o reconhecimento de bivalves quimiossimbiontes, sendo que, neste particular, a presença de rostrum e/ou torção da concha, são critérios decisivos.

Adicionalmente, uma síntese dos dados disponíveis na literatura indica que os bivalves quimiossimbiontes possuem as seguintes características:

a- São todos, sem exceção, escavadores;

b- Possuem concha com rostrum ou torção; 
c- Apresentam tamanho anormalmente grande, quando comparados ao dos animais que vivem em associação;

d- Possuem distribuição geográfica restrita nos ambientes marinhos do Recente e,

e- Colonizam ambientes estáveis, com fundo normalmente lamoso, anóxico ou com deficiência de oxigênio.

Embora a estratégia alimentar quimiossimbionte tenha sido identificada em raros grupos de animais do Permiano, diversas evidências morfológicas, sedimentológicas, estratigráficas e tectônicas sugerem que Anhembia froesi, Anhembia gigantea e Tambaquyra camargoi são excelentes candidatos "permianos" (parafraseando Seilacher, 1990) para serem bivalves quimiossimbiontes. Já foi mencionado que homoplasia é um dos principais critérios para identificação destes bivalves no registro fossilifero. Realmente, a característica mais notável da concha de Anhembia froesi e Anhembia gigantea é a presença do rostrum, o que torna estes animais morfológicamente muito semelhantes a Pleiodon adami e Arconaia lanceolata que são bivalves quimiossimbiontes do Pleistoceno e Recente (Seilacher, 1990; Savazzi \& Peiyi, 1992).

Uma das questões mais interessantes referentes aos bivalves da Formação Serra Alta e da base da Formação Corumbataí é a presença de gigantismo em algumas espécies. Por exemplo, bivalves como Tambaquyra camargoi, que apresentam espécimes com altura máxima próxima a $110 \mathrm{~mm}$ são encontrados com relativa freqüência nos litótipos destas unidades litoestratigráficas (Ghilardi et al., 1997; Mello et al., 1998a) (estampa 1, fig. 10). Os bivalves que ocorrem em associação, por outro lado, apresentam conchas pequenas (< $20 \mathrm{~mm}$ ), ou conchas finas e comprimidas.

Roopnarine (1996) demonstrou que a extinção de algumas espécies de bivalves Veneridae do Oligoceno e do Recente, nos mares tropicais da América do Norte, está fortemente relacionada com a variação de matéria orgânica no meio ambiente, cuja preservação, entretanto, apresenta baixo potencial. Um método indireto para obtenção deste dado é a análise da distribuição dos tamanhos corporais, dentro de uma comunidade. A figura 39 , demonstra a variação de tamanho máximo dos bivalves megadesmídeos encontrados nos grupos Tubarão e Passa Dois, da Bacia do Paraná. A metodologia de construção deste gráfico segue a de Roopnarine (1996). Nota-se que os maiores bivalves deste intervalo são encontrados justamente no intervalo referente à assembléia de Anhembia froesi (Rohn, 1994), 
correspondente à Formação Serra Alta e à base da Formação Corumbataí. Daí para o topo do Grupo Passa Dois há um decréscimo nas dimensões das conchas dos bivalves.

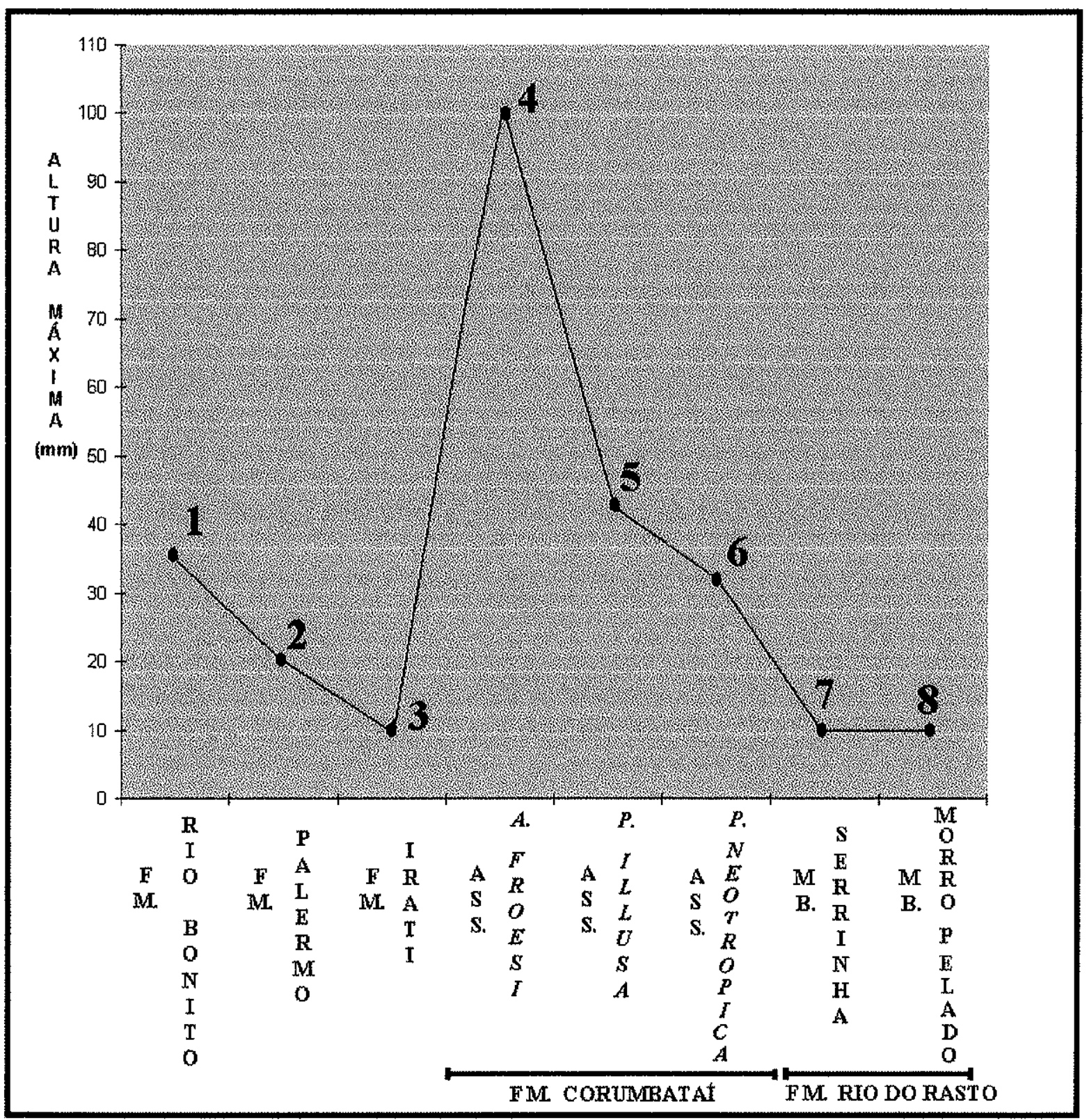

Figura 39- Distribuição dos tamanhos máximos de conchas de algumas espécies de anomalodesmatas do Neopaleozóico da Bacia do Paraná. Notar o maior valor localizado no intervalo correspondente à assembléia de Anhembia froesi (formações Serra Alta e Corumbataí). Explicação: 1- Myonia tayoensis $(35 \mathrm{~mm}) ; 2-$ Myonia riograndensis $(20 \mathrm{~mm}) ; 3$ - Maackia iratiensis $(10 \mathrm{~mm}) ; 4-$ Tambaquyra camargoi $(100,1 \mathrm{~mm})$; 5 - Casterella gratiosa $(43 \mathrm{~mm})$; 6- Ferrazia cardinalis $(32 \mathrm{~mm})$; 7- Leinzia similis $(10 \mathrm{~mm})$ e, 8- Relogiicola delicata $(10 \mathrm{~mm})$. Fonte: Beurlen (1957b), RochaCampos (1970), Rohn (1988), Simões (1992) e este trabalho. 
Uma possível explicação para este fato é a disponibilidade de recursos alimentares, tão crítica nas seqüências regressivas dos mares epicontinentais (ver Kauffman, 1975; Simões, 1992; Simões et al., 1998b). De acordo com Wignall (1994), os animais quimiossimbiontes seriam semelhantes aos detritívoros, utilizando recursos alimentares, cuja previsibilidade ao longo do tempo é estável, o que se reflete no maior tamanho das conchas. Neste caso, a dimensão dessas espécies poderia estar relacionada também à presença de um grande par de brânquias, alojando bactérias, semelhantemente ao que ocorre com outros bivalves do Mesozóico e Cenozóico.

Pelos mesmos motivos acima, os bivalves quimiossimbiontes tendem a apresentar uma distribuição geográfica muito restrita, já que não são capazes de colonizar outros ambientes, particularmente mais instáveis (Wignall, 1994). Assim, no registro geológico a distribuição vertical e horizontal destes bivalves é restrita. Curiosamente, este mesmo padrão é mostrado pelas espécies Anhembia froesi e Tambaquyra camargoi, as quais estão restritas à base da Formação Serra Alta e Corumbataí, na porção centro-oeste do Estado de São Paulo e, com duvidas, na região de Irati e Prudentópolis, Paraná (fig. 40), conforme demonstrado pelos dados de Beurlen (1954), Rohn (1994), Maranhão (1995) e Dutra (1997).

Outro ponto interessante refere-se ao substrato de vida das espécies Anhembia froesi e Tambaquyra camargoi. Segundo Mello et al. (1998a), estes bivalves são preservados em siltitos maciços ou no interior de concreções calcárias, epigenéticas, nas formações Serra Alta e Corumbataí. Conforme destacado por Sousa (1985) e Rohn (1994), estes litótipos estão associados a um espesso pacote de siltitos ou argilitos normalmente, maciços, com raras intercalações de arenitos finos. Estes sedimentos foram, provavelmente, depositados próximo ou abaixo do nível de base de ondas de tempestade, em condição de costa-a-fora (Sousa, 1985; Lavina, 1991; Rohn, 1994; Klein, 1997), com variação no teor de oxigênio (Sousa, 1985; Simões \& Rohn, 1996). Portanto, as condições nas quais os litótipos onde Anhembia froesi e Tambaquyra camargoi são encontradas, não diferem essencialmente daqueles de outros exemplos da literatura, já discutidos.

A questão acima não é, entretanto, desprovida de controvérsias. Por exemplo, as conchas infladas e espessas de Tambaquyra camargoi e Anhembia froesi indicam um hábito de vida escavador raso, porém em substrato arenoso. Conforme mencionado anteriormente, os bivalves que colonizam substrato muito fino (silte/argila) são lateralmente comprimidos, o que permite a esses organismos "flutuarem" no interior do substrato. Sob tais condições, 
bivalves com conchas infladas têm dificuldade de manter a posição de vida no interior do substrato, que é geralmente, fluídico. Para manter a posição de vida, há a necessidade de constante escavação, o que não é metabolicamente vantajoso. Assim, para explicar a presença desses bivalves nos siltitos e argilitos da Formação Serra Alta, sua possível associação com bactérias quimiotróficas e sua ocorrência com conchas articuladas fechadas, no interior de concreções epigenéticas, há a necessidade de elaboração de um cenário paleoambiental complexo.

No afloramento 2 por exemplo, de onde exemplares orientados de Tambaquyra camargoi e Anhembia froesi foram coletados, diversas intercalações de arenito fino centimétricas são observadas nos siltitos e argilitos, especialmente acima dos níveis contendo as concreções carbonáticas (veja, por exemplo, Sousa, 1985). Segundo Torello (1999), estas intercalações correspondem à tempestitos distais, mostrando que correntes tracionais de fundo eram capazes de transportar sedimentos em áreas onde predominava a decantação de finos. Além disso, diques clásticos de arenito fino ocorrem em intima associação a estes sedimentos, cuja origem sísmica já foi apontada por Riccomini (1995). Do que se pode observar em campo e da compilação dos dados da literatura, dois grandes grupos de diques clásticos são registrados no intervalo estratigráfico de ocorrência das malacofaunas estudadas. O primeiro é representado por diques clásticos, paralelos, ramificados, cuja base parece estar associada a presença de lentes de arenito, os quais são os prováveis alimentadores dos diques (Riccomini, 1995). O segundo, é representado também por diques clásticos de arenito fino ou muito fino, carbonático, que são interrompidos por concreções calcárias epigenéticas (Sousa, 1985). As características desses diques apontam, respectivamente, para liquefação (Riccomini, 1995) e para o preenchimento grão-a-grão de fissuras abertas (Sousa, 1985), induzidos por abalos sísmicos, como a hipótese mais provável para sua origem (Riccomini, 1995). Portanto, os bivalves encontrados articulados fechados no interior de "concreções carbonáticas" epigenéticas, estariam preservados no seu provável substrato de vida, isto é, camadas de arenito fino ou muito fino, que, posteriormente, em alguns casos, serviram como fonte de alimentação para os diques. A presença de conchas desarticuladas, normalmente pequenas e de bivalves articulados fechados, fora de sua posição de vida reforçam a idéia de que estas intercalações de arenito representam tempestitos distais. 


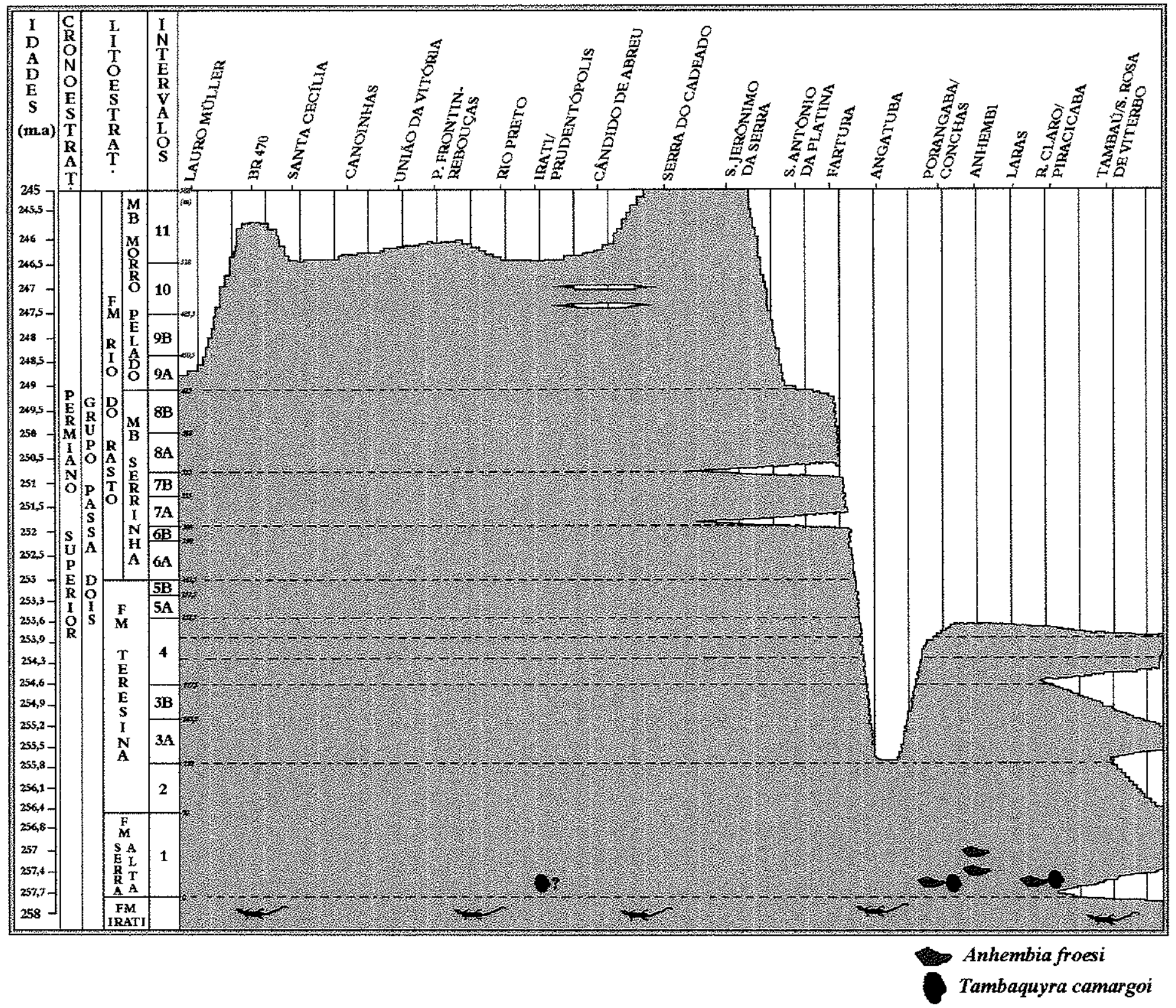

Figura 40-Distribuição vertical e horizontal de Anhembia froesi e Tambaquyra camargoi na Bacia do Paraná. Modificado de Rohn (1994). 
É curioso observar que os dados de literatura mostram que nas bacias intracratônicas diversas estruturas tectônicas sindeposicionais (e.g., falhas, fraturas, diques) permitem o escape de hidrocarbonetos, particularmente metano, no fundo oceânico. Nestes locais, a intensa oxidação do metano por bactérias conduz a uma extensiva cimentação carbonática, dando origem a estruturas semelhantes a "montículos", concreções e pseudobiohermas (Gailard \& Rolin, 1986; Beauchamp et al., 1989). Invariavelmente, a fauna associada a tais estruturas é representada por organismos quimiossimbiontes (Wignall, 1994). Embora, de momento, não seja possível comprovar, é sugestivo supor, portanto, que mecanismo semelhante tenha ocorrido durante a deposição da Formação Serra Alta, porque a Formação Irati, diretamente subjacente, poderia ser uma fonte de metano. É notável que compilando os dados de literatura (Santos et al., 1981; Sousa, 1985; Lavina, 1991; Rohn, 1994; Klein, 1997) parece haver uma intima relação entre o intervalo na Formação Serra Alta correspondente a presença de diques clásticos e as concreções carbonáticas, as quais sabe-se agora não são afossilíferas mas contém dentre outras, conchas de Anhembia froesi e Tambaquyra camargoi (Mello et al., 1998a). Deste modo, uma provável relação entre estes táxons e bactérias quimiotróficas é apontada não apenas pela análise paleoautoecológica, mas também pelos dados tafonômicos, estratigráficos e tectônicos, todos amplamente complementares entre si. 


\section{BIVALVES FÓSSEIS}

\section{COMO INDICADORES DA DINÂMICA SEDIMENTAR}




\section{BIVALVES FÓSSEIS COMO INDICADORES DA DINÂMICA SEDIMENTAR}

A análise paleoecológica combinada com o estudo bioestratinômico de alta resolução de concentrações fossilíferas dominadas por conchas de bivalves constituem importantes ferramentas para a análise sedimentológica, em especial para o reconhecimento de eventos de sedimentação rápida ou erosão de fundo, contemporâneos ao período de colonização do substrato por um dado grupo de bivalves (Simões, 1998; Simões \& Kowalewski, 1998a, b; Simões et al., no prelo). Tais processos estão normalmente associados a eventos de tempestades, os quais foram comuns durante a deposição dos sedimentos das formações Serra Alta (Simões \& Rohn, 1996; Mello et al., 1998a), Terezina e Corumbataí (Torello \& Simões, 1994; Rohn, 1994; Maranhão, 1995; Riccomini, 1995; Simões, 1996; Simões et al., 1996a; Klein, 1997; Klein et al., 1997a, b).

$\mathrm{O}$ fato dos bivalves serem animais bentônicos e, portanto, intimamente relacionados ao substrato torna-os particularmente suscetíveis às mudanças no regime sedimentar (e.g., taxa de sedimentação). Não apenas os indivíduos vivos são afetados por tais mudanças, mas também as conchas de animais mortos, já incorporados ou não ao substrato. Neste contexto, portanto, os agentes responsáveis por estas alterações ambientais (e.g., erosão de fundo, mudança textural dos sedimentos) podem ser identificados.

Adicionalmente, os bivalves da infauna mostram, aparentemente, adaptações distintas para a vida no substrato afetado por eventos de tempestade (e.g., estratégia exposta versus estratégia protegida, sensu Kondo, 1997, 1998). Essas estratégias foram reconhecidas também para os bivalves do Neopaleozóico da Bacia do Paraná (Simões et al., 1998c), sendo representados pelos escavadores rasos (estratégia exposta) intermediários e profundos (estratégia protegida) da classificação paleoecológica utilizada neste documento.

No contexto mais amplo da discussão acima, fica evidente, portanto, que o modo de preservação dos bivalves fósseis expressa o controle físico e ecológico exercido pela dinâmica sedimentar sobre a população de indivíduos vivos e restos esqueléticos de animais mortos, cujas relações entre o modo de vida e preservação podem ser reconstituídas pela tafonômia e paleoautoecologia. Estudo semelhante foi apresentado por Kondo (1997, 1998), para bivalves marinhos pleistocênicos. Kotzian (1995) também procurou aplicar raciocínio similar na análise paleoambiental da Formação Ponta Grossa (Devoniano), da Bacia do Paraná, com base em bivalves. Infelizmente, a análise da autora foi prejudicada por quatro motivos: a- 
inexistência de dados tafonômicos para as concentrações fossilíferas examinadas; b- dados provenientes de amostras depositadas em coleções científicas, coletadas sem qualquer preocupação com a orientação azimutal ou com a relação de topo e base das camadas; causência de dados estratigráficos de alta resolução para os sedimentos abaixo e/ou imediatamente acima do nível de ocorrência dos bivalves e, $d$ - ausência de dados prévios na literatura.

\subsection{Princípios Gerais da ANálise TAFonômica/ (Paleo)Autoecológica Combinada}

Antes de dar início a análise propriamente dita é oportuno mencionar aqui, de maneira breve, alguns dos princípios gerais que norteiam o raciocínio que será empregado na discussão mais adiante. Em primeiro lugar, deve ser considerada a seqüência de eventos postmortem para as conchas de bivalves da infauna, os quais são os elementos predominantes nas acumulações esqueléticas examinadas. Dentre estes eventos destacam-se a desarticulação, a fragmentação e a abrasão das conchas (Brett \& Baird, 1986). Todos estes processos estão normalmente associados à erosão do fundo (Brett \& Baird, 1986; Kidwell \& Bosence, 1991; Fürsich \& Oschmann, 1993; Kondo, 1997, 1998) e afetam apenas bivalves já mortos (Kondo, 1998), os quais devem estar preferencialmente expostos na interface água/sedimento. Por outro lado, o grau de desarticulação e fragmentação é função do tempo de exposição das conchas aos agentes de erosão e retrabalhamento do fundo (Kidwell \& Bosence, 1991). Sendo que a desarticulação das conchas se dá por deterioração bacteriana dos tecidos de conecção, o que ocorre em poucas semanas no ambiente marinho raso e oxigenado (Schäffer, 1972), a presença de conchas articuladas fechadas é um excelente indicador de rápida deposição. Conchas articuladas abertas, por outro lado, são indicativas de soterramento rápido, mas não abrupto (Allmon, 1985). Já as conchas dos bivalves da epifauna e semi-infauna bissada são facilmente retrabalhadas e desarticuladas (Kondo, 1998). Contribui para isso a própria natureza exposta do hábito de vida não enterrado e, normalmente, a ausência de dentes na charneira, o que não contribui para que as valvas fiquem unidas por um maior período de tempo. No quadro 10 e figura 41, estão sintetizadas as informações tafonômicas e (paleo)autoecológicas dos bivalves da infauna, semi-infauna e epifauna, e as possíveis informações (paleo)ambientais fornecidas. 


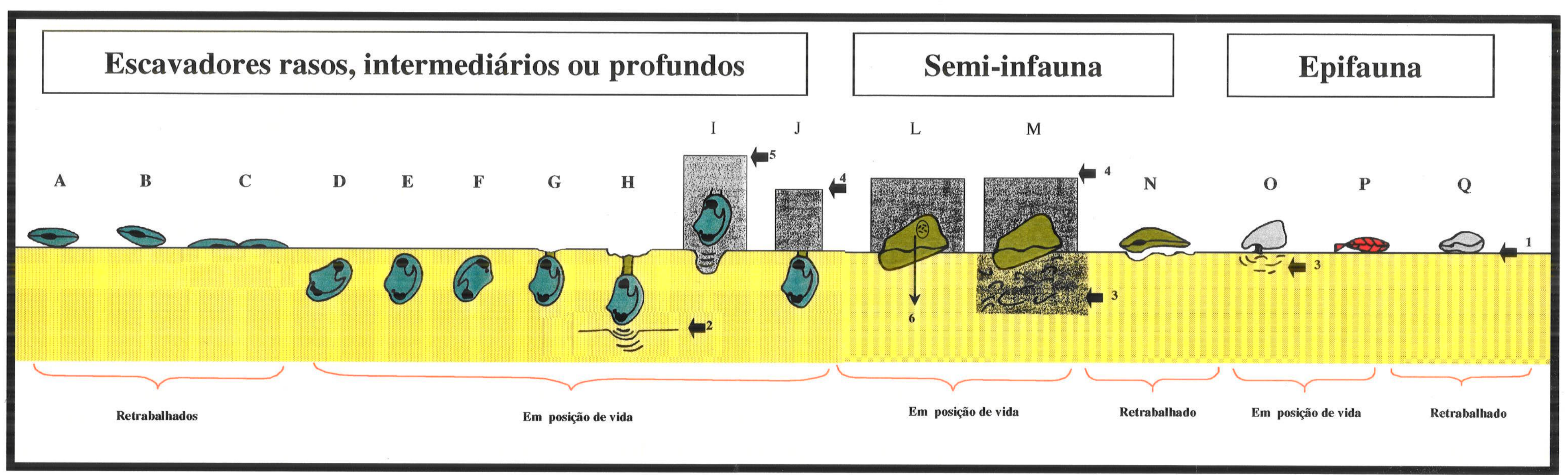

Figura 41 - Modo de ocorrência de conchas de bivalves marinhos, segundo o regime sedimentar e sua (paleo) autoecologia. Explicação: 1- contato água/sedimento; 2- antigo contato água/sedimento; 3- substrato rico em restos bioclásticos; 4- agradação de sedimento (deposição rápida); 5- agradação de sedimento (deposição lenta) e; 6- concha com encrustação ou bioerosão, na margem posterior. Exemplos relacionáveis ao quadro 10 . 
Quadro 10- Possíveis informações (paleo)ambientais fornecidas pelo modo de vida e preservação de conchas de bivalves fósseis. As inferências não podem ser estabelecidas apenas com base em uma feição isoladamente; dados tafonômicos, sedimentológicos e estratigráficos devem ser empregados. Explicação no texto.

\begin{tabular}{|c|c|c|}
\hline Evidência (Modo de Ocorrência) & Informação Paleoambiental & Exemplos \\
\hline $\begin{array}{l}\text { Bivalve escavador raso, concha articulada } \\
\text { fechada, plano de comissura horizontal em } \\
\text { relação ao plano de acamamento. }\end{array}$ & $\begin{array}{l}\text { Erosão de fundo, transporte lateral curto, seguido de rápida } \\
\text { sedimentação. Normalmente, o sedimento que recobre é mais fino } \\
\text { do que o substrato colonizado pela espécie. }\end{array}$ & $\begin{array}{l}\text { Brett \& Baird (1986); Torello \& Simões (1994); } \\
\text { Kondo (1997, 1998). } \\
\text { Fig. 39 A } \\
\end{array}$ \\
\hline $\begin{array}{l}\text { Bivalve escavador raso, concha articulada } \\
\text { fechada, plano de comissura ligeiramente } \\
\text { inclinado em relação ao plano de acamamento. }\end{array}$ & $\begin{array}{l}\text { O mesmo acima, porém afetando população de bivalves da infauna } \\
\text { rasa com conchas acentuadamente inequivivalves. }\end{array}$ & $\begin{array}{l}\text { Kondo (1998); Torello (1999). } \\
\text { Fig. } 39 \text { B }\end{array}$ \\
\hline $\begin{array}{l}\text { Bivalve escavador raso, concha articulada } \\
\text { fechada, ligamento preservado, plano de } \\
\text { comissura horizontal ou não, em relação ao } \\
\text { acamamento. }\end{array}$ & $\begin{array}{l}\text { Erosão de fundo seguida de soterramento abrupto de animais ainda } \\
\text { vivos. }\end{array}$ & $\begin{array}{l}\text { Runnegar (1968); Fürsich \& Oschmann (1993); } \\
\text { Torello \& Simões (1994); Simões \& Kowalewski } \\
\text { (1998a, b). } \\
\text { Fig. 39 C }\end{array}$ \\
\hline $\begin{array}{l}\text { Bivalve escavador profundo, concha articulada } \\
\text { fechada, plano de comissura horizontal em } \\
\text { relação ao plano de acamamento. }\end{array}$ & $\begin{array}{l}\text { Intensa erosão de fundo, maior do que } 20 \mathrm{~cm} \text {, para ambiente } \\
\text { marinho cenozóico. Difícil de estipular para o Paleozóico, } \\
\text { possivelmente maior do que } 5 \mathrm{~cm} \text {. }\end{array}$ & $\begin{array}{l}\text { Kondo (1987, 1997, 1998); Anelli et al. (1998); } \\
\text { Farro (1998). } \\
\text { Fig. 39 A }\end{array}$ \\
\hline $\begin{array}{l}\text { Bivalve escavador raso ou profundo; concha } \\
\text { articulada aberta ("butterflied".) }\end{array}$ & $\begin{array}{l}\text { O mesmo para o exemplo acima indicando, porém soterramento } \\
\text { rápido, mas não abrupto. }\end{array}$ & $\begin{array}{l}\text { Allmon (1985); Brett \& Baird (1986); Torello \& } \\
\text { Simões (1994); Simões \& Kowalewski (1998a, } \\
\text { b). } \\
\text { Fig. 39 C }\end{array}$ \\
\hline $\begin{array}{l}\text { Bivalve escavador profundo, concha articulada } \\
\text { fechada, plano de comissura inclinado em } \\
\text { cerca de } 40^{\circ} \text {, em relação ao plano de } \\
\text { acamamento. }\end{array}$ & $\begin{array}{l}\text { Bivalve soterrado por aumento brusco na taxa de sedimentação, } \\
\text { com ou sem erosão prévia do substrato. Se presente, a erosão não } \\
\text { foi suficiente para remover o animal. Bivalve possivelmente } \\
\text { preservado em posição de alimentação. }\end{array}$ & $\begin{array}{l}\text { Stanley (1970); Kondo (1987, 1997, 1998); } \\
\text { Simões \& Rocha-Campos (1994); Anelli et al. } \\
\text { (1998); Farro (1998). } \\
\text { Fig. 39 D }\end{array}$ \\
\hline $\begin{array}{l}\text { Bivalve escavador profundo, concha articulada } \\
\text { fechada, plano de comissura vertical, quase } \\
\text { reto em relação ao plano de acamamento. }\end{array}$ & O mesmo acima, porém bivalve preservado em posição de vida. & $\begin{array}{l}\text { Kondo }(1987,1997,1998) . \\
\text { Fig. } 39 \mathrm{E}\end{array}$ \\
\hline $\begin{array}{l}\text { Bivalve escavador raso ou profundo, plano de } \\
\text { comissura vertical em relação ao plano de } \\
\text { acamamento, margem anterior da concha para } \\
\text { cima em relação ao plano de acamamento. }\end{array}$ & $\begin{array}{l}\text { Mudança brusca na taxa de sedimentação, causando soterramento } \\
\text { de animais vivos. A movimentação da concha é indicada pela } \\
\text { posição da margem anterior, voltada para cima, mostrando uma } \\
\text { tentativa de escape mal sucedida. }\end{array}$ & $\begin{array}{l}\text { Kondo (1997); Simões \& Kowalewski (1998a). } \\
\text { Fig. } 39 \mathrm{~F}\end{array}$ \\
\hline $\begin{array}{l}\text { Bivalve escavador profundo, plano de } \\
\text { comissura vertical em relação ao plano de } \\
\text { acamamento, bivalve preservado logo abaixo } \\
\text { do contato erosivo. Tubo do sifão pode estar } \\
\text { preservado. }\end{array}$ & Erosão de fundo, seguida de soterramento abrupto. & $\begin{array}{l}\text { Kondo (1998). } \\
\text { Fig. } 39 \mathrm{G}\end{array}$ \\
\hline $\begin{array}{l}\text { Bivalve escavador profundo, plano de } \\
\text { comissura vertical em relação ao plano de } \\
\text { acamamento. Estruturas de escape presentes } \\
\text { modificando antigos planos de acamamento do } \\
\text { substrato. }\end{array}$ & $\begin{array}{l}\text { Diversos episódios de rápida erosão do substrato, animais se } \\
\text { locomovem para baixo ou interior do substrato, procurando manter } \\
\text { constantemente sua relação espacial com a interface } \\
\text { água/sedimento. Após os diversos episódios de erosão segue rápida } \\
\text { deposição do substrato. Tal preservação pode estar associada com } \\
\text { estruturas, tais como estratificação cruzada "hummocky". }\end{array}$ & $\begin{array}{l}\text { Frey \& Pemberton (1984); Simões \& Rocha- } \\
\text { Campos (1994); Farro (1998); Simões et al. (no } \\
\text { prelo). } \\
\text { Fig. } 39 \mathrm{H}\end{array}$ \\
\hline $\begin{array}{l}\text { Bivalve escavador profundo, plano de } \\
\text { comissura vertical em relação ao plano de } \\
\text { acamamento. Estrutura de escape presente. }\end{array}$ & $\begin{array}{l}\text { Diversos episódios de rápida deposição (agradação). Tentativa do } \\
\text { animal manter permanente contato com a nova superfície } \\
\text { (água/sedimento). Normalmente, o novo substrato não difere } \\
\text { (textura, granulometria) essencialmente do originalmente } \\
\text { colonizado. Se sim, isso mostra habilidade do organismo colonizar } \\
\text { ampla variedade de substratos. }\end{array}$ & $\begin{array}{l}\text { Frey \& Pemberton, (1984); Kondo }(1997,1998) . \\
\text { Fig. } 39 \text { I }\end{array}$ \\
\hline $\begin{array}{l}\text { Bivalve escavador profundo ou raso, plano de } \\
\text { comissura vertical em relação ao plano de } \\
\text { acamamento, animal preservado junto ao } \\
\text { contato entre os dois litótipos, contato brusco } \\
\text { não erosivo. }\end{array}$ & $\begin{array}{l}\text { Rápida deposição, normalmente de sedimentos finos, sem presença } \\
\text { de correntes tracionais de fundo. Animal não adaptado a } \\
\text { colonização de substrato mais fino, desfavorável à muitos bivalves } \\
\text { escavadores suspensívoros. }\end{array}$ & $\begin{array}{l}\text { Kranz, (1974); Kondo (1987, 1997, 1998); } \\
\text { Heikoop et al. (1997). } \\
\text { Fig. 39 J }\end{array}$ \\
\hline $\begin{array}{l}\text { Bivalve da semi-infauna, plano de comissura } \\
\text { inclinado cerca de } 40^{\circ} \text {, em relação ao plano de } \\
\text { acamamento. Substrato subjacente sem } \\
\text { bioclastos. }\end{array}$ & $\begin{array}{l}\text { Soterramento abrupto de animais vivos, na ausência de correntes } \\
\text { tracionais de fundo. Normalmente, a carena da concha esta } \\
\text { posicionada junto ao contato entre dois litótipos. Se a porção } \\
\text { posterior da concha (exposta em vida) apresentar sinais de } \\
\text { desgaste, encrustação, bioerosão ou corrosão, isso indica longo } \\
\text { período de não deposição de sedimentos, antes do soterramento } \\
\text { final. }\end{array}$ & $\begin{array}{l}\text { Bambach (1971); Fürsich (1980); Brett \& Baird } \\
\text { (1986); Speyer \& Brett (1991). } \\
\text { Fig. 39 L }\end{array}$ \\
\hline $\begin{array}{l}\text { Bivalve da semi-infauna, plano de comissura } \\
\text { inclinado cerca de } 40^{\circ} \text {, em relação ao plano de } \\
\text { acamamento. Substrato rico em bioclastos. }\end{array}$ & $\begin{array}{l}\text { Concentração internamente complexa. Presença de bioclastos pode } \\
\text { decorrer de vários fatores: transporte de elementos alóctones; } \\
\text { produção biológica natural, etc. Se a concentração subjacente ao } \\
\text { animal for do tipo coquinóide (padrão comum), isso indica período } \\
\text { de baixa taxa de sedimentação ou não deposição de sedimentos. } \\
\text { Presença de matriz fina indica que não houve um retrabalhamento } \\
\text { completo de finos. }\end{array}$ & $\begin{array}{l}\text { Fürsich (1980); Miller et al. (1988); Kondo \& } \\
\text { Kikuchi (1995); Anelli et al. (1998); Torello } \\
\text { (1999). } \\
\text { Fig. } 39 \text { M }\end{array}$ \\
\hline $\begin{array}{l}\text { Bivalve da semi-infauna, plano de comissura } \\
\text { horizontal ao plano de acamamento, concha } \\
\text { articulada fechada }\end{array}$ & $\begin{array}{l}\text { Rápida deposição de sedimentos após erosão do substrato. } \\
\text { Transporte lateral curto. }\end{array}$ & $\begin{array}{l}\text { Fürsich (1980); Stanley (1972); Kondo (1997, } \\
\text { 1998). } \\
\text { Fig. } 39 \mathrm{~N}\end{array}$ \\
\hline $\begin{array}{l}\text { Bivalve da epifauna, plano de comissura } \\
\text { vertical ao plano de acamamento, concha } \\
\text { articulada fechada. }\end{array}$ & Soterramento rápido, na ausência de correntes tracionais de fundo. & $\begin{array}{l}\text { Fürsich (1980). } \\
\text { Fig. } 39 \text { O }\end{array}$ \\
\hline $\begin{array}{l}\text { Bivalve da epifauna, plano de comissura } \\
\text { horizontal ao plano de acamamento, concha } \\
\text { articulada fechada. }\end{array}$ & $\begin{array}{l}\text { Soterramento abrupto, instantâneo, na ausência de correntes } \\
\text { tracionais de fundo. }\end{array}$ & $\begin{array}{l}\text { Fürsich (1980); Farro (1998). } \\
\text { Fig. } 39 \text { P }\end{array}$ \\
\hline $\begin{array}{l}\text { Bivalve da epifauna, plano de comissura } \\
\text { vertical, porém preservado com o plano de } \\
\text { comissura disposto horizontalmente. }\end{array}$ & Soterramento rápido, na presença de correntes tracionais de fundo & $\begin{array}{l}\text { Torello \& Simões (1994). } \\
\text { Fig. } 39 \text { Q }\end{array}$ \\
\hline
\end{tabular}


Além dos aspectos acima, fica evidente que a análise é grandemente favorecida quando elementos articulados estão presentes nas acumulações esqueléticas estudadas. Uma vez que elementos articulados podem representar animais preservados em posição de vida (veja, Rocha-Campos, 1969; Simões \& Rocha-Campos, 1994; Anelli et al., 1998; Farro, 1998, para exemplos paleozóicos brasileiros) e que esta é identificada com base na relação entre a concha articulada, a posição do plano de comissura em vida, com respeito à interface água/sedimento, e a posição do plano de comissura, em relação ao plano de acamamento do sedimento onde os fósseis ocorrem, há a necessidade do exame de espécimes orientados, especialmente com relação ao topo e base do nível fossilífero. Isso implica no reconhecimento prévio do modo de vida dos bivalves fossilizados, já que existem espécies que, em vida, estão dispostas no substrato com o plano de comissura orientado verticalmente (escavadores) ou horizontalmente (parte da epifauna, pectinídeos) em relação ao plano de acamamento. Em adição, no que tange às espécies escavadoras que estão dispostas com o plano de comissura vertical em relação ao acamamento, alguns autores (e.g., Kondo, 1997, 1998) reconhecem diferenças entre a posição de vida (plano de comissura em ângulo próximo a ou reto, em relação ao plano de acamamento) e a posição de alimentação (plano de comissura ligeiramente inclinado, cerca de $40^{\circ}$ ), ressaltando novamente a importância da observação de amostras orientadas.

O exame dos contatos estratigráficos (e.g., brusco, erosivo) imediatamente abaixo ou acima das ocorrências em estudo, fornece também dados paleoambientais úteis. Por exemplo, nos casos onde os fósseis estão preservados em posição de vida é possível, a partir de observação dos contatos estratigráficos, a identificação de períodos de degradação (erosão) ou agradação do substrato (fig. 41).

\subsection{Estudo de Caso}

Na prática, a análise apresentada no item 5.3 constitui por si só importante exemplo das relações existentes entre a bioestratinomia dos bivalves, sua paleoautoecologia e as características sedimentológicas e estratigráficas de um dado depósito sedimentar. O estudo tafonômico do arenito bioclástico de Ferraz (Simões \& Kowalewski, 1998a), Formação Corumbataí, constitui outro importante exemplo. Entretanto, uma vez que dados tafonômicos 
de detalhe não estão disponíveis para todas as ocorrências fossilíferas do Neopaleozóico do Estado de São Paulo, a fim de exemplificar e de demonstrar a potencialidade da análise sugerida, será discutida, neste item, a gênese complexa de uma concentração coquinóide, no topo da Formação Corumbataí (assembléia de Pinzonella neotropica), na região de Tambaú, SP (Dalponte \& Gonçalves, 1979; Torello, 1999). Os dados tafonômicos foram extraídos de Simões et al. (1998a) e, principalmente, de Torello (1999). A esses são aqui acrescentados os dados paleoautoecológicos dos bivalves presentes naquela concentração fossilífera.

Concentração Fossilífera: "Concentração fossilífera C" de Torello (1999).

Localização: Nas terras de propriedade do Sítio São João do Capão Redondo, na estrada secundária que liga Tambaú a Santa Rosa do Viterbo, na região de Tambaú (21 $39^{\circ} 36^{\prime}$ ' S e $\left.47^{\circ} 15^{\prime} 32^{\prime \prime} \mathrm{W}\right)$.

Unidade Litoestratigráfica: Formação Corumbataí, topo (Dalponte \& Gonçalves, 1979; Torello, 1999).

Unidade Bioestratigráfica: Biozona de Pinzonella neotropica (Rohn, 1994)

Descrição Resumida: Concentração fossilifera com espessura variando de 2 a $11 \mathrm{~cm}$, extensão lateral e geometria difíceis de serem estabelecidas, devido ao intemperismo dos sedimentos e à cobertura vegetal. Contato basal brusco e erosivo, contato superior possivelmente ondulado, brusco. O grau de empacotamento dos bioclastos é variável, desde disperso até denso, especialmente para o topo (fig. 42). Quando densamente empacotados os bioclastos estão aninhados. As espécies presentes estão representadas por formas escavadoras rasas (Pinzonella neotropica, Holdhausiella elongata, Jacquesia brasiliensis), escavadoras intermediárias (Cowperesia anceps) e da semi-infauna (Naiadopsis lamellosus). Suas conchas, cujo tamanho é variável $(<1$ até $8 \mathrm{~cm})$, ocorrem predominantemente desarticuladas, porém conchas articuladas abertas e fechadas (Naiadopsis lamellosus) são descritas no topo da concentração fossilífera. O estado de preservação das conchas também é variável, incluindo conchas inteiras, fragmentadas, com ou sem sinais de abrasão. 


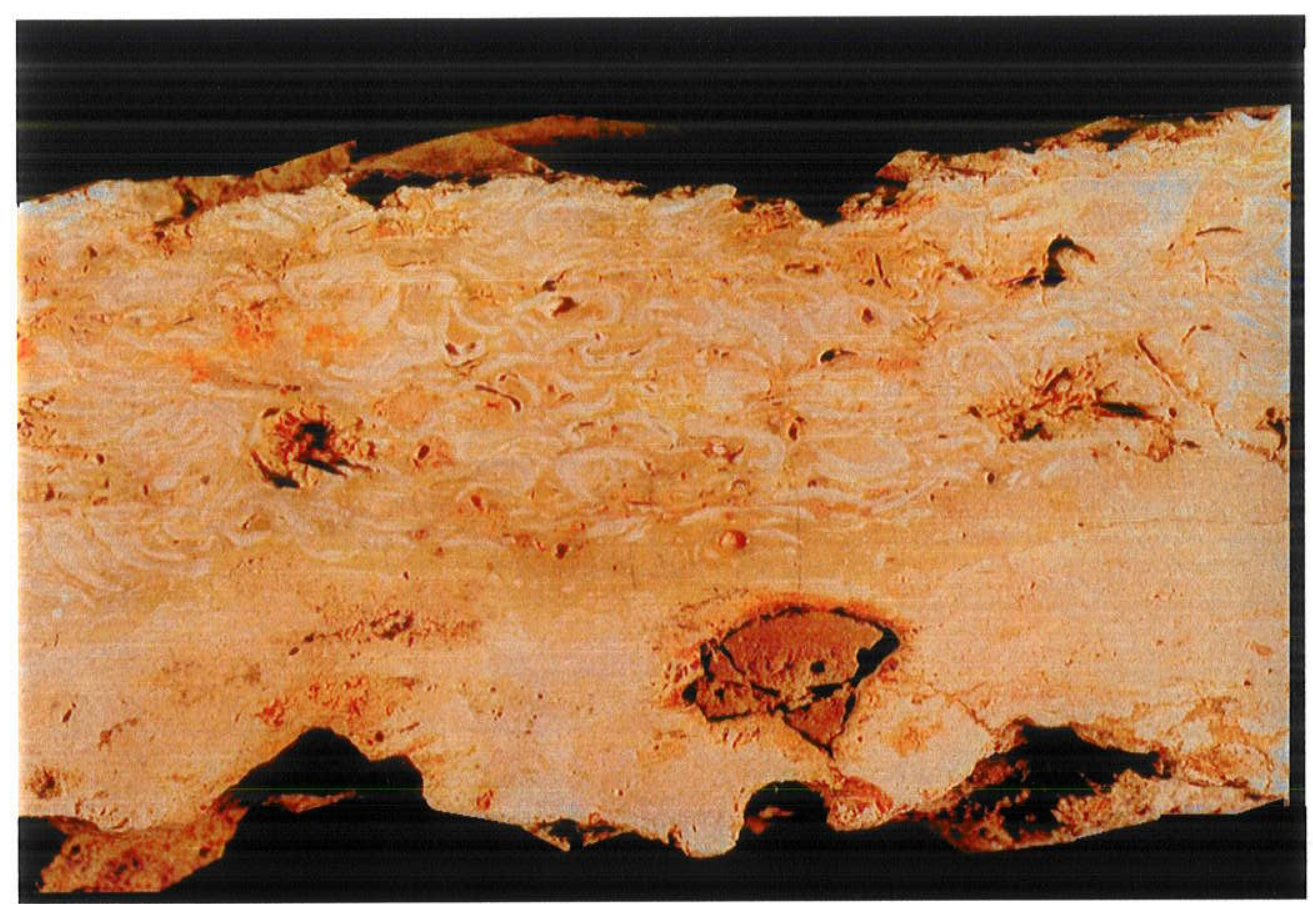

Figura 42- Concentração fossilífera C (sensu Torello, 1999). Notar o aumento do grau de empacotamento dos bioclastos em direção ao topo e o contato basal erosivo. Espessura da concentração 4,5 cm.

Interpretação: Concentração gerada por repetidos eventos de erosão de fundo, retrabalhamento e redeposição de finos (Simões et al., 1998a), correspondendo a um tempestito distal (Simões et al., 1998a; Torello, 1999).

Discussão: Na figura 43, estão incluídos os principais eventos que foram responsáveis pela gênese desta concentração fossilífera. Nem todos os eventos estão obrigatoriamente representados na figura, pois estes, muitas vezes, não ficam preservados como uma discreta camada sedimentar ou estão representados por acumulações esqueléticas. A seqüência de eventos inferida é, grosso modo, a apresentada na figura 43, embora o número de vezes que cada evento ocorreu é difícil de ser inferido. Note que este esquema não é idêntico ao apresentado por Torello (1999), ainda que os processos sedimentares que geraram a acumulação esquelética sejam os mesmos. Não há evidências, por exemplo, de que Naiadopsis lamellosus foi um animal gregário (veja Kondo \& Kikuchi, 1995, para um exemplo de bivalves gregários preservados no topo de uma coquina), tão pouco há indícios de que Naiadopsis lamellosus colonizou o mesmo tipo de substrato que Cowperesia anceps (veja item 5.3), lado a lado, num mesmo instante da história de acumulação da concentração estudada. 


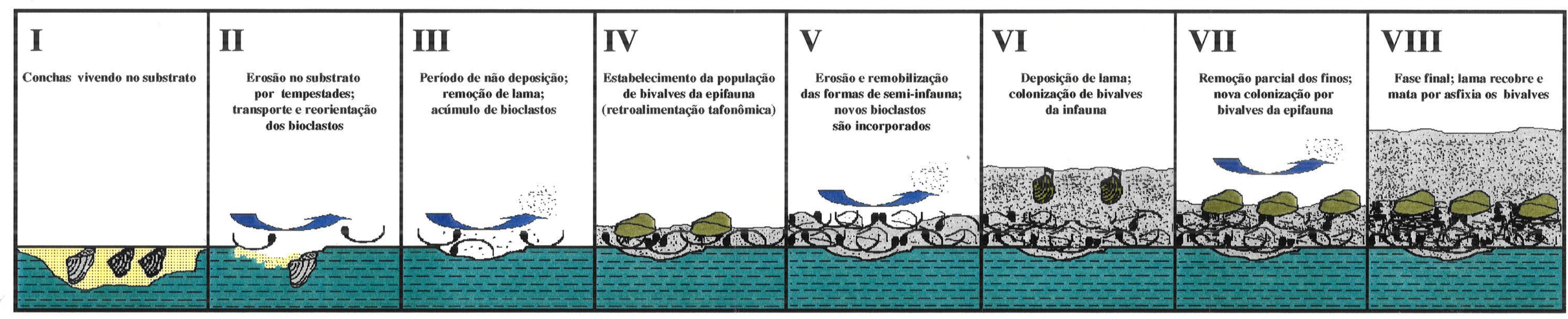

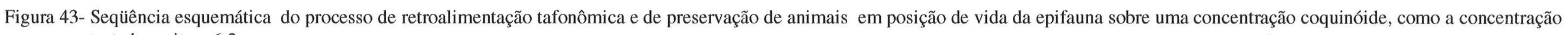
tratada no item 6.2 
Espécimes de Naiadopsis lamellosus em posição de vida no topo da "Concentração Fossilífera C" (sensu Torello, 1999) constituem a feição mais notável desta ocorrência (fig. 44). Os exemplares estão articulados fechados e com o plano de comissura inclinado cerca de 45 graus, em relação ao plano de acamamento. Esta posição é similar àquela descrita por Anelli et al. (1998) para outros anomalodesmatas paleozóicos. As evidências disponíveis indicam que os elementos em posição de vida estavam enterrados cerca de $1,6 \mathrm{~cm}$ no interior do pavimento de conchas (concentração coquinóide). Isso é inferido pelo fato das conchas estarem "enterradas" no pavimento bioclástico até a região da carena umbonal (fig. 44). Esta posição é muito semelhante à descrita por Kondo \& Kikuchi (1995) para bivalves marinhos do Pleistoceno que possuem hábito de vida similar ao inferido para Naiadopsis lamellosus. Entretanto, a feição mais importante é a compressão dorso-ventral mostrada por todos os espécimes articulados fechados de Naiadopsis lamellosus (fig. 44, B). Esta é também uma feição comum aos bivalves de infauna e semi-infauna preservados em posição de vida (Rocha-Campos, 1968; Bambach, 1971; Simões \& Rocha-Campos, 1994; Kotzian, 1995; Farro, 1998; Anelli et al., 1998).

O substrato original constituído pela acumulação de conchas, inclui não apenas estas, mas também alta proporção de matriz argilosa (Torello, 1999) (fig. 42). A grande quantidade de valvas desarticuladas, fragmentadas e algumas com intensa abrasão, especialmente das formas escavadoras rasas, como Pinzonella neotropica, constitui forte indício de que estes sofreram retrabalhamento na interface água/sedimento, antes do soterramento final, por eventos de tempestade (Simões et al., 1996a). Tais eventos são identificados pelas características da biofábrica que, neste caso, inclui conchas aninhadas e caoticamente distribuídas na matriz.

A presença de conchas articuladas fechadas, em posição de vida no topo desta acumulação indica a colonização deste substrato, cuja gênese estaria vinculada a episódios prévios de tempestade e retrabalhamento dos bioclastos. Obviamente, este substrato constituiu um local apropriado para a fixação das larvas de Naiadopsis lamellosus, adequado, portanto, aos invertebrados da semi-infauna. Kondo \& Kikuchi (1995) demonstraram que bivalves da semi-infauna bissada preferencialmente colonizam os substratos ricos em conchas que possuem alta proporção de lama, constituindo um substrato parcialmente mole. Nestes casos, os bivalves ficam fixados, e em parte apoiados, nos bioclastos do pavimento de conchas prévio, possibilitando, no entanto, sua escavação. Esta é necessária para manter o bivalve parcialmente enterrado (veja, por exemplo, Stanley, 1972). Portanto, no momento de 
colonização do substrato por Naiadopsis lamellosus o fundo não era constituído unicamente por um pavimento de conchas, acarpetando o substrato, mas sim pela presença de conchas imersas em matriz lamosa.

Durante o período de colonização do substrato rico em bioclastos, pelos bivalves da semi-infauna, dois aspectos importantes da dinâmica sedimentar devem ser notados. Em primeiro lugar, o substrato não pode ser constantemente retrabalhado por correntes tracionais de fundo e, em segundo lugar, as taxas de sedimentação de finos devem ser baixa. Os bivalves da semi-infauna bissada, suspensívoros, não podem, por exemplo, tolerar altas taxas de decantação de finos, pois sob tais condições haveria entupimento da cavidade interna do corpo. De fato, é notável que em concentrações do tipo coquina das formações Terezina e Corumbataí onde o processo de retrabalhamento foi intenso, inclusive com a quase completa eliminação de finos a presença de conchas de Naiadopsis lamellosus não é comum, estando todos os espécimes desarticulados e portanto, fora de sua posição de vida (Simões et al., 1996a).

No contexto acima, outra feição espetacular da "Concentração Fossilífera C" é conter também alta proporção de conchas desarticuladas, fragmentadas, com ou sem abrasão de Naiadopsis lamellosus, exibindo diversas classes de tamanho $(1-8 \mathrm{~cm})$, sugerindo diferentes episódios de colonização do substrato e retrabalhamento e indicando diferentes períodos de extensa retroalimentação tafonômica (fig. 43). O processo básico de deposição envolveria, portanto, a formação de acumulações ricas em conchas, inicialmente de formas escavadoras rasas (Pinzonella neotropica), possivelmente exumadas durante eventos de alta energia (tempestade) e rapidamente soterradas, como evidenciado pela ocorrência de conchas articuladas fechadas, com o plano de comissura horizontal em relação ao plano de acamamento (fig. 45; veja também Quadro 10), na base da concentração esquelética. Após tais eventos as condições retornariam a ser calmas, com a deposição do material fino colocado em suspensão durante o evento de tempestade. Conforme observado por Miller et al., (1988) e Brett \& Taylor (1997), nos mares epicontinentais estes sedimentos são depositados entre profundidades correspondentes à base das ondas de tempestade e ondas de tempo bom. Diversos autores (veja um sumário em Miller et al., 1988), entretanto, notaram que a camada que recobre a acumulação esquelética pode ser completa ou parcialmente removida por tempestades subseqüentes menos intensas. Sob tais condições o pavimento de conchas pode ser colonizado por invertebrados da epifauna e semi-infauna. Neste momento, como visto, as taxas de sedimentação devem ser baixas. Se estas condições não estiverem 


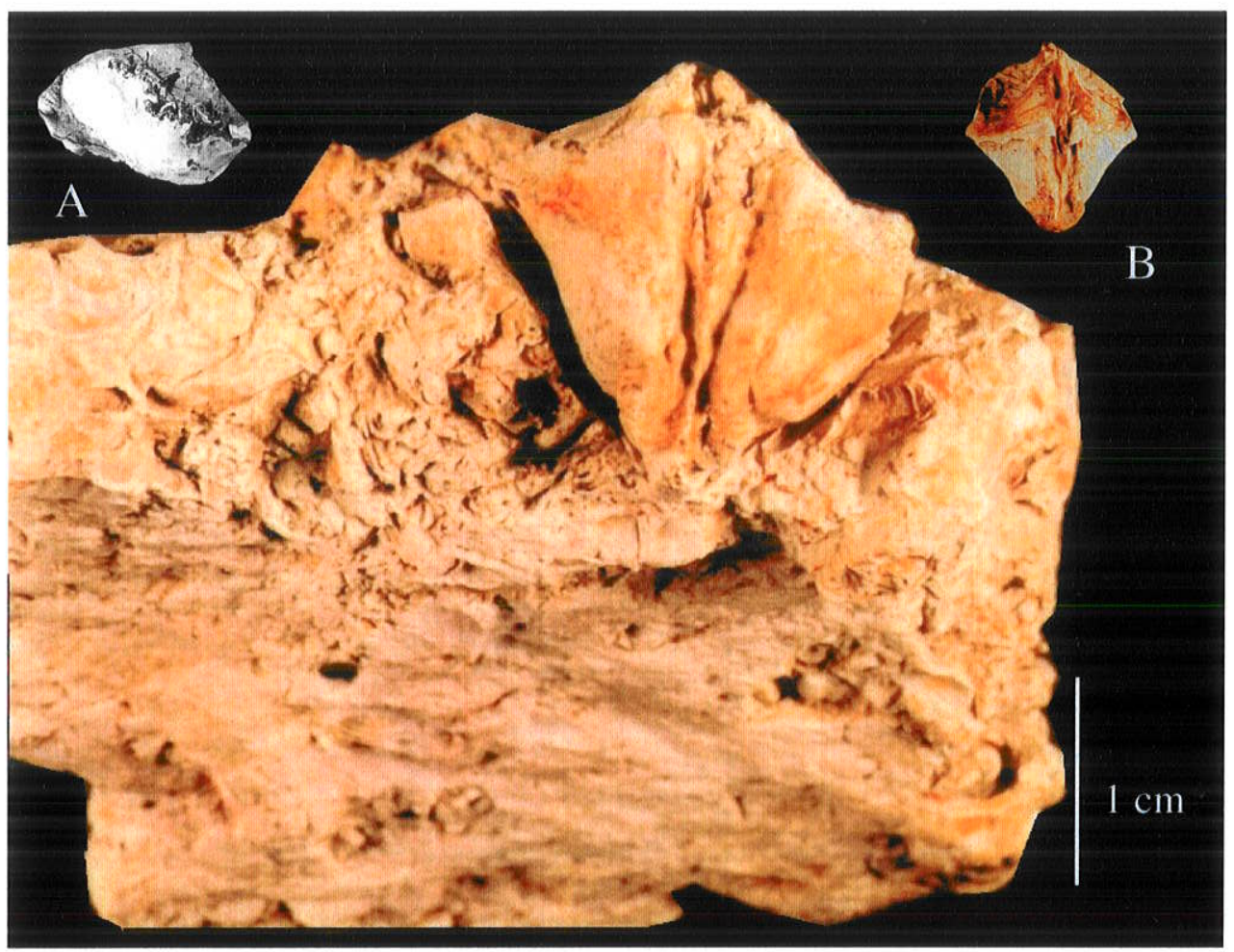

Figura 44- Exemplar de Naiadopsis lamellosus em provável posição de vida. Valva direita silicificada de exemplar da mesma espécie (A), vista frontal de um exemplar da mesma espécie demonstrando achatamento dorso-ventral (B).

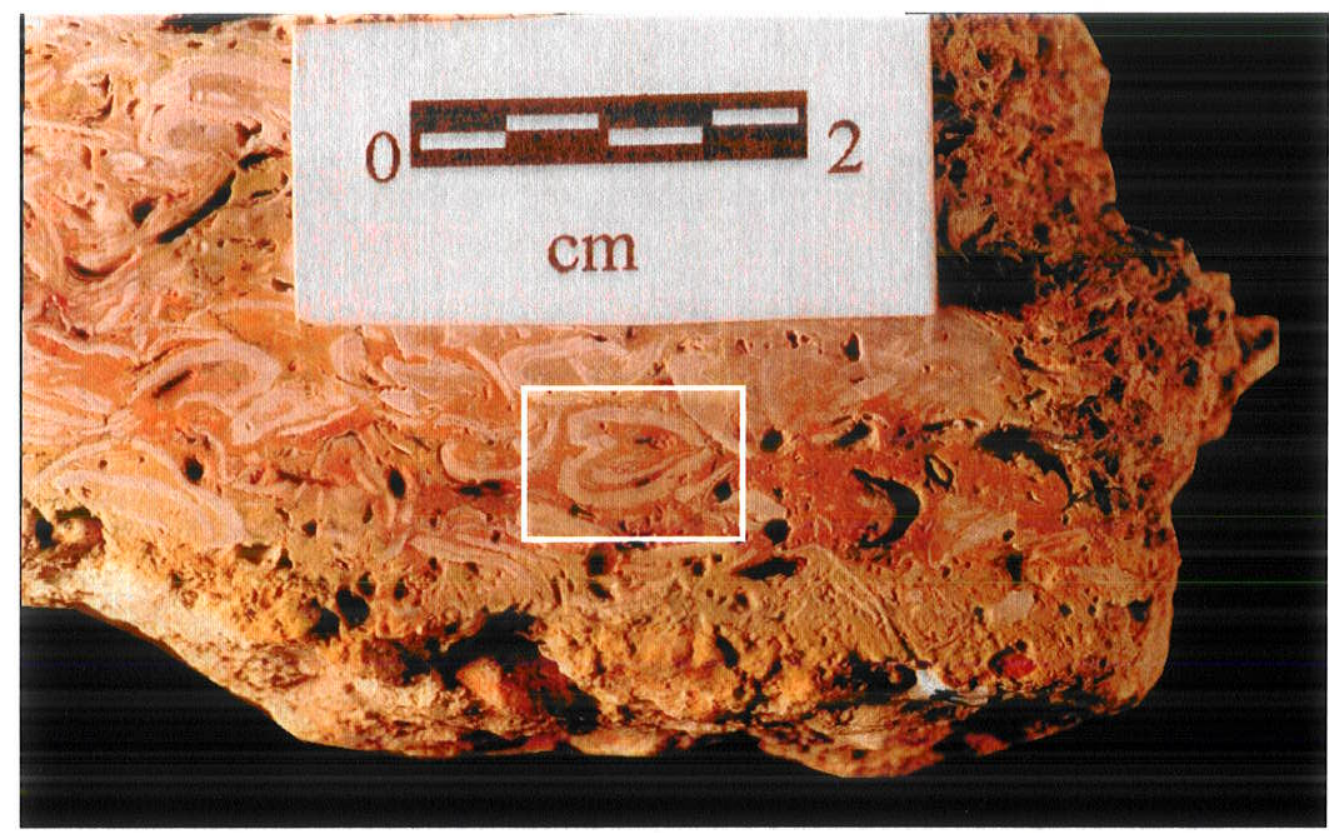

Figura 45- Seção da concentração fossilífera C (sensu Torello, 1999), notar a presença de concha de Pinzonella neotropica articulada fechada (detalhe). Explicação no texto. 
disponíveis os animais serão soterrados em posição de vida (Fürsich, 1980; Kondo \& Kikuchi, 1995; Heikoop et al., 1997; Simões et al., 1998a, c).

Um outro achado importante refere-se a descoberta de uma concentração coquinóide com características tafonômicas muito similares às da "Concentração Fossilífera C" (Torello, 1999). Esta concentração é representada por um bloco de sedimento de aproximadamente 30 $\mathrm{cm}$ de comprimento, $15 \mathrm{~cm}$ de largura e $10 \mathrm{~cm}$ de espessura. Sabe-se que o material provêm do nordeste do Estado de São Paulo, a localização exata do ponto de coleta infelizmente não é conhecida, uma vez que constitui material doado ao Laboratório de Paleozoologia Evolutiva do IBB/UNESP. Desta concentração foram recuperadas diversas conchas de Naiadopsis lamellosus articuladas fechadas (espécimes DPZ-1970 a 1977), todos mostrando um apreciável achatamento dorso-ventral. Em adição, foram encontrados também espécimes de Cowperesia anceps (espécimes DZP-1969a, b, j) articulados fechados. Deve ser ressaltado aqui, que anteriormente ao presente estudo e ao de Torello (1999) nenhuma concha articulada fechada de ambas as espécies era então conhecida.

A presença de Cowperesia anceps nesta ocorrência reveste-se de grande importância, pois conforme já discutido nos itens 4.1.4.1 e 5.3, esta espécie é representada por formas escavadoras rápidas em substrato fino (síltico ou argiloso). De fato, nas concentrações fossilíferas representadas por arenitos bioclásticos ou coquinas com alto grau de empacotamento, que correspondem a tempestitos proximais, conchas de Cowperesia anceps estão, normalmente, desarticuladas exibindo diferentes graus de preservação. Constituem estas elementos alóctones nestas concentrações fossilíferas.

Em decorrência dos aspectos acima, a presença de conchas articuladas de Cowperesia anceps em concentração coquinóide, com alta proporção de matriz fina, indica que este poderia ter constituído seu substrato original de vida. Conforme notado por Kidwell \& Jablonski (1983) o enriquecimento em bioclastos de um substrato anteriormente mole e instável é, normalmente, acompanhado da eliminação das formas de infauna, pois há maior dificuldade para escavação em decorrência da maior estabilidade e dureza oferecida.

Se está interpretação apresentada anteriormente for correta, a presença de lama na acumulação esquelética deve ter ocorrido em um período suficientemente longo para o estabelecimento da população de Cowperesia anceps, antes de sua eliminação parcial por eventos de tempestade subseqüentes, que tornaria o substrato agora susceptível à colonização pelas formas de semi-infauna, antes da nova deposição de lama. Portanto, as concentrações fossilíferas geradas sob tais condições são internamente complexas, representando um registro 
composto de eventos episódicos (tempestades, deposição de lama), posteriormente, em parte, retrabalhados por correntes ou mesmo por processos associados às tempestades subseqüentes. Conforme detalhadamente discutido por Simões (1998), nos ambientes marinhos do Recente, como no litoral da Malásia, esta interação entre sedimentação, produção de bioclastos e retrabalhamento e deposição de lama por eventos de tempestades é bem conhecida (Modelo Jeram), sendo freqüentemente acompanhada de mudanças na composição faunística (Seilacher, 1985) (fig. 46).

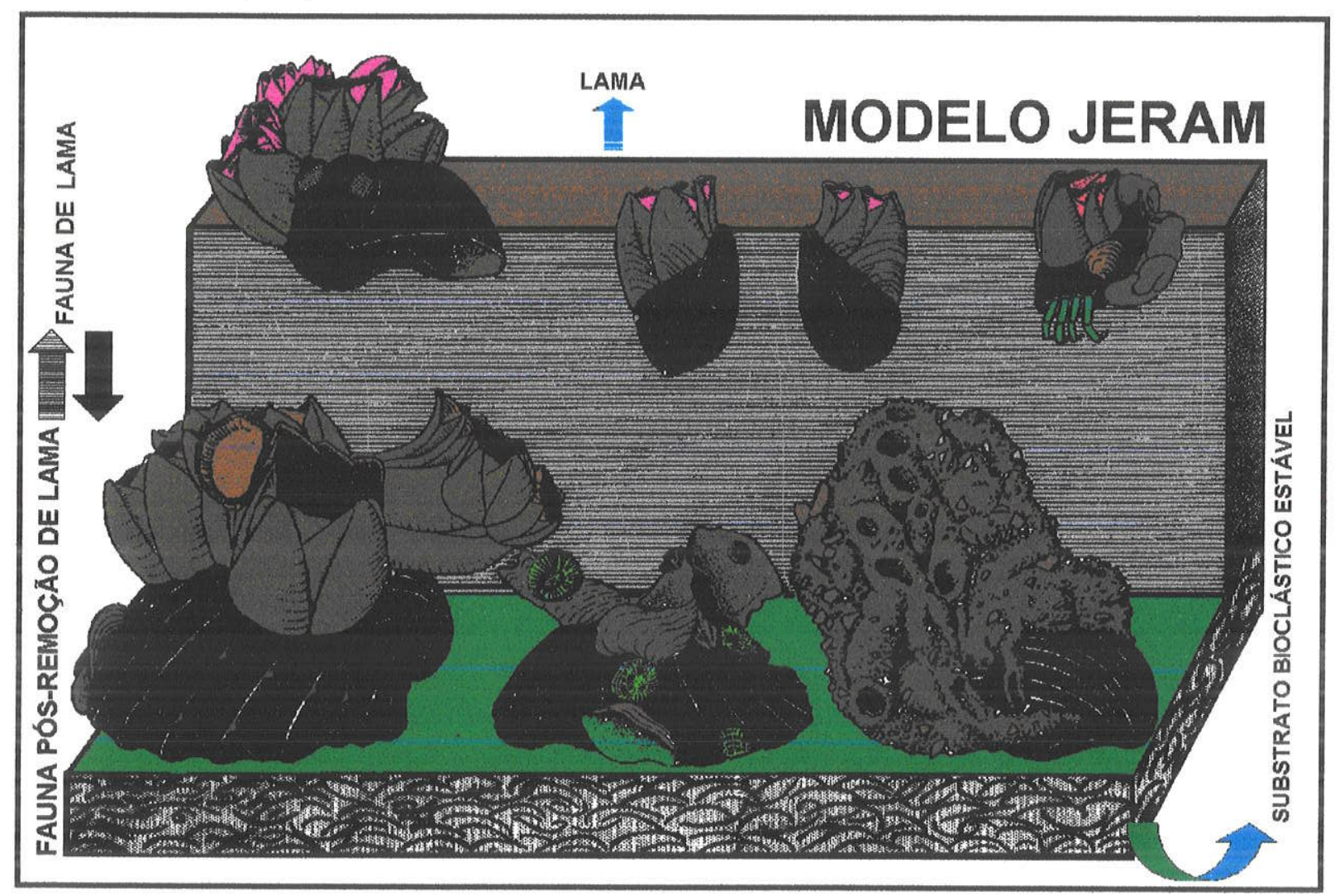

Figura 46- Processo de retroalimentação tafonômica decorrente de sucessivos eventos concentradores de material bioclástico em ambientes de planície de maré (litoral de Jeram, Malásia). Modificado de Seilacher (1985). 


\section{ANÁLISE PALEOSSINECOLÓGICA}




\section{ANÁLISE PALEOSSINECOLÓGICA}

A moderna pesquisa tafonômica em ambiente marinhos do Recente (Flessa \& Kowalewski, 1996; Kowalewski; et al., 1998) mostrou que o fenômeno de mistura temporal e espacial ("time-averaging") dos restos esqueléticos é um fenômeno natural, constituindo uma regra e não uma exceção, conforme poderia ser esperado. A datação de bioclastos (conchas de bivalves) coletados lateralmente (imediatamente adjacentes), com grande controle estratigráfico, em acumulações residuais, geradas em ambiente marinho raso, sugerem que o grau de mistura temporal é na ordem de $10^{2}$ a $10^{4}$ (Kowalewski et al., 1998, e referências neste artigo). Conseqüentemente, estes resultados demonstram que o fenômeno de mistura temporal não pode ser eliminado por coleta cuidadosa (mistura temporal analítica; Fürsich \& Aberhan, 1990). Tão pouco está ele associado ao processo de deposição, mas sim à presença de restos bioclásticos antigos no fundo (Kowalewski et al., 1998).

Diversas são as implicações do fenômeno de mistura temporal, as quais transcendem o escopo da Paleontologia. Entretanto, sua ocorrência é particularmente importante na análise paleossinecológica. Conforme demonstrado por Simões \& Kowalewski (1998a, b), concentrações fossilíferas pouco espessas podem ser internamente complexas, com baixa resolução temporal e espacial. Em decorrência disso, freqüentemente as concentrações fossilíferas mostram uma mistura de animais que embora ocorrendo lado-a-lado não foram contemporâneos. Mesmo nos casos onde o soterramento foi instantâneo a mistura temporal está presente (Heikoop et al., 1997; Simões et al., 1998a, c).

O principal desafio, portanto, para as reconstruções paleoessinecológicas é reduzir ao máximo possível a mistura ecológica imposta pelo fenômeno de "time-averaging". Simões \& Kowalewski $(1998 \mathrm{a}, \mathrm{c})$, adicionalmente, chamaram a atenção para o fato de que as reconstruções paleoautoecológicas, tipicamente representadas por blocos diagramas, não são justificáveis, uma vez que incluem populações e comunidades não contemporâneas. De fato, seria o mesmo que imaginar que Tintoretto e Van Gogh pintaram seus quadros numa mesma época simplesmente por estarem expostos numa mesma galeria de um Museu de Arte.

A análise autoecológica e bioestratinômica de alta resolução constituem ambas importantes ferramentas para as reconstruções paleossinecológicas, especialmente nos casos onde uma idade precisa dos restos esqueléticos não pode ser obtida. No presente capítulo, é 
sugerido um protocolo contendo 7 etapas, visando a obtenção de dados que possam propiciar interpretações paleossinecológicas mais fidedignas.

São as seguintes as etapas propostas:

Etapa 1. Envolve atividades preliminares como, por exemplo, a delimitação do escopo do estudo, os tipos de concentrações fossilíferas que serão analisadas, o intervalo estratigráfico abrangido, as fácies sedimentares envolvidas, etc. $O$ resgate de informações paleossinecológicas já disponíveis na literatura, mesmo que imprecisas quanto à questão da mistura temporal e espacial, é útil.

Etapa 2. Inclui, em grande parte, as atividades de coleta, tendo início com a localização e o reconhecimento no campo, da concentração ou grupo de concentrações que serão analisadas. No exemplo aqui apresentado, uma concentração fossilífera internamente complexa (sensu Kidwell \& Aigner, 1985; Simões, 1998; Simões \& Kowalewski, 1998a, b; Torello, 1999). Os procedimentos empregados na coleta são os de rotina para material paleontológico (Rösler, 1986), exigindo, porém, alguns cuidados básicos.

Em nossa experiência no Permiano da Bacia do Paraná, os sedimentos analisados estão freqüentemente silicificados e profundamente intemperizados. É comum, não obstante, os afloramentos fossilíferos aqui estudados estarem densamente recobertos por vegetação (Ragonha, 1980; Simões et al, 1996a). Conseqüentemente, o trabalho tem início com a remoção da cobertura vegetal (Simões et al, 1996a) e exposição dos sedimentos e da(s) concentração(ões) fossilífera(s). Tendo sido expostos e uma descrição preliminar feita, tem início a coleta propriamente dita.

A coleta envolve a remoção da concentração fossilífera na forma de blocos de rocha (Simões et al., 1996a; Simões, 1998; Simões \& Kowalewski, 1998a), com dimensão de aproximadamente $0,05 \mathrm{~m}^{3}$. A experiência mostra que os blocos com tal dimensão possibilitam a obtenção de um número considerável de fósseis, úteis para as análises estatísticas (Simões \& Kowalewski, 1998a), particularmente se o grau de empacotamento variar de denso a disperso (Kidwell \& Holland, 1991). Os blocos podem ser extraídos manualmente ou com o uso de martelete a gasolina. Durante a extração é importante orientar o bloco de rocha tanto quanto ao azimute, como à base e ao topo da camada. No caso do bloco partir durante a coleta, as diferentes partes poderão ser numeradas e do mesmo modo que um quebra-cabeças, ser reconstituído em laboratório. Obviamente, o bloco deve conter não apenas a concentração 
fossilifera em si, mas incluir também, se possível, parte dos sedimentos da base e do topo, mesmo que afossilíferos.

O número de blocos a serem coletados depende, em grande parte, da qualidade de exposição e da geometria (veja Kidwell et al., 1986, para os diferentes tipos de geometria) da concentração fossilífera estudada. Por exemplo, Simões et al. (1996a) no estudo tafonômico da coquina de Camaquã (Formação Corumbataí, assembléia de Pinzonella neotropica), cuja geometria é lenticular, com cerca de $120 \mathrm{~m}$ de extensão lateral; dividiram essa acumulação esquelética em 10 porções distintas. Destas, três foram aleatoriamente sorteadas com cartões numerados (Torello, informação verbal, 1999) e amostradas conforme as instruções acima. É importante destacar que os autores acima, além disso, coletaram amostras da porção mais espessa $(11 \mathrm{~cm})$ e delgada $(1 \mathrm{~cm})$ da coquina. Note que tal procedimento é importante, pois as características tafonômicas e a composição taxonômica dos elementos preservados numa concentração fossilífera pode variar tanto na vertical, como na horizontal.

Etapa 3. Abrange as atividades de laboratório. A preparação do bloco e dos fósseis depende largamente dos tipos de fossilização representados e do grau de intemperismo da matriz. No laboratório o bloco será secionado. Esse procedimento deverá ser realizado por um indivíduo treinado e experiente. Após esse procedimento, o bloco poderá ser lavado e os restos de vegetais extraídos.

Uma vez limpo, tem início uma descrição preliminar, porém atenta, de algumas feições tafonômicas e sedimentares da concentração fossilífera, que podem ser observadas ao longo das faces que foram cortadas. $\mathrm{Na}$ figura 47, existe uma reconstrução fundamentada nas feições tafonômicas e estruturas sedimentares presentes na face secionada de uma amostra do arenito bioclástico de Ferraz (Simões \& Kowalewski, 1998a). Note que, em aproximadamente $30 \mathrm{~cm}$ de espessura de sedimentos, há uma ampla variação nas características da biofábrica e da matriz (Simões \& Kowalewski, 1998a), mostrando, por exemplo, uma concentração residual basal (subunidade 1), pavimentos de conchas e superfícies de erosão (subunidade 2), uma camada com fósseis preservados em posição de vida invertida (subunidade 3) e, novamente, uma concentração densa de bivalves silicificados, formando um pavimento de conchas (subunidade 4) (Simões, 1998; Simões \& Kowalewski, 1998a). Uma vez reconhecidas estas feições, o bloco será agora partido horizontalmente ao longo dos planos que marcam tais subunidades. Habitualmente, em decorrência de diferenças no tipo de preservação dos fósseis, do grau de silicificação e do intemperismo da matriz, que podem ser 


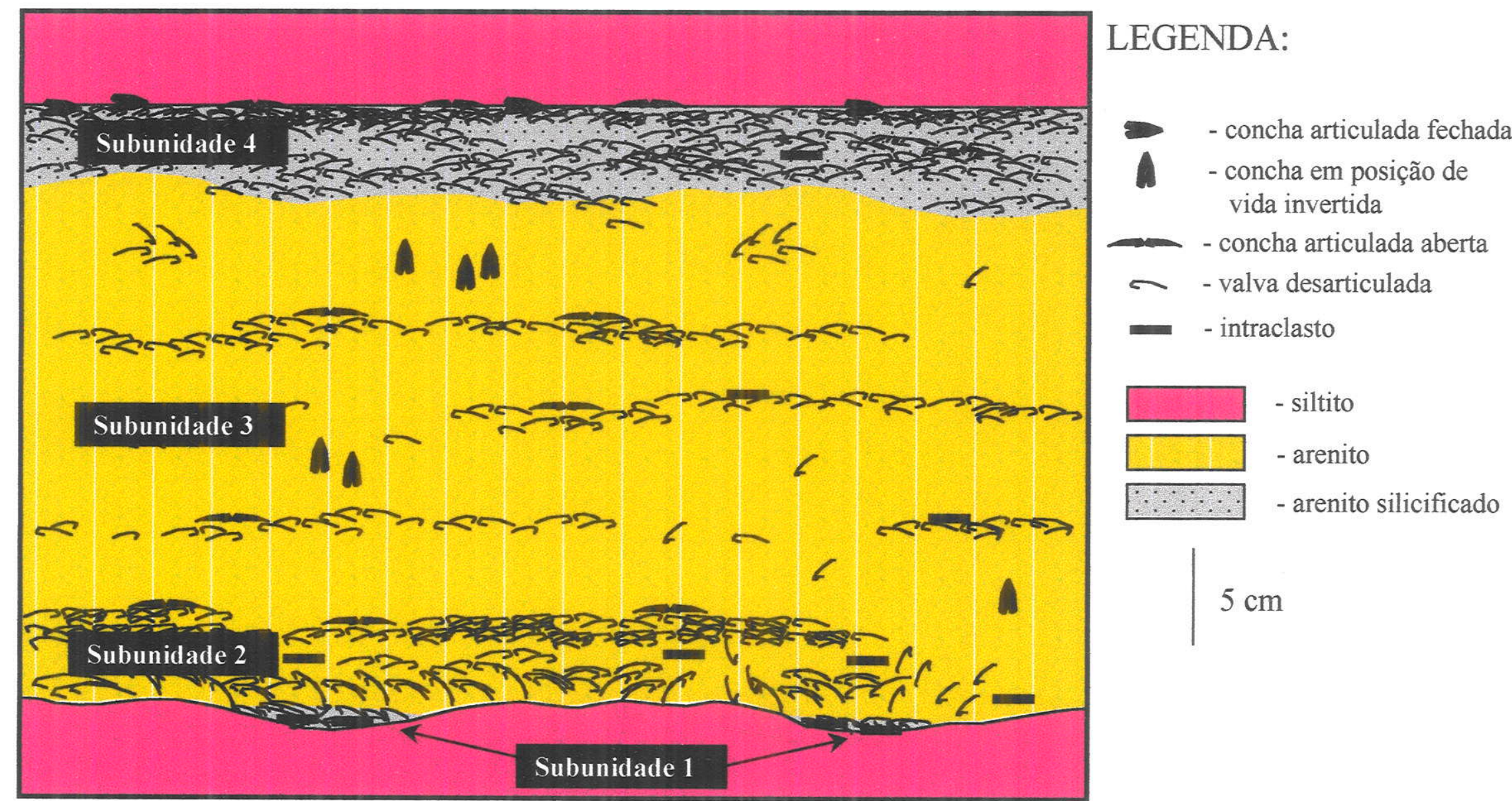

Figura 47- Seção composta do arenito bioclástico de Ferraz, mostrando seus contatos estratigráficos, bem como as feições tafonômicas e bioestratinômicas das 4 subunidades microestratigráficas reconhecidas, segundo Simões (1998) e Simões \& Kowalewski (1998a). 
distintas em cada subunidade, o bloco pode ser partido até com certa facilidade ao longo destes planos. Por exemplo, nas subunidades 1 e 4 do arenito bioclástico de Ferraz, tanto os fósseis como a matriz estão silicificados, enquanto nas subunidades 2 e 3 os fósseis ocorrem como moldes externos e internos (Simões \& Kowalewski, 1998a). É importante destacar que cada bloco, que agora representa cada uma das subunidades, deve estar também orientado, em relação ao bloco original.

Em seguida, cada bloco será preparado tanto do ponto de vista físico, como químico, considerando as características intrínsecas de cada um. No caso dos fósseis estarem silicificados a metodologia de preparação pode seguir a descrita por Simões (1988) e Simões \& Fittipaldi (1992). Entretanto, é IMPRESCINDívEL que os fósseis NÃo sejam extraídos da matriz. O que deve ser eliminado são os sedimentos em torno dos fósseis, mas a sua distribuição original deve ser mantida, pois a feição tafonômica é indispensável para a análise. Nos casos onde os fósseis estão preservados como moldes, não apenas os moldes internos são importantes (por conterem informações para a análise autoecológica), mas os externos também, pois podem fornecer informações tafonômicas (corrosão, bioerosão) valiosas. Em qualquer caso, porém, deve ser lembrado que todo bioclasto (partícula de origem orgânica maior que $2 \mathrm{~mm}$, sensu Kidwell, 1991), representando um fragmento ou organismo completo (não fragmentado) é importante para a análise.

Etapa 4. Envolve a análise qualitativa, como a descrição das feições tafonômicas (bioestratinômicas e diagenéticas), a classificação taxonômica e a descrição das feições morfofuncionais (internas e externas) dos fósseis presentes em cada subunidade.

Etapa 5. Inclui a análise quantitativa, para os elementos de cada subunidade. No caso das concentrações dominadas por bivalves (veja Torello \& Simões, 1994; Simões et al., 1996a; Klein, 1997; Simões \& Kowalewski, 1998a; Torello, 1999), braquiópodes (Kowalewski, 1996) e trilobitas (Speyer, 1987; Speyer \& Brett, 1996; Lima, 1997; Lima \& Simões, 1998), apenas para citar exemplos paleozóicos mais comuns, a preservação de cada exemplar é descrita, usando classes tafonômicas semi-quantitativas (Fürsich \& Flessa, 1987; Davies et al., 1989; Feige \& Fürsich, 1991; Flessa et al., 1993; Kowalewski et al., 1994, 1995; Simões \& Kowalewski, 1998a). As classes tafonômicas definidas, entretanto, só podem ser aplicadas para os exemplares substituídos (e.g., silicificados) ou moldes externos. Com a finalidade de comparar os diferentes padrões de preservação entre os fósseis de uma mesma subunidade ou 
entre estas, tafogramas ternários são construídos empregando-se o modo R (Kowalewski et al., 1995) ou o modo Q (Simões et al., 1996b). Paralelamente, são levantados os dados biométricos pertinentes ao(s) grupo(s) estudado(s). Em seção, os espécimes são ainda classificados quanto a sua orientação espacial relativa ao plano de acamamento. Em planta, a orientação azimutal dos espécimes alongados é tomada (Kidwell \& Bosence, 1991). Todos os dados quantitativos podem ser organizados em planilhas Microsoft Excel 7.0 ou superior. Os gráficos podem ser gerados usando DeltaGraph Professional 4.0.2 ou superior e as análises estatísticas são executadas utilizando o pacote de programas presentes no Statistical Analysis System (SAS) (veja SAS Intitute, 1989a, b; 1990).

Etapa 6. Abrange a interpretação dos dados, incluindo: a- reconstrução do hábito de vida de cada espécie analisada; b- a determinação dos padrões de preservação das diferentes espécies e entre exemplares de uma mesma espécie e, c- a interpretação dos processos sedimentares responsáveis pela gênese de cada subunidade. É nesta fase que o problema da mistura temporal e da mistura espacial, deve ser analisado, não só para todos os elementos de uma mesma subunidade, como para elementos de uma mesma espécie (mistura temporal desarmoniosa) (Kowalewski, 1997). Várias são as feições diagnósticas e sugestivas destes fenômenos (veja, por exemplo, Simões \& Kowalewski, 1998a). Os dados obtidos são confrontados com os da natureza sedimentológica e estratigráfica e a gênese da acumulação (cada subunidade) e sua história paleossinecológica determinada.

Etapa 7. Envolve o confronto dos dados obtidos e interpretados nas etapas 4, 5 e 6 e seu confronto com as hipóteses iniciais. Em certos casos, uma redefinição de hipóteses poderá ocorrer.

As sete etapas estão sintetizadas no fluxograma da figura 48. Apesar de se constituir um bom guia metodológico, certamente ele poderá ser ampliado e mais detalhado no futuro. 


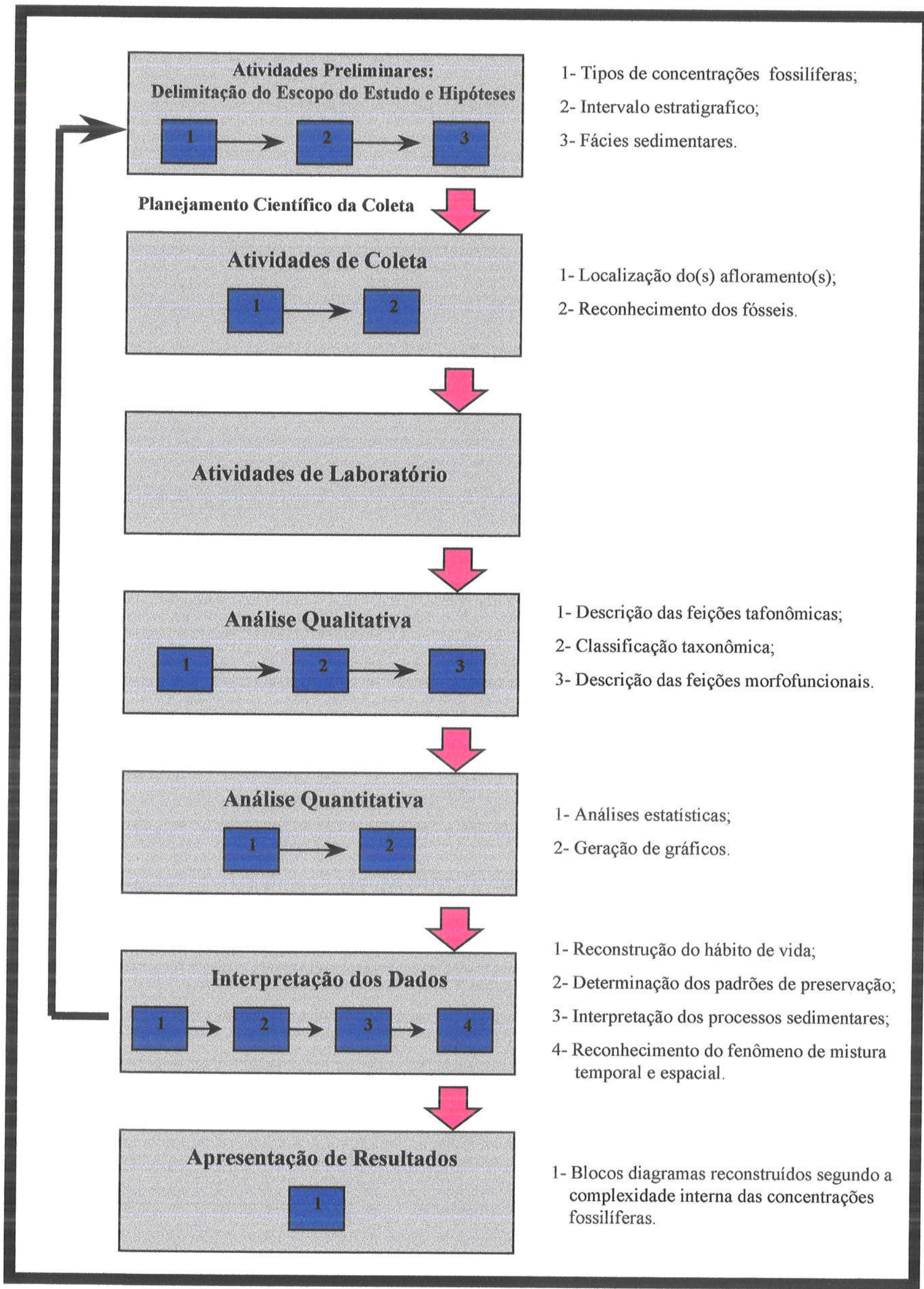

Figura 48- Fluxograma de trabalho e etapas na realização de uma análise paleoecológica levando em conta o estudo autoecológico e tafonômico de detalhe, como ponto de partida para a elaboração de hipóteses e reconstruções paleossinecológicas. 
CONCLUSÕES 


\section{Conclusões}

1) Conceitos da análise morfofuncional estabelecidos para bivalves viventes podem ser aplicados, com as devidas reservas, no estudo paleoautoecológico dos bivalves do Grupo Passa Dois (assembléias de Anhembia froesi, Pinzonella illusa e Pinzonella neotropica), da Bacia do Paraná, especialmente para as espécies que ocorrem com as conchas silicificadas;

2) Os resultados paleoautoecológicos obtidos fornecem dados importantes para a interpretação do modo de vida (e.g., profundidade e velocidade de escavação) e do habitat (e.g., batimetria, substrato) colonizado pelos bivalves estudados;

3) Dados paleoautoecológicos e tafonômicos podem ser combinados, fornecendo informações importantes sobre a dinâmica sedimentar (e.g., taxa de sedimentação), do ambiente de vida dos bivalves ou dos locais de origem e soterramento final das acumulações esqueléticas (concentração de material bioclástico);

4) $\mathrm{Na}$ assembléia de Anhembia froesi predominam as formas escavadoras rasas, lentas (Tambaquyra camargoi) e rápidas (Anhembia froesi); formas da semi-infauna (Barbosaia angulata) e formas da epifauna (?Anthraconaia mezzalirai);

5) $\mathrm{Na}$ assembléia de Pinzonella illusa ocorrem formas escavadoras rasas, rápidas (Favalia arcuata, Holdhausiella elongata e Runnegariella fragilis) e lentas (Pinzonella illusa, Terraiopsis aequilateralis, Othonella araguaiana; Plesiocyprinella carinata e Ferrazia cardinalis); escavadoras intermediárias rápidas (Cowperesia anceps e Angatubia cowperesioides) e lentas (Casterella gratiosa e Itatamba paraima); formas escavadoras profundas lentas (Roxoa corumbataiensis); e formas da epifauna bissada (Coxesia mezzalirai);

6) Na assembléia de Pinzonella neotropica são encontradas formas escavadoras, lentas (Jacquesia brasiliensis e Pinzonella neotropica); formas escavadoras profundas, lentas (Roxoa intricans); e formas da semi-infauna bissada (Naiadopsis lamellosus);

7) Em muitos casos, as formas escavadoras rasas e intermediárias, da semi-infauna e da epifauna, não estão preservadas no provável substrato de vida (e.g., ?Anthraconaia mezzalirai, Barbosaia angulata, Cowperesia anceps, Coxesia mezzalirai, Runnegariella fragilis, Jacquesia brasiliensis e Pinzonella neotropica). Essas espécies estão mais sujeitas à mistura temporal (time-averaging) e à mistura espacial 
(spatial-averaging), face ao modo de vida mais exposto à ação dos distúrbios físicos de fundo (e.g., correntes tracionais);

8) Todas as espécies examinadas eram suspensívoras, possuindo, no caso das espécies escavadoras, sifões curtos (e.g., Plesiocyprinella carinata) ou longos (Roxoa intricans);

9) Pela primeira vez, no Permiano, são identificados bivalves com estruturas decorrentes do ataque de organismos predadores, durófagos de origem ainda desconhecida. Essas estruturas são representadas por orificios circulares ou ovais, preferencialmente na região mediana da valva, identificadas nas conchas das seguintes espécies: Casterella gratiosa, Plesiocyprinella gratiosa, Pinzonella illusa e Terraiopsis aequilateralis (assembléia de Pinzonella illusa);

10) A alta proporção de bivalves escavadores nas assembléias estudadas não é feição comum no Neopaleozóico. Pode ter contribuído para isso a pressão seletiva exercida por processo sedimentares (e.g., tempestades) e por predação. Evidências fornecidas por exemplos similares em mares epicontinentais do Devoniano (Grupo Halminton, Nova Iorque) e do Pleistoceno (Japão, Nova Zelandia) suportam essas conclusões;

11) A baixa proporção de bivalves da epifauna nos sedimentos das formações Serra Alta, Terezina e Corumbataí pode estar relacionada à três fatores principais: a- baixa disponibilidade de substratos grossos, estáveis favoráveis à colonização por bivalves bissados; b- alto grau de estresse ambiental, sugerido também por informações estratigráficas que caracterizam o intervalo estudado (assembléias Anhembia froesi, Pinzonella illusa e Pinzonella neotropica) e, c- as condições batimétricas predominantemente rasas reinantes durante a deposição das formações Terezina e Corumbataí, favorecendo o retrabalhamento das acumulações esqueléticas e de outros substratos ricos em material bioclástico. O constante retrabalhamento destes sedimentos dificultaria a colonização pelas formas de epifauna e semi-infauna bissadas;

12) Nenhuma concha dentre as cerca de 3000 observadas, das 25 espécies analisadas, apresenta feições morfológicas (e.g., claustrum, torção de valvas, tubérculos) ou tafonômicas (e.g., pontos de dissolução na região umbonal, injúrias restauradas) características de bivalves dulcícolas ou que estiveram expostos por prolongados períodos de tempo à água doce. Por outro lado, feições morfológicas típicas de bivalves marinhos são encontrados em várias espécies. Por exemplo, esculturas assimétricas ocorrem em Cowperesia anceps e Tambaquyra camargoi; 
ornamentação radial está presente em Ferrazia cardinalis; dentição heterodonte em Pinzonella illusa e Terraiopsis aequilateralis; lúnula foi verificada em Pinzonella illusa, Casterella gratiosa e Plesiocyprinella carinata e, por fim, concha anteriormente expandida ocorre em Runnegariella fragilis. Adicionalmente, feições bioestratinômicas (e.g., predação por durófagos) que não são conhecidas em bivalves de água doce, foram notadas nas conchas de Pinzonella illusa, Terraiopsis aequilateralis e Plesiocyprinella carinata;

13) Os dados acima permitem afirmar apenas que os bivalves das assembléias Anhembia froesi, Pinzonella illusa e Pinzonella neotropica não foram dulcícolas, não sendo possível precisar o teor de salinidade do ambiente, que deve ter sido altamente variável, segundo informações sedimentológicas, estratigráficas e micropaleontológicas;

14) Sugere-se, pela primeira vez, que Anhembia froesi e Tambaquyra camargoi, bivalves comuns nos sedimentos da Formação Serra Alta e base da Formação Corumbataí, são bons candidatos permianos a serem incluídos no rol de bivalves quimiossimbióticos. Feições anatômicas como rostrum e grande desenvolvimento corpóreo, típicos de bivalves quimosimbiontes são notáveis nessas espécies. As características estratigráficas, paleoambientais e, inclusive, de tectônica sindeposicional, constituem evidências favoráveis a esta interpretação;

15) A combinação de dados tafonômicos e paleoecológicos possibilita a interpretação de eventos sedimentares atuantes na gênese das concentrações fossilíferas. Utilizandose, como exemplo, os espécimes de Naiadopsis lamellosus preservados articulados fechados e provavelmente em posição de vida, pôde-se determinar a provável seqüência de eventos geradores desta concentração internamente complexa, representando um registro composto de eventos episódicos (tempestades, deposição de lama), posteriormente retrabalhados por correntes ou mesmo por processos associados às tempestades subsequentes. Este fato caracteriza uma retroalimentação tafonômica entre a espécie Naiadopsis lamellosus, típica de semi-infauna, e conchas de outras espécies da infauna (e.g., Pinzonella neotropica, Cowperesia anceps);

16) A mistura temporal e espacial de bioclastos é um fenômeno natural, reconhecido em acumulações esqueléticas de diferentes idades. No Permiano da Bacia do Paraná, em grande parte, como decorrência das condições predominantemente de águas rasas, as concentrações fossilíferas, mormente representadas por tempestitos proximais, apresentam alto grau de mistura temporal. Esse fato dificulta as reconstruções 
paleossinecológicas. Entretanto, análises paleoautoecológicas (morfologia funcional) e bioestratinômicas prévias, de alta resolução, abrem uma nova perspectivas para trabalhos futuros. Propõe-se, para isso, como passo inicial, um protocolo com sete etapas distintas, possibilitando a verificação mais acurada de hipóteses paleossinecológicas. 


\section{BIBLIOGRAFIA}




\section{BIBLIOGRAFIA}

ALEXANDER, R. R. (1993) Correlation of shape and habit with sediment grain size for selected species of the bivalve Anadara. Lethaia, 26: 153-162.

ALLMON, R. A. (1985) "Butterflied" bivalves as paleoenvironmental indicators. In: GEOLOGICAL SOCIETY OF AMERICA. Abstracts with Program, 17: p. 512.

AMORIN, D.S. (1997) Elementos Básicos de Sistemática Filogenética. Segunda Edição. Editora Holos e Sociedade Brasileira de Entomologia, Ribeirão Preto, SP, 276p.

ANELLI, L. E. (1994) Pelecipodes da Formação Piaui (Pensilvaniano Médio), Bacia do Parnaíba, Brasil. Universidade de São Paulo, São Paulo, SP (Dissertação de Mestrado- Instituto de Geociências, inédita), $148 \mathrm{p}$.

ANELLI, L. E.; SIMÕES, M. G. \& ROCHA-CAMPOS, A. C. (1995) Life Mode of Some Brazilian Late Paleozoic Anomalodesmata. In: X Canadian Paleontology Conference and International Symposium on the Paleobiology and Evolution of the Bivalvia, Drumbeller, Alberta. Program and Abstracts, 5, p.2.

ANELLI, L.E.; SIMÕES, M.G. \& ROCHA-CAMPOS, A.C. (1998) Life mode of some brazilian Upper Paleozoic Anomalodesmatans. In: P.A. JOHNSTON \& J.W. HAGGART (eds.) Bivalves-An Eon of evolution-paleobiological studies honoring Norman D. Newell, University of Calgary Press, pp. 69-74.

ANSELL, A. D. \& TRUEMAN, E. R. (1967) Observations on burrowing in Glycymeris glycymeris (L.)

(Bivalvia, Arcacea). J. exp. mar. Biol. Ecol., 1: 65-75.

BAMBACH, R.K. (1971). Adaptations in Grammysia obliqua. Lethaia, 4:169-183.

BASSETT, M. G. \& LAWSON, J. D. (eds.) (1984) Autoecology of Silurian organisms. Spec. Pap. Palaeontol., 32. 295p.

BEAUCHAMP, B.; KROUSE, H. R.; HARRISON, J. C.; NASSICHUK, W. W. \& ELUIK, L. S. (1989) Cretaceous cold-seep communities and methane-derived carbonates in the Canadian Arctic. Science, 244: 53-56

BEURLEN, K. (1954) Horizontes fossilíferos das Camadas Serra Alta do Paraná. Bol. DGM-DNPM, 152: 130.

BEURLEN, K. (1957a) Faunas salobras fósseis e o tipo ecológico-paleogeográfico das faunas Gondwânicas no Brasil. An. Acad. Bras. Ci., 29 (2): 229-241.

BEURLEN, K. (1957b) Um lamelibrânquio do Folhelho Irati de São Mateus do Sul, Estado do Paraná. DGMDNPM, notas preliminares e estudos, 98: 1-5.

BRANDSHAW, M.A. \& McCARTAN, L. (1991) Palaeoecology and systematics of Early Devonian bivalves from the Horlick Formation, Ohio Range, Antartica. Alcheringa, 15:1-42.

BRENCHLEY, P. J. \& HARPER, D. A. T. (1998) Palaeoecology: ecosystems, environments and evolution. Chapmann Stiall, 402p.

BRETT, C. E. \& BAIRD, G. C. (1986) Comparative taphonomy: a key to paleoenvironmental interpretation based on fossil preservation. Palaios, 4: 303-309.

BRETT, C.E. \& TAYLOR, W.L. (1997) The Homocrinus beds: Silurian Crinoid Lagerstätten of Western New York and Southern Ontario. In: BRETT, C.E. \& BAIRD, G.C. (eds.) Paleontological Events: 
stratigraphic, ecological, and evolutionary implications. Columbia University Press, New York, pp. 181223.

BRETT, C. E.; BOUCOT, A. J.; JONES, B. (1993) Absolute depths on Silurian benthic assemblages. Lethaia, 26: $25-40$.

CARTER, R. M. (1967a) On Lison's model of bivalve shell form, and its biological interpretations. Proc. Malac. Soc. Lond, 37: 265-278.

CARTER, R. M. (1967b) The shell ornament of Hysteroconcha and Hecuba (bivalvia): a test case for inferential functional morphology. Veliger, 10(1): 59-71.

CARTER, R. M. (1968) On the biology and paleontology of some predators of bivalved Mollusca. Palaeogeogr., Palaeoclimatol., Palaeoecol, 4: 29-65.

CAVANAUGH,C. M. (1983) Symbiotic chemoautotrophic bacteria in marine invertebrates from sulphide-rich habitats. Nature, 302: 58-61.

DALPONTE, J. C. \& GONÇALVES, N. M. M. (1979) Contribuição ao estudo da Formação Estrada Nova (P) na região de Tambaú, SP. Ci Cult, 31(7): 759-771.

DAVIES, D. J.; POWELL, E. N. \& STANTON, R. J. (1989) Taphonomic signature as a function of environmental process: shells and shell beds in a hurricane-influenced inlet on the Texas coast. Palaeogeogr., Palaeoclimatol., Palaeoecol, 72: 317-356.

DAVIS, J. D. (1925) Quantitative studies on the fauna of the sea bottom, $\mathrm{n}^{\circ} 2$. Southern north Sea: great Britain Fish. Invest., 8 (11): 1-50.

DODD, J. R. \& STANTON, R. J., JR. (1981) Paleoecology concepts and applications. Willey, New York, $502 \mathrm{p}$

DUFF, K. L. (1975) Paleoecology of betuminous shale: the Lower Oxford Clay of central England. Paleontology, 18: 443-482.

DUTRA, M. F. A. (1997) Tempo e Modo de Evolução dos Pelecípodes do Grupo Passa Dois (Permiano Superior), da Bacia do Paraná, Brasil. Universidade Estadual Paulista, Botucatu, SP (Dissetação de Graduação-Instituto de Biociências), $85 \mathrm{p}$.

DUDLEMEYER, P. (1968) Some methodology problems in a holistic approach to functional morphology. Acta Biotheoretica, 18: 203-214.

ELDER, W.P. (1989) Molluscan extinction patterns across the Cenomanian - Turonian Stage boundary in the western interior of the United States. Paleobiology, 15(3):299-320.

FARRo, A. P. C. (1998) Análise Tafonômica e Paleoecológica das "camadas Allorisma" da Formação Rio do Sul, Subgrupo Itararé: um Lagerstätten do Permiano Inferior,Bacia do Paraná, Brasil. Universidade Estadual Paulista, Botucatu, SP (Dissetação de Graduação-Instituto de Biociências), 59p.

FEIGE, A. \& FÜRSICH, F. T. (1991) Taphonomy of the Recent molluscs of Bahia la Choya (Gulf of California, Sonora, Mexico). Zitteliana, 18: 89-133.

FELBECK, H. (1983) Sulfide oxidation and carbon fixation by the gutless clam Solemya reidian animalbacteria symbiosis. Journal of Comparative Physiology, 152:3-11.

FELBECK, H.; CHILDRESS, J. J. \& SOMERO, G. N. (1981) Calvin-Benson cycle and sulphide oxidation enzymes in animals from sulphide-rich habitats. Nature, 293: 291-293. 
FISHER, D. C. (1985) Evolutionary morphology: beyond the analogous, the anectodal, and the ad hoc. Paleobiology, 11(1): 120-138.

FLESSA, K. W. \& KOWALEWSKI, M. (1994) Shell survival and time-averaging in nearshore andshellfenvironments: estimates from the radiocarbon literature. Lethaia, 27: 153-165.

FLESSA, K. W.; CUTLER, A. H. \& MELDAHL, K. (1993) Time and taphonomy: Quantitative estimates of time-averaging and stratigraphic disorder in a shallow marine habitat: Paleobiology, 19: 266-286.

FREY, R. W. \& PEMBERTON, S. G. (1984) Trace fossil models. In: WALKER, R. (ed.) Facies model, Second edition, Reprint Series 1, pp. 189-208.

FÜRSICH, F.T. (1976) Fauna-substrate relationships in the Corallian of England: Lethaia, 9: 343-356.

FÜRSICH, F. T. (1977) Corallian (Upper Jurassic) marine benthic associations from England and Normandy. Paleontology, 20: 337-385.

FÜRSICH, F.T. (1980) Preserved life position of some Jurassic bivalves. Paläont. Z., 54: 289-300.

FÜRSICH, F. T. (1982) Rhytmic bedding and shell bed formation in the Upper Jurassic of East Greenland. In: EINSELE, G \& SEILACHER, A. (eds.) Cyclic and Event Stratification. Springer, Berlim, pp. 208-222.

FÜRSICH, F. T. (1994) Paleoecology and evolution of Mesozoic salinity controlled benthic macroinvertebrade associations. Lethaia, 26: 327-346.

FÜRSICH, F. T. \& ABERHAN, M. (1990) Significance of time-averaging for paleocommunity analysis. Lethaia, 23:143-152.

FÜRSICH, F. T. \& FLESSA, K. (1987) Taphonomy of tidal flat molluses in the northern Gulf of California: Paleoenvironmental analysis despite the perils of preservation. Palaios, 2: 543-559.

FÜRSICH, F. T. \& OSCHMANN, W. (1986) Storm shell beds of Nanogyra virgula in the upper Jurassic of France. N. Jahrbuch f. Geologie v. Paläontologie, Abhardlungen, 182: 141-161.

FÜRSICH, F. T. \& OSCHMANN, W. (1993) Storm shell beds as tools in basin analysis: the Jurassic of Kachchh, western India. J. Geol. Soc. Lond, 150: 169-185.

FÜRSICH, F. T. \& WERNER, W. (1984) Benthic associations and their environmental significance in the Lusitanian Basin (Upper Jurassic, Portugal). N. Jahrbuch f. Geologie v. Paläontologie, Abhardlungen., 172: 271-329.

FÜRSICH, F. T. ; OSCHMANN, W.; JAITLY, A. K. \& SINGH, I. B. (1991) Faunal response to transgressiveregressive cycles: example from the Jurassic of western India. Palaeogeogr., Palaeoclimatol., Palaeoecol., 85: 149-159.

GAILARD, C. \& ROLIM, Y. (1986) Paléobiocoenoses susceptibles d'être liées à des sources sous-marine en milieu sédimentaire. L'example des Terres Noires (SE France) et des tepee buttes de la Pierra Shale Formation (Colorado, USA). Comp. Rend. Acad. Sci., ser II, 303: 1503-1508.

GHILARDI, R. P. (1995) Paleoautoecologia dos pelecípodes da assembléia de Pinzonella illusa Reed (Permiano Superior), Bacia do Paraná, Brasil. Universidade Estadual Paulista, Botucatu, SP (Dissertação de Graduação-Instituto de Biociências), 52p.

GHILARDI, R. P. (1996) Paleoautoecologia dos pelecípodes da assembléia de Pinzonella illusa Reed, Formação Corumbataí (Permiano Superior), Bacia do Paraná, Brasil. In: II WORKSHOP CIENTÍfICO 
DE PÓS-GRADUAÇÃO DO INSTITUTO DE GEOCIÊNCIAS-USP, São Paulo, Resumos do II Workshop..., p. 36 .

GHILARDI, R.P. \& SIMÕES, M.G. (1997) Muscle scars of a few Permian bivalves (Serra Alta Formation), Paraná Basin. An. Acad. Bras. Ci., 69(2): 279.

GHILARDI, R.P.; TORELLO, F.F.; MELLO, L.H.C. \& SIMÕES, M.G. (1995) O significado paleoecológico de Naiadopsis lamellosus Mendes, Formação Corumbataí (Neopermiano), Bacia do Paraná, Brasil. In: X CONGRESSO DE INICIAÇÃO CIENTÍFICA DA UNESP, Guaratinguetá, Resumos do Congresso..., p 53.

GHILARDI, R.P.; SIMÕES, M.G.; MELLO, L.H.C. \& TORELLO, F.F. (1997) The oldest occurrence of pelecypods shells in Corumbatá Formation (Late Permian), Paraná Basin, Brazil. In: XV CONGRESSO BRASILEIRO DE PALEONTOLOGIA, São Pedro, Boletim de Resumos..., p.64.

GOULD, S. J. \& VBRA, E. S. (1982) Exaptation- a missing term in science of form. Paleobiology, 8(1): 4-15.

GRANT, R. E. (1972) The lophophore anf feeding mechanism of the Productidina (Brachiopoda). $J$. Paleontol, 46: 213-249.

GRAY, J. (1988) Evolution of the freshwater ecosystem: the fossil record. Palaeogeogr., Palaeoclimatol., Palaeoecol., 62: 1-214.

GROSSMAN, E. L. (1993) Evidence that inoceramid were benthic and harbored chemosynthetic symbionts: comments and reply. Geology, 2: 94-95.

HALLAM, A. (1976) Stratigraphic distribution and ecology of European jurassic bivalves. Lethaia, 9: 245-259.

HEIKOOP, J. M.; TSUJTA, C. J.; HEIKOOP, C. E.; RISK, M. J. \& DICKIN, A. P. (1997) Effects of volcanic ashfall in ancient marine benthic communities: comparasion of a nearshore and offshore environment. Lethaia, 29: 125-139.

HERBST, R.; MORTON, L. S. \& FERRANDO, L. A. (1987) Los pelecipodos dulceacuicolas del Permico Superior del Paraguay y Uruguay. Rev. Ass. Ci. Nat. Lit., 18 (2): 105-228.

HOLME, N. A. (1961) Notes on the mode of life of the Tellinidae (Lamellibranchia). Marine Biol. Assoc. UK Jour., 41: 699-703.

HOLZ, M. (1997) Early Permian sequence stratigraphy and paleophisiology of the Paraná Basin in northeastern Rio Grande do Sul State, Brazil. An. Acad. Bras. Ci., 65: 521-543.

HOLZ, M. (1998) The Eo-Permian coal seansoft the Paraná Basin in the southernmost Brazil: an analysis of the depositional conditions using sequence stratigraphy concepts. Int. J. Coal Geol., 36: 141-163.

IPT (1981) Mapa geológico do Estado de São Paulo. Instituto de Pesquisas Tecnológicas do Estado de São Paulo.

JOHNSTON, P. J. (1993) Lower Devonian Pelecypoda from southeastern Australia. Mem. Assoc. Austral. Palaeontol., 14, 134p.

JOHNSTON, P. \& COLLON, C. G. (1998) The bivalve heresis- Inoceramidae are Cryptodonta not Pteriomorpha. In: P.A. JOHNSTON \& J.W. HAGGART (eds.) Bivalves-An Eon of evolutionpaleobiological studies honoring Norman D. Newell, University of Calgary Press, pp. 347-360.

JOHNSTON, P. \& ZHANG, R. (1998) Re-interpretation of Sinodora Pojeta and Zhang, 1984, an unusual bivalve (Trigonioida) from Devoniam of China. In: P.A. JOHNSTON \& J.W. HAGGART (eds.) 
Bivalves-An Eon of evolution- paleobiological studies honoring Norman D. Newell, University of Calgary Press, pp. 361-375.

KAUFFMAN, E. G. (1969) Form, function, and evolution. In R. C. MOORE (ed.) Treatise on Invertebrate Paleontology, Part N, Mollusca 6. Geol. Soc. Amer. and Univ. Kansas Press, pp. N120-N205

KAUFFMAN, E.G. (1975) The value of benthic Bivalvia in Cretaceous biostratigraphy of the Western Interior. In: CADWELL, W. G. E. (ed.) The Cretaceous system in the western Interior of North America- Selected aspects. Geological association of Canada, special Paper 13.

KAUFFMAN, E.G. (1977) Evolutionary rates and biostratigraphic potential of marine benthos: In: E.G. KAUFFMAN \& J.E. HAZEL (eds.) Concepts and methods of biostratigraphy. Dowden, Hutchinson \& Ross, Inc., pp.65-72.

KAUFFMAN, E. G. (1988) The case of the missing community: low-oxigen adapted Paleozoic and Mesozoic bivalves ("flat clams") and bacterial symbiosis in typical Phanerozoic seas. In: GEOLOGICAL SOCIETY AMERICAN MEETING. Abstracts and Programs, A48.

KIDWELL, S.M. (1991) The stratigraphic condensation of marine transgressive records: origin of major shell deposits in Miocene of Maryland. J. Geol., 97(1):1-24.

KIDWELL, S. M. \& AIGNER, T. (1985) Sedimentary dynamics of complex shell beds: implications for ecological and evolutionary patterns. In: BAYER, U. \& SEILACHER, A. (eds.) Sedimentary and evolutionary cycles. Springer-Verlag, Berlim, pp. 382- 395.

KIDWELL, S. M. \& BOSENCE, D. W. (1991) Taphonomy and time-averaging of marine shelly faunas. In: ALLISON, P. A. \& BRIGGS, D. E. G. (eds.) Taphonomy: releasing the data locked in the fossil record, Press, pp 115-209.

KIDWELL, S. M. \& BRENCHLEY, P. J. (1994) Patterns in bioclastic accumulation through the Fanerozoic changes in input or in destruction? Geology, 22: 1139-1143.

KIDWELL, S. M. \& BRENCHLEY, P. J. (1996) Evolution of the fossil record: thickness trends in marine skeletal accumulations and their implications. In: JABLONSKY, D. H.; ERWIN, D. H.; LIPPIS, J. H. \& BRENCLEY, P. J. (eds.) Evolutionary Paleobiology. University of Chicago Press, pp. 290-336.

KIDWELL, S. M. \& JABLONSKI, D. (1983) Taphonomic feedback ecological consequences of shell accumulation. In: TEVESZ, J. S. \& MCCALL, P. L. (eds.) Biotic interactions in Recent and fossil benthic communities. Plenum Press, New York and London.

KIDWELL, S. M. \& HOLLAND, S. M. (1991) Field description of coarse bioclastic fabrics. Palaios, 6: 426434.

KIDWELL, S.M.; FÜRSICH, F. T. \& AIGNER, T. (1986) Conceptual framework for the analysis of fossil concentrations. Palaios, 1: 228-238.

KITCHING, I. J. (1992) The distinction of character polarity. In: FOREY, P. L.; HUMPHRIES, C. J.; SCOTLAND, R. W.; SIEBERT, D. J. \& WILLIAMS, D. M. (eds.) Cladistics a practical course in systematics. Oxford, Chaendon Press, pp. 22-43.

KLEIN, C. (1997) Contribuição ao estudo das concentrações fossiliferas do Grupo Passa Dois na região de Tiarajú, RS e suas implicações paleoambientais. Universidade do Vale do Rio Sinos, São Leopoldo, RS (Dissertação de Mestrado-Centro de Ciências Tecnológicas, inédita), 153p. 
KLEIN, C.; LEIPNITZ, I. I.; SIMÕES, M. G. \& NOWATZKI, C. H. (1997a) Concentrações fossiliferas de pelecípodes da Formação Terezina (Permiano Superior), Bacia do Paraná, na região de Tiarajú, RS, Brasil.. In: XV CONGRESSO BRASILEIRO DE PALEONTOLOGIA, São Pedro, Boletim de Resumos..., p.69.

KLEIN, C.; SIMÕES, M. G.; LEIPNITZ, I. I. \& RICHTER, M. (1997b) Interpretação dos dados tafonômicos na deposição de peixes e pelecípodes da Formação Terezina (Grupo Passa Dois), na região de Tiarajú, RS. In: XV CONGRESSO BRASILEIRO DE PALEONTOLOGIA, São Pedro, Boletim de Resumos..., p.166.

KONDO, Y. (1987) Burrowing depth of infaunal bivalves of living species and its relation to shell morphology. Trans. Proc. Palaeont. Soc. Jpn, 148: 306-323.

KONDO, Y. (1989) "In situ" observation of a bathyal bivalve Limopsis tajimae by means of box core sampling, with comparative description of the fossil counterparts. Venus, 48 (1): 27-39.

KONDO, Y. (1990) Preserved life orientations of soft-bottom infaunal bivalves: documentation of some Quaternary forms from Chiba, Japan. Nat. Hist. Res., 1: 31-42.

KONDO, Y. (1997) Inferred bivalve response to rapid burial in a Pleistocene shallow-marine deposit from New Zealand. Palaeogeogr., Palaeoclimatol, Palaeoecol, 128: 87-100.

KONDO, Y. (1998) Adaptative strategies of suspension feeding, soft-bottom infaunal bivalves to physical disturbance: evidence from fossil preservation. In: P.A. JOHNSTON \& J.W. HAGGART (eds.) Bivalves-An Eon of evolution- paleobiological studies honoring Norman D. Newell, University of Calgary Press, pp. 377-391.

KONDO, Y. \& KIKUCHI, N. (1995) "Shelly softground" colonized by an endobyssate bivalve Modiulus kurulensis: an example of taphonomic feedback from the Pleistocene of Kanazawa, Japan. Trans. Proc. of Paleontol. Soc. Jpn, New Series, 180: 290-302.

KONDO, Y. \& STACE, K. (1995) Burrowing ability and life position of Toheroa (Paphies ventricosa: Mesodesmatidae), a unusually large, deep-burrowing ocean beach Bivalve endemic to New Zealand. Venus, 54 (1): 67-76.

KOTZIAN, C. B. (1995) Estudo Sistemático e Morfo-funcional de bivalves (Mollusca) das formações Vila Maria (Siluriano) e Ponta Grossa (Devoniano), Bacia do Paraná, Brasil: interpretação do regime hidrodinâmiconsedimetar. Universidade Federal do Rio Grande do Sul, Porto Alegre, RS (Tese de Doutoramento- Instituto de Geociências, inédita), 377p + XIX estampas.

KOWALEWSKI, M. (1996) Time-averaging, overcompleteness, and the geological record. J. Geol., 104: 317 326.

KOWALEWSKI, M. (1997) The reciprocal taphonomic model. Lethaia, 30: 86-88.

KOWALEWSKI, M. \& BAMBACH, R.K. (1998) Phanerozoic history of drilling predation and marine ecological revolutions. In: GEOLOGICAL SOCIETY OF AMERICA ANNUAL MEETING, Toronto, Abstracts and Programs, 30(7):A-41.

KOWALEWSKI, M; FLESSA, K. W. \& AGGEN, J. A. (1994) Taphofacies analysis of Recent shelly cheniers (beach ridges), northeastern Baja California, Mexico. Facies 31: 209-242.

KOWALEWSKI, M.; FLESSA, K. W. \& HALLMANN, D. P. (1995) Ternary taphograms: Triangular diagrams applied to taphonomic analysis. Palaios, 10:478-483. 
KOWALEWSKI, M; GOODFRIEND, G. A. \& FLESSA, K. W. (1998) High-resolution estimates of temporal mixing within shell beds: the evils and virtues of time-averaging. Paleobiology, 24: 287304.

KOWALEWSKI, M.; SIMÕES, M. G.; TORELLO, F. F.; MELLO, L. H. C. \& GHILARDI, R. P. (no prelo) Drilling Predation in the Permian. J. Paleontol.

KRANZ, P. M. (1974) Computer simulation of fossil assemblage formation undr conditions of anastrophic burial. J. Paleontol., 48: 800-808.

KRIZ, J. (1984) Autoecology and ecogeny of Silurian Bivalvia. In: BASSETT, M. G. \& LAWSON, J. D. (eds.) Autoecology of Silurian organisms. Spec. Pap. Palaeontol., 32: 183-196.

LANDIM, P. M. B. (1970) O Grupo Passa Dois (P) na Bacia do Rio Corumbataí. Bol. DGM-DNPM, 252: $1-103$.

LAVINA, E. L. (1991) Geologia sedimentar e paleogeorgafia do Neopermiano e Eotriássico (Intervalo Kazaniano-Scythiano) da Bacia do Paraná. Universidade Federal do Rio Grande do Sul, Porto Alegre, RS (Tese de Doutoramento-Instituto de Geociências), 333p.

LAVINA, E. L.; ARAÚJO-BARBERENA, D. C. \& AZEVEDO, S. A. K. (1991) Tempestades de inverno e altas taxas de mortalidade de répteis Mesossauros. Um exemplo a partir do afloramento Passo São Borja, RS. Pesquisas, 18 (1): 64-70.

LEVINTON, J. S. (1984) Understanding the autecology of extinct organisms. In: BASSETT, M. G. \& LAWSON, J. D. (eds.) Autoecology of Silurian organisms. Spec. Pap. Palaeontol, 32: 17-26.

LEVINTON J. S. (1991) Variable feeding behaviour in three species of Macoma (Bivalvia: Tellinacea) as a response to water flow and sediment transport. Mar. Biol., 110:375-383.

LILJEDAHL, L. (1985) Ecological aspects of a silicified bivalve fauna from the Silurian of Gotland. Lethaia, 18: 53-60.

LILJEDAHL, L. (1994) Silurian nuculoid and modiomorphid bivalves from Sweden. Fossils and Strata, 33: 1-89.

LIMA, A. P. (1997) Tafonomia comparada dos trilobitas Calmoniideos e Homalonotideos, da Formação Ponta Grossa (Devoniano), região de jaguariaiva, PR: implicaçòes paleobiológicas $e$ paleoecológicas. Universidade Estadual Paulista, Botucatu, SP (Dissetação de GraduaçãoInstituto de Biociências), 46p.

LIMA, A. P. \& SIMÕES, M. G. (1998) Comparative taphonomy of Calmoniid and Homalonotiid trilobites from Ponta Grossa Formation (Devonian), Jaguariaíva Member, Paraná Basin, Brazil: Paleobiological and paleoecological implications. In: XL CONGRESSO BRASILEIRO DE GEOLOGIA, Belo Horizonte, Anais..., p.445.

MACLEOD, K. G. \& HOPPE, K. A. (1992) Evidence that inoceramid bivalves were benthic and hardbored chemosynthetic symbionts. Geology, 20:117-120.

MARANHÃO, M. S. A. S. (1986) Contribuição ao conhecimento da malacofauna das camadas basais da Formação Corumbatai (Permiano) Estado de São Paulo. Universidade de São Paulo, São Paulo, SP (Dissertação de Mestrado-Instituto de Geociências, inédita), 89p. 
MARANHÃO, M.S.A.S. (1995) Fósseis das formações Corumbatai e Estrada Nova do Estado de São Paulo: subsídios ao conhecimento paleontológico e bioestratigráfico. Universidade de São Paulo, São Paulo, SP (Tese-Doutorado-Instituto de Geociências, inédita), 2v.

MARSH, L. F. (1984) Mode of live and autoecology of Silurian-Devoniam Grammysiidae (Bivalvia). Paleontology, 27(4): 679-691.

MATOS, S. L. F. (1995) O contato entre o Grupo Passa Dois e a Formação Pirambóia na borda leste da Bacia do Paraná no Estado de Sáo Paulo. Universidade de São Paulo, São Paulo, SP (Dissertação de Mestrado-Instituto de Geociências, inédita), 120p.

MCALESTER, A. L. \& RHOADS, D. C. (1967) Bivalves as Bathymetric Indicators. Mar. Geol., 5: 383-388.

MC GHEE, G. (1978) Analysis of the shell torsion phenomenan in the bivalvia. Lethaia, 11:315-329.

MELlo, L. H. C. (1999) Análise Cládistica dos Bivalves do Grupo Passa Dois (Neopermiano), Bacia do Paraná, Brasil: implicações taxonômicas, evolutivas e paleobiogeográficas. Universidade de São Paulo, São Paulo, SP (Dissertação de Mestrado- Instituto de Geociências, inédita), 160p.

MELLO, L.H.C.; GHILARDI, R.P. \& TORELLO, F.F. (1998a) Some biostratinomic aspects of carbonate concretions from Serra Alta Formation (Late Permian), Paraná Basin, Brazil. In: XL CONGRESSO BRASILEIRO DE GEOLOGIA, Belo Horizonte, Anais..., p.452.

MELLO, L. H. C.; MARQUES, A. C.; GHILARDI, R. P. \& SIMÕES, M. G. (1998b) Taxonomic position of the permian genera Anhembia and Leinzia and the phylogenetic consistency of the extinct family Megadesmidae (Bivalvia, Anomalodesmata) In: XVII MEETING OF THE WILLI HENNIG SOCIETY, São Paulo, Program and Abstracts, p. 43.

MENDES, J.C. (1944) Lamelibrânquios triássicos de Rio Claro (Estado de São Paulo). Bol. Fac. Fil. Ciên. Let., 50, Geologia, 2:27-34, São Paulo.

MENDES, J.C. (1952) A Formação Corumbataí na região do Rio Corumbataí (estratigrafia e descrição dos lamelibrânquios). Bol. Fac. Fil. Ciên. Let., 145, Geologia, 8:1-119.

MENDES, J. C. (1962) Lamelibrânquios permianos do oólito de Angatuba, Estado de São Paulo; Formação Corumbataí. Bol. Soc. Bras. Geol., 11 (1): 37-56.

MENDES, J. C. (1963) Novos aspectos da estratigrafia das camadas eogondâwanicas da Bacia do Paraná. Eng. Min. Met., 38 (226): 189-192.

MENDES, J.C. (1967) The Passa Dois Group (the Brazilian portion of the Parana Basin). In: J.J. BIGARELA, R.D. BECKER, \& I.D. PINTO (eds.), Problems in Brazilian Gondwana Geology: Universidade Federal do Paraná, Instituto de Geologia, Curitiba, pp. 119-166.

MENDES, J. C. (1988) Paleontologia Básica. T. A. QUEIROZ (ed.). Editora da Universidade de São Paulo. São Paulo, SP, Brasil. 347 p.

MEZZALIRA, S. (1957) Ocorrências fossiliferas novas da Séria Passa Dois na região de Limeira-Rio ClaroPiracicaba. Bol. Soc. Bras. Geol., 43:1-41.

MILLER, K. B.; BRETT, C. E. \& PARSONS, K. M. (1988) The paleoecological significance of storm generated disturbance within a Middle Devonian epeiric sea. Palaios, 3: 35-52.

NAIR, N. B. \& ANSELL, A. (1968) Characteristics of penetration of the substratum by some marine bivalve molluscs. Proc. Malac. Soc. Lond., 38: 179-197. 
NEWELL, N. D.; IMBRIE, J.; PURDY, E. G. \& THURBEN, D. L. (1959) Organisms, communities and bottom facies, Great Bahama Bank. Bull. Am. Nat. Hist., 117: 177-228.

NOBUHARA, T. \& TANAKA, T. (1993) Paleoecology of Akebiconcha kawamurai (Bivalvia: Vesicomyidae) from Pliocene Tamari Silt Formation in the Kakegawa area, central Japan. Palaeogeogr., Palaeoclimatol., Palaeoecol., 102: 27-40.

ÓLAFSSON, E. B. (1986) Density dependence in suspension-feeding and deposit-feeding populations of the bivalve Macoma balthica: a field experiment. J. An. Ecol., 55: 517-526.

PAUL, C. R. (1975) A reappraisal of the paradigm method of functional analysis in fossils. Lethaia, 8: 15-21.

PICKERILL, R. K. \& BRENCHLEY, P. J. (1991) Paleoscene 12: benthic macrofossils as paleoenvironmental indicators in marine siliciclastic facies. Geosc. Can., 18: 119-138.

PURDY, E. G. (1964) Sediments as substrates. In: NEWELL, N. (ed.) Approaches to Palaeoecology, John Imbrie. John Wiley and Sons, Inc., New York. 340p.

RAGONHA, E. W. (1980) Características físicas da zona de Pinzonella illusa e Plesiocyprinella carinata da Formação Corumbataí- Grupo Passa Dois, na região de Rio Claro (SP). In: XXI CONGRESSO BRASILEIRO DE GEOLOGIA, Camboriú, SC, Anais..., pp. 3106-3117.

RAGONHA, E. W. (1984) Taxionomia de dentes e espinhos de Xenacanthodii (Chondrichtyes, Elasmobranchii) da Formação Corumbataí. Considerações cronológicas e paleoambientais. Universidade de São Paulo, São Paulo, SP (Tese de Doutoramento-Instituto de Geociências), 166p.

RAUP, D. M. (1972) Approaches to morphologic analysis. In: SCHOPF, T. J. M. (ed.) Models in Paleobiology. Freeman Cooper, San Francisco, USA. pp. 28-45.

REID, R.G.B. \& BERNARD, D.G. (1980) Gutless bivalves. Science, 208:609-610.

REID, R. G. B. \& BRAND, D. G. (1986) Sulfide-Oxidizing symbiosis in Lucinaceans: implications for bivalve evolution. Veliger, 29(1): 3-24.

REID, R. G. B. \& REID, A. (1969) Feeding process of members of the genus Macoma (Mollusca: Bivalvia). Can. J. Zool., 47: 649-657.

REIF, W. E-. (1983) Functional morphology and evolutionary ecology. Paläont. Z., 57(3/4): 255-266.

REIF, W. E-.; THOMAS, R. D. K. \& FISCHER, M. S. (1985) Constructional morphology: the analysis of constraints in evolution. Acta Biotheoretica, 34: 233-248.

RICCOMINI, C. (1995) Tectonismo gerador e formador dos depósitos sedimentares pós-gondvânicos da porção centro-leste do Estado de São Paulo e áreas vizinhas. Universidade de São Paulo, São Paulo, SP (Tese de Livre-Docência- Instituto de Geociências, inédita), 100p

ROCHA-CAMPOS, A.C. (1968) Representantes dos Pholadomyidae (Bivalvia) aparentemente preservados em posição de vida em sedimentos do Paleozóico Superior do Brasil. Ci. Cult., 20 (2): 160.

ROCHA-CAMPOS, A.C. (1969) Moluscos e braquiópodes Eogondvânicos do Brasil e Argentina. Universidade de São Paulo, São Paulo, SP (Tese de Livre-Docência- Intituto de Geociências), 158p.

ROCHA-CAMPOS, A.C. \& SIMÕES, M.G. (1993) Australomya sinuosa sp.n., um novo megadesmídeo (Mollusca, Pelecypoda) da Formação Rio Bonito (Permiano), Bacia do Paraná, Brasil. An. Acad. Bras. Ci., 65(1):29-39. 
ROCHA-CAMPOS, A. C.; SIMÕES, M. G. \& MATOS, S. L. F. (1990) Uma nova assembléia de bivalves silicificados, na parte superior da Formação Teresina (Neopermiano), Estado de São Paulo. In: XXXVI CONGRESSO BRASILEIRO DE GEOLOGIA, Natal, Boletim de Resumos..., p. 30.

ROHN, R. (1988) Bioestratigrafia e paleoambientes da Formação Rio do Rasto na borda leste da Bacia do Paraná (Permiano Superior, Estado do Paraná). Universidade de São Paulo, São Paulo, SP (Dissertação de Mestrado- Instituto de Geociências), 2v.

ROHN, R (1994) Evolução ambiental da Bacia do Paraná durante o Neopermiano no leste de Santa Catarina e do Paraná. Universidade de São Paulo, São Paulo, SP (Tese de Doutoramento-Instituto de Geociências), $2 \mathrm{v}$.

ROHN, R.; PERINOTO, J. A. J.; FÚlFARO, V. J.; SAAD, A. R. \& SIMÕES, M. G. (1995) On the significance of the Pinzonella neotropica assemblage (Upper Permian) for the Parana Basin-Brazil and Paraguay. In: XI SIMPÓSIO SUL-BRASILEIRO DE GEOLOGIA- I ENCONTRO DE GEOLOGIA DO CONE SUL, Porto Alegre, SBG, Boletim de Resumos Expandidos..., pp.260-261.

ROOPNARINE, P. D. (1996) Systematics, biogeography and extinction of Chionine bivalves (Bivalvia: Veneridae) in tropical america: Early Oligocene-Recent. Malacologia, 38 (1-2): 103-142.

RÖSLER, O. (1986) Fósseis In: Manual de Coleta de Amostras em Geociências, Bol. Núcleo SP/SBG, 2: 1521.

RUDWICK, M. J. S. (1961) The feeding mechanism of the Permian Brachiopod Prorichtofenia. Paleontology, 3: 450-471.

RUDWICK, M. J. S. (1964a) The inference of function from structure in fossils. British Philos. Sci. Jour., 15: $27-40$.

RUDWICK, M. J. S. (1964b) The function of zigzag deflections in the comissures of fossil brachiopods. Paleontology, 7: 135-171.

RUNNEGAR, B. (1966) Systematics and biology of some desmodont bivalves from the Australian Permian. $J$. Geol. Soc. Aus., 13: 373-386.

RUNNEGAR, B. (1967) Desmodont bivalves from the Permian of eastern Australia. Bull. Bur. Min. Res., Geo. Geoph., 96:1-96.

RUNNEGAR, B. (1968) Preserved ligaments in Australian Permian bivalves. Paleontology, 11 (1): 94-103.

RUNNEGAR, B. (1974) Evolutionary history of the bivalve Subclass Anomalodesmata. J. Paleontol., 48(5):904-939.

RUNEGAR, B. (1979) Pholadomya candida Sowerby: the last cadaver anomalodesmata, The Veliger, 22 (2): 171-173.

RUNNEGAR, B. \& NEWELL, N.D. (1971) Caspian-like relict molluscan fauna in South American Permian. Bull. Am. Mus, Nat. Hist., 146: 1-66.

SANCHEZ, T. M. (1991) Functional morphology and autoecology of Silurian and Devonian nuculoid bivalves from Western Argentina. Zbl. Geol. Paläont. Teil 1, 6: 1815-1839.

SANDERS, H. L. (1956) Oceanography of Long Island Sound, 1952-1954. X. The biology of marine bottom communities. Yale Univ. Bingham Oceanogr. Collection Bull., 15: 345-413. 
SANDERS, H. L. (1958) Benthic studies in Buzzards Bay. I Animal-sediment relationships. _Limnol. and Oceanogr., 3: 245-258

SANTOS, P. R.; BORDIGNON, J. L. \& STEVEAUX, J. C. (1981) Seção Colunar Pântano Grande/Santa Cruz (BR 471/RS). IPT Relatório RT 043181,7p. São Paulo. Inédito.

SAS Institute (1989a) SAS/STAT User's Guide, Version 6, $4^{\text {th }}$ ed. Sas Institute, Cary, v. 1, 943 pp., v. 2,846 p.

SAS Institute (1989b) SAS/IML Software, version 6, $1^{\text {st }}$ ed. Sas Institute, Cary, 501p.

SAS Institute (1990) SAS ${ }^{(1)}$ Procedures Guide: Version 6, $3^{\text {rd }}$ ed., Sas Institute, Cary, 705p.

SAVAZZI, E. (1981) Barbatia mytiloides and the evolution of shell torsion in arcid pelecypods. Lethaia, 14: 143-150.

SAVAZZI, E. (1982) Shell sculpture and burrowing in the bivalves Scapharca inaequivalvis and Acanthocardia tuberculata. Stutt. Beit. Natur. Serie A (Biologie), 353: 1-12.

SAVAZZI, E. (1984a) Functional morphology and autoecology of Pseudoptera (bakevellid bivalves, Upper Cretaceous of Portugal). Palaeogeogr., Palaeoclimatol., Palaeoecol., 46: 313-324.

SAVAZZI, E. (1984b) Adaptative significance of shell torsion in mytilid bivalves. Paleontology, 27: $307-314$.

SAVAZZI, E. (1989) Shell torsion and life habit in the Recent mytilid bivalve Modiulus philippinarum. Palaeogeogr., Palaeoclimatol., Palaeoecol., 72: 277-282.

SAVAZZI, E. (1990) Shell biomechanics in the bivalve Laternula. Lethaia, 23: 93-101.

SAVAZ7I, E. \& PEIYI, Y. (1992) Some morphological adaptations in freshwater bivalves. Lethaia, 25: 195209.

SCHÄFFER, W. (1972) Ecology and paleoecology of marine environments. University of Chicago Press, Chicago, 450p.

SEILACHER, A. (1970) Arbeitskonzept zur Konstruktionsmorphologie. Lethaia, 3: 393-396.

SEILACHER, A. (1972) Divaricate patterns in pelecypod shells. Lethaia, 5 (3): 325-343.

SEILACHER, A. (1973) Fabricational noise in adaptative morphology. Sist. Zool., 27: 451-465.

SEILACHER, A. (1984) Constructional morphology of bivalves: evolutionary pathways in primary versus secondary soft-botton dwellers. Paleontology, 27 (2): 207-237.

SEILACHER, A. (1985) The Jeram model: event ondesation in a modern intertidal environment. In: FRIEDMANN, G. (ed.) Sedimentary and evolutionary cycles, Lectures Notes in Earth Sciences, 1: 336342 .

SEILACHER, A. (1990) Aberrations in bivalve evolution related to photo- and chemosymbiosis. Hist. Biol., 3: 289-311.

SEILACHER, A. (1991) Self-Organizing morphogenetic mechanisms as processors of evolution. Rev. Esp. Paleontol., $n^{\circ}$ Extraordinário, pp. 5-11.

SEILACHER, A. (1998) Rudists as Bivalvian Dinossaurs. In: P.A. JOHNSTON \& J.W. HAGGART (eds.) Bivalves-An Eon of evolution- paleobiological studies honoring Norman D. Newell, University of Calgary Press, pp. 423-436.

SIGNOR III, W. (1982) A critical re-evaluation of the paradigm method. N. Jb. Geol. Paläont. Abh., 164: 5963. 
SIMÕES, M.G. (1988) Técnicas de preparação de bivalves silicificados, com vistas ao estudo da morfologia interna. In: XV CONGRESSO BRASILEIRO DE ZOOLOGIA, Curitiba, Resumos..., p.49.

SIMÕES, M.G. (1992) Pelecípodes da Formação Palermo (Permiano) de São Sepé (RS) e Guiratinga (MT): implicaçôes na evolução da fauna neopaleozóica da Bacia do Paraná, Brasil. Universidade de São Paulo, São Paulo, SP (Tese de Doutoramento-Instituto de Geociências), 286p.

SIMÕES, M.G. (1996) Pelecypod taphofacies of Corumbataí Formation (Late Permian), in central São Paulo State, Paraná Basin, Brazil. In: XXXIX CONGRESSO BRASILEIRO DE GEOLOGIA, Salvador, Anais..., pp.298-300.

SIMÕES, M.G. (1998) Tafonomia, timenaveraging e resolução espacial de concentrações fossiliferas internamente complexas: um estudo de casos do Permiano, Bacia do Paraná- Brasil e suas implicações paleoecológicas. Universidade Estadual Paulista, Botucatu, SP (Tese de Livre - Docência- Instituto de Biociências) 160p.

SIMÕES, M. G. \& ANELLI, L. E. (1995) Runnegariella, um novo gênero de megadesmidae (Pelecypoda) da Formação Corumbataí (Neopermiano), Bacia do Paraná, Brasil. Rev. Geoci. 14 (2): 161-173.

SIMÕES, M. G. \& COSTA, P. (1992) Morfologia funcional e modo de vida de Coxesia mezzalirai Mendes (Mollusca, Pelecypoda), Formação Corumbataí (Neopermiano), Bacia do Paraná, Brasil. In: IV CONGRESSO DE INICIAÇÃO CIENTÍFICA DA UNESP, Araçatuba, Resumos..., pp.161-162.

SIMÕES, M.G. \& FITTIPALDI, F.C. (1987) Bivalves do Grupo Passa Dois, Permiano da Bacia do Paraná: sinopse das pesquisas. In: VI SIMPÓSIO REGIONAL DE GEOLOGIA, Rio Claro, Atas..., v.1, pp.281295

SIMÕES, M.G. \& FITTIPALDI, F.C. (1988) A contribuição dos bivalves permianos da Bacia do Paraná ao estudo da evolução paleogeográfica. In: XV CONGRESSO BRASILIERO DE ZOOLOGIA, Curitiba, Resumos..., p.50.

SIMÕES, M.G. \& FITIPALDI, F.C. (1992) Fósseis da região de Rio Claro, SP. Arquivo do Município, Rio Claro, $77 \mathrm{p}$.

SIMÕES, M.G. \& KOWALEWSKI, M. (1998a) Shell beds as paleoecological puzzles; a case study from the Upper Permian of the Paraná Basin, Brazil. Facies, 38: 175-196.

SIMÕES, M.G. \& KOWALEWSKI, M. (1998b) Genetic complexity and geobiological implications of "simple" shell beds: an example from the Upper Permian of the Paraná Basin, Brazil. J. Afr. Ear. Sci., 27 (1A): 179-180.

SIMÕES, M.G. \& MELLO, L.H.C (1996) Sistemática e paleocologia de Casterella gratiosa Mendes (Mollusca, Pelecypoda), Formações Terezina e Corumbataí (Permiano Superior), Bacia do Paraná, Brasil. Acta Geol. Leopol., 43(XIX):5-23.

SIMÕES, M.G. \& ROCHA-CAMPOS, A.C. (1990a) Megadesmídeos (Mollusca, Bivalvia), neopaleozóicos da Bacia do Paraná:estado do conhecimento e problemas. An. Acad. Bras. Ci., 62(4):104.

SIMÕES, M.G. \& ROCHA-CAMPOS, A.C. (1990b) Paleoecologia dos bivalves neopaleozóicos da Bacia do Paraná, Brasil. In: I JORNADAS CIENTÍFICAS DO INSTITUTO DE GEOCIÊNCIAS/USP, São Paulo, Boletim Especial..., pp.130-131. 
SIMÕES, M.G. \& ROCHA-CAMPOS, A.C. (1992) Pelecípodes neopaleozóicos da Bacia do Paraná, Brasil: perspectiva bioestratigráfica. In: XXXVII CONGRESSO BRASILEIRO DE GEOLOGIA, São Paulo, Boletim de Resumos Expandidos..., pp.500-502.

SIMÕES, M.G. \& ROCHA-CAMPOS, A.C. (1993) Systematics and paleoecology of the pelecypods of the Palermo Formation (Permian), Paraná Basin, Brazil. An. Acad. Bras. Ci., 65(3):324.

SIMÕES, M.G. \& ROCHA-CAMPOS, A.C. (1994) An autochthonous Late Paleozoic pelecypod assemblage from the Rio do Sul Formation (Permian), Paraná Basin, Brazil. In: XXXVIII CONGRESSO BRASILEIRO DE GEOLOGIA, Balneário Camboriú, Boletim de Resumos Expandidos..., pp.206-207

SIMÕES, M.G. \& ROHN, R. (1996) On the significance of a phosphatic concentration at Serra Alta Formation (Passa Dois Group, Late Permian), Paraná Basin, Brazil. In: XXXIX CONGRESSO BRASILEIRO DE GEOLOGIA, Salvador, Anais..., pp.295-297.

SIMÕES, M.G.; TORELLO, F.F. \& ROCHA-CAMPOS, A.C. (1994) Proximal storm shell beds or coquinas in the Corumbataí Formation (Pinzonella illusa assemblage; Late Permian), in Rio Claro, SP, Paraná Basin, Brazil. In: XXXVIII CONGRESSO BRASILEIRO DE GEOLOGIA, Balneário Camboriú, Boletim de Resumos Expandidos..., pp.226-227.

SIMÕES, M.G.; TORELLO, F.F. \& ROCHA-CAMPOS, A.C. (1996a) Gênese e classificação da coquina de Camaquã (assembléia de Pinzonella neotropica), Formação Corumbataí (Permiano Superior), Rio Claro, SP. An. Acad. Bras. Ci., 68(4):545-557.

SIMÕES, M.G.; TORELLO, F.F.; MELLO, L.H.C.; PASSOS, J.R.S. \& GHILARDI, R.P. (1996b) Aplicação de tafogramas ternários no estudo das assinaturas tafonômicas de concentrações fossilíferas da Formação Corumbataí (Permiano), Bacia do Paraná, Brasil. In: XXXIX Congresso Brasileiro de Geologia, Salvador, Anais..., p.301-302.

SIMÕES, M.G.; MARQUES, A.C.; MELLO, L.H.C. \& ANELLI, L.E. (1997) Philogenetic analysis of the genera of the extinct family Megadesmidae (Pelecypoda, Anomalodesmata), with remarks on its paleoecology and taxonomy. J. Comp. Biol., 2: 75-90.

SIMÕES, M. G.; KOWALEWSKI, M.; TORELLO, F. F. \& ANELLI, L. E. (1998a) Long-term time-averaging despite abrupt burial: Paleozoic obrution deposits from epeiric settings of Paraná Basin, Brazil. Geol. Soc. Am. Ann. Meet., Abstracts with Programs, p. 384.

SIMÕES, M.G.; ROCHA-CAMPOS, A.C. \& ANELLI, L.E. (1998b) Paleoecology and evolution of Permian pelecypod assemblages (Paraná Basin) from Brazil. In: JOHNSTON, P.A. \& HAGGART, J.W. (eds.) Bivalves - An Eon of evolution: paleobiological studies honoring Norman D. Newell, University of Calgary Press, Calgary, pp. 443-452.

SIMÕES, M. G.; TORELLO, F. F.; KOWALEWSKI, M.; KLEIN, C.; MELLO, L. H. C. \& GHILARDI, R. P. (1998c) Are the obrution deposits the most precise and best resolved beds inevent stratigraphy? Some Paleozoic examples from the Paraná Basin, Brazil. In: XL CONGRESSO BRASILEIRO DE GEOLOGIA, Belo Horizonte, Anais..., p. 444.

SIMÕES, M. G; KOWALEWSKI, M.; TORELLO, F. F. \& KLEIN, C. (no prelo) High resolution taphonomy of the Paleozoic obrution deposits from epeiric settings of Paraná Basin, Brasil: the paleobiological consequences and paleoecological implications of abrupt buria. Geology. 
SOHN, I. G. \& ROCHA-CAMPOS, A. C. (1990) Late Paleozoic (Gondwanan) ostracodes in the Corumbataí Formation, Paraná Basin, Brazil. J. Paleontol., 64 (1): 116-128.

SOUSA, S.H.M. (1985) Fácies sedimentares das Formações Estrada Nova e Corumbataí no Estado de São Paulo. Universidade de São Paulo, São Paulo, SP (Dissertação Mestrado- Instituto de Geociências), 142p. SOUTWARD, E. C. (1986) Gill symbionts in Thyasirids and other bivalve molluscs. J. Mar. Biol. Ass. UK, 66: 889-914.

SPEYER, S. E. (1987) Comparative taphonomy and palaecology of trilobite Lagerstätten. Alcheringa, 11 (2): 205-232.

SPEYER, S. E. \& BRETT, C. E. (1986) Trilobite taphonomy and Middle Devonian taphofacies. Palaios, 1: 312-327.

SPEYER, S. E. \& BRETT, C. E. (1991) Taphonomic controls: backgrounds and episodic process in fossil assemblage preservation. In: ALLISON, P. A . \& BRIGGS, D. E. G. (eds.) Taphonomy: releasing the data locked in the fossil record. Plenum Press, pp.501-545.

STANLEY, S. M. (1968) Post-Paleozoic adaptative radiation of infaunal bivalve molluscs- a consequence of mantle fusion and siphon formation. J. Paleontol., 42: 214-229.

STANLEY, S. M. (1969) Bivalve mollusk burrowing aided by shell ornamentation. Science, 166: 634-635.

STANLEY, S.M. (1970) Relation of shell form to life habits of the Bivalvia (Mollusca) Geol. Soc. Amer., Mem., 125: 1-296.

STANLEY, S.M. (1972) Funcional morphology and evolution of byssally attached molluscs. J. Paleontol., 46(2): 165-212.

STANLEY, S. M. (1975) Why clams have the shape they have: an experimental analysis of burrowing. Paleobiology, 1: 48-58.

STANLEY, S.M. (1977) Coadaptation in the Trigoniidae, a remarkable family of burrowing bivalves. Palaeontology, 20(4):869-899.

STANLEY, S. M. (1981) Infaunal survival: alternative functions of the shell ornamentation in the bivalvia (mollusca). Paleobiology, 7(3): 384-393.

STANLEY, S. M. (1985) Adaptative morphology of the shell in bivalves and gastropods. In: TRUEMAN, E. R. \& CLARKE, M. R. (eds.) The Mollusca, 10. Academic Press, pp 105-182.

STASEK, C. R. (1963) Geometrical form and gnomonic growth in the bivalved mollusca. J. Morphol., 112: 215-231.

STASEK, C. R. (1966) Views on the comparative anatomy of the bivalved Mollusca, Malacologia, 5: 67-68.

SUGUiO, K.; SALATI, E. \& BARCELOS, J.H. (1974) Calcários oolíticos de Taguaí (SP) e seu possível significado paleoambiental na deposição da Formação Estrada Nova: Rev. Bras. Geoci., 4: 142-166.

THOMAS, R.D.K. (1975) Functional morphology, ecology and evolutionary conservatism in the Glycymerididae (Bivalvia). Paleontology, 18(2):217-254.

THOMAS, R.D.K. (1979) Shell form and the ecological range of living and extinct Arcoida. Paleobiology, 4(2): 181-194.

THORSON, G. (1957) Bottom communities. Geol. Soc, Am. Memb., 67: 461-534. 
THORSON, G. (1966) Some factors influencing the recruitment and establishment of marine benthic communities. Neth. J. Sec. Res., 3: 267-293.

TORELLO, F. F. (1999) Análise bioestratinômica de concentrações fossiliferas da assembléia de Pinzonella neotropica (Reed), Formação Corumbataí (Permiano), região de Tambaú, nordeste do Estado de São Paulo. Universidade de São Paulo, São Paulo, SP (Dissertação de Mestrado- Instituto de Geociências), $128 \mathrm{p}$.

TORELLO, F.F. \& SIMÕES, M.G. (1994) Características tafonômicas da assembléia de Pinzonella illusa Reed, Formação Corumbataí (Neopermiano), Bacia do Paraná, Brasil. Acta Geol. Leopol., 39/1(17):159173.

TORELLO, F.F. \& SIMÕES, M.G. (1997) Concentrações fossilíferas da Formação Corumbataí (Permiano), Bacia do Paraná, na região de Tambaú, SP. In: An. Acad. Bras. Ci., 69(2):282.

TORELLO, F.F.; SIMOES, M.G. \& MELLO, L.H.C. (1997) On addition to the paleobiogeographic knowledge of the Passa Dois Group (Late Permian) pelecypods, Paraná Basin, Brazil. In: XV CONGRESSO BRASILEIRO DE PALEONTOLOGIA, São Pedro. Boletim de Resumos...,. p. 71.

TRUEMAN, E. R.; BRAND, A. R. \& DAVIS, P. (1966) The effect of substrate and shell shape on the burrowing of some common bivalves. Proc. malac. Soc. Lond., 37: 97-109.

VERMEIJ, G. J. (1977) The Mesozoic marine resolution: evidence from snails, predators and grazers. Paleobiology, 2: 245-258.

VERMEIJ, G.J. (1983) Traces and trends in predation, with special reference to bivalved animals. Palaeontology, 26:455-465.

VERMEIJ, G. J. (1987) Evolution and escalation: an ecological history of life. Princeton, N. J., Princeton University Press. 450p.

VERMEIJ, G. J. \& DUDLEY, E. C. (1985) Distribution of adaptations: a comparison between the functional shell morphology of freshwater and marine pelecypods. In: WILBUR, K. M.; TRUEMAN, E. R. \& CLARKE, M. R. (eds.) The Mollusca, 10. Academic Press, pp. 461-478.

VETTER, R.D.; POWELL, M.A. \& SOMERO, G.N. (1991) Metazoan adaptations to hydrogen sulphide. In: BRYANT, C. (ed.) Metazoan life without oxigen. Chapman and Hall, London, pp. 109-128.

WATTERS, G. T. (1993) Some aspects of the functional morphology of the shell of infaunal bivalves (Mollusca). Malacologia, 35 (2): 315-342.

WIGNALL (1990) Benthic palaecology of the Late Jurassic Kimmeridge Clay of England. Spec. Pap. Palaeontol., 43.

WIGNALL, P.B. (1994) Black Shales. Clarendon Press, Oxford, 127p.

WOOBER, F. J. (1968) A faunal analysis of the Lias (Lower Jurassic) of South Wales (Great Britain). Palaeogeogr., Palaeoclimatol., Palaeoecol., 5: 269-308.

WRIGHT, R. P. (1973) Marine Jurassic of Wyoming and South Dakota: its paleoenvironments and paleobiogeography. Paperson Paleont., 2, 49p.

YONGE, C. M. (1953) The monomyariam condition in the Lamellibranchia. R. Soc. Edinburgh, Trans., 62: 443-478.

YONGE, C. M. (1957) Mantle fusin in the Lamellibranchia. Pubbl. Staz. Zool. Napoli, 29: 151-171. 
YONGE, C. M. (1962) On the primitive significance of the byssus in the Bivalvia and its effects in evolution. J. Mar. Biol. Ass. U. K., 42: 113-125. 
ANEXOS 


\section{Anexo I}

Tabelas de medidas e índices dos bivalves do Grupo Passa Dois utilizados nesse estudo.

Legenda:

O número se refere ao registro de tombo do exemplar na Coleção Científica do Laboratório de Paleozoologia Evolutiva, Departamento de Zoologia, IBB/UNESP. Exemplares depositados no Departamento de Geologia Sedimentar e Ambiental/USP, quando presentes, estão indicados com o prefixo GP1T e GP1E. Espécimes depositados no American Museum of Natural History, EUA e no Departamento Nacional da Produção Nacional, RJ, estão indicados pelas siglas AMNH e DGM, respectivamente.

Medidas em milimetros.

Larguras medidas através de uma valva (multiplicar por 2 para obter a largura total), exceto quando indicado articulação.

$\mathrm{VD}=$ valva direita

$\mathrm{VE}=$ valva esquerda

$M=$ concha em molde

$S=$ concha silicificada

$\mathrm{CM}=$ contra molde

$\mathrm{C}=$ comprimento

$\mathrm{CA}=$ comprimento anterior

$A=$ altura

$\mathrm{L}=$ largura

$\mathrm{C} / \mathrm{A}=$ alongamento

$\mathrm{A} / \mathrm{L}=$ obesidade

$\mathrm{CA} / \mathrm{C}=$ alongamento anterior

\section{Assembléia Anhembia froesi}

\section{Epifauna}

\section{?Anthraconaia mezzalirai}

\begin{tabular}{|c|c|c|c|c|c|c|c|c|c|c|c|c|}
\hline $\mathbf{n}^{\circ}$ & Afloramento & VD & VE & $\mathbf{M}$ & $\mathbf{S}$ & $\mathbf{C}$ & $\mathbf{C A}$ & $\mathbf{A}$ & $\mathbf{L}$ & $\mathbf{C} / \mathbf{A}$ & $\mathbf{A} / \mathbf{L}$ & CA/C \\
\hline & & & & & & & & & & & & \\
\hline 2307 & Rio Claro & & & $\mathbf{X}$ & & 8,0 & 1,0 & 3,0 & & 2,67 & & 0,12 \\
\hline 2327 & Rio Claro & $\mathbf{X}$ & & $\mathbf{X}$ & & 19,0 & 3,5 & 10,0 & & 1,9 & & 0,18 \\
\hline 2337 & Rio Claro & $\mathbf{X}$ & $\mathbf{X}$ & & 10,0 & 1,0 & 3,0 & & 3,33 & & 0,1 \\
\hline 2406 & Rio Claro & & $\mathbf{X}$ & $\mathbf{X}$ & & 6,0 & 0,5 & 3,0 & & 2,0 & & 0,08 \\
\hline $\begin{array}{c}\text { GP/1T } \\
7 / 92\end{array}$ & Anhembi & $\mathbf{X}$ & & & $\mathbf{X}$ & 30,8 & 10,9 & 6,0 & & 2,82 & & 0,19 \\
\hline GP/1T & Anhembi & $\mathbf{X}$ & & & $\mathbf{X}$ & 28,5 & 15,0 & 8,5 & & 1,9 & & 0,30 \\
$7 / 92$ & & & & & & & & & & & & \\
\hline \multicolumn{8}{|c|}{ Média } \\
\hline
\end{tabular}




\section{Semi-infauna}

\section{Barbosaia angulata}

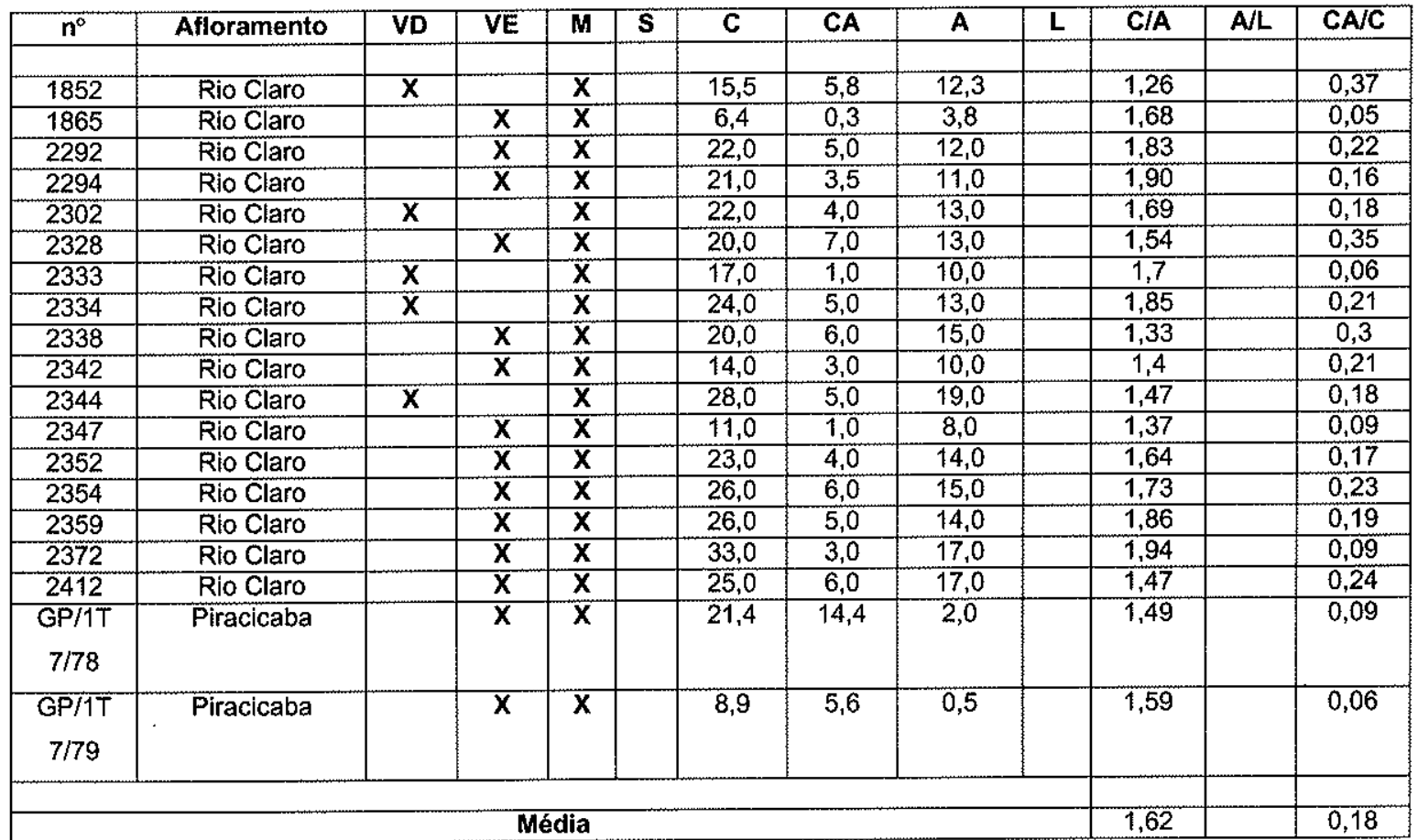

\section{Infauna Rasa}

\section{Anhembia froesi}

\begin{tabular}{|c|c|c|c|c|c|c|c|c|c|c|c|c|}
\hline$n^{\circ}$ & afloramento & VD & VE & $M$ & $\mathbf{s}$ & $\mathrm{C}$ & CA & $\mathbf{A}$ & $L$ & $\mathbf{C} / \mathbf{A}$ & $\mathrm{A} / \mathrm{L}$ & CA/C \\
\hline 2888 & Porangaba & $x$ & & & & 64,0 & 10,0 & 19,0 & 4,0 & 3,37 & 2,37 & 0,16 \\
\hline 2889 & Porangaba & & $\mathrm{x}$ & & & 72,0 & 18,0 & 22,0 & 6,0 & 3,27 & 1,5 & 0,25 \\
\hline 2890 & Porangaba & & $x$ & & & 71,0 & 17,0 & 25,0 & 5,0 & 2,84 & 2,5 & 0,24 \\
\hline $\begin{array}{c}\text { GP/1T } \\
7 / 89\end{array}$ & Anhembi & & $\mathbf{x}$ & & $x$ & 84,0 & 20,0 & 20,0 & & 4,2 & & 0,24 \\
\hline $\begin{array}{c}\mathrm{GP} / 1 \mathrm{~T} \\
7 / 90\end{array}$ & Anhembi & $\mathbf{x}$ & & & $x$ & 63,0 & 20,0 & 11,0 & & 3,5 & & 0,17 \\
\hline $\begin{array}{c}\text { GP/1T } \\
7 / 91\end{array}$ & Anhembi & & $x$ & & $x$ & 98,0 & 33,3 & 27,5 & & 2,95 & & 0,28 \\
\hline & & & & & & & & & & 3,36 & 2,12 & 0,22 \\
\hline
\end{tabular}




\section{Holdhausiella almeidai}

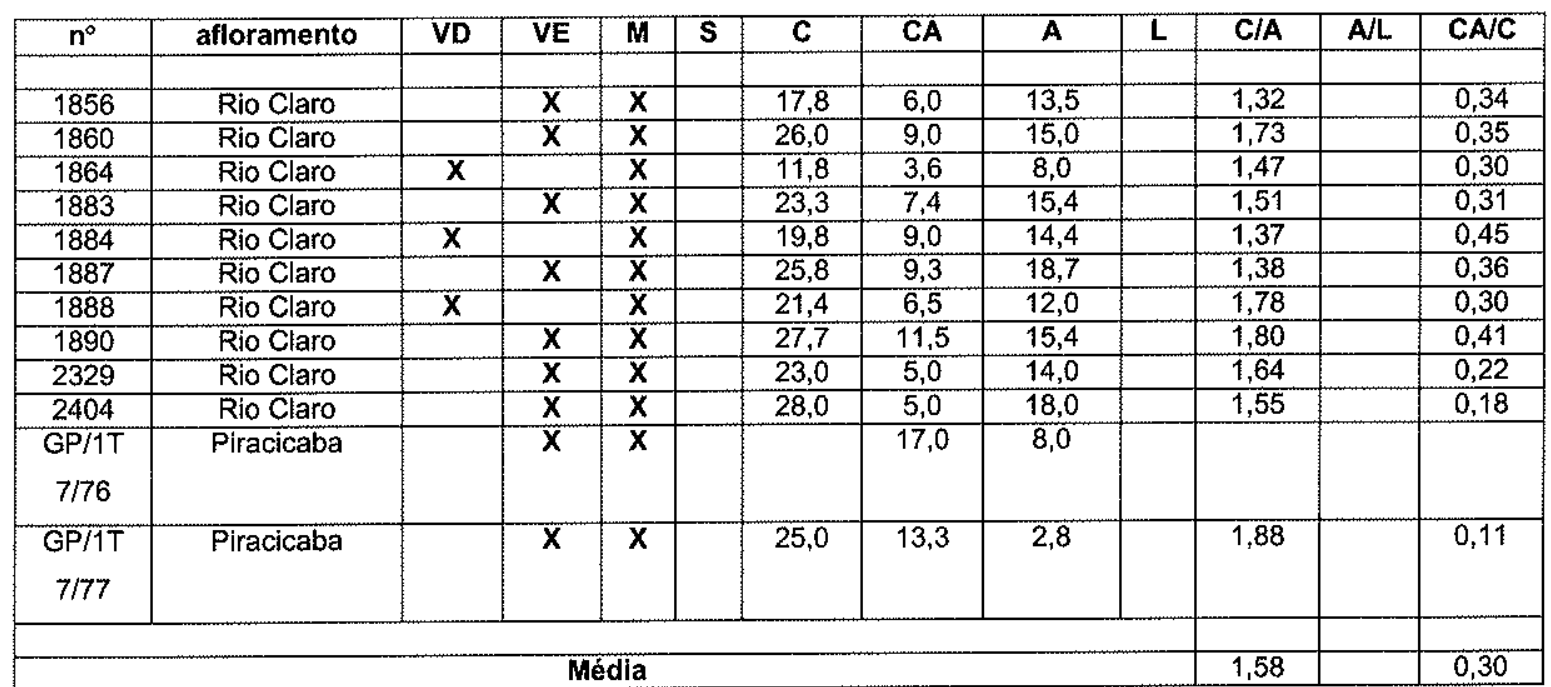

\section{Maackia contorta}

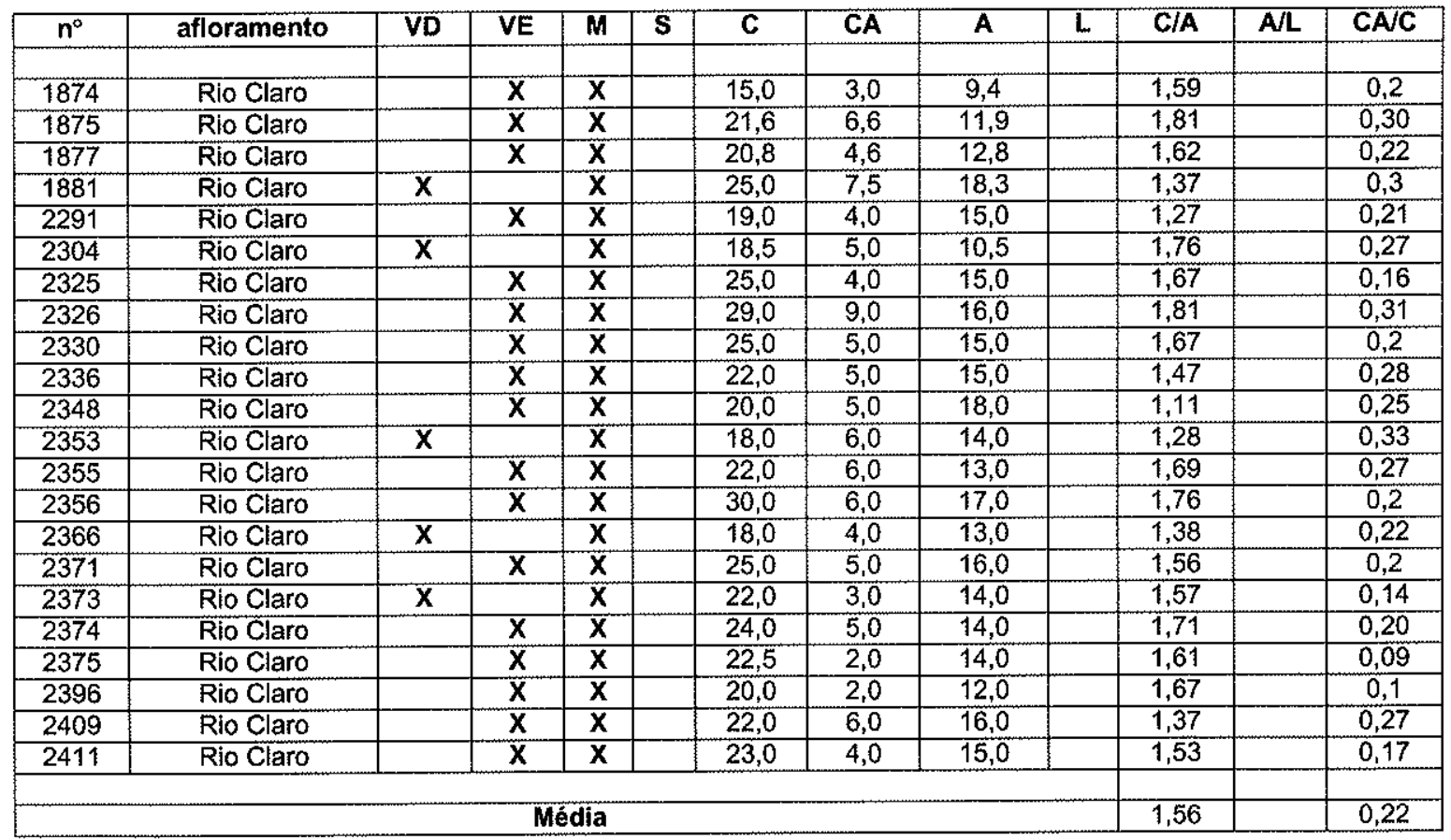

\section{Mendesia piracicabensis}

\begin{tabular}{|c|c|c|c|c|c|c|c|c|c|c|c|c|}
\hline$n^{\circ}$ & afloramento & VD & VE & $M$ & $\mathbf{S}$ & $\mathrm{C}$ & $\mathrm{CA}$ & A & $\mathrm{L}$ & C/A & $\mathrm{A} / \mathrm{L}$ & CAVC \\
\hline & & . & & & & & & & & & & \\
\hline 1853 & Rio Claro & & $\bar{X}$ & $\bar{x}$ & & 14,8 & 3,9 & 11,2 & & 1,32 & & 0,26 \\
\hline 1858 & Rio Claro & & $\bar{x}$ & $\mathbf{X}$ & & 20,2 & 5,5 & 11,0 & & 1,84 & & 0,27 \\
\hline 1859 & Rio Claro & $\bar{X}$ & & $\bar{x}$ & & 16,1 & 6,3 & 9,5 & & 1,69 & & 0,39 \\
\hline 1862 & Rio Claro & $\mathrm{X}$ & & $\mathrm{X}$ & & 20,1 & 5,8 & 11,2 & & 1,79 & & 0,29 \\
\hline 1871 & Rio Claro & $\mathrm{X}$ & & $\mathrm{X}$ & & 24,0 & 6,0 & 12,0 & & 2,0 & & 0,25 \\
\hline 1873 & Rio Claro & $x$ & & $\mathrm{X}$ & & 22,0 & 9,0 & 15,0 & & 1,47 & & 0,41 \\
\hline 1876 & Rio Claro & $\mathrm{X}$ & & $x$ & & 24,3 & 8,3 & 13,8 & & 1,76 & & 0,34 \\
\hline
\end{tabular}




\begin{tabular}{|c|c|c|c|c|c|c|c|c|c|}
\hline 1878 & Rio Claro & & $\mathrm{X}$ & 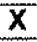 & 24,7 & 8,7 & 12,0 & 2,06 & 0,35 \\
\hline 1882 & Rio Claro & & $\mathrm{X}$ & $x$ & 24,8 & 6,3 & 15,0 & 1,65 & 0,25 \\
\hline 2320 & Rio Claro & & $x$ & $X$ & 15,0 & 2,0 & 10,0 & 1,5 & 0,13 \\
\hline 2332 & Rio Claro & $\bar{x}$ & & $\bar{x}$ & 25,0 & 7,0 & 17,5 & 1,43 & 0,28 \\
\hline 2339 & Rio Claro & $?$ & $\mathrm{X}$ & $x$ & 25,0 & 6,0 & 13,0 & 1,92 & 0,24 \\
\hline 2341 & Rio Claro & $\bar{X}$ & & $x$ & 12,0 & 5,0 & 6,0 & 2 & 0,42 \\
\hline 2357 & Rio Claro & $\bar{x}$ & & $\bar{x}$ & 19,0 & 4,0 & 12,0 & 1,58 & 0,21 \\
\hline 2362 & Rio Claro & & $x$ & $x$ & 28,0 & 7,0 & 19,0 & 1,47 & 0,25 \\
\hline 2363 & Rio Claro & & $\mathbf{x}$ & $x$ & 30,0 & 7,0 & 16,0 & 1,87 & 0,23 \\
\hline 2368 & Rio Claro & & $\bar{x}$ & $\mathbf{x}$ & 17,0 & 4,0 & 10,0 & 1,7 & 0,23 \\
\hline 2369 & Rio Claro & & $x$ & $\mathbf{X}$ & 23,0 & 4,0 & 14,0 & 1,64 & 0,17 \\
\hline 2370 & Rio Claro & & $\mathbf{X}$ & $\bar{x}$ & 18,0 & 3,0 & 10,0 & 1,8 & 0,17 \\
\hline 2376 & Rio Claro & & $\mathbf{x}$ & $\mathbf{x}$ & 23,0 & 3,0 & 13,0 & 1,76 & 0,13 \\
\hline 2377 & Rio Claro & $\mathbf{X}$ & & $\mathbf{X}$ & 28,0 & 2,0 & 18,0 & 1,55 & 0,07 \\
\hline 2400 & Rio Claro & & $\mathrm{X}$ & $\mathbf{x}$ & 24,0 & 4,0 & 16,0 & 1,5 & 0,17 \\
\hline 2401 & Rio Claro & & $\mathrm{x}$ & $\mathbf{X}$ & 15,0 & 4,0 & 11,0 & 1,36 & 0,27 \\
\hline 2408 & Rio Claro & & $\mathrm{X}$ & $\mathbf{X}$ & 18,0 & 3,0 & 10,0 & 1,8 & 0,17 \\
\hline 2410 & Rio Claro & & & $x$ & 7,0 & 1,0 & 3,0 & 2,33 & 0,14 \\
\hline & & & & & & & & 1,71 & 0,24 \\
\hline
\end{tabular}

\section{Tambaquyra camargoi}

\begin{tabular}{|c|c|c|c|c|c|c|c|c|c|c|c|c|}
\hline $\mathbf{n}^{\circ}$ & afloramento & VD & VE & M & S & C & CA & A & L & C/A & A/L & CA/C \\
\hline & & & & & & & & & & & & \\
\hline 1855 & Rio Claro & & $\mathrm{X}$ & $\mathrm{X}$ & & 16,3 & 5,0 & 11,4 & & 1,43 & & 0,31 \\
\hline 1901 & Rio Claro & & $\mathrm{X}$ & $\mathrm{X}$ & & & 31,0 & 72,0 & & & & \\
\hline 2250 & Porangaba & & $\mathrm{X}$ & & & 100,4 & 33,0 & 100,1 & 60 & 1,0 & 1,6 & 0,33 \\
& & & & & & & & & $(\mathrm{X} 2)$ & & & \\
\hline 2251 & Porangaba & $\mathrm{X}$ & & & & 40,0 & 16,0 & 42,0 & 15,0 & 0,9 & 1,4 & 0,4 \\
\hline 2895 & Porangaba & & $\mathrm{X}$ & & & 31,0 & 7,0 & 30,0 & 10 & 1,0 & 1,5 & 0,22 \\
\hline 2896 & Porangaba & & $\mathrm{X}$ & & & 40,0 & 7,0 & 37,0 & & 1,1 & & 0,17 \\
\hline 2898 & Porangaba & & $\mathrm{X}$ & & & 86,0 & 26,0 & 87,0 & & 0,9 & & 0,30 \\
\hline \multicolumn{7}{|c|}{ Média } \\
\hline
\end{tabular}

\section{Assembléia Pinzonella illusa}

\section{Epifauna}

\section{Coxesia mezzalirai}

\begin{tabular}{|c|c|c|c|c|c|c|c|c|c|c|c|c|}
\hline $\mathbf{n}^{\circ}$ & afloramento & VD & $\mathbf{V E}$ & $\mathbf{M}$ & $\mathbf{S}$ & $\mathbf{C}$ & $\mathbf{C A}$ & $\mathbf{A}$ & $\mathbf{L}$ & $\mathbf{C} / \mathbf{A}$ & $\mathbf{A} / \mathbf{L}$ & $\mathbf{C A} / \mathbf{C}$ \\
\hline & & & & & & & & & & & & \\
\hline 1980 & Rio Claro & $\mathbf{X}$ & & $\mathbf{X}$ & & 26,0 & 0,5 & 6,0 & 3,0 & 4,3 & 1,0 & 0,02 \\
\hline $\begin{array}{c}\text { AMNH } \\
28991\end{array}$ & Rio Claro & articulada & & $\mathbf{X}$ & 13,0 & 1,0 & 5,03 & & 2,6 & & 0,07 \\
\hline $\begin{array}{c}\text { DGM } \\
4025\end{array}$ & Rio Claro & $\mathbf{X}$ & & & $\mathbf{X}$ & 17,0 & 1,5 & 6,5 & & 2,6 & & 0,08 \\
\hline $\begin{array}{c}\text { DGM } \\
4411\end{array}$ & Rio Claro & & $\mathbf{X}$ & & $\mathbf{X}$ & 22,3 & 1,6 & 7,6 & & 2,9 & & 0,07 \\
\hline \multicolumn{8}{|c|}{ Média } \\
\hline
\end{tabular}




\section{Infauna rasa}

\section{Favalia arcuata}

\begin{tabular}{|c|c|c|c|c|c|c|c|c|c|c|c|c|}
\hline $\mathrm{n}^{\circ}$ & afloramento & VD & VE & MI & $\mathbf{S}$ & C & $\mathrm{CA}$ & $\mathbf{A}$ & $\mathrm{L}$ & C/A & $\mathrm{A} / \mathrm{L}$ & CA/C \\
\hline & & & & & & & & & & & & \\
\hline 504 & Rio Claro & $\bar{x}$ & & $x$ & & 22,2 & 05,9 & 10,0 & & 2,22 & & 0,26 \\
\hline 505 & Rio Claro & & $x$ & $\mathbf{X}$ & & 23,2 & 07,5 & 11,0 & & 2,10 & & 0,32 \\
\hline 506 & Rio Claro & $\mathbf{x}$ & & $\mathrm{X}$ & & & 07,1 & 10,5 & 02,2 & & & \\
\hline $507 a b$ & Rio Claro & & $\mathbf{X}$ & $\mathrm{x}$ & & 26,0 & 09,8 & 11,2 & 02,5 & 2,32 & & 0,37 \\
\hline 508 & Rio Claro & & $\bar{x}$ & $\mathbf{X}$ & & 26,4 & 08,0 & 11,1 & 02,0 & 2,37 & 2,5 & 0,30 \\
\hline 509 & Rjo Claro & & $\mathbf{X}$ & $\bar{x}$ & & & 06,7 & 10,0 & 01,6 & & 2,0 & \\
\hline 510 & Rio Claro & & $\bar{x}$ & $\mathbf{x}$ & & & 08,9 & 12,4 & 02,6 & & 3,1 & \\
\hline 511 & Rio Claro & $\mathbf{X}$ & & $\mathbf{x}$ & & 27,6 & 08,7 & 12,6 & & 2,19 & 3,9 & 0,31 \\
\hline 513 & Rio Claro & & $\mathbf{x}$ & & $\mathbf{X}$ & & 06,0 & 10,8 & 01,9 & & & \\
\hline 569 & Rio Claro & $\mathbf{X}$ & & $x$ & & 28,7 & 08,0 & 12,5 & 02,5 & 2,30 & 3,29 & 0,28 \\
\hline 570 & Rio Claro & $X$ & & $\mathbf{X}$ & & 20,5 & 07,0 & 10,3 & 02,4 & 1,99 & & 0,34 \\
\hline 615 & Rio Claro & & $\bar{x}$ & $x$ & & 25,7 & 07,5 & 11,0 & 02,0 & 2,33 & 2,2 & 0,29 \\
\hline 648 & Rio Claro & $\mathbf{X}$ & & $\mathbf{x}$ & & & 07,0 & 12,7 & 02,2 & & 2,6 & \\
\hline 2795 & Rlo Claro & & $\bar{x}$ & $\mathbf{X}$ & & 32,3 & 08,8 & 17,4 & 03,0 & 1,85 & 2,9 & 0,27 \\
\hline 2797 & Rio Claro & & $\bar{X}$ & $\mathbf{x}$ & & 26,2 & 07,2 & 13,7 & & 1,91 & & 0,27 \\
\hline 2799 & Rio Claro & & $\mathrm{x}$ & $\mathbf{X}$ & & 26,0 & 06,6 & 11,9 & 02,2 & 2,18 & 2,70 & 0,25 \\
\hline 2801 & Rio Claro & $\mathbf{X}$ & & $\mathbf{X}$ & & & 07,8 & 15,2 & 02,3 & & 3,30 & \\
\hline 2802 & Rio Claro & & $\bar{X}$ & $\mathbf{x}$ & & 25,4 & 06,7 & 12,7 & 02,2 & 2,00 & 2,88 & 0,26 \\
\hline 2803 & Rio Claro & & $\mathrm{X}$ & $\mathbf{X}$ & & 21,0 & 06,8 & 11,2 & 02,0 & 1,87 & 2,8 & 0,32 \\
\hline 2805 & Rio Claro & $\mathbf{x}$ & & $\mathbf{X}$ & & & 06,7 & 10,8 & 02,5 & & 2,16 & \\
\hline 2806 & Rio Claro & & $\mathrm{X}$ & $x$ & & 27,5 & 07,1 & 13,7 & 02,7 & 2,01 & 2,54 & 0,26 \\
\hline 2807 & Rio Claro & $\mathbf{X}$ & & $x$ & & 22,7 & 06,5 & 10,8 & 02,2 & 2,10 & 2,45 & 0,29 \\
\hline 2808 & Rio Claro & & $\bar{X}$ & $\mathrm{x}$ & & 30,5 & 09,0 & 14,8 & 02,4 & 2,06 & 3,08 & 0,30 \\
\hline 2809 & Rio Claro & $\mathrm{X}$ & & $\mathbf{x}$ & & 27,2 & 08,8 & 12,8 & 02,7 & 2,13 & 2,37 & 0,30 \\
\hline 2811 & Rio Claro & $X$ & & $\mathbf{X}$ & & & 09,3 & 12,0 & 02,3 & & 2,61 & \\
\hline 2812 & Rio Claro & & 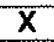 & $\mathrm{X}$ & & & & 13,3 & 02,4 & & 2,77 & \\
\hline 2900 & Rio Claro & & $\mathbf{X}$ & $\bar{x}$ & & 13,0 & 03,0 & 06,0 & 01,2 & 2,16 & 2,5 & 0,23 \\
\hline 2902 & Rio Claro & $\bar{x}$ & & $\bar{x}$ & & 28,5 & 06,8 & 13,0 & 02,4 & 2,19 & 2,71 & 0,23 \\
\hline 2903 & Rio Claro & $\mathrm{X}$ & & $\mathrm{X}$ & & 26,5 & 06,8 & 11,5 & 02,3 & 2,30 & 2,5 & 0,25 \\
\hline 2904 & Rio Claro & & $\bar{x}$ & $x$ & & 23,9 & 05,0 & 10,4 & 02,2 & 2,29 & 2,36 & 0,20 \\
\hline $\begin{array}{c}\text { GP/1T } \\
954\end{array}$ & Angatuba & & $\mathrm{X}$ & & $x$ & 26,0 & 06,9 & 11,2 & 03,0 & 2,32 & 1,87 & 0,27 \\
\hline $\begin{array}{c}\text { GP/1T } \\
955\end{array}$ & Angatuba & & $\bar{x}$ & & $x$ & 17,2 & 05,0 & 07,3 & 02,4 & 2,36 & 1,52 & 0,29 \\
\hline $\begin{array}{c}\text { GP/1T } \\
956\end{array}$ & Angatuba & $\bar{X}$ & & & $\mathrm{x}$ & 21,9 & 06,2 & 08,9 & 02,7 & 2,46 & 1,65 & 0,28 \\
\hline $\begin{array}{c}\text { GP/1T } \\
957\end{array}$ & Angatuba & & $\mathbf{X}$ & & $x$ & 31,0 & 08,4 & 12,5 & 03,1 & 2,48 & 2,01 & 0,27 \\
\hline & & & & Mé & & & & & & 2,18 & 2,57 & 0,28 \\
\hline
\end{tabular}

\section{Ferrazia cardinalis}

\begin{tabular}{|c|c|c|c|c|c|c|c|c|c|c|c|c|}
\hline $\mathbf{n}^{\circ}$ & afloramento & $\mathbf{V D}$ & $\mathbf{V E}$ & $\mathbf{M I}$ & $\mathbf{S}$ & $\mathbf{C}$ & $\mathbf{C A}$ & $\mathbf{A}$ & $\mathbf{L}$ & $\mathbf{C} / \mathbf{A}$ & $\mathbf{A} / \mathbf{L}$ & $\mathbf{C A} \mathbf{C}$ \\
\hline & & & & & & & & & & & & \\
\hline 50,2 & Angatuba & $\mathbf{X}$ & & & $\mathbf{X}$ & 21,0 & 5,0 & 21,0 & 6,0 & 1,0 & 1,75 & 0,24 \\
\hline 618 & Rio Claro & $\mathbf{X}$ & & & $\mathbf{X}$ & 26,0 & 5,0 & 26,0 & 6,0 & 1,0 & 2,17 & 0,19 \\
\hline 619 & Rio Claro & $\mathbf{X}$ & & & $\mathbf{X}$ & 28,0 & 5,0 & 27,0 & 5,0 & 1,03 & 2,7 & 0,18 \\
\hline 657 & Rio Claro & & $\mathbf{X}$ & & $\mathbf{X}$ & 19,0 & 2,0 & 18,0 & 7,0 & 1,05 & 1,28 & 0,10 \\
\hline 836 & Rio Claro & $\mathbf{X}$ & & & $\mathbf{X}$ & 27,0 & 6,0 & 27,0 & 12,0 & 1,0 & 1,13 & 0,22 \\
\hline 837 & Rio Claro & $\mathbf{X}$ & & & $\mathbf{X}$ & 28,0 & 6,0 & 28,0 & 13,0 & 1,0 & 1,08 & 0,21 \\
\hline \multicolumn{8}{|c|}{ Média } \\
\hline \multicolumn{8}{|c|}{}
\end{tabular}




\section{Holdhausiella elongata}

\begin{tabular}{|c|c|c|c|c|c|c|c|c|c|c|c|c|}
\hline$n^{\circ}$ & Afloramento & VD & VE & $\mathrm{MI}$ & $\mathbf{S}$ & C & CA & $\mathbf{A}$ & $E$ & C/A & A/L & $\mathrm{CA} / \mathrm{C}$ \\
\hline & & & & & & & & & & & & \\
\hline 521 & Rio Claro & & $\mathrm{X}$ & $x$ & & 20,5 & 05,8 & 10,1 & 04,2 & 2,02 & 1,20 & 0,28 \\
\hline 524 & Rio Claro & & $\mathbf{X}$ & $x$ & & 23,8 & 06,5 & 10,7 & 03,6 & 2,22 & 1,48 & 0,27 \\
\hline 525 & Rio Claro & & & $x$ & & 19,4 & 05,4 & 08,9 & & 2,17 & & 0,27 \\
\hline $529 a b$ & Rio Claro & & $\mathbf{X}$ & $\bar{x}$ & & 21,2 & 05,5 & 11,0 & 02,5 & 1,93 & 2,2 & 0,26 \\
\hline 530 & Rio Claro & & $\mathrm{X}$ & & $\mathbf{X}$ & & 06,9 & 12,8 & 03,8 & & 1,68 & \\
\hline 616 & Rio Claro & & $\bar{X}$ & $X$ & & & & 11,0 & 03,5 & & 1,57 & \\
\hline 617 & Rio Claro & $\mathrm{X}$ & & & & 18,1 & 04,8 & 09,2 & & 1,97 & & 0,27 \\
\hline 628 & Rio Claro & $\mathbf{X}$ & & $\bar{X}$ & & & 08,0 & 10,4 & 02,7 & & 1,92 & \\
\hline 658 & Rio Claro & & $\bar{X}$ & $\bar{x}$ & & & 05,0 & 08,6 & 03,1 & & 1,39 & \\
\hline 1792 & Tambaú & $x$ & & $\bar{X}$ & & 20,4 & 06,1 & 08,9 & 02,4 & 2,29 & 1,85 & 0,30 \\
\hline 1937 & Rio Claro & $\bar{x}$ & & $\bar{x}$ & & 25,5 & 06,0 & 13,4 & 04,7 & 1,90 & 1,42 & 0,24 \\
\hline 2750 & Rio Claro & & $\bar{X}$ & $\mathrm{X}$ & & 25,6 & 06,7 & 12,9 & 04,0 & 1,98 & 1,61 & 0,26 \\
\hline $2821 a$ & Rio Claro & & $\bar{x}$ & $\mathrm{X}$ & & 27,2 & 06,6 & 13,1 & 04,0 & 2,08 & 1,63 & 0,24 \\
\hline $2821 b$ & Rio Claro & $\bar{x}$ & & $\mathrm{x}$ & & 19,1 & 04,5 & 09,0 & 02,4 & 2,12 & 1,85 & 0,24 \\
\hline & & & & Mé & & & & & & 2,07 & 1,65 & 0,26 \\
\hline
\end{tabular}

\section{Othonella araguaiana}

\begin{tabular}{|c|c|c|c|c|c|c|c|c|c|c|c|c|}
\hline$n^{\circ}$ & afloramento & VD & VE & MI & $\mathbf{S}$ & C & CA & $\mathbf{A}$ & $\mathbf{L}$ & CIA & $\mathbf{A} / \mathbf{L}$ & $\mathrm{CA} / \mathrm{C}$ \\
\hline & & & & & & & & & & & & \\
\hline 2764 & Rio Claro & $\mathrm{x}$ & & & $\overline{\mathbf{X}}$ & 35,0 & 7,0 & 26,0 & 6,0 & 1,35 & 2,17 & 0,2 \\
\hline $\begin{array}{l}\mathrm{GP} / 1 \mathrm{~T} \\
7 / 980\end{array}$ & Rio Claro & $\mathbf{x}$ & & & $\mathbf{X}$ & 25,0 & 5,0 & 22,0 & 5,0 & 1,14 & 2,2 & 0,2 \\
\hline $\begin{array}{l}\text { GP/1T } \\
7 / 981\end{array}$ & Rio Claro & & $\bar{X}$ & & $\bar{x}$ & 29,0 & 4,0 & 24,0 & 6,0 & 1,21 & 2 & 0,14 \\
\hline & & & & Mé & & & & & & 1,23 & 2,12 & 0,18 \\
\hline
\end{tabular}

\section{Pinzonella illusa}

\begin{tabular}{|c|c|c|c|c|c|c|c|c|c|c|c|c|}
\hline$n^{\circ}$ & afloramentos & VD & VE & $M i$ & $S$ & $\mathrm{C}$ & $\mathrm{CA}$ & A & L & $\mathrm{C} / \mathrm{A}$ & $\mathrm{A} / \mathrm{L}$ & $\mathrm{CA} \bar{C}$ \\
\hline & & & & & & & & & & & & \\
\hline 2 & Rio Claro & $X$ & & $\mathbf{X}$ & & 15,4 & 4,6 & 12,0 & 2,7 & 1,28 & 2,20 & 0,30 \\
\hline 3 & Rio Claro & $x$ & & & $\bar{X}$ & 19,5 & 3,0 & 16,0 & 6,5 & 1,21 & 1,23 & 0,15 \\
\hline 4 & Rio Claro & & $\bar{X}$ & & $\bar{X}$ & 14,4 & 3,6 & 11,5 & 4,0 & 1,25 & 1,43 & 0,25 \\
\hline 5 & Rio Claro & & $\bar{X}$ & & $\bar{X}$ & 22,5 & 3,0 & 19,0 & 6,5 & 1,18 & 1,46 & 0,13 \\
\hline 6 & Rio Claro & & $\mathbf{X}$ & & $\bar{X}$ & 23,0 & 1,0 & 18,0 & 6,0 & 1,28 & 1,50 & 0,04 \\
\hline 7 & Rio Claro & $\bar{X}$ & & & $\bar{X}$ & 12,5 & & & & & & \\
\hline 8 & Rlo Claro & $\bar{x}$ & & & $\bar{X}$ & 20,5 & 4,9 & 18,6 & 5,2 & 1,10 & 1,79 & 0,24 \\
\hline 9 & Rio Claro & & $\bar{x}$ & & $\bar{X}$ & 14,2 & 2,0 & 12,5 & & 1,14 & & 0,14 \\
\hline 10 & Rio Claro & $\bar{x}$ & & & $\bar{X}$ & 14,5 & 2,4 & 11,0 & 4,5 & 1,32 & 1,22 & 0,17 \\
\hline 11 & Rio Claro & $X$ & & & $\bar{X}$ & 17,5 & 3,4 & 14,7 & 4,6 & 1,19 & 1,60 & 0,19 \\
\hline 12 & Rio Claro & & $\mathbf{X}$ & & $\bar{X}$ & 14,0 & 1,6 & 11,3 & 3,5 & 1,24 & 1,61 & 0,11 \\
\hline 13 & Rio Claro & & $x$ & & $x$ & 18,0 & 3,0 & 14,5 & 6,0 & 1,24 & 1,21 & 0,17 \\
\hline 14 & Rio Claro & & $\mathbf{X}$ & & $\bar{X}$ & 20,5 & 3,1 & 18,0 & 6,8 & 1,14 & 1,32 & 0,15 \\
\hline 15 & Rio Claro & & $\mathrm{X}$ & & $X$ & 12,3 & 2,4 & 10,4 & & 1,18 & & 0,20 \\
\hline 16 & Rio Claro & & $\bar{X}$ & & $\mathrm{X}$ & 20,9 & 2,9 & 19,3 & 5.7 & 1,08 & 1,69 & 0,14 \\
\hline 17 & Rio Claro & $\bar{x}$ & & & $\mathbf{X}$ & 11,3 & 1.4 & 8,9 & 3,3 & 1,27 & 1,35 & 0,12 \\
\hline 18 & Rio Claro & & $\bar{X}$ & & $\bar{x}$ & 19,7 & 2,9 & 14,3 & 3,9 & 1,38 & 1,83 & 0,15 \\
\hline 19 & Rio Claro & $x$ & & & $\mathbf{X}$ & 21,7 & 2,4 & 19,2 & 7,0 & 1,13 & 1,37 & 0,11 \\
\hline 20 & Rio Claro & $\mathrm{X}$ & & & 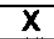 & 19,0 & 3,0 & 15,0 & 5,5 & 1,27 & 1,36 & 0,16 \\
\hline 21 & Rio Claro & & $\bar{X}$ & & $\mathrm{X}$ & 18,3 & 1,6 & 15,7 & 4,9 & 1,17 & 1,60 & 0,09 \\
\hline 22 & Rio Claro & $\bar{X}$ & & & $x$ & 12,6 & 2,0 & 7,8 & & 1,62 & & 0,16 \\
\hline 23 & Rio Claro & & $\bar{x}$ & & $x$ & 14,3 & 2,1 & 13,3 & 4,9 & 1,08 & 1,36 & 0,15 \\
\hline
\end{tabular}




\begin{tabular}{|c|c|c|c|c|c|c|c|c|c|c|c|}
\hline 24 & Rio Claro & & $\mathbf{X}$ & $\bar{x}$ & 11,8 & 2,8 & 11,4 & & 1,04 & & 0,24 \\
\hline 26 & Rjo Claro & $\mathrm{X}$ & & $\bar{X}$ & 16,0 & 2,4 & 12,4 & 3,6 & 1,29 & 1,72 & 0,15 \\
\hline 27 & Rio Claro & & $\bar{x}$ & $\bar{x}$ & 16,7 & 1,9 & 12,7 & 5,4 & 1,31 & 1,18 & 0,11 \\
\hline 28 & Rio Claro & & $\bar{X}$ & $X$ & 16,4 & 1,2 & 13,6 & 3,9 & 1,21 & 1,74 & 0,07 \\
\hline 29 & Rio Claro & & $\bar{x}$ & $x$ & 16,6 & 1,7 & 12,9 & 4,9 & 1,29 & 1,32 & 0,10 \\
\hline 30 & Rio Claro & & $\bar{x}$ & $\bar{x}$ & 17,2 & 1,5 & 13,9 & 4,5 & 1,24 & 1,54 & 0,09 \\
\hline 31 & Rio Claro & & $X$ & $\mathbf{X}$ & 15,8 & 1,7 & 11,8 & 4,3 & 1,34 & 1,37 & 0,11 \\
\hline 32 & Rio Claro & & $\bar{X}$ & $\bar{x}$ & 14,8 & 1,5 & 13,3 & 3,9 & 1,11 & 1,71 & 0,10 \\
\hline 33 & Rio Claro & & $\bar{X}$ & $X$ & 14,3 & 1,4 & 11,3 & 3,7 & 1,27 & 1,53 & 0,10 \\
\hline 34 & Rio Claro & Arti & & $X$ & 13,2 & 1,3 & 10,4 & 7,3 & 1,28 & 0,71 & 0,10 \\
\hline 35 & Rio Claro & & $\bar{x}$ & $\bar{X}$ & 12,8 & & 10,3 & 3,5 & 1,24 & 1,47 & \\
\hline 36 & Rio Claro & & $\bar{X}$ & $\bar{x}$ & 15,9 & 2,3 & 12,9 & 3,1 & 1,23 & 2,08 & 0,14 \\
\hline 37 & Rio Claro & & $\mathbf{X}$ & $\bar{x}$ & 15,1 & 2,0 & 12,3 & & 1,23 & & 0,13 \\
\hline 38 & Rio Claro & $x$ & & $\bar{x}$ & 19,3 & 3,6 & 3,6 & 4,8 & 5,36 & 0,38 & 0,19 \\
\hline 39 & Rio Claro & & $\bar{X}$ & $\mathbf{X}$ & 11,0 & 1,1 & 10,0 & 2,7 & 1,10 & 1,85 & 0,10 \\
\hline 40 & Rio Claro & & $\mathrm{X}$ & $\mathrm{X}$ & 10,5 & 1,4 & 9,6 & 2,3 & 1,09 & 2,09 & 0,13 \\
\hline 41 & Rio Claro & & $\bar{x}$ & $\mathrm{X}$ & 10,8 & 1,0 & 9,6 & 2,9 & 1,13 & 1,66 & 0,09 \\
\hline 42 & Rio Claro & & $x$ & $\mathrm{X}$ & 13,0 & 1,8 & 10,7 & 4,2 & 1,21 & 1,27 & 0,14 \\
\hline 43 & Rio Claro & & $\bar{x}$ & $\mathrm{X}$ & 11,3 & 1,5 & 9,2 & 2,9 & 1,23 & 1,59 & 0,13 \\
\hline 44 & Rio Claro & & $\bar{x}$ & $\mathrm{X}$ & 11,9 & 1,4 & 9,9 & 2,8 & 1,20 & 1,77 & 0.12 \\
\hline 45 & Rio Claro & & $\bar{x}$ & $\mathbf{X}$ & 20,5 & 2,0 & 18,3 & 5,8 & 1,12 & 1,58 & 0,10 \\
\hline 46 & Rio Claro & & $\bar{x}$ & $\mathrm{X}$ & 13,8 & 1,3 & 11,8 & 3,2 & 1,17 & 1,84 & 0,09 \\
\hline 47 & Rlo Claro & & $\bar{x}$ & $\mathrm{X}$ & 10,0 & 1,4 & 8,3 & 2,9 & 1,20 & 1,43 & 0,14 \\
\hline 48 & Rio Claro & & $\ddot{x}$ & $\mathrm{X}$ & 10,4 & 1,0 & 8,4 & 3,5 & 1,24 & 1,20 & 0,10 \\
\hline 49 & Rio Claro & & $\bar{x}$ & $\mathrm{X}$ & 9,4 & 0,9 & 7,6 & 2,7 & 1,24 & 1,41 & 0,10 \\
\hline 50 & Rio Claro & & $\mathrm{X}$ & $\mathrm{X}$ & 9,6 & 1,1 & 7,1 & 3,0 & 1,35 & 1,18 & 0,11 \\
\hline 51 & Rio Claro & $x$ & & $\mathbf{X}$ & 17,0 & 1,7 & 13,1 & 4,2 & 1,30 & 1,56 & 0,10 \\
\hline 52 & Rio Claro & $\mathbf{x}$ & & $\mathbf{X}$ & 17,3 & 1,6 & 13,0 & 3,6 & 1,33 & 1,81 & 0,09 \\
\hline 54 & Rio Claro & & $\bar{x}$ & 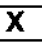 & & 2,0 & 14,9 & 4,3 & & 1,73 & \\
\hline 55 & Rio Claro & $x$ & & $\mathbf{X}$ & & & 16,9 & 7,1 & & 1,19 & \\
\hline 56 & Rio Claro & & $\bar{x}$ & 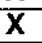 & 14,8 & 1,8 & 11,4 & 4,3 & 1,30 & 1,33 & 0,12 \\
\hline 58 & Rio Claro & $x$ & & $x$ & 23,6 & 4,7 & 21,1 & 6,4 & 1,12 & 1,65 & 0,20 \\
\hline 59 & Rio Claro & $\mathrm{x}$ & & $\mathbf{x}$ & 19,3 & 4,9 & 18,0 & 5,0 & 1,07 & 1,80 & 0,25 \\
\hline 60 & Rio Claro & & & $\mathrm{X}$ & 16,8 & 5,0 & 17,4 & 11,0 & 0,97 & 0,79 & 0,30 \\
\hline 61 & Rio Claro & & & 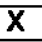 & 16,0 & 3,0 & 13,3 & 6,9 & 1,20 & 0,96 & 0,19 \\
\hline 62 & Rio Claro & $x$ & & $x$ & 15,4 & 4,0 & 12,7 & 2,8 & 1,21 & 2,27 & 0,26 \\
\hline 63 & Rio Claro & $x$ & & $x$ & 15,8 & 3,9 & 12,0 & 3,8 & 1,32 & 1,58 & 0,25 \\
\hline 64 & Rio Claro & & $x$ & $X$ & 14,6 & 3,0 & 13,1 & 5,9 & 1,11 & 1,11 & 0,21 \\
\hline 65 & Rio Claro & & $\mathrm{x}$ & $\bar{x}$ & 21,2 & 3,3 & 17,4 & 5,6 & 1,22 & 1.55 & 0,16 \\
\hline 66 & Rio Claro & $\mathbf{X}$ & & $X$ & 19,5 & 3,0 & 14,9 & 4,8 & 1,31 & 1,55 & 0,15 \\
\hline 67 & Rio Claro & & $\mathrm{x}$ & $x$ & 17,1 & 1,6 & 16,6 & 4,9 & 1,03 & 1,69 & 0,09 \\
\hline 68 & Rio Claro & & $\mathrm{X}$ & $X$ & 21,4 & 1,6 & 19,6 & 6,6 & 1,09 & 1,48 & 0,07 \\
\hline 69 & Rio Claro & & $\mathrm{X}$ & $X$ & 18,4 & 2,1 & 16,5 & 5,0 & 1,12 & 1,65 & 0,11 \\
\hline 70 & Rio Claro & & $\mathrm{X}$ & $\mathrm{X}$ & 18,2 & 2,5 & 15,0 & 3,0 & 1,21 & 2,50 & 0,14 \\
\hline 71 & Rio Claro & $x$ & & $X$ & & 2,9 & 12,8 & 4,3 & & 1,49 & \\
\hline 72 & Rio Claro & $\mathbf{x}$ & & $\mathbf{X}$ & 16,4 & 4,3 & 13,5 & 3,5 & 1,21 & 1,93 & 0,26 \\
\hline 73 & Rio Claro & & $\mathrm{X}$ & $x$ & 13,5 & 1,2 & 12,8 & 3,5 & 1,05 & 1,83 & 0,09 \\
\hline 74 & Rio Claro & $x$ & & $x$ & 12,8 & 2,4 & 10,3 & 3,1 & 1,24 & 1,66 & 0,19 \\
\hline 75 & Rio Claro & $\mathrm{X}$ & & $x$ & 14,4 & 2,7 & 11,6 & 3,5 & 1,24 & 1,66 & 0,19 \\
\hline 76 & Rio Claro & & $\mathrm{x}$ & $\mathbf{x}$ & 11,3 & 1,8 & 10,5 & 3,0 & 1,08 & 1,75 & 0,16 \\
\hline 77 & Rio Claro & & $\mathrm{X}$ & $\mathbf{x}$ & 19,6 & 3,1 & 16,4 & 4,6 & 1,20 & 1,78 & 0,16 \\
\hline 78 & Rio Claro & & $\mathbf{X}$ & $x$ & & 3,8 & 17,3 & 5,8 & & 1,49 & \\
\hline 79 & Rio Claro & $\mathrm{x}$ & & $\mathrm{X}$ & 16,4 & 3,6 & 14,6 & 4,7 & 1,12 & 1,55 & 0,22 \\
\hline 80 & Rio Claro & $\mathrm{x}$ & & $X$ & 14,3 & 3,0 & 11,9 & 3,8 & 1,20 & 1,57 & 0,21 \\
\hline 81 & Rio Claro & $X$ & & $x$ & 15,3 & 3,0 & 13,1 & 3,3 & 1,17 & 1,98 & 0,20 \\
\hline 82 & Rio Claro & & $\mathrm{X}$ & $x$ & 16,0 & 2,7 & 14,5 & 5,8 & 1,10 & 1,25 & 0,17 \\
\hline 83 & Rio Claro & Arti & & $\mathrm{X}$ & 22,7 & 2,9 & 20,0 & 9,0 & 1,13 & 2,22 & 0,13 \\
\hline 84 & Rio Claro & & $x$ & $x$ & & & 18,2 & 5,7 & & 1,60 & \\
\hline 85 & Rio Claro & & $\mathrm{x}$ & $\mathrm{x}$ & & 3,1 & 17,2 & 6,4 & & 1,34 & \\
\hline 86 & Rio Claro & & $x$ & $\bar{X}$ & 18,7 & 1,6 & 17,2 & 4,7 & 1,09 & 1,83 & 0,09 \\
\hline 87 & Rio Claro & & $x$ & $\mathrm{X}$ & 14,4 & 2,4 & 11,8 & 3,1 & 1,22 & 1,90 & 0,17 \\
\hline 88 & Rio Claro & $\mathrm{x}$ & & $\mathbf{x}$ & 17,2 & 2,7 & 14,0 & 3,7 & 1,23 & 1,89 & 0,16 \\
\hline 89 & Rio Claro & & $x$ & $x$ & 16,2 & 2,2 & 13,0 & 4,5 & 1,25 & 1,44 & 0,14 \\
\hline 90 & Rio Claro & & $x$ & $x$ & 15,7 & 2,8 & 13,1 & 4,7 & 1,20 & 1,39 & 0,18 \\
\hline 91 & Rio Claro & $\mathbf{X}$ & & $x$ & 16,4 & 3,0 & 13,0 & 3,9 & 1,26 & 1,67 & 0,18 \\
\hline 92 & Rio Claro & $x$ & & $x$ & 16,8 & 3,6 & 15,6 & 4,9 & 1,08 & 1,59 & 0,21 \\
\hline 94 & Rio Claro & $x$ & & $x$ & 17,7 & 3,1 & 13,9 & 3,7 & 1,27 & 1,88 & 0,18 \\
\hline 96 & Rio Claro & $x$ & & $\mathbf{X}$ & 16,0 & 3,6 & 12,7 & 2,1 & 1,26 & 3,02 & 0,23 \\
\hline 98 & Rio Claro & & $\mathrm{x}$ & $x$ & 19,1 & 3,6 & & 5,0 & & & 0,19 \\
\hline 100 & Rio Claro & & $x$ & $X$ & 14,6 & 1,8 & 11,8 & 4,9 & 1,24 & 1,20 & 0,12 \\
\hline 101 & Rio Claro & & $x$ & $x$ & & 2,4 & 18,5 & 6,3 & & 1,47 & \\
\hline 102 & Rio Claro & & $\mathbf{X}$ & $x$ & & & 14,6 & 6,0 & & 1,22 & \\
\hline
\end{tabular}




\begin{tabular}{|c|c|c|c|c|c|c|c|c|c|c|c|c|}
\hline 103 & Rio Claro & & $\bar{X}$ & & $\bar{x}$ & 14,8 & 2,1 & 12,7 & 3,3 & 1,17 & 1,92 & 0,14 \\
\hline 109 & Rio Claro & $\mathrm{X}$ & & & $\mathbf{X}$ & & 1,9 & & & & & \\
\hline 110 & Rio Claro & & $\mathrm{X}$ & & $\mathbf{X}$ & & 1,4 & 8,8 & 2,4 & & 1,83 & \\
\hline 111 & Rio Claro & & $\mathbf{x}$ & & $\bar{X}$ & 6,8 & 1,4 & 6,0 & 3,2 & 1,13 & 0,94 & 0,21 \\
\hline 112 & Rio Claro & & $\mathrm{X}$ & & $\mathrm{X}$ & 6,8 & 0,8 & 5,8 & 0,8 & 1,17 & 3,63 & 0,12 \\
\hline 113 & Rio Claro & $\mathrm{X}$ & & & $\mathbf{X}$ & & 0,8 & & 1,6 & & & \\
\hline 114 & Rio Claro & & $\mathrm{X}$ & & $\mathbf{X}$ & & 2,4 & 16,6 & 3,5 & & 2,37 & \\
\hline 115 & Rlo Claro & & $\mathbf{X}$ & & 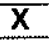 & 15,5 & & & & & & \\
\hline 116 & Rio Claro & & $\bar{X}$ & & $x$ & 13,8 & 3,7 & 11,9 & & 1,16 & & 0,27 \\
\hline 117 & Rio Claro & & $\mathbf{X}$ & & $x$ & & 2,5 & 14,0 & 3,9 & & 1,79 & \\
\hline 118 & Rio Claro & & $x$ & & $\mathbf{X}$ & 21,2 & 3,3 & 19,4 & 6,5 & 1,09 & 1,49 & 0,16 \\
\hline 120 & Rio Claro & $x$ & & & $\mathbf{X}$ & 12,6 & 3,0 & 11,0 & & 1,15 & & 0,24 \\
\hline 121 & Rio Claro & & $\mathrm{X}$ & & $x$ & & 2,5 & & 1,6 & & & \\
\hline 122 & Rio Claro & & $\bar{x}$ & & $\mathbf{X}$ & 12,8 & 1,5 & 10,8 & & 1,19 & & 0,12 \\
\hline 125 & Rio Claro & & $\mathrm{X}$ & & $\mathrm{X}$ & 16,0 & 2,3 & 14,2 & & 1,13 & & 0,14 \\
\hline 126 & Rio Claro & & $\mathrm{x}$ & & $\bar{x}$ & & 2,9 & & 3,5 & & & \\
\hline 127 & Rio Claro & $\mathbf{X}$ & & & $x$ & & 3,9 & 13,3 & 3,4 & & 1,96 & \\
\hline 128 & Rio Claro & $\bar{x}$ & & & $\mathbf{X}$ & & 3,7 & & 1,0 & & & \\
\hline 130 & Rio Claro & $x$ & & & $\mathbf{X}$ & 12,0 & 2,0 & 10,1 & 3,9 & 1,19 & 1,29 & 0,17 \\
\hline 131 & Rio Claro & $\bar{x}$ & & & $X$ & & 3,8 & & 3,4 & & & \\
\hline 132 & Rlo Claro & & $\mathbf{X}$ & & $x$ & 9,8 & 1,4 & 7,5 & & 1,31 & & 0,14 \\
\hline 133 & Rio Claro & $x$ & & & 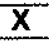 & & 3,3 & 14,3 & 3,5 & & 2,04 & \\
\hline 134 & Rio Claro & $\mathrm{x}$ & & & $x$ & 15,4 & 2,8 & 11,8 & & 1,31 & & 0,18 \\
\hline 135 & Rjo Claro & & $\mathbf{X}$ & & $\bar{x}$ & & 2,4 & & 3,0 & & & \\
\hline 136 & Rio Claro & & 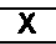 & & $\mathrm{X}$ & 11,1 & 1,0 & 8,3 & 2,5 & 1,34 & 1,66 & 0,09 \\
\hline 137 & Rio Claro & & $\mathbf{X}$ & & $\bar{X}$ & & 2,4 & & 1,2 & & & \\
\hline 138 & Rio Claro & & $\bar{X}$ & & $\mathbf{X}$ & & 3,0 & 14,4 & 2,4 & & 3,00 & \\
\hline 139 & Rio Claro & & $\mathbf{X}$ & & $\mathbf{x}$ & 14,6 & 1,4 & 15,1 & & 0,97 & & 0,10 \\
\hline 140 & Rio Claro & $\mathrm{X}$ & & & $\mathbf{X}$ & & 3,1 & & 2,7 & & & \\
\hline 141 & Rio Claro & & $\mathbf{X}$ & & $\mathbf{X}$ & & 3,3 & & 3,9 & & & \\
\hline 143 & Rio Claro & $\bar{x}$ & & & $\mathbf{X}$ & & 2,8 & & 2,4 & & & \\
\hline 144 & Rio Claro & & $\mathrm{X}$ & & $\mathbf{X}$ & 14,2 & 1,6 & 12,3 & 2,4 & 1.15 & 2,56 & 0,11 \\
\hline 145 & Rio Claro & & $\mathrm{X}$ & & $\mathbf{X}$ & & 2,8 & & 4,2 & & & \\
\hline 146 & Rio Claro & & $\bar{x}$ & & $\mathbf{x}$ & 12,0 & 2,5 & 11,8 & 2,7 & 1,02 & 2,19 & 0,21 \\
\hline 147 & Rio Claro & $\mathbf{X}$ & & & $x$ & 12,0 & 2,4 & 9,4 & 2,4 & 1,28 & 1,96 & 0,20 \\
\hline 148 & Rio Claro & Art & ada & & $\mathbf{X}$ & 13,8 & 2,6 & 11,6 & 5,9 & 1,19 & 0,98 & 0,19 \\
\hline 149 & Rio Claro & & $\bar{X}$ & & $x$ & 17,2 & 3,4 & 13,5 & 4,9 & 1,27 & 1,38 & 0,20 \\
\hline 150 & Rio Claro & & $\mathbf{X}$ & & $\bar{x}$ & 12,4 & 2,6 & 10,9 & & 1,14 & & 0,21 \\
\hline 151 & Rio Claro & & $\mathrm{X}$ & & $x$ & 13,3 & 2,0 & 11,3 & 3,3 & 1,18 & 1,71 & 0,15 \\
\hline 152 & Rio Claro & & $\mathbf{x}$ & & $\mathbf{X}$ & 14,0 & 2,7 & 12,3 & 2,2 & 1,14 & 2,80 & 0.19 \\
\hline 153 & Rio Claro & $\mathrm{X}$ & & & $\mathbf{X}$ & 16,2 & 4,5 & & 0,9 & & & 0,28 \\
\hline 154 & Rio Claro & & $\mathbf{X}$ & & $\mathbf{X}$ & & 3,8 & 20,0 & 5,0 & & 2,00 & \\
\hline 155 & Rio Claro & & $\mathrm{X}$ & & $\bar{X}$ & & 0,9 & 7,4 & 1,1 & & 3,36 & \\
\hline 156 & Rio Claro & $x$ & & & $\mathbf{X}$ & 17,0 & 4,6 & 12,8 & 4,4 & 1,33 & 1,45 & 0,27 \\
\hline 157 & Rio Claro & & $\mathbf{X}$ & & $\mathrm{X}$ & 18,1 & 2,6 & 15,0 & 5,0 & 1,21 & 1,50 & 0,14 \\
\hline 158 & Rio Claro & & $\mathbf{X}$ & & $\mathbf{X}$ & 18,7 & 2,8 & & 5,4 & & & 0,15 \\
\hline 159 & Rio Claro & $X$ & & & $\mathrm{X}$ & 14,0 & & 11,5 & 3,4 & 1,22 & 1,69 & \\
\hline 550 & Rio Claro & & $\mathbf{X}$ & & $\bar{X}$ & & & 10,3 & & & & \\
\hline 552 & Rio Claro & & $\mathbf{X}$ & & $\bar{X}$ & 14,3 & 2,8 & 11,8 & 4,4 & 1,21 & 1,34 & 0,20 \\
\hline 553 & Rio Claro & & $\mathrm{X}$ & & $\mathrm{X}$ & 11,9 & 1,4 & 9,4 & 3,0 & 1,27 & 1,57 & 0,12 \\
\hline 554 & Rio Claro & & $\bar{X}$ & & $\bar{x}$ & 13,9 & 2,9 & 10,4 & 4,2 & 1,34 & 1,24 & 0,21 \\
\hline 555 & Rio Claro & & $\mathbf{X}$ & & $\bar{X}$ & & & 10,3 & 3,9 & & 1,32 & \\
\hline 556 & Rio Claro & 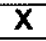 & & & $\mathbf{X}$ & 12,9 & 2,4 & 10,6 & 3,9 & 1,22 & 1,36 & 0,19 \\
\hline 557 & Rio Claro & $\mathbf{X}$ & & & $\bar{X}$ & & 2,0 & 9,4 & 3,7 & & 1,27 & \\
\hline 558 & Rjo Claro & & $x$ & & $\bar{x}$ & 14,1 & 2,8 & 13,9 & 5,5 & 1,01 & 1,26 & 0,20 \\
\hline 560 & Rio Claro & & $\mathrm{X}$ & & $\mathbf{X}$ & 12,4 & 1,1 & 11,2 & 3,0 & 1,11 & 1,87 & 0,09 \\
\hline 562 & Rio Claro & & $\mathbf{X}$ & & $\mathbf{x}$ & 12,6 & 3,3 & 10,4 & 2,8 & 1,21 & 1,86 & 0,26 \\
\hline 563 & Rio Claro & & $\mathbf{X}$ & & $\mathbf{X}$ & & & 12,9 & 5,8 & & 1,11 & \\
\hline 564 & Rio Claro & $\bar{x}$ & & & $\mathbf{X}$ & 18,8 & 2,8 & 15,0 & 5,3 & 1,25 & 1,42 & 0,15 \\
\hline 565 & Rio Claro & $\mathbf{x}$ & & & $\mathbf{X}$ & 16,4 & 2,6 & 12,3 & 4,7 & 1,33 & 1,31 & 0,16 \\
\hline 566 & Rio Claro & $x$ & & & $\mathbf{X}$ & 18,8 & 4,5 & 15,3 & 7,1 & 1,23 & 1,08 & 0,24 \\
\hline 568 & Rio Claro & $x$ & & $\mathbf{X}$ & & 10,5 & 2,4 & 7,2 & & 1,46 & & 0,23 \\
\hline 573 & Rio Claro & & $\mathbf{X}$ & & $\bar{X}$ & & & 16,9 & 5,6 & & 1,51 & \\
\hline 574 & Rio Claro & & $\mathrm{X}$ & & $\bar{x}$ & 15,0 & 1,5 & 12,5 & 3,0 & 1,20 & 2,08 & 0,10 \\
\hline 575 & Rio Claro & & $\mathbf{X}$ & & $\mathbf{X}$ & 12,7 & 1,6 & 8,9 & 3,7 & 1,43 & 1,20 & 0,13 \\
\hline 576 & Rio Claro & & $X$ & & $x$ & & 1,4 & 11,3 & 4,4 & & 1,28 & \\
\hline 578 & Rio Claro & $x$ & & & $\mathbf{X}$ & 11,0 & 1,4 & 8,4 & 2,1 & 1,31 & 2,00 & 0,13 \\
\hline 579 & Rio Claro & & $\mathrm{X}$ & & $\mathbf{X}$ & 9,3 & 2,2 & & 3,0 & & & 0,24 \\
\hline 581 & Rio Claro & & $\mathrm{X}$ & & $\mathbf{X}$ & 5,1 & 0,5 & 3,8 & 1,7 & 1,34 & 1,12 & 0,10 \\
\hline 582 & Rio Claro & & ada & & $\mathbf{x}$ & 15,8 & 2,1 & 11,9 & 10,0 & 1,33 & 1,19 & 0,13 \\
\hline 583 & Rio Claro & & $\mathbf{X}$ & & $\mathbf{X}$ & 18,9 & 3,1 & & 5,0 & & & 0,16 \\
\hline 584 & Rio Claro & 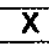 & & & $\mathbf{X}$ & & 2,7 & 9,0 & 2,1 & & 2,14 & \\
\hline
\end{tabular}




\begin{tabular}{|c|c|c|c|c|c|c|c|c|c|c|c|}
\hline 585 & Rio Claro & & $\mathbf{X}$ & $\bar{x}$ & & & 19,5 & 5,0 & & 1,95 & \\
\hline 586 & Rio Claro & & $x$ & $\mathbf{X}$ & & & 12,4 & 4,0 & & 1,55 & \\
\hline 588 & Rio Claro & & $\mathbf{x}$ & $\mathbf{x}$ & 12,5 & & 9,6 & 2,7 & 1,30 & 1,78 & \\
\hline 589 & Rio Claro & & $x$ & $x$ & & 2,8 & 8,9 & 4,6 & & 0,97 & \\
\hline 592 & Rio Claro & $\mathbf{X}$ & & $\mathbf{x}$ & 12,1 & 2,8 & 9,9 & 2,9 & 1,22 & 1,71 & 0,23 \\
\hline 601 & Rio Claro & $\mathbf{X}$ & & $x$ & & 3,3 & 12,9 & 3,8 & & 1,70 & \\
\hline 602 & Rio Claro & 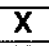 & & $\mathrm{x}$ & & & 10.9 & 3,7 & & 1,47 & \\
\hline 603 & Rio Claro & $\mathbf{x}$ & & $x$ & 11,1 & 2,5 & 9,2 & 2,7 & 1,21 & 1,70 & 0,23 \\
\hline 604 & Rio Claro & & $x$ & $\mathrm{x}$ & 8,9 & 2,9 & 5,9 & 2,3 & 1,51 & 1,28 & 0,33 \\
\hline 605 & Rio Claro & & $\mathrm{x}$ & $x$ & & & 10,0 & 4,5 & & 1,11 & \\
\hline 606 & Rio Claro & $x$ & & $\mathbf{X}$ & & 2,8 & 9,0 & 3,0 & & 1,50 & \\
\hline 607 & Rio Claro & & $\mathrm{x}$ & $\mathrm{X}$ & 9,3 & 1,1 & 7,4 & 2,0 & 1,26 & 1,85 & 0,12 \\
\hline 608 & Rio Claro & $\mathrm{x}$ & & $\mathrm{X}$ & & & 10,6 & 3,5 & & 1,51 & \\
\hline 609 & Rio Claro & & $\mathrm{x}$ & $X$ & 15,0 & 2,1 & 13,0 & 4,6 & 1,15 & 1,41 & 0,14 \\
\hline 610 & Rio Claro & & $x$ & $x$ & 12,4 & 2,6 & 10,8 & 3,4 & 1,15 & 1,59 & 0,21 \\
\hline 611 & Rio Claro & & $\mathrm{x}$ & $x$ & 14,9 & 2,5 & 13,3 & 5,5 & 1,12 & 1,21 & 0,17 \\
\hline 612 & Rio Claro & $x$ & & $X$ & 12,0 & 2,4 & 10,9 & 3,4 & 1,10 & 1,60 & 0,20 \\
\hline 620 & Rio Claro & & $\mathbf{x}$ & $\mathrm{X}$ & 15,0 & 2,9 & 12,5 & 10,0 & 1,20 & 0,63 & 0,19 \\
\hline 622 & Rio Claro & & $x$ & $\mathrm{X}$ & & & 18,8 & 8,9 & & 1,06 & \\
\hline 623 & Rio Claro & $\mathbf{x}$ & & $x$ & 10,1 & 2,3 & 7,8 & 2,4 & 1,29 & 1,63 & 0,23 \\
\hline 624 & Rio Claro & & $\mathrm{X}$ & $\bar{x}$ & 20,0 & 3,0 & 18,2 & 4,5 & 1,10 & 2,02 & 0,15 \\
\hline 629 & Rio Claro & & $\mathrm{X}$ & $\mathrm{X}$ & 15,1 & 1,9 & 12,2 & 4,4 & 1,24 & 1,39 & 0,13 \\
\hline 634 & Rio Claro & & $x$ & $x$ & 11,3 & 1,8 & 10,0 & & 1,13 & & 0,16 \\
\hline 635 & Rio Claro & & $x$ & $x$ & 11,9 & 2,7 & 9,9 & 2,8 & 1,20 & 1,77 & 0,23 \\
\hline 636 & Rio Claro & & $x$ & $\mathrm{X}$ & & & 5,8 & 2,8 & & 1,04 & \\
\hline 637 & Rio Claro & & $\mathrm{x}$ & $X$ & 14,5 & & 11,0 & 3,3 & 1,32 & 1,67 & \\
\hline 638 & Rio Claro & $\mathbf{X}$ & & $\mathbf{X}$ & & 2,0 & 11,5 & 3,5 & & 1,64 & \\
\hline 639 & Rio Claro & & $x$ & $\mathbf{x}$ & & & 18,0 & 8,5 & & 1,06 & \\
\hline 640 & Rio Claro & & $x$ & $\mathbf{X}$ & 12,0 & 2,0 & 10,3 & 3,4 & 1,17 & 1,51 & 0,17 \\
\hline 641 & Rio Claro & & $x$ & $\mathbf{X}$ & 11,9 & 2,0 & 8,9 & 3,0 & 1,34 & 1,48 & 0,17 \\
\hline 642 & Rio Claro & & $\mathrm{x}$ & $\mathrm{X}$ & 14,0 & 1,8 & 13,0 & 5,0 & 1,08 & 1,30 & 0,13 \\
\hline 643 & Rio Claro & & $\mathrm{X}$ & $\mathbf{x}$ & & 1,9 & 11,0 & 4,7 & & 1,17 & \\
\hline 649 & Rio Claro & & $\mathrm{X}$ & $\mathrm{X}$ & 16,0 & 1,9 & 13,0 & 5,6 & 1,23 & 1,16 & 0,12 \\
\hline 650 & Rio Claro & & $\mathrm{X}$ & $x$ & & 2,5 & 10,4 & 3,4 & & 1,53 & \\
\hline 651 & Rio Claro & & $\bar{x}$ & $x$ & 14,0 & 2,2 & 11,0 & 3,7 & 1,27 & 1,49 & 0,16 \\
\hline 652 & Rio Claro & & $x$ & $X$ & 17,7 & 2,0 & 9,5 & 5,2 & 1,86 & 0,91 & 0,11 \\
\hline 653 & Rio Claro & & $\mathbf{X}$ & $x$ & 16,0 & 1,6 & 13,8 & 5,4 & 1,16 & 1,28 & 0,10 \\
\hline 654 & Rio Claro & & $X$ & $\bar{x}$ & 12,9 & 1,2 & 11,4 & 4,0 & 1,13 & 1,43 & 0.09 \\
\hline 655 & Rio Claro & & $X$ & $\mathbf{x}$ & & 1,9 & 11,7 & 3,1 & & 1,89 & \\
\hline 656 & Rio Claro & & $\mathrm{X}$ & $\mathrm{x}$ & & & 12,9 & 4,3 & & 1,50 & \\
\hline 665 & Rio Claro & & $\mathrm{X}$ & $x$ & 11,9 & 3,2 & & 2,9 & & & 0,27 \\
\hline 666 & Rio Claro & $\mathbf{X}$ & & $\mathrm{x}$ & 11,0 & 2,0 & 8,5 & 4,0 & 1,29 & 1,06 & 0,18 \\
\hline 667 & Rio Claro & & $\mathrm{X}$ & $x$ & 10,4 & 1,4 & 5,5 & 2,7 & 1,89 & 1,02 & 0,13 \\
\hline 668 & Rio Claro & $\mathbf{X}$ & & $\mathrm{X}$ & & & 12,5 & 4,9 & & 1,28 & \\
\hline 669 & Rio Claro & & $\mathbf{X}$ & $\mathbf{X}$ & 13,3 & 2,5 & 10,8 & 3,9 & 1,23 & 1,38 & 0,19 \\
\hline 670 & Rio Claro & $\mathbf{X}$ & & $x$ & 17,8 & 3,5 & 13,8 & 4,7 & 1,29 & 1,47 & 0,20 \\
\hline 671 & Rio Claro & & $X$ & $X$ & 12,6 & 2,5 & 10,2 & 3,1 & 1,24 & 1,65 & 0,20 \\
\hline 672 & Rio Claro & $\mathrm{X}$ & & $x$ & 11,5 & 2,8 & 9,5 & 3,1 & 1,21 & 1,53 & 0,24 \\
\hline 673 & Rio Claro & & $X$ & $\mathbf{x}$ & 12,2 & 1,9 & & 2,4 & & & 0,16 \\
\hline 674 & Rio Claro & & $x$ & $x$ & 16,4 & 3,8 & 13,7 & 5,6 & 1,20 & 1,22 & 0,23 \\
\hline $705 a$ & Rio Claro & & $\mathrm{X}$ & $\mathbf{x}$ & 19,6 & 3,3 & 11,2 & 6,6 & 1,75 & 0,85 & 0,17 \\
\hline $705 b$ & Rio Claro & $\mathrm{X}$ & & $x$ & 19,0 & 3,2 & 18,2 & 6.1 & 1,04 & 1,49 & 0,17 \\
\hline 706 & Rio Claro & \multicolumn{2}{|c|}{ Articulada } & $\mathrm{x}$ & 20,3 & 3,0 & 17,5 & 18,2 & 1,16 & 0,96 & 0,15 \\
\hline 713 & Rio Claro & & $\bar{x}$ & $x$ & & & 12,0 & 3,6 & & 1,67 & \\
\hline 714 & Rio Claro & & $\bar{X}$ & $x$ & 15,0 & 2,6 & 13,3 & 4,4 & 1,13 & 1,51 & 0,17 \\
\hline 715 & Rio Claro & & $x$ & $x$ & 20,0 & 3,5 & 17,5 & 6.4 & 1,14 & 1,37 & 0,18 \\
\hline 716 & Rio Claro & $\mathbf{X}$ & & $x$ & 12,0 & 2,5 & 11,6 & 3.9 & 1,03 & 1,49 & 0,21 \\
\hline 717 & Rio Claro & & $x$ & $\mathbf{x}$ & 12,0 & 1,6 & 9,5 & 3.5 & 1,26 & 1,36 & 0,13 \\
\hline 722 & Rio Claro & & $x$ & $x$ & 17,5 & 3,1 & 15,6 & 5,1 & 1,12 & 1,53 & 0,18 \\
\hline 723 & Rio Claro & $\bar{x}$ & & $\mathbf{X}$ & 17.5 & 2,9 & 15,0 & 5,5 & 1,17 & 1,36 & 0,17 \\
\hline 724 & Rio Claro & & $x$ & $x$ & 11,7 & 1,8 & 8,8 & 3,5 & 1,33 & 1,26 & 0,15 \\
\hline 725 & Rio Claro & $x$ & & $\mathbf{x}$ & & 3,2 & 17,7 & 6,8 & & 1,30 & \\
\hline 726 & Rio Claro & & $\mathrm{x}$ & $x$ & & & 15,5 & 5,9 & & 1,31 & \\
\hline 728 & Rio Claro & & $X$ & $x$ & 18,5 & 2,8 & 16,7 & 7,5 & 1,11 & 1,11 & 0,15 \\
\hline 729 & Rio Claro & & $\mathrm{X}$ & $\mathrm{x}$ & 17,8 & 5,0 & 14,4 & 5,8 & 1,24 & 1,24 & 0,28 \\
\hline 731 & Rio Claro & & $x$ & $\mathbf{x}$ & 9,9 & 2,5 & & 2,5 & & & 0,25 \\
\hline 732 & Rio Claro & \multicolumn{2}{|c|}{ Articulada } & $x$ & 6,0 & 0,9 & 4,3 & 2,5 & 1,40 & 1,72 & 0,15 \\
\hline 733 & Rio Claro & $\bar{x}$ & & $\mathbf{x}$ & 10,4 & 2,0 & 7,7 & 2,7 & 1,35 & 1,43 & 0,19 \\
\hline 734 & Rio Claro & $\mathrm{X}$ & & $x$ & 15,0 & 3,0 & 12,5 & 4,4 & 1,20 & 1,42 & 0,20 \\
\hline 737 & Rio Claro & $\mathrm{X}$ & & $x$ & 16,9 & 3,4 & 13,9 & 4,0 & 1,22 & 1,74 & 0,20 \\
\hline 738 & Rio Claro & & $\bar{x}$ & $\mathrm{X}$ & & & 15,5 & 4,2 & & 1,85 & \\
\hline 750 & Rio Claro & \multicolumn{2}{|c|}{ Articulada } & $\mathbf{X}$ & 21,2 & 2,8 & 20,4 & 13,3 & 1,04 & 1,53 & 0,13 \\
\hline
\end{tabular}




\begin{tabular}{|c|c|c|c|c|c|c|c|c|c|c|}
\hline 751 & Rio Claro & Articulada & $\mathbf{x}$ & 17,5 & 4,7 & 17,4 & 17,4 & 1,00 & 0,98 & 0,27 \\
\hline 752 & Rio Claro & Articulada & $x$ & 10,0 & 1,6 & 8,9 & 7,0 & 1.12 & 1,27 & 0,16 \\
\hline 753 & Rio Claro & $\mathbf{x}$ & $x$ & 13,9 & 1,3 & 11,9 & 2,8 & 1,17 & 2,13 & 0,09 \\
\hline 1938 & & $x$ & & 19,0 & & 16,0 & & 1,19 & & \\
\hline 1939 & & $x$ & & 17,0 & & 15,0 & & 1,13 & & \\
\hline & & & & & & & & 1,24 & 1,55 & 0,17 \\
\hline
\end{tabular}

\section{Plesiocyprinella carinata}

\begin{tabular}{|c|c|c|c|c|c|c|c|c|c|c|c|c|}
\hline$n^{\circ}$ & afloramento & VD & VE & MI & $\mathbf{s}$ & C & CA & $\mathbf{A}$ & $\mathbf{L}$ & C/A & ALL. & CA/C \\
\hline & & & & & & & & & & & & \\
\hline 440 & Rio Claro & & $\bar{x}$ & & $x$ & & & 35,4 & 9,7 & & 1,82 & \\
\hline 441 & Rio Claro & & $\bar{x}$ & & $x$ & & 8,8 & & 7,6 & & & \\
\hline 442 & Rio Claro & & $\bar{x}$ & & $\bar{x}$ & 40,5 & 9,4 & 34,2 & 13,8 & 1,18 & 1,24 & 0,23 \\
\hline 443 & Rio Claro & & $\bar{x}$ & & $\bar{x}$ & & 6,4 & 25,8 & 9,1 & & 1,42 & \\
\hline 448 & Rio Claro & $\bar{x}$ & & & $\bar{x}$ & 24,6 & 7,7 & 18,3 & 9 & 1,34 & 1,01 & 0,31 \\
\hline 449 & Rio Claro & & $\mathrm{x}$ & & $x$ & 22,9 & 6,9 & 17,2 & 6,6 & 1,33 & 1,30 & 0,30 \\
\hline 450 & Rio Claro & & $\mathrm{x}$ & & $x$ & 34,9 & 10,9 & 32,8 & 12,8 & 1,06 & 1,28 & 0,31 \\
\hline 454 & Rio Claro & & $\bar{X}$ & & $\bar{X}$ & & 7,2 & & 15,3 & & & \\
\hline 455 & Rio Claro & & $\overline{\mathbf{X}}$ & & $\bar{x}$ & & & 31,3 & 15,3 & & 1,02 & \\
\hline 456 & Rio Claro & & $x$ & & $\bar{x}$ & 43,3 & 10,5 & 34,8 & 12,9 & 1,24 & 1,35 & 0,24 \\
\hline $457 a$ & Rio Claro & $\bar{x}$ & & & $x$ & 40,7 & & 35,1 & 15,5 & 1,16 & 1,13 & \\
\hline $457 \mathrm{~b}$ & Rio Claro & $\bar{x}$ & & & $x$ & & 16,3 & & 11,8 & & & \\
\hline 458 & Rio Claro & $\bar{x}$ & & & $\bar{x}$ & 9,2 & 2,8 & 7 & 2,1 & 1,31 & 1,66 & 0,30 \\
\hline 459 & Rio Claro & $\bar{x}$ & & & $\bar{x}$ & & & 38 & 10 & & 1,9 & \\
\hline 460 & Rio Claro & & $x$ & $\bar{x}$ & & & 12,3 & 36,4 & 10,9 & & 1,67 & \\
\hline 463 & Rio Claro & & $x$ & & $x$ & & 4,5 & $\sqrt{14,2}$ & 6,3 & & 1,12 & \\
\hline 466 & Rio Claro & & $\mathrm{X}$ & & $\bar{x}$ & 37,2 & 8,7 & 31,5 & 11,3 & 1,18 & 1,39 & 0,23 \\
\hline 467 & Rio Claro & & $\bar{x}$ & $\mathrm{x}$ & & & 8,8 & 34,2 & 11,8 & & 1,45 & \\
\hline 468 & Rio Claro & & $\mathrm{x}$ & & $\mathrm{x}$ & & 6,8 & & 8,4 & & & \\
\hline 469 & Rio Claro & $\bar{x}$ & & & $\bar{X}$ & & 8,1 & & 10,3 & & & \\
\hline 470 & Rio Claro & & $\bar{x}$ & & $\bar{x}$ & & 6,8 & 22,9 & 6,6 & & 1,73 & \\
\hline 471 & Rio Claro & & $\mathrm{X}$ & & $\mathrm{X}$ & & 11,5 & & 12,9 & & & \\
\hline 593 & Rio Claro & & $\mathbf{x}$ & & $\bar{x}$ & 33,7 & 10,9 & & 11 & & & 0,32 \\
\hline 594 & Rio Claro & $x$ & & & $x$ & & & 35 & 11,3 & & 1,55 & \\
\hline 600 & Rio Claro & $\overline{\mathbf{X}}$ & & & & & 4,3 & 13,7 & 5,6 & & 1,22 & \\
\hline 647 & Rio Claro & & $\mathrm{x}$ & & $\mathrm{X}$ & 40,4 & 19,7 & 29,9 & 9,8 & 1,35 & 1,52 & 0,49 \\
\hline 681 & Rio Claro & & & & $\bar{x}$ & 40,2 & 6,4 & 35,4 & 38 & 1,13 & 0,93 & 0,16 \\
\hline 735 & Rio Claro & & $\bar{x}$ & & & & 8,6 & & 10,9 & & & \\
\hline & & & & Méc & & & & & & 1,23 & 1,39 & 0,29 \\
\hline
\end{tabular}

\section{Runnegariella fragilis}

\begin{tabular}{|c|c|c|c|c|c|c|c|c|c|c|c|c|}
\hline $\mathbf{n}^{\circ}$ & Afloramento & VD & VE & MI & $\mathbf{S}$ & C & CA & A & $L$ & C/A & $A / L$ & CA/C \\
\hline & & & & & & & & & & & & \\
\hline 832 & Porangaba & $x$ & & & $\mathbf{X}$ & 5,0 & 1,0 & 3,9 & 0,6 & 1,28 & 3,25 & 0,2 \\
\hline 833 & Porangaba & \multicolumn{2}{|c|}{ Articulado } & & $\bar{x}$ & 11,0 & 4,5 & 8,8 & 5,0 & 1,25 & 1,76 & 0,41 \\
\hline 834 & Porangaba & $\bar{x}$ & & & $x$ & 4,2 & 2,0 & 3,0 & 0,8 & 1,4 & 1,87 & 0,48 \\
\hline & & & & Més & & & & & & 1.31 & 2.29 & 0.36 \\
\hline
\end{tabular}




\section{Terraiopsis aequilateralis}

\begin{tabular}{|c|c|c|c|c|c|c|c|c|c|c|c|c|}
\hline$n$ & afloramento & VD & VE & MI & $\mathbf{S}$ & C & CA & $\bar{A}$ & $\mathrm{~L}$ & $\mathrm{C} / \mathrm{A}$ & AlL & CA/C \\
\hline & & & & & & & & & & & & \\
\hline 406 & Rio Claro & & $\mathrm{x}$ & & $\mathbf{x}$ & & 8,8 & 13,6 & 3,4 & & 2,0 & \\
\hline 407 & Rio Claro & 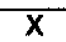 & & & $\mathrm{X}$ & & & 15,4 & 5,4 & & $\overline{1,42}$ & \\
\hline 408 & Rio Claro & & $\mathbf{x}$ & & $x$ & 21 & & & 4,9 & & & \\
\hline 411 & Rio Claro & & $\bar{X}$ & & $\bar{X}$ & & 5,9 & & 4,4 & & & \\
\hline 412 & Rio Claro & $\bar{x}$ & & & $\mathbf{X}$ & & 4,4 & 10 & 2,4 & & 2,08 & \\
\hline 413 & Rio Claro & $\bar{x}$ & & & $x$ & & 5,2 & 14,7 & 4,3 & & 1,71 & \\
\hline 414 & Rio Claro & & & & $\bar{X}$ & 23,1 & 6,4 & 19,2 & 12,8 & 1,20 & 1,5 & 0,28 \\
\hline 416 & Rio Claro & & $\mathbf{X}$ & & $\bar{x}$ & & & 11,4 & 4,8 & & 1,19 & \\
\hline 418 & Rio Claro & $x$ & & & $x$ & & 6,4 & 16 & 4,8 & & 1,66 & \\
\hline 419 & Rio Claro & $\bar{x}$ & & & $x$ & & 7,4 & 14,6 & 4,9 & & 1,49 & \\
\hline 420 & Rio Claro & & $\mathrm{X}$ & & $\mathrm{X}$ & & & 15,8 & 6 & & 1,31 & \\
\hline 421 & Rio Claro & & $\mathrm{X}$ & & $x$ & & 6,9 & & 6,9 & & & \\
\hline 422 & Rio Claro & & $\mathrm{X}$ & & $\bar{x}$ & & 5.7 & 15,5 & 4,9 & & 1,58 & \\
\hline 423 & Rio Claro & $\bar{X}$ & & & $\bar{X}$ & 16,4 & 5,4 & 12,3 & 5,4 & 1,33 & 1,14 & 0,33 \\
\hline 424 & Rio Claro & & $\bar{x}$ & & $\bar{x}$ & & 4,7 & 15,5 & 5,6 & & 1,38 & \\
\hline 425 & Rio Claro & & $\bar{x}$ & & $x$ & & 5,3 & 11,9 & 5,5 & & 1,08 & \\
\hline 426 & Rio Claro & & $\bar{x}$ & & $\bar{x}$ & 23,3 & 7.7 & 18,3 & 7,9 & 1,27 & 1,16 & 0,33 \\
\hline 427 & Rio Claro & & $X$ & & $x$ & & 6,6 & 7,3 & 6,8 & & 0,53 & \\
\hline 428 & Rio Claro & & $\bar{x}$ & & $\bar{X}$ & 27,7 & 8,6 & 20,2 & 6,4 & 1,37 & 1,58 & 0,31 \\
\hline 429 & Rio Claro & $\bar{x}$ & & & $x$ & & 5,8 & 13,9 & 3,4 & & 2,04 & \\
\hline 430 & Rio Claro & $\bar{x}$ & & & $\bar{x}$ & & 7,4 & 14 & 5,7 & & 1,22 & \\
\hline 432 & Rio Claro & & $\bar{x}$ & & $\bar{x}$ & 18,5 & 5,6 & 14,7 & 4,8 & 1,26 & 1,53 & 0,3 \\
\hline 433 & Rio Claro & & $\bar{X}$ & & $x$ & 19,3 & 6,1 & 14,2 & 5,5 & 1,36 & 1,29 & 0,32 \\
\hline 434 & Rio Claro & & $\bar{x}$ & & $x$ & 14,8 & 5,0 & 11,6 & 4,6 & 1,27 & 1,26 & 0,34 \\
\hline 435 & Rio Claro & $\bar{x}$ & & & $x$ & & 6,6 & 16,3 & 5,6 & & 1,45 & \\
\hline 436 & Rio Claro & $\overline{\mathbf{X}}$ & & & $\bar{x}$ & 16,8 & 7,4 & 12,4 & 5,9 & 1,35 & 1,05 & 0,44 \\
\hline 437 & Rio Claro & & $x$ & & $\bar{x}$ & 10.3 & 2,6 & 8,4 & 3,9 & 1,23 & 1,07 & 0,25 \\
\hline 544 & Rio Claro & & $\bar{x}$ & & $\bar{X}$ & & 7,0 & 15,6 & 5,8 & & 1,34 & \\
\hline 545 & Rio Claro & & $x$ & & $\mathrm{x}$ & 15,5 & 4,6 & 13,8 & 3,6 & 1,12 & 1,91 & 0,30 \\
\hline 627 & Rio Claro & $x$ & & & $x$ & & 6,3 & 14,8 & 6,5 & & 1,38 & \\
\hline 646 & Rio Claro & & $\mathbf{X}$ & & $\bar{x}$ & & 6,9 & 13,3 & 5,4 & & 1,23 & \\
\hline 710 & Rio Claro & & $x$ & & $x$ & 24,0 & & 20,2 & 6,3 & 1,19 & 1,60 & \\
\hline 711 & Rio Claro & & $\mathbf{X}$ & & $x$ & & & 18,1 & 6,4 & & 1,41 & \\
\hline 739 & Rio Claro & $\bar{X}$ & & & $\mathbf{X}$ & 9,3 & 3,4 & 7,4 & 1,6 & 1,25 & 2,31 & 0,36 \\
\hline 741 & Rio Claro & & $\bar{x}$ & & $\bar{x}$ & & 6,8 & 17,3 & 6,9 & & 1,25 & \\
\hline 742 & Rio Claro & & $x$ & & $x$ & 17,9 & 4,7 & 15 & 6,6 & 1,19 & 1,13 & 0,26 \\
\hline & & & & édia & & & & & & 1,26 & 1,43 & 0,32 \\
\hline
\end{tabular}

\section{Infauna intermediária}

\section{Angatubia cowperesioides}

\begin{tabular}{|c|c|c|c|c|c|c|c|c|c|c|c|c|}
\hline $\mathbf{n}^{\circ}$ & afloramento & $\mathbf{V D}$ & $\mathbf{V E}$ & $\mathbf{M I}$ & $\mathbf{S}$ & $\mathbf{C}$ & $\mathbf{C A}$ & $\mathbf{A}$ & $\mathbf{L}$ & $\mathbf{C} / \mathbf{A}$ & $\mathbf{A} / \mathbf{L}$ & $\mathbf{C A} / \mathbf{C}$ \\
\hline $\begin{array}{c}\text { GP/1T } \\
7 / 45\end{array}$ & Angatuba & $\mathbf{X}$ & & & $\mathbf{X}$ & 18,0 & 4,0 & 12,0 & 3,0 & 1,5 & 2 & 0,22 \\
\hline $\begin{array}{c}\text { GP/1T } \\
7 / 942\end{array}$ & Angatuba & & $\mathbf{X}$ & & $\mathbf{X}$ & 18,0 & 4,0 & 11,0 & 3,0 & 1,64 & 1,83 & 0,22 \\
\hline $\begin{array}{c}\text { GP/1T } \\
7 / 943\end{array}$ & Angatuba & $\mathbf{X}$ & & & $\mathbf{X}$ & 16,0 & 3,0 & 10,0 & 2,0 & 1,6 & 2,5 & 0,18 \\
\hline $\begin{array}{c}\text { GP/1T } \\
7 / 944\end{array}$ & Angatuba & $\mathbf{X}$ & & & $\mathbf{X}$ & 16,0 & 4,0 & 11,0 & 2,5 & 1,45 & 2,2 & 0,25 \\
\hline $\begin{array}{c}\text { GP/1T } \\
7 / 945\end{array}$ & Angatuba & $\mathbf{X}$ & & & $\mathbf{X}$ & 14,0 & 4,0 & 9,0 & 2,5 & 1,55 & 1,8 & 0,28 \\
\hline & & & & & & & & & & \\
\hline
\end{tabular}


Casterella gratiosa

\begin{tabular}{|c|c|c|c|c|c|c|c|c|c|c|c|c|}
\hline $\mathrm{n}^{\circ}$ & afloramento & VD & VE & $M I$ & $\mathbf{S}$ & C & CA & A & $\mathrm{L}$ & $\mathrm{C} / \mathrm{A}$ & $\mathrm{A} / \mathrm{L}$ & CA/C \\
\hline & & & & & & & & & & & & \\
\hline 476 & Rio Claro & & $\mathrm{x}$ & & $\mathrm{X}$ & 23,3 & 5 & & 6,4 & & & 0,21 \\
\hline 477 & Rio Claro & $x$ & & $x$ & & & 11,6 & 24 & 6,9 & & 1,74 & \\
\hline 479 & Rio Claro & $x$ & & & $\bar{x}$ & & 8,4 & & 9,1 & & & \\
\hline 480 & Rio Claro & & $x$ & $\mathrm{X}$ & & 28,6 & 9,6 & 23,3 & 9,0 & 1,23 & 1,29 & 0,33 \\
\hline 481 & Rio Claro & & $\bar{X}$ & $x$ & & 18,4 & 7,5 & 12,8 & 4,6 & 1,43 & 1,39 & 0,41 \\
\hline 483 & Rio Claro & $\mathrm{x}$ & & & $\mathrm{x}$ & 34,8 & 8,4 & 26,8 & 10,2 & 1,30 & 1,31 & 0,24 \\
\hline 485 & Rjo Claro & $x$ & & & $x$ & 30,3 & 8,4 & 23,8 & 9,5 & 1,27 & 1,25 & 0,27 \\
\hline 486 & Rio Claro & $\mathrm{X}$ & & $\mathrm{X}$ & & 30,5 & 10,7 & 24,5 & 7,4 & 1,24 & 1,65 & 0,35 \\
\hline 489 & Rio Claro & $\bar{x}$ & & $\mathrm{X}$ & & 18,8 & 6,6 & 15,6 & 12,8 & 1,20 & 1,22 & 0,35 \\
\hline 490 & Rio Claro & & $\mathrm{X}$ & $\mathbf{X}$ & & 18,3 & 5,3 & 14,3 & 6,9 & 1,28 & 1,04 & 0,29 \\
\hline 491 & Rio Claro & $x$ & & $\mathrm{X}$ & & 18 & 4,2 & 14,6 & 3,8 & 1,23 & 1,92 & 0,23 \\
\hline 492 & Rio Claro & $X$ & & & $\mathrm{X}$ & & & 22,9 & 8,4 & & 1,36 & \\
\hline 494 & Rio Claro & & $x$ & $\bar{x}$ & & 27 & 7,6 & & 7,2 & & & 0,28 \\
\hline 495 & Rio Claro & & $\mathrm{x}$ & $\bar{x}$ & & 26,9 & 7,6 & 21,5 & 8,8 & 1,25 & 1,22 & 0,28 \\
\hline 571 & Rio Claro & & $x$ & $X$ & & 18,8 & 4,7 & 16,1 & 4,0 & 1,17 & 2,01 & 0,25 \\
\hline 572 & Rio Claro & & $\bar{X}$ & $\mathrm{X}$ & & & 6,8 & 20,5 & 11 & & 0,93 & \\
\hline 708 & Rio Claro & & $\mathbf{X}$ & $x$ & & 22,8 & 6,0 & 12,9 & 8,6 & 1,77 & 0,75 & 0,26 \\
\hline 709 & Rjo Claro & & $\mathrm{x}$ & & $\mathrm{x}$ & 32,9 & 7,7 & 26,9 & 9,0 & 1,22 & 1,49 & 0,23 \\
\hline 718 & Rio Claro & & $\bar{x}$ & $\mathrm{X}$ & & 32 & 9,9 & & 7,4 & & & 0,31 \\
\hline 743 & Rio Claro & & $\mathrm{X}$ & & $\mathrm{X}$ & 28,5 & 8,3 & 21,8 & 8,0 & 1,30 & 1,36 & 0,29 \\
\hline 744 & Rio Claro & $\bar{x}$ & & $\bar{x}$ & & 29 & 9,3 & 25,1 & 7,8 & 1,15 & 1,61 & 0,32 \\
\hline & & & & Méc & & & & & & 1,29 & 1,38 & 0,29 \\
\hline
\end{tabular}

\section{Cowperesia anceps}

\begin{tabular}{|c|c|c|c|c|c|c|c|c|c|c|c|c|}
\hline$\overline{n^{\circ}}$ & afloramento & VD & $\mathrm{VE}$ & MI & $\mathbf{s}$ & C & CA & A & $\mathbf{L}$ & C/A & A/L. & CA/C \\
\hline & & & & & & & & & & & & \\
\hline 534 & Rio Claro & $\bar{x}$ & & $\bar{x}$ & & 11,4 & 4,9 & 6,6 & & 1,73 & & 0,43 \\
\hline 536 & Rio Claro & & $\mathrm{X}$ & & $\bar{X}$ & 10,4 & 3,9 & 7,4 & 2,1 & 1,40 & 1,76 & 0,37 \\
\hline 537 & Rio Claro & $\bar{x}$ & & $\mathbf{X}$ & & 9,4 & 5,4 & 6,3 & & 1,49 & & 0,57 \\
\hline 613 & Rio Claro & & $\mathbf{X}$ & $\bar{x}$ & & 9,0 & 4,5 & & & & & 0,5 \\
\hline 614 & Rio Claro & & $x$ & $\bar{x}$ & & 6,4 & 2,9 & 3,6 & & 1,78 & & 0,45 \\
\hline 645 & Rio Claro & & $\bar{x}$ & $\bar{x}$ & & 12,5 & 5,4 & 8,3 & & 1,50 & & 0,43 \\
\hline 1437 & Tambaú & & $\mathrm{x}$ & & $\bar{x}$ & 9,3 & 0,6 & 6,9 & & 1,35 & & 0,06 \\
\hline 1438 & Tambaú & & $\bar{x}$ & & $\bar{x}$ & 10 & 1,4 & 8,4 & & 1,19 & & 0,14 \\
\hline 1439 & Tambaú & & $\mathrm{X}$ & & $\bar{x}$ & 8,2 & 0,5 & 3,9 & & 2,10 & & 0,06 \\
\hline 1443 & Tambaú & & $\bar{x}$ & & $\bar{x}$ & 7,5 & 0,4 & 4,4 & & 1,70 & & 0,05 \\
\hline 1444 & Tambaú & & $\bar{x}$ & & $\bar{x}$ & 7,5 & 0,4 & 3,2 & & 2,34 & & 0,05 \\
\hline 1445 & Tambaú & & $\bar{x}$ & & $x$ & 8,8 & 0,3 & 4,5 & & 1,96 & & 0,03 \\
\hline 1450 & Tambaú & & $\bar{x}$ & & $x$ & 6,8 & 0,6 & 5 & & 1,36 & & 0,09 \\
\hline 1453 & Tambaú & & $\mathrm{X}$ & & $x$ & 5 & 0,1 & 3 & & 1,67 & & 0,02 \\
\hline 1457 & Tambaú & & $\mathrm{X}$ & & $x$ & 7,4 & 0,3 & 4,1 & & 1,80 & & 0,04 \\
\hline 1459 & Tambaú & $\bar{X}$ & & & $\bar{x}$ & 4,0 & 0,1 & 1,9 & & 2,10 & & 0,02 \\
\hline 1464 & Tambaú & & $\bar{X}$ & & $\bar{x}$ & 8,4 & 0,4 & 7,4 & & 1,13 & & 0,05 \\
\hline 1468 & Tambaú & $\bar{x}$ & & & $\bar{x}$ & 9,8 & 1,7 & 6 & & 1,63 & & 0,17 \\
\hline 1469 & Tambaú & & $\bar{x}$ & & $\bar{x}$ & 7,5 & 0,9 & 5,8 & & 1,3 & & 0,12 \\
\hline 1475 & Tambaú & & $\bar{x}$ & & $x$ & 6,4 & 0,2 & 3,3 & & 1,94 & & 0,03 \\
\hline 1477 & Tambaú & $\bar{x}$ & & & $\bar{x}$ & 9,4 & 0,8 & 4 & & 2,35 & & 0,08 \\
\hline 1478 & Tambaú & $\ddot{x}$ & & & $x$ & 8,8 & 0,5 & 5,8 & & 1,52 & & 0,06 \\
\hline 1481 & Tambaú & & $\bar{X}$ & & $x$ & 6,6 & 0,3 & 4,8 & & 1,37 & & 0,04 \\
\hline 1487 & Tambaú & $\bar{x}$ & & & $x$ & 8,9 & 1 & 5,8 & & 1,53 & & 0,1 \\
\hline 1489 & Tambaú & $x$ & & & $x$ & 9,8 & 0,7 & 6 & & 1,63 & & 0,07 \\
\hline 1493 & Tambaú & $x$ & & & $x$ & 4,8 & 0,2 & 3 & & 1,6 & & 0,04 \\
\hline 1494 & Tambaú & & $\bar{x}$ & & $x$ & 10 & 0,5 & 5,3 & & 1,89 & & 0,05 \\
\hline 1495 & Tambaú & & $\bar{x}$ & & $x$ & 10,4 & 0,8 & 7,6 & & 1,37 & & 0,08 \\
\hline 1496 & Tambaú & $\mathrm{X}$ & & & $\bar{x}$ & 8,8 & 1,3 & 6.9 & & 1,27 & & 0,15 \\
\hline
\end{tabular}




\begin{tabular}{|c|c|c|c|c|c|c|c|c|c|c|c|c|}
\hline 1500 & Tambaú & & $\bar{x}$ & & $\bar{X}$ & 7,4 & 0,4 & 3,4 & & 2,17 & & 0,05 \\
\hline 1503 & Tambaú & $\mathrm{x}$ & & & $\mathbf{x}$ & 7,5 & 1 & 4,4 & & 1,7 & & 0,13 \\
\hline 1504 & Tambaú & $\bar{x}$ & & & $\mathrm{X}$ & 10.4 & 0,8 & 5,2 & & 2 & & 0,08 \\
\hline 1505 & Tambaú & & $x$ & & $\mathbf{X}$ & 9,4 & 0,6 & 6 & & 1,57 & & 0,06 \\
\hline 1509 & Tambaú & & $\mathbf{x}$ & & $\mathrm{x}$ & 6,9 & 0,3 & 4,6 & & 1,5 & & 0,04 \\
\hline 1513 & Tambaú & $\bar{x}$ & & & $\bar{x}$ & 11,5 & 1,8 & 5,8 & & 1,98 & & 0,16 \\
\hline 1518 & Tambaú & $\mathrm{X}$ & & & $\mathrm{X}$ & 11,6 & 0,7 & 7,5 & & 1,55 & & 0,06 \\
\hline 1523 & Tambaú & $\bar{x}$ & & & $\bar{x}$ & 10,4 & 0,9 & 6,4 & & 1,6 & & 0,08 \\
\hline 1524 & Tambaú & & $x$ & & $x$ & 8,9 & 0,7 & 5 & & 1,78 & & 0,08 \\
\hline 1525 & Tambaú & $\bar{x}$ & & & $\mathrm{X}$ & 7,5 & 0,6 & 5,5 & & 1,36 & & 0,08 \\
\hline 1538 & Tambaú & $\bar{X}$ & & & $\mathbf{X}$ & 9,8 & 1,6 & 6 & & 1,63 & & 0,16 \\
\hline 1542 & Tambaú & $x$ & & & $x$ & 9 & 0,4 & 7 & & 1,28 & & 0,04 \\
\hline 1545 & Tambaú & & $\bar{x}$ & & $x$ & 7 & 1 & 4,6 & & 1,52 & & 0,14 \\
\hline 1547 & Tambaú & $\mathrm{X}$ & & & $x$ & 10,2 & 0,8 & 5,9 & & 1,73 & & 0,08 \\
\hline 1548 & Tambaú & & $x$ & & $\bar{x}$ & 11 & 0,9 & 6,8 & & 1,62 & & 0,08 \\
\hline 1550 & Tambaú & & $\bar{X}$ & & $\mathbf{X}$ & 8.5 & 0,4 & 4,5 & & 1,89 & & 0,05 \\
\hline 1723 & Tambaú & & $\bar{x}$ & & $x$ & 7,4 & 1 & 6,9 & & 1,07 & & 0,13 \\
\hline 1724 & Tambaú & $\bar{x}$ & & & $x$ & 12,4 & 1,9 & 6,5 & & 1,9 & & 0,15 \\
\hline 1725 & Tambaú & $\mathrm{X}$ & & & $x$ & 11,8 & 0,9 & 5,9 & & 2 & & 0,08 \\
\hline 1726 & Tambaú & $x$ & & & $x$ & 8,8 & 1 & 6 & & 1,47 & & 0,11 \\
\hline 1731 & Tambaú & & $\bar{x}$ & & $\mathbf{X}$ & 12,8 & 2,5 & 9 & & 1,42 & & 0,19 \\
\hline 1739 & Tambaú & $\bar{x}$ & & & $\mathrm{X}$ & 6,3 & 0,5 & 2,4 & & 2,62 & & 0,08 \\
\hline 1744 & Tambaú & $\mathrm{X}$ & & & $\mathrm{X}$ & 7,8 & 0,7 & 5,9 & & 2 & & 0,09 \\
\hline 1794 & Tambaú & $x$ & & & $x$ & 8.9 & 1 & 7 & & 1,27 & & 0,11 \\
\hline 1795 & Tambaú & & $x$ & & $x$ & 15,3 & 2,4 & 11 & & 1,39 & & 0,16 \\
\hline 1796 & Tambaú & $\mathrm{x}$ & & & $x$ & 9,4 & 0,5 & 6,8 & & 1,38 & & 0,05 \\
\hline $1969 a$ & & & \multirow{2}{*}{\multicolumn{2}{|c|}{$\begin{array}{l}\text { Articulada } \\
\text { Articulada }\end{array}$}} & $\bar{x}$ & & 0,56 & 1,1 & 0,7 & 1,31 & 1,57 & 0,39 \\
\hline $1969 b$ & & & & & $\mathrm{X}$ & 1,85 & 0,7 & 1,1 & 0,83 & 1,32 & 1,68 & 0,39 \\
\hline $1969 d$ & & & 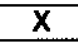 & & $\mathbf{X}$ & & & 1,3 & 0,3 & & 2,1 & \\
\hline $1969 f$ & & & $\mathrm{X}$ & & $x$ & 1,55 & 0,74 & 1.42 & 0,37 & 1,37 & 1,14 & 0,38 \\
\hline $1969 \mathrm{fg}$ & & & & $x$ & $\mathbf{X}$ & 1,57 & 0,6 & 1,16 & 0,25 & 1,35 & 2,32 & 0,38 \\
\hline $1969 \mathrm{~h}$ & & & & $\mathrm{x}$ & $\mathrm{X}$ & & & 1,08 & 0,26 & & 2,07 & \\
\hline $1969 i$ & & & & & $\mathbf{x}$ & 1,44 & 0,5 & 1,1 & 0,2 & 1,31 & 2,75 & 0,35 \\
\hline $1969 \mathrm{j}$ & & & \multicolumn{2}{|c|}{ Articulada } & $\mathbf{x}$ & 1,5 & 0,5 & 1,2 & 0,51 & 1,25 & 2,35 & 0,33 \\
\hline $\begin{array}{c}\text { GP/1T } \\
451\end{array}$ & Rio Claro & $\mathrm{X}$ & & $x$ & & 18,0 & 7,0 & 14,0 & 4,0 & 1,28 & 1,75 & 0,39 \\
\hline $\begin{array}{c}\text { GP/1T } \\
45 \text { II }\end{array}$ & Rio Claro & & $\bar{X}$ & $\bar{X}$ & & 16,0 & 6,0 & 12,0 & 3,0 & 1,33 & 2,0 & 0,12 \\
\hline $\begin{array}{c}\text { GP/1T } \\
45 \mathrm{III}\end{array}$ & Rio Claro & & $\bar{x}$ & $\mathbf{X}$ & & 16,5 & 5,0 & 13,0 & 3,0 & 1,27 & 2,17 & 0,30 \\
\hline $\begin{array}{l}\text { GP/1T } \\
45 \mathrm{IV}\end{array}$ & Rio Claro & & $\bar{x}$ & $\bar{X}$ & & 17,0 & 4,0 & 11,0 & 3,0 & 1,54 & 1,83 & 0,24 \\
\hline $\begin{array}{l}\text { GP/1T } \\
45 \mathrm{~V}\end{array}$ & Rio Claro & & $\bar{X}$ & $x$ & & 17,0 & 5,0 & 13,0 & 3,0 & 1,31 & 2,17 & 0,29 \\
\hline $\begin{array}{l}\mathrm{GP} / 1 \mathrm{~T} \\
45 \mathrm{VI}\end{array}$ & Rio Claro & & $\bar{X}$ & $\bar{X}$ & & 17,0 & 4,5 & 11,0 & 2,0 & 1,54 & 2,75 & 0,26 \\
\hline $\begin{array}{c}\mathrm{GP} / 1 \mathrm{~T} \\
46\end{array}$ & Rio Claro & $\mathrm{X}$ & & $\bar{x}$ & & 14,0 & 6,0 & 9,5 & & 1,47 & & 0,43 \\
\hline $\begin{array}{c}\mathrm{GP} / 1 \mathrm{~T} \\
47\end{array}$ & Rio Claro & $\bar{X}$ & & $\bar{x}$ & & 10,0 & 3,0 & 7,5 & & 1,33 & & 0,3 \\
\hline $\begin{array}{c}\mathrm{GP} / 1 \mathrm{~T} \\
48\end{array}$ & Rio Claro & $\bar{X}$ & & $\bar{x}$ & & 12,0 & 4,0 & 8,0 & 3,0 & 1,5 & 1,33 & 0,33 \\
\hline $\begin{array}{c}\mathrm{GP} / 1 \mathrm{~T} \\
49\end{array}$ & Rio Claro & $x$ & & $\bar{X}$ & & 15,0 & 3,5 & 11,0 & 3,8 & 1,36 & 1,49 & 0,23 \\
\hline $\begin{array}{c}\text { GP/1T } \\
511 \\
\end{array}$ & Rio Claro & $\mathrm{X}$ & & $\bar{X}$ & & 14,0 & 4,5 & 11,0 & 2,0 & 1,27 & 2,75 & 0,32 \\
\hline $\begin{array}{c}\mathrm{GP} / 1 \mathrm{~T} \\
51 \|\end{array}$ & Rio Claro & & $\bar{X}$ & $x$ & & 13,0 & 4,0 & 10,0 & 2,0 & 1,3 & 2,5 & 0,31 \\
\hline $\begin{array}{c}\text { GP/1T } \\
51111\end{array}$ & Rio Claro & & $\bar{x}$ & $\mathrm{X}$ & & 17,0 & 7,5 & 13,0 & 2,5 & 1,31 & 2,6 & 0,44 \\
\hline $\begin{array}{c}\text { GP/1T } \\
52\end{array}$ & Rio Claro & $\mathbf{X}$ & & $\bar{x}$ & & 14,5 & 5,0 & 11,0 & 2,0 & 1,32 & 2,75 & 0,34 \\
\hline $\begin{array}{c}\mathrm{GP} / 1 \mathrm{~T} \\
53 \\
\end{array}$ & Rio Claro & & $\bar{x}$ & $\bar{x}$ & & 12,0 & 4,0 & 9,0 & 2,0 & 1,33 & 2,25 & $0, \overline{33}$ \\
\hline $\begin{array}{c}\mathrm{GP} / 1 \mathrm{~T} \\
541 \\
\end{array}$ & Rio Claro & & $\bar{x}$ & $\mathrm{X}$ & & 10,5 & 3,2 & 9,5 & & 1,11 & & 0,30 \\
\hline $\begin{array}{c}\text { GP/1T } \\
54 \mathrm{II}\end{array}$ & Rio Claro & $\bar{x}$ & & $\mathbf{X}$ & & 10,5 & 4,0 & 7,0 & & 1,5 & & 0,38 \\
\hline $\begin{array}{l}\text { GP/1T } \\
54111 \\
\end{array}$ & Rio Claro & & $x$ & $\bar{x}$ & & 11,0 & & 8,0 & & 1,37 & & \\
\hline GP/1T & Rio Claro & & $x$ & $x$ & & 11,0 & 4,0 & 7,0 & 1,0 & 1,57 & 3,5 & 0,36 \\
\hline
\end{tabular}




\begin{tabular}{|c|c|c|c|c|c|c|c|c|c|c|c|c|}
\hline 54 IV & & & & & & & & & \\
\hline $\begin{array}{c}\text { GP/1T } \\
515\end{array}$ & Rio Claro & $\mathbf{X}$ & & $\mathbf{X}$ & & 17,0 & 4,5 & 12,0 & 3,0 & 1,41 & 2,0 & 0,26 \\
\hline $\begin{array}{c}\text { GP/1T } \\
516\end{array}$ & Rio Claro & & $\mathbf{X}$ & $\mathbf{X}$ & & 17,5 & 6,0 & 12,0 & 3,0 & 1,41 & 2,0 & 0,34 \\
\hline \multicolumn{3}{|c|}{ Média } \\
\hline \multicolumn{10}{|c|}{}
\end{tabular}

Itatamba paraima

\begin{tabular}{|c|c|c|c|c|c|c|c|c|c|c|c|c|}
\hline$n^{\circ}$ & afloramento & VD & VE & MI & $\mathbf{s}$ & $\mathrm{C}$ & CA & $\bar{A}$ & $\mathbf{L}$ & $\mathrm{C} / \mathrm{A}$ & $\mathrm{A} / \mathrm{L}$ & CA/C \\
\hline & & & & & & & & & & & & \\
\hline 496 & Angatuba & $\bar{x}$ & & & $\mathbf{X}$ & & 10,4 & & 12,6 & & & \\
\hline 497 & Angatuba & & $\mathbf{X}$ & & $\mathbf{X}$ & & 8,3 & 31,4 & 12,4 & & & \\
\hline 498 & Angatuba & $\bar{x}$ & & & $x$ & 36,8 & 9,6 & 29,9 & 11 & 1,23 & 1,36 & 0,28 \\
\hline 499 & Angatuba & $\bar{X}$ & & & $x$ & & & 26,8 & 10,8 & & 1,24 & \\
\hline 500 & Angatuba & $\bar{X}$ & & & $\mathrm{X}$ & & & 42,7 & 16 & & 1,33 & \\
\hline 501 & Angatuba & & $\bar{x}$ & & $x$ & & & 40,7 & 15,8 & & 1,29 & \\
\hline & & & & Méc & & & & & & 1,23 & 1,30 & 0,28 \\
\hline
\end{tabular}

\section{Infauna profunda}

\section{Roxoa corumbataiensis}

\begin{tabular}{|c|c|c|c|c|c|c|c|c|c|c|c|c|}
\hline$n^{\circ}$ & afloramento & VD & VE & MI & $\mathbf{S}$ & C & CA & $\mathbf{A}$ & $\mathrm{L}$ & $C / A$ & A/L & CA/C \\
\hline & & & & & & & & & & & & \\
\hline 532 & Rio Claro & $\bar{X}$ & & & $\bar{X}$ & 24,0 & 4,0 & 11,0 & 3,0 & 2,18 & 1,83 & 0,16 \\
\hline 533 & Rio Claro & & $\mathbf{X}$ & $\mathbf{X}$ & & 21,0 & 4,0 & 9,0 & 3,0 & 2,33 & 1,5 & 0,19 \\
\hline 550 & Rio Claro & & $\bar{x}$ & & $\bar{x}$ & 25,0 & 3,0 & 14,0 & 5,0 & 1,78 & 1,4 & 0,12 \\
\hline 551 & Rio Claro & \multicolumn{2}{|c|}{ Articulada } & $\mathbf{X}$ & & 26,0 & 7,0 & 14,0 & 8,0 & 1,85 & 0,87 & 0,27 \\
\hline 625 & Rio Claro & $\mathrm{X}$ & & $x$ & & 23,0 & 6,0 & 12,0 & 4,0 & 1,92 & 1,5 & 0,26 \\
\hline 678 & Rio Claro & $x$ & & & $\bar{x}$ & 27,0 & 6,0 & 15,0 & 3,0 & 1,8 & 2,5 & 0,22 \\
\hline 680 & Rlo Claro & $\bar{x}$ & & $x$ & & 25,0 & 6,0 & 13,0 & 3,0 & 1,92 & 2,17 & 0,24 \\
\hline 1846 & Rio Claro & & $\bar{X}$ & $x$ & & 25,0 & 7,0 & 11,0 & 5,0 & 2,27 & 1,1 & 0,28 \\
\hline & Rio Claro & $\bar{x}$ & & $x$ & & 24,0 & 4,0 & 11,0 & 4,0 & 6,0 & 1,37 & 0,17 \\
\hline $\begin{array}{c}\text { GP/1T } \\
7 / 62\end{array}$ & Rio Claro & $\bar{x}$ & & & $\bar{X}$ & 31,0 & 7,0 & 15,0 & 4,0 & 2,06 & 1,87 & 0,22 \\
\hline $\begin{array}{c}\mathrm{GP} / 1 \mathrm{~T} \\
7 / 65\end{array}$ & Rio Claro & \multicolumn{2}{|c|}{ Articulada } & $x$ & & 20 & 4,0 & 13,0 & 7,0 & 1,85 & 0,93 & 0,17 \\
\hline \multicolumn{10}{|c|}{ Média } & 2,36 & 1,55 & 0,21 \\
\hline
\end{tabular}




\section{Assembléia Pinzonella neotropica}

\section{Semi-infauna}

\section{Naiadopsis lamellosus}

\begin{tabular}{|c|c|c|c|c|c|c|c|c|c|c|c|c|}
\hline$n^{0}$ & afloramento & VD & VE & MI & $\mathbf{S}$ & C & CA & $\mathbf{A}$ & $\mathrm{L}$ & $\mathrm{C} / \mathrm{A}$ & A/L & CA/C \\
\hline & & & & & & & & & & & & \\
\hline 1446 & Tambaú & $\mathbf{X}$ & & & $\mathrm{X}$ & 44,0 & & 22,0 & 9,0 & 2,0 & 2,44 & \\
\hline 1475 & Tambaú & & $\bar{x}$ & & $\mathbf{x}$ & 45,0 & & 24,0 & 11,0 & 1,87 & 2,04 & \\
\hline 1745 & Tambaú & $\bar{x}$ & & & $x$ & 34,0 & & 14,0 & 10,0 & 2,42 & 1,7 & \\
\hline 1748 & Tambaú & & $\bar{X}$ & & $x$ & 42,0 & 2,5 & 18,0 & 10,0 & 2,33 & 2,1 & 0,05 \\
\hline 1754 & Tambaú & $\bar{x}$ & & & $\mathrm{X}$ & 43,0 & 3,0 & 23,0 & 16,0 & 1,87 & 1,34 & 0,07 \\
\hline 1757 & Tambaú & $\bar{x}$ & & & $\mathbf{x}$ & 39,0 & 6,0 & 20,0 & 14,0 & 1,95 & 1,39 & 0,15 \\
\hline 1760 & Tambaú & $\bar{x}$ & & & $\mathrm{X}$ & 46,0 & 5,0 & 20,0 & 11,0 & 2,3 & 2,09 & 0.10 \\
\hline 1765 & Tambaú & & $\bar{x}$ & & $\mathrm{x}$ & 32,0 & 2,5 & 14,0 & 10,0 & 2,28 & 1,6 & 0,08 \\
\hline 1767 & Tambaú & $\mathbf{X}$ & & & $\mathrm{X}$ & 39,0 & 3,0 & 18,0 & 7,0 & 2,17 & 2,78 & 0,08 \\
\hline 1770 & Tambaú & $\bar{x}$ & & & $x$ & 45,0 & 4,5 & 21,0 & 12,0 & 2,14 & 1,87 & 0,1 \\
\hline 1772 & Tambaú & $\bar{x}$ & & & $\mathbf{x}$ & 44,0 & 4,0 & 14,0 & 11,0 & 3,14 & 2,0 & 0,09 \\
\hline 1773 & Tambaú & & $\bar{X}$ & & $\mathbf{X}$ & 44,0 & & 21,0 & 10,0 & 2,09 & 2.2 & \\
\hline 1774 & Tambaú & & $\bar{X}$ & & $\mathbf{X}$ & 46,0 & & 21,0 & 12,0 & 2,19 & 1,92 & \\
\hline 1777 & Tambaú & & $\bar{x}$ & & $x$ & 23,0 & 1,0 & 7,0 & & 3,28 & & 0,04 \\
\hline 1778 & Tambaú & $\bar{X}$ & & & $\bar{x}$ & 38,0 & 3,0 & 17,0 & 8,0 & 2,23 & 2,37 & 0,07 \\
\hline 1780 & Tambaú & $\bar{x}$ & & & $\mathbf{X}$ & 39,0 & 4,5 & 21,0 & 9,0 & 1,86 & 2,17 & 0,11 \\
\hline 1783 & Tambaú & $\bar{x}$ & & & $\mathbf{X}$ & 36,0 & 3,0 & 20,0 & 9,0 & 1,8 & 2,0 & 0,08 \\
\hline 1785 & Tambaú & $\bar{x}$ & & & $\mathrm{X}$ & 45,0 & 2,5 & 22,0 & 13,0 & 2,04 & 1,73 & 0,05 \\
\hline 1786 & Tambaú & $x$ & & & $X$ & 37,0 & 2,5 & 20,0 & 12,0 & 1,85 & 1,54 & 0,07 \\
\hline 1787 & Tambaú & $x$ & & & $\mathrm{X}$ & 45,0 & 5,0 & 20,0 & 11,0 & 2,25 & 2,04 & 0,11 \\
\hline 1788 & Tambaú & \multicolumn{2}{|c|}{ Articulada } & & $\mathbf{X}$ & 33,0 & 6,0 & 22,0 & 23,0 & 1,5 & 0,72 & 0,18 \\
\hline 1972 & Tambaú & \multicolumn{2}{|c|}{ Articulada } & & $\mathrm{X}$ & 40,0 & 5,0 & 17,0 & 31,0 & 2,35 & 0,64 & 0,12 \\
\hline 1974 & Tambaú & \multicolumn{2}{|c|}{ Articulada } & & $\mathbf{X}$ & 41,0 & 3,0 & 21,0 & 27,0 & 1,95 & 0,76 & 0,07 \\
\hline 1975 & Tambaú & \multicolumn{2}{|c|}{ Articulada } & & $\bar{x}$ & 39,0 & 1,0 & 16,0 & 19,0 & 2,43 & 1,03 & 0,02 \\
\hline 1976 & Tambaú & \multicolumn{2}{|c|}{ Articulada } & & $\mathbf{x}$ & 36,0 & 3,0 & 15,0 & 21,0 & 2,4 & 0,86 & 0,08 \\
\hline 1978 & Tambaú & \multicolumn{2}{|c|}{ Articulada } & & $x$ & 27,0 & 1,0 & 11,0 & 17,0 & 2,45 & 0,79 & 0,04 \\
\hline 2551 & Tambaú & $x$ & & & $x$ & 34,0 & 2,5 & 15,0 & 7,0 & 2,27 & 2,42 & 0,07 \\
\hline 2553 & Tambaú & $\mathbf{X}$ & & & $x$ & 56,0 & 4.5 & 18,0 & 13,0 & 3,11 & 2,15 & 0,08 \\
\hline 2559 & Tambaú & $\bar{x}$ & & & $\mathbf{x}$ & 44,0 & 5,0 & 18,0 & 6,0 & 2,44 & 3,66 & 0,11 \\
\hline 2561 & Tambaú & & $\mathbf{X}$ & & $\mathbf{x}$ & 59,0 & 3,5 & 39,0 & 6,0 & 1,51 & 4,92 & 0,06 \\
\hline 2562 & Tambaú & $\bar{x}$ & & & $x$ & 36,0 & 4,0 & 15,0 & 9,0 & 2,4 & 2,0 & 0,11 \\
\hline 2563 & Tambaú & $\bar{x}$ & & & $x$ & 45,0 & 2,5 & 18,0 & 10,0 & 2,5 & 2,25 & 0,05 \\
\hline 2564 & Tambaú & $x$ & & & $\mathrm{x}$ & 44,0 & 3,0 & 14,0 & 10,0 & 3,14 & 2,2 & 0,07 \\
\hline & & & & Mé & & & & & & 2,27 & 1,91 & 0,08 \\
\hline
\end{tabular}

\section{Infauna rasa}

\section{Jacquesia brasiliensis}

\begin{tabular}{|c|c|c|c|c|c|c|c|c|c|c|c|c|}
\hline$\overline{n^{\circ}}$ & afloramento & VD & $\overline{\text { VE }}$ & MI & $\mathbf{S}$ & C & CA & A & $\bar{L}$ & C/A & AlL & CA/C \\
\hline & & & & & & & & & & & & \\
\hline 528 & Anhembi & & $\bar{x}$ & & $\bar{x}$ & & & 23,3 & 5,8 & & 2,01 & \\
\hline 1789 & Tambaú & & $\bar{X}$ & & $\bar{x}$ & & & 12,0 & 9,4 & & 0,64 & \\
\hline 1790 & Tambaú & & $\bar{X}$ & & $\bar{x}$ & 31,0 & 7,0 & 17,8 & 6,4 & 1.74 & 1,39 & 0,22 \\
\hline 1791 & Tambaú & & $X$ & & $x$ & 30,0 & 5,4 & 25,6 & 9,4 & 1,17 & 1,36 & 0,18 \\
\hline 1793 & Tambaú & & 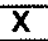 & & $\bar{x}$ & & 4,4 & 17,4 & 8,2 & & 1,06 & \\
\hline $\begin{array}{c}\text { GP/1T } \\
7 / 38\end{array}$ & Rio Claro & & $\bar{x}$ & & & 31,6 & 10,6 & 20,6 & 8,8 & 1,53 & 1.17 & 0,34 \\
\hline & & & & Méc & & & & & & 1,48 & 1,27 & 0,25 \\
\hline
\end{tabular}




\section{Pinzonella neotropica}

\begin{tabular}{|c|c|c|c|c|c|c|c|c|c|c|c|c|}
\hline$n^{\circ}$ & afloramento & VD & VE & MI & $\mathbf{S}$ & C & $\mathrm{CA}$ & $\bar{A}$ & $\mathrm{~L}$ & $\mathrm{C} / \mathrm{A}$ & $\overline{A L}$ & CAVC \\
\hline & & & & & & & & & & & & \\
\hline 160 & Anhembi & & $\mathbf{x}$ & & $\bar{X}$ & 8,0 & 0,5 & 6,0 & 1,7 & 1,34 & 1,76 & 0,06 \\
\hline 161 & Anhembi & $x$ & & & $\mathrm{X}$ & 7,7 & 0,6 & 4,9 & 1,7 & 1,6 & 1,44 & 0,08 \\
\hline 162 & Anhembi & $X$ & & & $x$ & 11,4 & 0,9 & 6,3 & 1,7 & 1,8 & 1,85 & 0,08 \\
\hline 163 & Anhembi & $x$ & & & $\bar{x}$ & 9,6 & 0,6 & 5,9 & 1,6 & 1,63 & 1,84 & 0,06 \\
\hline 164 & Anhembi & $\mathrm{X}$ & & & $\bar{x}$ & 5,8 & 0,2 & 3,7 & 0,7 & 1,57 & 2,64 & 0,03 \\
\hline 165 & Annembi & $\mathrm{X}$ & & & $\bar{X}$ & 6,6 & 0,8 & 4,6 & 1,4 & 1,43 & 1,64 & 0,12 \\
\hline 166 & Anhembi & $\bar{x}$ & & & $\mathbf{X}$ & 5,4 & 0,5 & 3,1 & 0,9 & 1,74 & 1,72 & 0,09 \\
\hline 167 & Anhembi & $\mathbf{X}$ & & & $\mathbf{X}$ & 6,4 & 0,7 & 4,5 & 1,0 & 1,42 & 2,25 & 0,11 \\
\hline 168 & Anhembi & $\bar{X}$ & & & $\mathrm{X}$ & 9,3 & 0,8 & 7,4 & 2,0 & 1,26 & 1,85 & 0,09 \\
\hline 169 & Anhembi & $\mathrm{X}$ & & & $x$ & 7,8 & 0,8 & 5,9 & 1,5 & 1,32 & 1,97 & 0,10 \\
\hline 170 & Anhembi & $X$ & & & $x$ & 9,3 & 1,4 & 5.5 & 1,5 & 1,7 & 1,83 & 0,15 \\
\hline 171 & Anhembi & $\bar{X}$ & & & $\bar{X}$ & 9,4 & 1,0 & 6,6 & 1,7 & 1,42 & 1,94 & 0,11 \\
\hline 172 & Anhembi & $x$ & & & $\mathbf{x}$ & 7,7 & 0,9 & 6.1 & 1,3 & 1,26 & 2,34 & 0,17 \\
\hline 173 & Anhembi & $X$ & & & $x$ & 7,3 & 0,3 & 4,9 & 1,5 & 1,49 & 1,63 & 0,04 \\
\hline 174 & Anhembi & $x$ & & & $\bar{X}$ & 8,3 & 0,6 & 5,9 & 1,6 & 1,41 & 1,84 & 0,07 \\
\hline 175 & Anhembi & $\mathrm{X}$ & & & $\bar{x}$ & 12,3 & 1,2 & 8,4 & 3,7 & 1,46 & 1,13 & 0,1 \\
\hline 176 & Anhembi & $\mathrm{X}$ & & & $\mathbf{X}$ & 10,4 & 1,0 & 7,4 & 3,4 & 1,40 & 1,09 & 0,1 \\
\hline 177 & Anhembi & $\mathrm{X}$ & & & $\mathbf{X}$ & 8,9 & 0,8 & 5,8 & 1,8 & 1,53 & 1,61 & 0,09 \\
\hline 178 & Anhembi & $\mathrm{X}$ & & & $\mathrm{X}$ & 8,9 & 0,9 & 6,4 & 1,3 & 1,4 & 2,46 & 0,1 \\
\hline 179 & Anhembi & & $x$ & & $\mathrm{X}$ & & & 4,6 & 1,6 & & 1,44 & \\
\hline 180 & Anhembi & & $\mathbf{X}$ & & $\bar{x}$ & 6,9 & 0,8 & 6,4 & 1,8 & 1,08 & 1,78 & 0,1 \\
\hline 181 & Anhembi & $\bar{x}$ & & & $x$ & 8,3 & 1,3 & 6,9 & 1,8 & 1,2 & 1,92 & 0,16 \\
\hline 182 & Anhembi & & $x$ & & $\bar{x}$ & 8,3 & 0,7 & 6,5 & 1,9 & 1,28 & 1,71 & 0,08 \\
\hline 183 & Anhembi & & $x$ & & $\bar{x}$ & 7,3 & 0,7 & 4,9 & 1,8 & 1,49 & 1,36 & 0,09 \\
\hline 184 & Anhembi & & $x$ & & $x$ & 8,4 & 0,7 & 5,6 & 2,3 & 1,5 & 1,22 & 0,08 \\
\hline 185 & Anhembi & & $\bar{x}$ & & $x$ & 9,2 & 0,9 & 6.2 & 2,7 & 1,49 & 2,30 & 0,1 \\
\hline 186 & Anhembi & $x$ & & & $x$ & & 1,6 & 6,6 & 1,6 & & 2,06 & \\
\hline 187 & Anhembi & & $\mathrm{X}$ & & $x$ & 9,8 & 0,8 & 8,3 & 2,7 & 1,18 & 1,54 & 0,08 \\
\hline 188 & Anhembi & & $\mathrm{X}$ & & $\mathbf{x}$ & 8,3 & 0,8 & 5,0 & 1,6 & 1,66 & 1,56 & 0,09 \\
\hline 189 & Anhembi & $x$ & & & $\mathrm{X}$ & 8,0 & 1,1 & 5,8 & 1,7 & 1,38 & 1,7 & 0,14 \\
\hline 190 & Anhembi & & $X$ & & $\mathrm{X}$ & 8,4 & 1,1 & 5,8 & 2,5 & 1,45 & 1,16 & 0,13 \\
\hline 191 & Anhembi & & $x$ & & $\bar{x}$ & 8,3 & 1,3 & & 1,8 & & & 0,16 \\
\hline 192 & Anhembi & & $\bar{X}$ & & $\bar{x}$ & 6.0 & 0,6 & 4,0 & 1,4 & 1,5 & 1,43 & 0,1 \\
\hline 193 & Anhembi & $x$ & & & $\mathrm{X}$ & 6.8 & 0,9 & 4,8 & 1,7 & 1,42 & 1,41 & 0,17 \\
\hline 194 & Anhembi & & $\bar{X}$ & & $\mathbf{X}$ & 12,9 & 1,8 & 7,6 & 2,0 & 1,7 & 1,9 & 0,14 \\
\hline 195 & Anhembi & & $x$ & & $\mathrm{X}$ & & & 11,3 & 3,9 & & 1,45 & \\
\hline 197 & Anhembi & & $x$ & & $\bar{x}$ & & & 6,3 & 2,0 & & 1,57 & \\
\hline 198 & Anhembi & $\bar{x}$ & & & $\bar{x}$ & 8,4 & 0,8 & 6,8 & 1,8 & 1,23 & 1,89 & 0,09 \\
\hline 199 & Anhembi & & $x$ & & $\bar{x}$ & & 0,1 & 4,0 & 1,4 & & 1,43 & \\
\hline 200 & Anhembi & $X$ & & & $\mathrm{X}$ & & 1,3 & 6,4 & 1,8 & & 1,78 & \\
\hline 201 & Anhembi & $\mathrm{X}$ & & & $\bar{X}$ & & & & 3,0 & & & \\
\hline 203 & Anhembi & & $\bar{x}$ & & $x$ & 9,4 & 0,5 & & 2,6 & & & 0,05 \\
\hline 205 & Anhembi & $\mathrm{X}$ & & & $\mathrm{X}$ & 8,3 & 0,3 & 4,7 & 1,1 & 1,76 & 2,14 & 0,04 \\
\hline 206 & Anhembi & $x$ & & & $\mathrm{X}$ & 8,6 & 1,4 & 5.8 & 1,5 & 1,48 & 1,9 & 0,16 \\
\hline 207 & Anhembi & $x$ & & & $\bar{x}$ & 10,6 & 2,4 & 7,6 & 1,4 & 1,39 & 2,7 & 0,23 \\
\hline 208 & Anhembi & $\mathrm{X}$ & & & $x$ & 9,7 & 1,3 & 7,7 & 2,3 & 1,26 & 1,67 & 0,13 \\
\hline 209 & Anhembi & $\bar{x}$ & & & $\mathrm{x}$ & 9,0 & 0,5 & 6,4 & 1,6 & 1,4 & 2,0 & 0,05 \\
\hline 210 & Anhembi & & $\mathrm{X}$ & & $\bar{x}$ & 9,9 & 1,6 & 8,0 & 2,4 & 1,24 & 1,67 & 0,16 \\
\hline 211 & Annembi & & $\bar{x}$ & & $\bar{x}$ & 8,4 & 1,0 & 6,8 & 1,6 & 1,23 & 2,12 & 0,12 \\
\hline 212 & Anhembi & & $\mathrm{X}$ & & $\bar{x}$ & 6,8 & 0,9 & 4,5 & 2,0 & 1,51 & 1,12 & 0.13 \\
\hline 213 & Anhembi & & $x$ & & $\mathrm{X}$ & 10,2 & 0,8 & 6,4 & 3,0 & 1,59 & 1,07 & 0,08 \\
\hline 214 & Anhembi & $X$ & & & $\bar{X}$ & 10,5 & 0,5 & 7,4 & 1,8 & 1,42 & 2,05 & 0,05 \\
\hline 217 & Anhembi & $X$ & & & $\mathrm{X}$ & 12,7 & 1,4 & 8,4 & 2,4 & 1,51 & 1,75 & 0,11 \\
\hline 218 & Anhembi & & $\bar{x}$ & & $\bar{x}$ & 9,8 & 0,5 & 6,8 & 1,9 & 1,44 & 1,79 & 0,05 \\
\hline 219 & Anhembi & & $x$ & & $x$ & 10,9 & 0,4 & & 2,7 & & & 0,04 \\
\hline 220 & Anhembi & & $\bar{x}$ & & $\mathrm{X}$ & 9,4 & 0,8 & 8,4 & 2,0 & 1,12 & 2,1 & 0,08 \\
\hline 221 & Anhembi & & $\bar{x}$ & & $\mathrm{X}$ & 11,6 & 1,6 & 9,4 & 3,5 & 1,23 & 1,34 & 0,14 \\
\hline 223 & Anhembi & & $x$ & & $\bar{X}$ & & 0,4 & 6,6 & 1,9 & & 1,74 & \\
\hline 224 & Anhembi & $x$ & & & $\mathbf{X}$ & 7,6 & 1,5 & 4,7 & 1,5 & 1,62 & 1,57 & 0,2 \\
\hline 225 & Anhembi & $X$ & & & $\bar{x}$ & 6,9 & 0,7 & 4,9 & 1,6 & 1,41 & 1,53 & 0,1 \\
\hline 227 & Anhembi & $X$ & & & $\mathbf{X}$ & 13,4 & 3,5 & 12,3 & 2,8 & 1,09 & 2,2 & 0,26 \\
\hline
\end{tabular}




\begin{tabular}{|c|c|c|c|c|c|c|c|c|c|c|c|}
\hline 228 & Anhembi & & $x$ & $x$ & 13,0 & 1,8 & 8,3 & 3,0 & 1,56 & 1,89 & 0,13 \\
\hline 230 & Anhembi & $\mathrm{X}$ & & $\bar{x}$ & 7,7 & 1,0 & 6,7 & 1,6 & 1,15 & 2,00 & 0,13 \\
\hline 231 & Anhembi & & $x$ & $\mathrm{X}$ & 11,0 & 1,0 & 8,5 & 2,9 & 1,3 & 1,46 & 0,09 \\
\hline 232 & Anhembi & $\bar{X}$ & & $x$ & 10,3 & 1,1 & 7,6 & 3,0 & 1,35 & 2,5 & 0,1 \\
\hline 233 & Anhembi & & $\bar{x}$ & $\mathrm{X}$ & 13,5 & 1,4 & 12,3 & 4,3 & 1,1 & 1,43 & 0,1 \\
\hline 235 & Anhembi & $\mathrm{X}$ & & $\mathrm{x}$ & 8,4 & 0,6 & 5,6 & 0,9 & 1,5 & 3,1 & 0,07 \\
\hline 237 & Anhembi & & $\bar{x}$ & $\bar{X}$ & 21,7 & 2,0 & 15,3 & 4,5 & 1,41 & 1,7 & 0,09 \\
\hline 238 & Anhembi & & $x$ & $\bar{X}$ & 7,5 & 0,7 & 5,0 & 1,4 & 1,5 & 1,8 & 0,09 \\
\hline 239 & Anhembi & & $x$ & $x$ & 6,4 & 0,4 & 4,5 & 1,0 & 1,42 & 2,25 & 0,06 \\
\hline 240 & Anhembi & & $x$ & $x$ & 8,8 & 0,5 & 6,6 & 2,6 & 1,33 & 1,27 & 0,06 \\
\hline 241 & Anhembi & & $\bar{x}$ & $\bar{X}$ & 7,4 & 0,7 & 5,5 & 1,5 & 1,35 & 1,83 & 0,09 \\
\hline 242 & Anhembi & & $x$ & $x$ & 8,3 & 1,0 & 6,3 & 2,7 & 1,31 & 1,17 & 0,12 \\
\hline 243 & Anhembi & & $x$ & $\mathrm{X}$ & 8,3 & 0,6 & 6,0 & 1,9 & 1,38 & 1,58 & 0,07 \\
\hline 244 & Anhembi & & $x$ & $\mathrm{X}$ & 5,7 & 0,8 & 3,8 & 1,3 & 1,5 & 1,46 & 0,14 \\
\hline 245 & Anhembi & & $x$ & $x$ & 6,8 & 0,6 & 4,4 & 1,8 & 1,54 & 1,2 & 0,09 \\
\hline 246 & Anhembi & & $x$ & $x$ & 8,4 & 0,6 & 5,0 & 1,9 & 1,68 & 1,3 & 0,07 \\
\hline 247 & Anhembi & & $\bar{x}$ & $x$ & 7,4 & 0,9 & 4,9 & 1,8 & 1,51 & 1,36 & 0,12 \\
\hline 248 & Anhembi & & $x$ & $\bar{X}$ & 5,3 & 0,7 & 3,4 & 0,8 & 1,56 & 2,1 & 0,05 \\
\hline 249 & Anhembi & & $x$ & $\bar{X}$ & 6,4 & 0,3 & 4,7 & 1,6 & 1,36 & 1,47 & 0,05 \\
\hline 250 & Anhembi & & $x$ & $x$ & 8,3 & 1,7 & 6,4 & 1,6 & 1,3 & 2,0 & 0,2 \\
\hline 251 & Anhembi & & $\mathrm{X}$ & $x$ & 6,6 & 0,6 & 4,7 & 1,6 & 1,4 & 1,47 & 0,09 \\
\hline 252 & Anhembi & & $x$ & $\mathrm{X}$ & 10,4 & 1,4 & 8,5 & 2,4 & 1,22 & 1,77 & 0,13 \\
\hline 253 & Anhembi & & $x$ & $\bar{X}$ & 8,4 & 0,5 & 6,7 & 2,7 & 1,25 & 1,24 & 0,06 \\
\hline 254 & Anhembi & & $\mathrm{X}$ & $\bar{X}$ & 8,8 & 1,1 & 5,8 & 2,4 & 1,52 & 1,2 & 0,13 \\
\hline 255 & Anhembi & & $x$ & $\bar{x}$ & 6,6 & 0,7 & 5,7 & 1,7 & 1,16 & 1,67 & 0,11 \\
\hline 256 & Anhembi & & $x$ & $x$ & 6,9 & 0,8 & 5,6 & 1,8 & 1,23 & 1,5 & 0,12 \\
\hline 257 & Anhembi & & $x$ & $\bar{X}$ & 9,4 & 1,3 & 7,3 & 2,4 & 1,28 & 1,52 & 0,14 \\
\hline 258 & Anhembi & & $\mathrm{X}$ & $\bar{X}$ & 8,2 & 1,0 & 6,3 & 1,7 & 1,3 & 1,85 & 0,12 \\
\hline 259 & Anhembl & & $\bar{x}$ & $x$ & 6,5 & 0,7 & 4,5 & 1,5 & 1,45 & 1,5 & 0,11 \\
\hline 260 & Anhembi & & $x$ & $x$ & 7,3 & 0,9 & 4,4 & 1,3 & 1,66 & 1,69 & 0,12 \\
\hline 261 & Anhembi & & $x$ & $\bar{X}$ & 7,7 & 1,0 & 6,4 & 1,9 & 1,2 & 1,68 & 0,13 \\
\hline 262 & Anhembi & & $x$ & $\bar{X}$ & 8,0 & 0,8 & 6,3 & 2,3 & 1,27 & 1,37 & 0,1 \\
\hline 263 & Anhembi & & $x$ & $\mathrm{X}$ & 8,5 & 0,7 & 5,3 & 2,0 & 1,6 & 1,32 & 0,08 \\
\hline 264 & Anhembi & & $x$ & $x$ & 9,4 & 0,6 & 7,5 & 2,0 & 1,25 & 1,87 & 0,06 \\
\hline 265 & Anhembi & & $x$ & $x$ & 7,2 & 0,5 & 4,9 & 1,6 & 1,47 & 1,53 & 0,07 \\
\hline 266 & Anhembi & & $x$ & $x$ & 6.4 & 0,7 & 4,7 & 1,4 & 1,36 & 1,68 & 0,11 \\
\hline 267 & Anhembi & & $x$ & $\mathbf{X}$ & 8,4 & 0,9 & 6,3 & 2,4 & 1,33 & 1,31 & 0,11 \\
\hline 268 & Anhembi & & $X$ & $\mathrm{X}$ & 6,8 & 1,0 & 5,4 & 1,6 & 1,26 & 1,69 & 0,15 \\
\hline 269 & Anhembi & & $\bar{x}$ & $x$ & 8,4 & 0,9 & 6,4 & 1,7 & 1,31 & 1,88 & 0,11 \\
\hline 270 & Anhembi & & $\bar{x}$ & $\bar{x}$ & 7,3 & 1,0 & 5,8 & 2,3 & 1,26 & 1,26 & 0,14 \\
\hline 271 & Anhembi & & $\mathbf{X}$ & $\mathrm{X}$ & 8,1 & 0,6 & 5,5 & 1,9 & 1,47 & 1,45 & 0,07 \\
\hline 272 & Anhembi & & $x$ & $x$ & 5,8 & 0,5 & 3,9 & 1,2 & 1,49 & 1,62 & 0,09 \\
\hline 273 & Anhembi & & $\bar{x}$ & $x$ & 8,9 & 0,6 & 7,3 & 2,4 & 1,22 & 2,37 & 0,07 \\
\hline 274 & Anhembi & & $\mathrm{X}$ & $\bar{x}$ & 15,8 & 1,3 & 13,3 & 4,8 & 1,19 & 1,38 & 0,08 \\
\hline 275 & Anhembi & & $\bar{X}$ & $\bar{X}$ & 14,2 & 1,2 & 10,3 & 3,5 & 1,39 & 1,47 & 0,08 \\
\hline 276 & Anhembi & & $\bar{x}$ & $\bar{x}$ & 9,9 & 0,9 & 6,9 & 2,7 & 1,43 & 1,28 & 0,09 \\
\hline 277 & Anhembi & & $\bar{x}$ & $x$ & 8,8 & 1,3 & 6,4 & 2,3 & 1,37 & 1,39 & 0,15 \\
\hline 278 & Anhembi & & $x$ & $\mathrm{X}$ & 12,0 & 1,8 & 6,5 & 2,3 & 1,85 & 1,41 & 0,15 \\
\hline 279 & Anhembi & & $\mathrm{X}$ & $\mathrm{X}$ & 8,8 & 0,9 & 6,4 & 2,3 & 1,37 & 1,39 & 0.1 \\
\hline 280 & Anhembi & & $\bar{x}$ & $\bar{X}$ & 9,7 & 1,0 & 7,2 & 2,3 & 1,35 & 1.56 & 0,1 \\
\hline 281 & Anhembi & & $x$ & $x$ & 7,8 & 0,3 & 5,6 & 2,0 & 1,40 & 1,4 & 0,04 \\
\hline 282 & Anhembi & & $\bar{x}$ & $x$ & 11,3 & 0,8 & 8,5 & 3,1 & 1,33 & 1,37 & 0,07 \\
\hline 283 & Anhembi & & $\bar{x}$ & $x$ & 10,9 & 1,1 & 9,3 & 2,4 & 1,17 & 1,93 & 0.1 \\
\hline 284 & Anhembi & & $x$ & $\bar{x}$ & 10,3 & 0,8 & 8,0 & 2,6 & 1,3 & 1,54 & 0,08 \\
\hline 285 & Anhembi & & $\mathrm{X}$ & $\bar{x}$ & 12,0 & 1,0 & 9,4 & 3,6 & 1,28 & 1,3 & 0,08 \\
\hline 286 & Anhembi & & $\bar{x}$ & $\mathrm{x}$ & 14,4 & 1,0 & 11,4 & 4,1 & 1,26 & 1,39 & 0,07 \\
\hline 287 & Anhembi & & $\bar{x}$ & $\bar{x}$ & 9,6 & 0,6 & 6,9 & 2,4 & 1,39 & 1,4 & 0,06 \\
\hline 288 & Anhembi & & $\mathrm{X}$ & $\mathbf{X}$ & 14,2 & 0,6 & 8,3 & 2,9 & 1,71 & 1,43 & 0,04 \\
\hline 289 & Anhembi & & $\mathbf{x}$ & $\bar{x}$ & 8,9 & 0,3 & 5,5 & 1,6 & 1,62 & 1,72 & 0,03 \\
\hline 290 & Anhembi & & $\bar{x}$ & $\bar{x}$ & 11,4 & 0,4 & 8,0 & 2,8 & 1,42 & 1,43 & 0,03 \\
\hline 291 & Anhembi & & $\mathrm{X}$ & $x$ & 7.9 & 0,4 & 4,9 & 1,8 & 1,6 & 1,36 & 0,05 \\
\hline 292 & Anhembi & & $\bar{X}$ & $x$ & 9,3 & 0,6 & 6,9 & 2,8 & 1,35 & 1,23 & 0,06 \\
\hline 293 & Anthembi & & $X$ & $x$ & 9,6 & 0,5 & 7,3 & 2,4 & 1,31 & 1,52 & 0,05 \\
\hline 294 & Anhembi & & $\bar{x}$ & $\mathbf{x}$ & 13,3 & 0,7 & 10,8 & 3,4 & 1,67 & 1,6 & 0,05 \\
\hline 295 & Anhembi & & $\mathrm{X}$ & $\mathbf{X}$ & 10,3 & 0,7 & 8,0 & 2,9 & 1,3 & 1,38 & 0,08 \\
\hline 296 & Anhembi & & $\mathbf{x}$ & $\bar{x}$ & 10,4 & 0,8 & 7,7 & 2,7 & 1,35 & 1,42 & 0,08 \\
\hline 297 & Anhembi & & $\mathrm{X}$ & $x$ & 8,8 & 0,5 & 7,7 & 2,6 & 1,14 & 1,48 & 0,06 \\
\hline 298 & Anhembi & & $\mathrm{X}$ & $\bar{x}$ & 13,6 & 1,5 & 11,5 & 4,2 & 1,18 & 1,37 & 0.11 \\
\hline 299 & Anthembi & & $x$ & $\mathrm{X}$ & 10,4 & 0,4 & 8,3 & 3,0 & 1,25 & 1,38 & 0,04 \\
\hline 300 & Anhembi & & $\mathrm{X}$ & 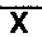 & 10,6 & 0,7 & 8,3 & 2,5 & 1,27 & 1,66 & 0,07 \\
\hline
\end{tabular}




\begin{tabular}{|c|c|c|c|c|c|c|c|c|c|c|c|}
\hline 301 & Anhembi & & $\bar{x}$ & $\bar{x}$ & 12,7 & 1,4 & 10,0 & 3,6 & 1,27 & 1,39 & 0,11 \\
\hline 302 & Anhembi & & $\bar{x}$ & $\bar{X}$ & 8.8 & 0,5 & 6,4 & 2,8 & 1,37 & 1,14 & 0,06 \\
\hline 303 & Anhembi & & $\bar{X}$ & $\mathbf{X}$ & 9,8 & 0,5 & 7,6 & 2,9 & 1,29 & 1,31 & 0,05 \\
\hline 304 & Anhembi & & $\mathrm{X}$ & $X$ & 14,4 & 0.9 & 10,8 & 3,6 & 1,33 & 1,5 & 0,06 \\
\hline 305 & Antiembi & & $X$ & $X$ & 10,9 & 0,7 & 8,6 & 3,5 & 1,27 & 1,23 & 0,06 \\
\hline 306 & Anhembi & & $x$ & $x$ & 9,4 & 0,4 & 11,7 & 1,9 & 0,8 & 3,08 & 0,04 \\
\hline 307 & Anhembi & & $\mathrm{X}$ & $\bar{x}$ & 9,4 & 0,6 & 6,0 & 2,4 & 1,57 & 1,25 & 0,06 \\
\hline 308 & Anhembi & & $\bar{X}$ & $\bar{X}$ & 11,6 & 0,6 & 9,4 & 3,4 & 1,23 & 1,38 & 0,05 \\
\hline 309 & Anhembl & & $\mathrm{X}$ & $\mathbf{x}$ & 13,8 & 0,3 & 7,8 & 2,9 & 1,77 & 1,34 & 0,02 \\
\hline 310 & Anhembi & & $\bar{x}$ & $\bar{x}$ & 10,3 & 1,4 & 7,4 & 2,6 & 1,39 & 1,42 & 0,13 \\
\hline 311 & Anhembi & & $\bar{x}$ & $X$ & 10,5 & 0,4 & 6,3 & 2,2 & 1,66 & 1,43 & 0,04 \\
\hline 312 & Anhembi & & $x$ & $x$ & 7,3 & 0,3 & 4,0 & 1,4 & 1,82 & 1,43 & 0,04 \\
\hline 313 & Anhembi & & $\mathrm{X}$ & $\bar{x}$ & 10,3 & 0,5 & 6,9 & 2,5 & 1,49 & 1,38 & 0,05 \\
\hline 314 & Anhembi & & $\mathbf{x}$ & $X$ & 11,9 & 0,8 & 8,0 & 2,5 & 1,48 & 1,6 & 0,07 \\
\hline 315 & Anhembi & & $x$ & $\bar{x}$ & 10,0 & 0,6 & 7,4 & 2,5 & 1,35 & 1,48 & 0,06 \\
\hline 316 & Anhembi & & $\mathbf{X}$ & $\mathbf{X}$ & 11,6 & 0,6 & 9,2 & 2,6 & 1,26 & 1,77 & 0,05 \\
\hline 317 & Anhembi & & $\mathrm{x}$ & $\mathbf{X}$ & 11,8 & 1,0 & 8,9 & 3,1 & 1,32 & 1,43 & 0,08 \\
\hline 318 & Anhembl & & $X$ & $x$ & 14,6 & 1,3 & 12,7 & 4,9 & 1,15 & 1,29 & 0,09 \\
\hline 319 & Anhembi & & $X$ & $\bar{x}$ & 9,2 & 0,6 & 6,6 & 1,6 & 1,39 & 2,06 & 0,06 \\
\hline 320 & Anhembi & & $\mathrm{x}$ & $x$ & & & 9,0 & 2,7 & & 1,67 & \\
\hline 321 & Anhembi & & $\bar{x}$ & $\mathbf{X}$ & & 0,8 & 9,8 & 3,1 & & 1,58 & \\
\hline 322 & Anhembi & & $\bar{x}$ & $\mathrm{X}$ & & & 8,6 & 3,6 & & 1,65 & \\
\hline 323 & Anhembi & & $\mathbf{X}$ & $\mathbf{X}$ & & & 7,5 & 2,5 & & 1,5 & \\
\hline 324 & Anhembi & & $\mathbf{X}$ & $\bar{x}$ & 13,7 & 0,7 & & 2,0 & & & 0,05 \\
\hline 325 & Anhembi & & $x$ & $\mathbf{x}$ & 11,3 & 0,8 & 6,3 & 2,7 & 1,79 & 1,17 & 0,07 \\
\hline 326 & Anhembi & $\mathrm{x}$ & & $x$ & 10,6 & 2,0 & 6,4 & 1,8 & 1,65 & 2,0 & 0,19 \\
\hline 328 & Anhembi & & $\mathbf{X}$ & $\mathbf{x}$ & 8,1 & 1,1 & 6,8 & 2,2 & 1,19 & 1,5 & 0,13 \\
\hline 329 & Anhembi & $\mathrm{x}$ & & $\mathbf{x}$ & 10,3 & 1,9 & 8,8 & 1,8 & 1,17 & 2,4 & 0,18 \\
\hline 330 & Anhembi & $x$ & & $\mathbf{X}$ & 9,0 & 2,0 & & 2,5 & & & 0,22 \\
\hline 331 & Anhembi & $x$ & & $x$ & & & 5,9 & 1,5 & & 1,97 & \\
\hline 332 & Anhembi & $x$ & & $x$ & 10,6 & 2,8 & 8,4 & 1,9 & 1,26 & 2,21 & 0,26 \\
\hline 333 & Anhembi & & $x$ & $\bar{X}$ & 8,8 & 1,0 & 7,3 & 2,0 & 1,20 & 1,82 & 0,11 \\
\hline 335 & Anhembi & $x$ & & $\mathbf{X}$ & 9,4 & 0,7 & 4,5 & 1,2 & 2,09 & 1,87 & 0,07 \\
\hline 336 & Anhembi & & $\mathrm{x}$ & $x$ & 12,8 & 1,3 & 9.9 & 2,9 & 1,29 & 1,7 & 0,10 \\
\hline 338 & Anhembi & $\mathbf{x}$ & & $\bar{X}$ & 10,4 & 1.5 & 6,0 & 2,1 & 1,73 & 1,43 & 0,14 \\
\hline 339 & Anhembi & & $\bar{x}$ & $x$ & 9,0 & 0,8 & 6.4 & 2,5 & 1,4 & 1,28 & 0,09 \\
\hline 340 & Anhembi & & $\mathbf{X}$ & $\mathbf{X}$ & 6,8 & 1,0 & 5,5 & 1,6 & 1,23 & 1,71 & 0,15 \\
\hline 341 & Anhembi & & $\mathbf{X}$ & $\bar{X}$ & & & 5,9 & 2,0 & & 1,47 & \\
\hline 342 & Anhembi & $\mathbf{X}$ & & $\mathbf{X}$ & 9,4 & 1,0 & & 2,5 & & & 0,1 \\
\hline 343 & Anhembi & & $\mathbf{X}$ & $\mathbf{X}$ & 9,4 & 1,0 & 6,9 & 2,2 & 1,36 & 3,14 & 0,1 \\
\hline 344 & Anhembi & & $\mathrm{X}$ & $\mathbf{x}$ & 7,7 & 0,3 & 6,0 & 2,0 & 1,28 & 1,5 & 0,04 \\
\hline 345 & Anhembi & $x$ & & $x$ & 8,8 & 0,8 & 7,3 & 1,3 & 1,20 & 2,8 & 0,09 \\
\hline 348 & Anhembl & $\mathrm{x}$ & & $x$ & 9,4 & 1,6 & 6,6 & 2,0 & 1,42 & 1,65 & 0,17 \\
\hline 349 & Anhembi & & $x$ & $x$ & 8,4 & 1,0 & 7,4 & 1,8 & 1,13 & 2,05 & 0,12 \\
\hline 354 & Anhembi & $x$ & & $\bar{x}$ & 5,5 & 0,7 & 4,6 & 1,1 & 1,19 & 2,09 & 0,13 \\
\hline 355 & Anhembi & $\mathrm{X}$ & & $\mathbf{x}$ & 9,4 & 1,2 & 5,5 & 1,6 & 1.71 & 1,72 & 0,13 \\
\hline 356 & Anhembi & $x$ & & $x$ & 6,6 & 1,1 & 5,4 & 1,4 & 1,22 & 1,93 & 0,17 \\
\hline 359 & Anhembi & & $\bar{x}$ & $\bar{x}$ & 8,5 & 0,8 & 6,8 & 2,1 & 1,25 & 1,62 & 0,09 \\
\hline 361 & Anhembi & $x$ & & $X$ & 8,0 & 1,3 & 5,0 & 1,6 & 1,6 & 1,56 & 0,16 \\
\hline 362 & Anhembi & & $x$ & $x$ & 11,6 & 2,8 & & 2,6 & & & 0,24 \\
\hline 363 & Anhembi & & $\bar{x}$ & $\mathrm{X}$ & 10,0 & 0,7 & 7,8 & 2,7 & 1,28 & 1,45 & 0,07 \\
\hline 364 & Anhembi & & $\mathbf{X}$ & $\mathbf{X}$ & 10,3 & 0,7 & 8,5 & 2,3 & 1,21 & 1,85 & 0,07 \\
\hline 368 & Anhembi & & $\mathbf{X}$ & $\bar{x}$ & 8,5 & 0,6 & 7,3 & 2,7 & 1,16 & 1,35 & 0,07 \\
\hline 371 & Anhembi & $x$ & & $\mathrm{X}$ & 9,8 & 0,9 & 4,9 & 1,5 & 2,0 & 1,63 & 0,09 \\
\hline 372 & Anhembi & & $\mathbf{x}$ & $x$ & 12,0 & 0,9 & & 2,5 & & & 0,07 \\
\hline 373 & Anhembi & $\mathbf{x}$ & & $\mathbf{x}$ & 13,3 & 2,5 & 6,8 & 1,3 & 1,95 & 2,61 & 0,19 \\
\hline 374 & Anhembi & $x$ & & $\mathbf{X}$ & 10,0 & 1,0 & 8,0 & 2,4 & 1,25 & 1,67 & 0,1 \\
\hline 375 & Anhembi & & 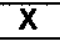 & 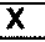 & 8,3 & 0,7 & 6,3 & 2,0 & 1,31 & 1,57 & 0,08 \\
\hline 377 & Anhembi & & $x$ & $X$ & 7,7 & 0,5 & 6,0 & 2,3 & 1,28 & 1,3 & 0,06 \\
\hline 378 & Anhembi & & $\bar{x}$ & $\bar{X}$ & 9,4 & 0,8 & 7,9 & 2,0 & 1,19 & 1,98 & 0,08 \\
\hline 381 & Anhembi & $\mathbf{x}$ & & $\mathbf{x}$ & 8,5 & 1,2 & 7,6 & 1,6 & 1,12 & 2,37 & 0,14 \\
\hline 383 & Anhembi & & $\bar{x}$ & $\mathbf{X}$ & 9,8 & 0,8 & 7,5 & 2,6 & 1,3 & 1,44 & 0,08 \\
\hline 384 & Anhembi & & $\bar{X}$ & $X$ & & 1,3 & & 2,9 & & & \\
\hline 389 & Anhembi & $x$ & & $x$ & 10,9 & 0,8 & 8,4 & 2,7 & 1,3 & 1,56 & 0,07 \\
\hline 393 & Anhembi & & $\mathbf{X}$ & $\bar{x}$ & 10,3 & 0,9 & 6,9 & 2,4 & 1,49 & 1,44 & 0,09 \\
\hline 394 & Anhembi & & $\mathbf{X}$ & $\mathbf{X}$ & 7,5 & 0,8 & 6,9 & 2,3 & 1,09 & 1,5 & 0,11 \\
\hline 396 & Anhembi & $\mathbf{x}$ & & $\mathbf{x}$ & 11,4 & 1,0 & 8,3 & 2,6 & 1,37 & 1,6 & 0,09 \\
\hline 397 & Anhembi & & $x$ & $x$ & 16,3 & 2,0 & 12,0 & 5,6 & 1,36 & 1,07 & 0,12 \\
\hline 398 & Anhembi & & $x$ & $x$ & 8,5 & 0,6 & 7,6 & 2,9 & 1,12 & 1,31 & 0,07 \\
\hline 399 & Anhembi & & $x$ & $x$ & 7,7 & 0,5 & 7,4 & 2,8 & 1,04 & 1,32 & 0,06 \\
\hline
\end{tabular}




\begin{tabular}{|c|c|c|c|c|c|c|c|c|c|c|c|c|}
\hline 400 & Anhembi & $\bar{X}$ & & & $x$ & 10,8 & 1,0 & 7,4 & 1,5 & 1,46 & 2,47 & 0,09 \\
\hline 402 & Anhembi & & $\bar{x}$ & & $\bar{x}$ & & 1,9 & 13,6 & 4,0 & & 1,7 & \\
\hline 403 & Anhembi & $x$ & & & $\bar{X}$ & 13,2 & 1,9 & 9,7 & 2,8 & 1,36 & 1,73 & 0,14 \\
\hline 404 & Anhembi & & $x$ & & $\bar{x}$ & 11,4 & 1,3 & 9,9 & 3,1 & 1,15 & 1,6 & 0,1 \\
\hline 405 & Anhembi & $x$ & & & $\bar{x}$ & 11,6 & 1,5 & 7,9 & 2,6 & 1,47 & 1,52 & 0,13 \\
\hline 1250 & Tambaú & $\mathrm{x}$ & & $\bar{X}$ & & 4,3 & 0,2 & 1,4 & 0,3 & 3,07 & 2,33 & 0,05 \\
\hline 1251 & Tambaú & & $\bar{x}$ & $\mathbf{X}$ & & 6,4 & 0,2 & 2.9 & & 2,21 & & 0,03 \\
\hline 1252 & Tambaú & $\mathrm{X}$ & & $x$ & & 4,4 & 0,2 & 2,4 & & 1,83 & & 0,04 \\
\hline 1253 & Tambaú & & $\bar{x}$ & $x$ & & 8,8 & 0,5 & 3,4 & & 2,59 & & 0,06 \\
\hline 1254 & Tambaú & & $x$ & $x$ & & 3,6 & 0,1 & 1,8 & & 2,0 & & 0,03 \\
\hline 1255 & Tambaú & & $\bar{x}$ & $x$ & & 9,4 & 0,6 & 4,5 & 0,6 & 2,09 & 3,75 & 0,06 \\
\hline 1258 & Tambaú & & $\bar{x}$ & $x$ & & 10,6 & 1,1 & 3,2 & 1,3 & 3,31 & 1,23 & 0,1 \\
\hline 1260 & Tambaú & & $\bar{x}$ & $x$ & & 4,3 & 0,3 & 2,4 & 0,6 & 1,79 & 2,0 & 0,07 \\
\hline 1262 & Tambaú & & $\bar{x}$ & $\bar{x}$ & & 9,4 & 0,9 & 6,5 & 1,3 & 1,45 & 2,5 & 0,09 \\
\hline 1265 & Tambaú & & $x$ & $\mathrm{X}$ & & 8,8 & 0.5 & 2,8 & 0,4 & 3,14 & 3,5 & 0,06 \\
\hline 1269 & Tambaú & & $\bar{x}$ & $\mathrm{x}$ & & 5.5 & 0,2 & 2,6 & 0,7 & 2,11 & 1,86 & 0,04 \\
\hline 1270 & Tambaú & & $x$ & $x$ & & 4,0 & 0,2 & 2,4 & & 1,67 & & 0,05 \\
\hline 1274 & Tambaú & $\bar{x}$ & & $\bar{x}$ & & 4,3 & 0,2 & 1,6 & & 2,7 & & 0,05 \\
\hline 1275 & Tambaú & & $\mathrm{X}$ & $\mathrm{X}$ & & 7,0 & 0.8 & 2,9 & & 2,41 & & 0,11 \\
\hline 1278 & Tambaú & & $\bar{x}$ & $\mathrm{X}$ & & 7,6 & 0,7 & 2,9 & & 2,62 & & 0,09 \\
\hline 1280 & Tambaú & & $\bar{X}$ & $x$ & & 5,5 & 0,3 & 3,0 & 0,8 & 1,83 & 1,87 & 0,05 \\
\hline 1281 & Tambaú & $\mathrm{x}$ & & $\bar{x}$ & & 12,0 & 1,0 & 5,5 & & 2,18 & & 0,08 \\
\hline 1282 & Tambaú & & $x$ & $\mathrm{X}$ & & 6,6 & 0,2 & 2,9 & & 2,27 & & 0,03 \\
\hline 1284 & Tambaú & $x$ & & $x$ & & 6,0 & 0,2 & 5,1 & & 1,18 & & 0,03 \\
\hline 1290 & Tambaú & $x$ & & $\mathrm{x}$ & & 10,9 & 1,2 & 7,4 & & 1,47 & & 0,11 \\
\hline 1305 & Tambaú & $x$ & & $\bar{x}$ & & 16,8 & 1,5 & 8,4 & & 2,0 & & 0,09 \\
\hline 1316 & Tambaú & $x$ & & $\bar{x}$ & & 7,6 & 0,6 & 3,8 & & 2,0 & & 0,08 \\
\hline 1317 & Tambaú & & $\bar{x}$ & $x$ & & 9,3 & 0,3 & 4,4 & & 2,11 & & 0,05 \\
\hline 1321 & Tambaú & $x$ & & $\mathrm{X}$ & & 5,3 & 0,2 & 3,2 & & 1,66 & & 0,04 \\
\hline 1326 & Tambaú & & 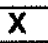 & $\bar{x}$ & & 7,4 & 0,4 & 4,5 & & 1,64 & & 0,05 \\
\hline 1327 & Tambaú & & $\bar{x}$ & $x$ & & 5,2 & 0,3 & 1,8 & & 2,89 & & 0,06 \\
\hline 1329 & Tambaú & & $\mathbf{X}$ & $\mathbf{X}$ & & 7,9 & 0,3 & 3,4 & & 2,32 & & 0,04 \\
\hline 1330 & Tambaú & & $x$ & $x$ & & 8,0 & 0,5 & 2,6 & & 3,08 & & 0,06 \\
\hline 1351 & Tambaú & $x$ & & $x$ & & 2,4 & 0,1 & 1,3 & & 1,85 & & 0,04 \\
\hline 1352 & Tambaú & & $\mathbf{X}$ & $x$ & & 5,8 & 0,3 & 2,0 & & 2,9 & & 0,05 \\
\hline 1357 & Tambaú & & $x$ & $x$ & & 5,9 & 0,5 & 2,3 & & 2,56 & & 0,08 \\
\hline 1365 & Tambaú & & $\bar{X}$ & $x$ & & 10,1 & 0,3 & 4,8 & & 2,10 & & 0,03 \\
\hline 1369 & Tambaú & & 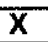 & $x$ & & 6,5 & 0,5 & 3,8 & & 1,71 & & 0,08 \\
\hline 1371 & Tambaú & $\bar{x}$ & & & & 13,3 & 1,3 & 5,5 & 1,3 & 2,42 & 2,11 & 0,1 \\
\hline 1403 & Tambaú & & $x$ & $\bar{x}$ & & 2,9 & 0,1 & 1,6 & & 1,81 & & 0,03 \\
\hline 1424 & Tambaú & & $\bar{x}$ & $\mathbf{x}$ & & 11,8 & 0,3 & 2,6 & & 4,54 & & 0,02 \\
\hline 1551 & Tambaú & & $\bar{X}$ & $x$ & & & & 5,0 & 1,6 & & 1,56 & \\
\hline 1552 & Tambaú & & $\bar{x}$ & $\bar{x}$ & & 6,9 & 0,4 & 3,8 & & 1,81 & & 0,06 \\
\hline 1553 & Tambaú & & $x$ & $x$ & & 12,6 & 0,7 & 6,9 & & 1,83 & & 0,06 \\
\hline 1554 & Tambaú & & $\bar{x}$ & $x$ & & 4,6 & 0,2 & 2,4 & & 1,92 & & 0,04 \\
\hline 1555 & Tambaú & $\bar{x}$ & & $x$ & & 5,4 & 0,4 & 2,5 & & 2,16 & & 0,07 \\
\hline 1557 & Tambaú & & $x$ & $\mathbf{x}$ & & 6,4 & 0,6 & 3,5 & 1,5 & 1,83 & 1,17 & 0,09 \\
\hline 1559 & Tambaú & $\mathrm{X}$ & & $x$ & & 4,9 & 0,7 & 3,1 & & 1,58 & & 0,14 \\
\hline 1560 & Tambaú & $x$ & & $x$ & & & & 3,3 & & & & \\
\hline 1561 & Tambaú & & $\bar{x}$ & $\mathbf{X}$ & & 5,0 & 0,5 & 3,4 & & 1,47 & & 0,1 \\
\hline 1562 & Tambaú & & $\mathrm{X}$ & $\mathrm{X}$ & & 6,4 & 0,4 & 3,5 & 1,3 & 1,83 & 1,35 & 0,06 \\
\hline 1564 & Tambaú & & $x$ & $\mathrm{X}$ & & 6,8 & 0,4 & 3,9 & 0,6 & 1,74 & 3,25 & 0,06 \\
\hline 1565 & Tambaú & & $\bar{x}$ & $x$ & & 6,5 & 0,8 & 4,0 & 1,4 & 1,6 & 0,36 & 0,12 \\
\hline 1567 & Tambaú & & $x$ & $\mathrm{x}$ & & 10,3 & 0,9 & 4,5 & 1,8 & 2,29 & 1,25 & 0,09 \\
\hline 1568 & Tambaú & & $\mathbf{x}$ & $x$ & & 8,4 & 0,8 & 5,4 & & 1,56 & & 0,09 \\
\hline 1570 & Tambaú & $\mathrm{X}$ & & $\mathrm{X}$ & & 4,0 & 0,8 & 2,9 & & 1,39 & & 0,2 \\
\hline 1574 & Tambaú & & $x$ & $\bar{x}$ & & 7,8 & 1,0 & 4,4 & & 1,77 & & 0,13 \\
\hline 1575 & Tambaú & & $\mathrm{X}$ & $\mathrm{X}$ & & 6,0 & 0,9 & 3,0 & & 2,0 & & 0,15 \\
\hline 1576 & Tambaú & & $x$ & $\bar{x}$ & & 8,0 & 0,8 & 4,5 & 0,8 & 1,78 & 2,8 & 0,1 \\
\hline 1578 & Tambaú & & $\mathbf{x}$ & $\bar{x}$ & & 3,9 & 0,7 & 2,7 & & 1,44 & & 0,18 \\
\hline 1580 & Tambaú & & $\bar{x}$ & $\mathrm{X}$ & & 4,4 & 0,7 & 2,8 & & 1,57 & & 0.16 \\
\hline 1581 & Tambaú & & $\mathrm{x}$ & $\mathbf{x}$ & & 4,6 & 0,6 & 2,5 & & 1,84 & & 0,13 \\
\hline 1583 & Tambaú & $\bar{x}$ & & $x$ & & 11,3 & 0,8 & 5,0 & & 2,26 & & 0,07 \\
\hline 1584 & Tambaú & $x$ & & $\mathbf{x}$ & & 10,2 & 0,2 & 7,0 & & 1,46 & & 0,02 \\
\hline 1585 & Tambaú & & $\mathrm{x}$ & $\mathrm{x}$ & & 4,6 & 0,2 & 2,0 & & 2,3 & & 0,04 \\
\hline 1586 & Tambaú & & $\bar{x}$ & $\mathbf{x}$ & & 2,9 & 0,1 & 2,4 & & 1,21 & & 0,03 \\
\hline 1587 & Tambaú & & $x$ & $x$ & & 13,3 & 1,7 & 8,5 & 4,0 & 1,56 & 1,06 & 0,13 \\
\hline 1588 & Tambaú & & $\bar{x}$ & $x$ & & 11,9 & 0,8 & 3,6 & & 3,30 & & 0,07 \\
\hline 1589 & Tambaú & & $\mathrm{X}$ & $\bar{x}$ & & 5,2 & 0,1 & 2,0 & & 2,6 & & 0,02 \\
\hline 1591 & Tambaú & $x$ & & $x$ & & 3,4 & 0,1 & 1,4 & & 2,43 & & 0,03 \\
\hline
\end{tabular}




\begin{tabular}{|c|c|c|c|c|c|c|c|c|c|c|c|}
\hline 1592 & Tambaú & & $\bar{X}$ & $\bar{X}$ & 3,0 & 0,1 & 1,2 & & 2,5 & & 0,03 \\
\hline 1593 & Tambaú & & $x$ & $\bar{x}$ & 6,4 & 0,4 & 3,6 & & 1,78 & & 0,06 \\
\hline 1594 & Tambaú & & $\bar{x}$ & $\bar{x}$ & 10,4 & 1,4 & 7,6 & & 1,37 & & 0,13 \\
\hline 1595 & Tambaú & & $x$ & $x$ & 5,0 & 0,3 & 3,1 & & 1,61 & & 0,06 \\
\hline 1596 & Tambaú & & $\mathrm{X}$ & $\bar{X}$ & 4,6 & 0,8 & 2,7 & & 1,7 & & 0,17 \\
\hline 1597 & Tambaú & & $x$ & $x$ & 3,0 & 0,3 & 2,5 & & 1,2 & & 0,1 \\
\hline 1598 & Tambaú & $\mathrm{X}$ & & $x$ & 5,8 & 0,8 & 2,7 & & 2,15 & & 0,14 \\
\hline 1600 & Tambaú & & $x$ & $\bar{x}$ & 6,4 & 1,0 & 3,2 & & 2,0 & & 0,16 \\
\hline 1602 & Tambaú & & $x$ & $\bar{x}$ & 8,0 & 1,1 & 3,8 & & 2,1 & & 0,14 \\
\hline 1603 & Tambaú & & $x$ & $\bar{x}$ & 3,6 & 0,3 & 3,6 & & 1,0 & & 0,08 \\
\hline 1604 & Tambaú & & $\mathrm{X}$ & $\bar{x}$ & 7,5 & 0,4 & 3,3 & & 2,08 & & 0,05 \\
\hline 1605 & Tambaú & $x$ & & $\bar{x}$ & 5,6 & 0,8 & 3,4 & & 1,65 & & 0,14 \\
\hline 1606 & Tambaú & $\mathrm{X}$ & & $x$ & 5,5 & 0,6 & 2,9 & & 1,89 & & 0,11 \\
\hline 1607 & Tambaú & $\bar{x}$ & & $\bar{x}$ & 5,0 & 0,3 & 1,5 & & 3,33 & & 0,06 \\
\hline 1608 & Tambaú & $\mathrm{X}$ & & $x$ & 6,3 & 0,4 & 2,0 & & 3,15 & & 0,06 \\
\hline 1609 & Tambaú & & $\mathrm{X}$ & $x$ & 2,9 & 0,8 & 4,7 & & 0,62 & & 0,27 \\
\hline 1610 & Tambaú & & $\mathbf{X}$ & $\bar{x}$ & 9,0 & 0,7 & 3,0 & & 3,0 & & 0,08 \\
\hline 1611 & Tambaú & & $x$ & $\bar{x}$ & 5,7 & 0,4 & 2,8 & & 2,03 & & 0,07 \\
\hline 1727 & Tambaú & & $\bar{X}$ & $\bar{x}$ & 4,9 & 0,1 & 1,9 & & 2,58 & & 0,02 \\
\hline 1728 & Tambaú & & $\bar{X}$ & $\bar{x}$ & 10,4 & 1,3 & 6,3 & 1,8 & 1,65 & 1,75 & 0,12 \\
\hline 1729 & Tambaú & & $\bar{X}$ & $x$ & 6.5 & 0,7 & 3,1 & & 2,10 & & 0,11 \\
\hline 1730 & Tambaú & & $\bar{x}$ & $x$ & 10,3 & 0,9 & 5,8 & 1,2 & 1,77 & 2,42 & 0,09 \\
\hline 1732 & Tambaú & & $\mathbf{X}$ & $\bar{x}$ & 8,5 & 0,6 & 3,3 & & 2,57 & & 0,07 \\
\hline 1733 & Tambaú & & $\mathrm{X}$ & $\bar{x}$ & 9,6 & 1,4 & 5,1 & & 1,88 & & 0,14 \\
\hline 1735 & Tambaú & & $\bar{x}$ & $x$ & 9,8 & 0,6 & 4,8 & & 2,04 & & 0,06 \\
\hline 1736 & Tambaú & $x$ & & $\bar{x}$ & 11,8 & 0,6 & 6,3 & & 1,87 & & 0,05 \\
\hline 1738 & Tambaú & $\mathrm{X}$ & & $x$ & 5,5 & 0,8 & 2,6 & & 2,11 & & 0,14 \\
\hline & & & & Mé & & & & & 1,61 & 1,70 & 0,09 \\
\hline
\end{tabular}

\section{Infauna profunda}

\section{Roxoa intricans}

\begin{tabular}{|c|c|c|c|c|c|c|c|c|c|c|c|c|}
\hline $\mathrm{n}^{\circ}$ & afloramento & VD & VE & $\mathrm{MI}$ & $\mathbf{S}$ & C & $\mathbf{C A}$ & $\mathbf{A}$ & $L$ & C/A & A/L & CA/C \\
\hline $\begin{array}{c}\text { GP/1T } \\
7 / 63\end{array}$ & Corumbataí & $\bar{x}$ & & & $\bar{x}$ & 20,0 & 5,0 & 11,0 & $\overline{2,0}$ & 1,81 & 2,75 & 0,25 \\
\hline $\begin{array}{c}\mathrm{GP} / 1 \mathrm{~T} \\
7 / 64\end{array}$ & Corumbataí & $\bar{X}$ & & & $\bar{x}$ & 19,0 & 4,0 & 10,0 & 3,0 & 1,9 & 1,67 & 0,21 \\
\hline & & & & $\bar{M}$ & & & & & & 1,86 & 2,21 & 0,23 \\
\hline
\end{tabular}




\section{ESTAMPA I}

Figs. 1-2

Fig. 3

Figs 4-5

Fig. 6

Figs. 7-9

Figs $10-12$
Barbosaia angulata Mendes, 1952

1, molde interno, vista lateral da valva esquerda, X 2.4, $\mathrm{DZP} / 2372 ; 2$, esquema gráfico, vista lateral da valva esquerda mostrando musculatura adutora posterior e linha integropaliada, $\mathrm{DZP} / 2372$.

Maackia contorta Mendes, 1954

3 , molde interno, vista lateral da valva esquerda mostrando dupla carena, X 1.8, DZP/ 2336.

Mendesia piracicabensis Maranhão, 1986

4, molde interno, vista lateral da valva direita, X 2, DZP/1871;

5 , esquema gráfico, vista lateral da valva direita mostrando musculatura adutora anterior, posterior e linha integropaliada, DZP/1871.

? Anthraconaia mezzalirai Maranhão, 1995

6, molde externo, vista lateral da valva esquerda, $\mathrm{X}$ 2.4, $\mathrm{DZP} / 2327$.

Anhembia froesi (Mendes), 1949

7, molde interno, vista lateral da valva esquerda, $\mathrm{X} 1$, $\mathrm{DZP} / 2889$, setas: $\mathrm{R}=$ Rostrum, $\mathrm{LP}=$ Linha palial; 8, esquema gráfico, vista lateral da valva esquerda mostrando musculatura adutora anterior e linha integropaliada, DZP/2889; 9, molde interno, vista lateral da valva esquerda, X $0.7, \mathrm{DZP} / 2889$, seta: $\mathrm{AA}=$ Músculo adutor anterior.

Tambaquyra camargoi (Beurlen), 1954

10 , molde interno, vista lateral da valva direita, $\mathrm{X} 0.6$, $\mathrm{DZP} / 2250$, seta: $\mathrm{AA}=$ Músculo adutor anterior; 11 , esquema gráfico, vista lateral da valva direita mostrando musculatura adutora anterior, DZP/2250; 12, molde externo, vista lateral da valva direita mostrando ornamentação concêntrica, X 1.4, DZP 2895 . 


\section{ESTAMPA I}
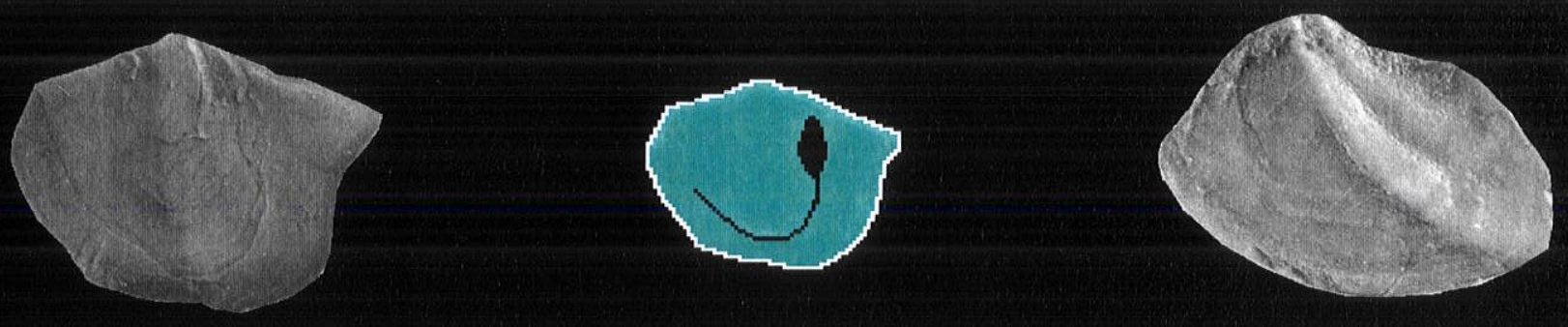

1

2

3
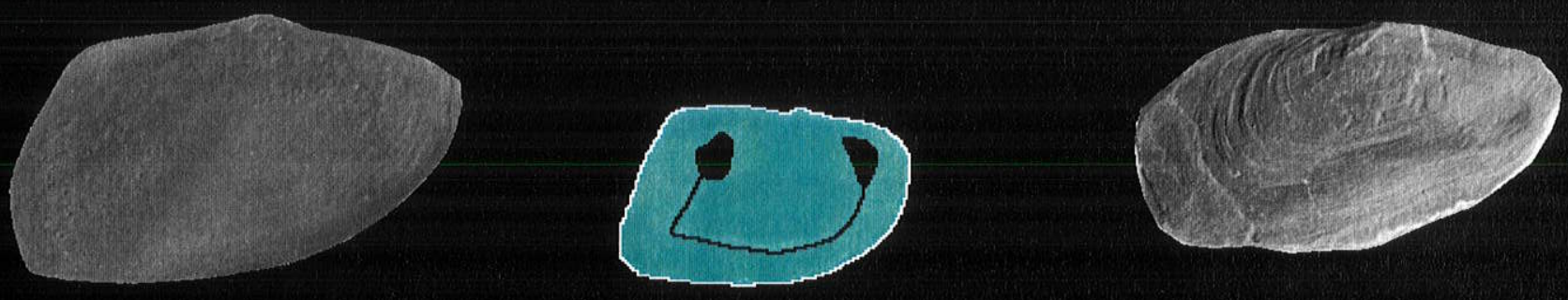

4

5

6
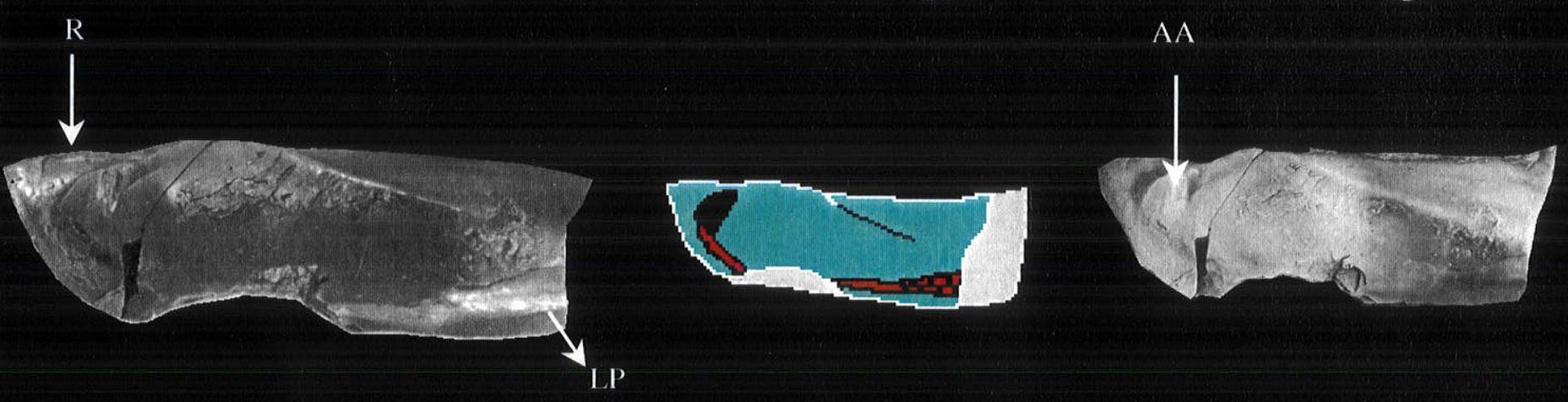

7

8

9
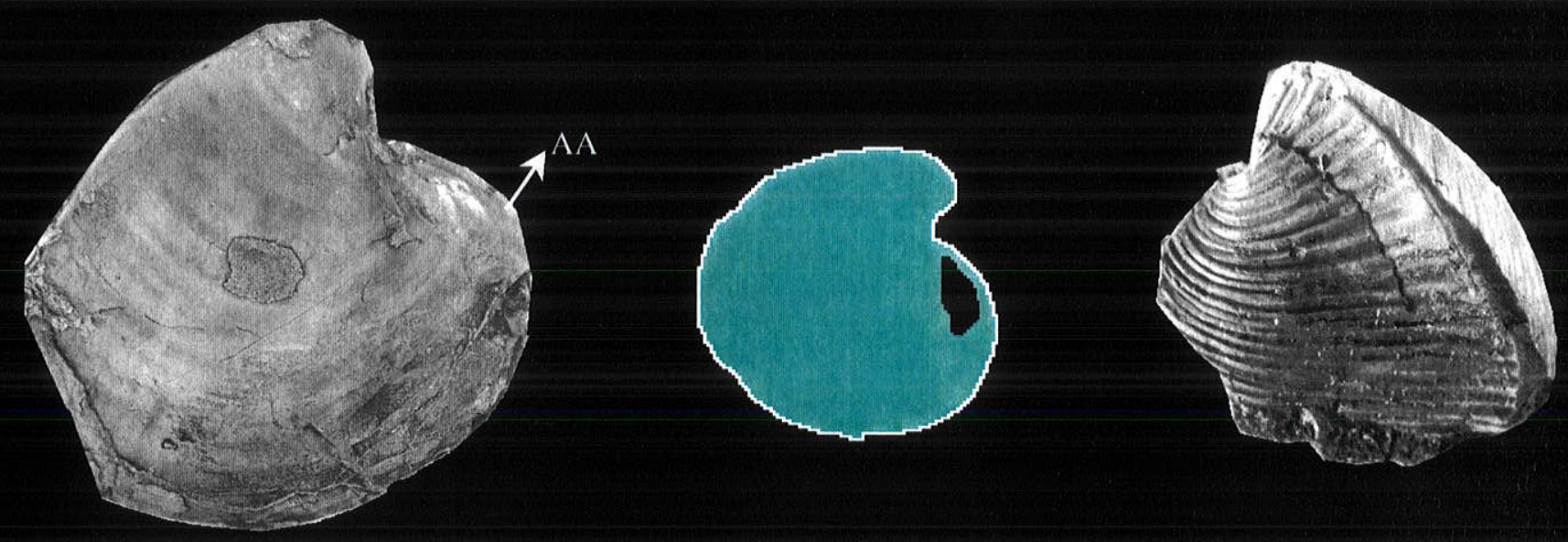

10

11 


\section{ESTAMPA II}

Fig. 1

Fig. 2

Fig. 3

Fig. 4

Figs. 5-6

Fig. 7

Figs. 8-9

Fig. 10

Figs. 11-12
Othonella araguaiana Mendes, 1963

1 , concha silicificada, vista lateral da valva direita, X $1.3, \mathrm{DZP}$ 2764.

Favalia arcuata Mendes, 1962

2, concha silicificada, vista lateral da valva direita mostrando forma laminar da concha, X 1.9, GP1T/954.

Runnegariella fragilis Simões \& Anelli, 1995

3 , concha silicificada, vista lateral da valva mostrando porção anterior da concha expandida, X 3.6, DZP 833.

Itatamba paraima Simões et al., 1997

4, concha silicificada, vista lateral da valva esquerda, X 1.3, DGP 7-947.

Pinzonella illusa Reed, 1932

5 , concha silicificada, vista interna da valva direita mostrando musculatura adutora anterior e linha integropaliada, X 2.5, DZP $20 ; 6$, concha silicificada, vista dorsal das valvas conjugadas mostrando maior largura meso-posterior, X 2.5, não catalogada.

Casterella gratiosa Mendes, 1952

7 , molde interno, vista interna da valva direita, X 1.8, DZP 472, seta: $\mathrm{SP}=$ Sinus palial.

Plesiocyprinella carinata Holdhaus, 1918

8 , concha silicificada, vista lateral da valva esquerda, $\mathrm{X} 2$, AMNH 28976; 9, concha silicificada, vista dorsal das valvas conjugadas mostrando maior largura meso-posterior e obesidade pronunciada, X 1.6, DGM 5020-1.

Ferrazia cardinalis Reed, 1932

10, concha silicificada, vista lateral da valva esquerda mostrando ornamentação radial, X 1.4, DGP 7-958.

Roxoa corumbataiensis Mendes, 1952

11, concha silicificada, vista lateral da valva esquerda, $X 3$, GP1T/65; 12, concha silicificada, vista dorsal das valvas conjugadas mostrando a forma da concha cilíndrica e grande descontinuidade sifonal, X 1.6, GP1T/65. 


\section{ESTAMPA II}
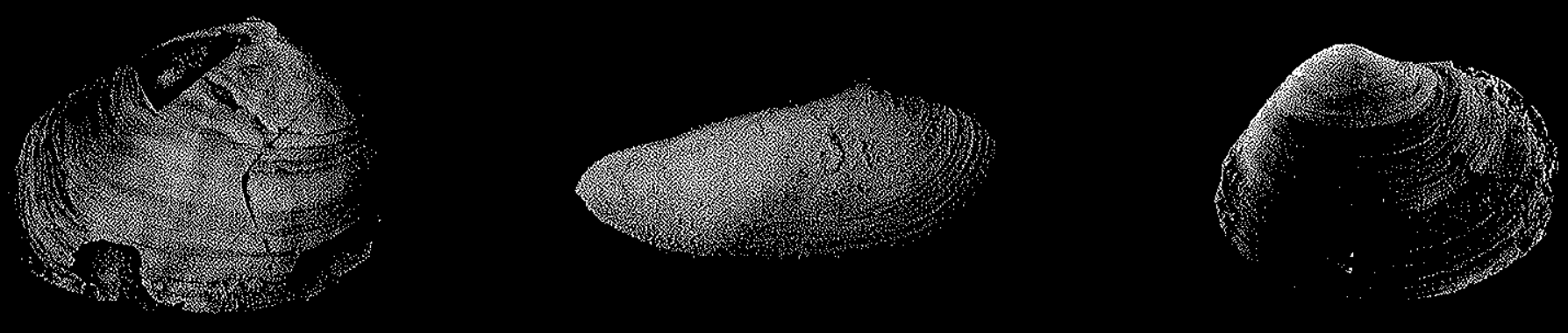

2

3

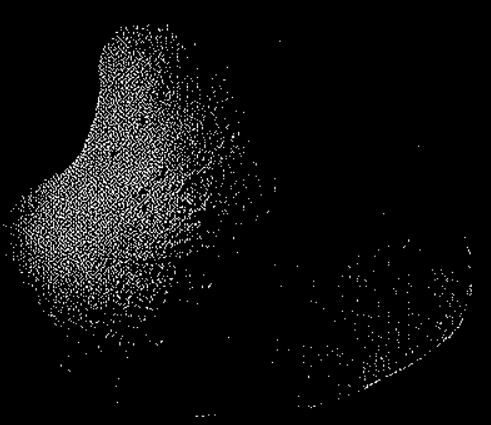

4
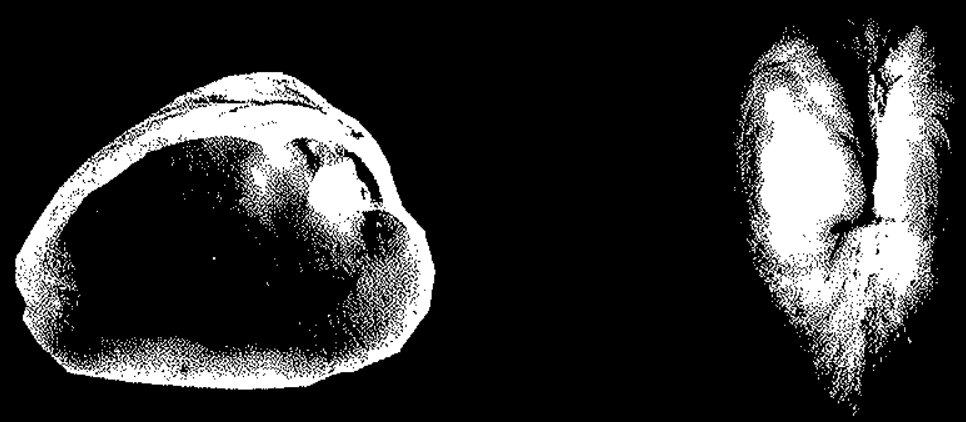

5

6
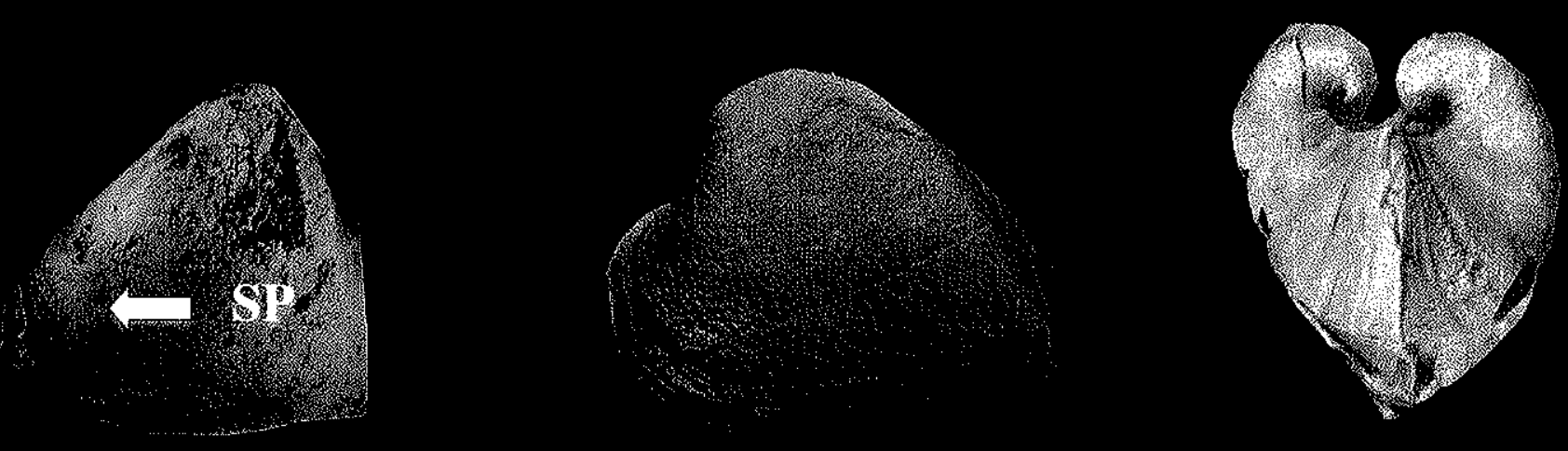

7

8

9
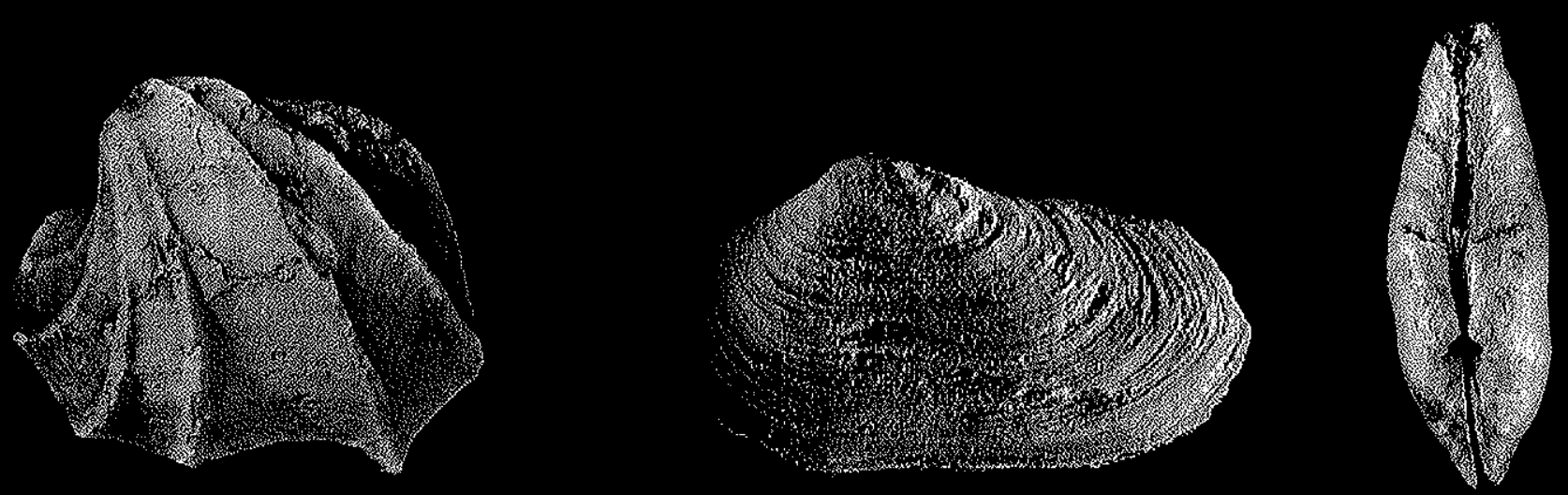


\section{ESTAMPA III}

Fig. 1

Fig. 2

Fig. 3

Fig. 4

Fig. 5

Fig. 6

Figs. 7-8

Fig. 9

Figs. 10-11

\author{
Angatubia cowperesioides Mendes, 1962 \\ 1 , concha silicificada, vista lateral da valva direita, $\mathrm{X} 3.8$, \\ GP1T/945.
}

Cowperesia anceps (Reed), 1935

2 , concha silicificada, vista lateral da valva direita mostrando forte ornamentação concêntrica em seção, X 3.2, DGP 7/52, seta: Or= ornamentação concêntrica.

Coxesia mezzalirai Mendes, 1952

3 , concha silicificada, vista lateral da valva direita mostrando forma "mitilóide" da concha, X 2.5, DGM 4025.

Holdhausiella elongata (Holdhaus), 1918 4, concha silicificada, vista lateral da valva esquerda, X 2.3,
DZP 2750 .

Terraiopsis aequilateralis (Mendes), 1952

5 , concha silicificada, vista interna da valva direita mostrando dentição heterodonta, setas: $\mathrm{AA}=$ Músculo adutor anterior, $\mathrm{LP}=$ Linha palial, X 2.3, DGP, não catalogada.

Pinzonella neotropica (Reed), 1928 6, concha silicificada, vista lateral da valva esquerda, X 2.7 ,
DZP 2669 .

Naiadopsis lamellosus Mendes, 1952

7, concha silicificada, vista lateral da concha esquerda, X 1.4, DZP 1109, seta: musculatura adutora anterior; 8 , concha silicificada, vista dorsal das valvas conjugadas mostrando maior largura na região central das conchas, X 1.4, DZP 1972.

Jacquesia brasiliensis (Reed), 1929

9, molde interno, vista lateral da valva esquerda, X 1.6, DZP 1791.

Roxoa intricans (Mendes), 1944

10 , concha silicificada, vista lateral da valva direita, $X 3.4$, DGP

$7 / 64 ; 11$, concha silicificada, vista interna da valva direita, $X$ 2.4, DGM 40/6, seta: $\mathrm{SP}=$ Sinus palial. 


\section{ESTAMPA III}
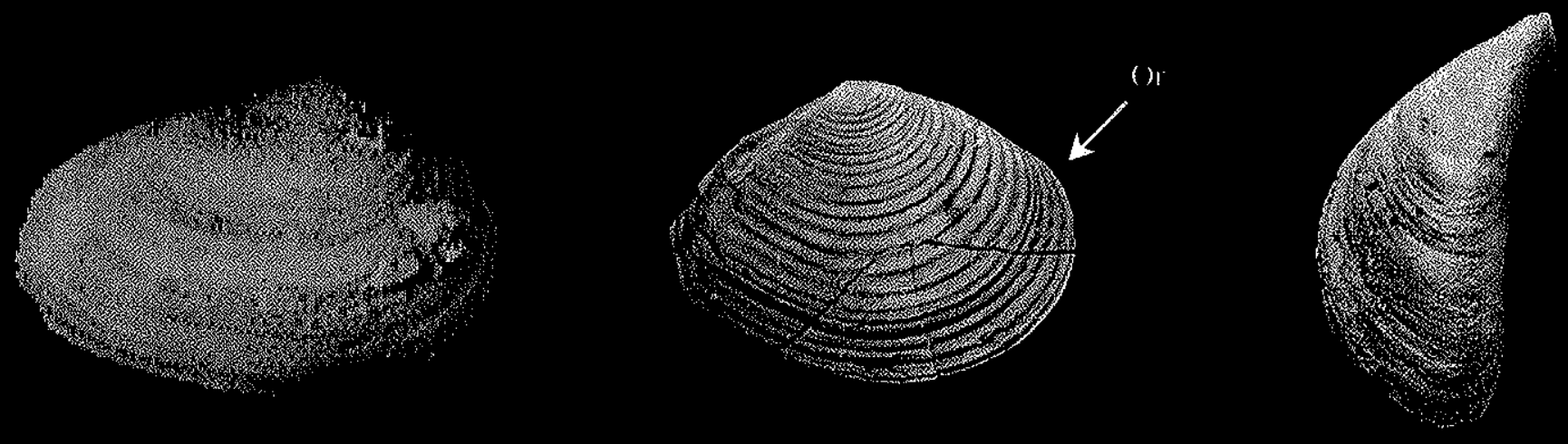

2

3
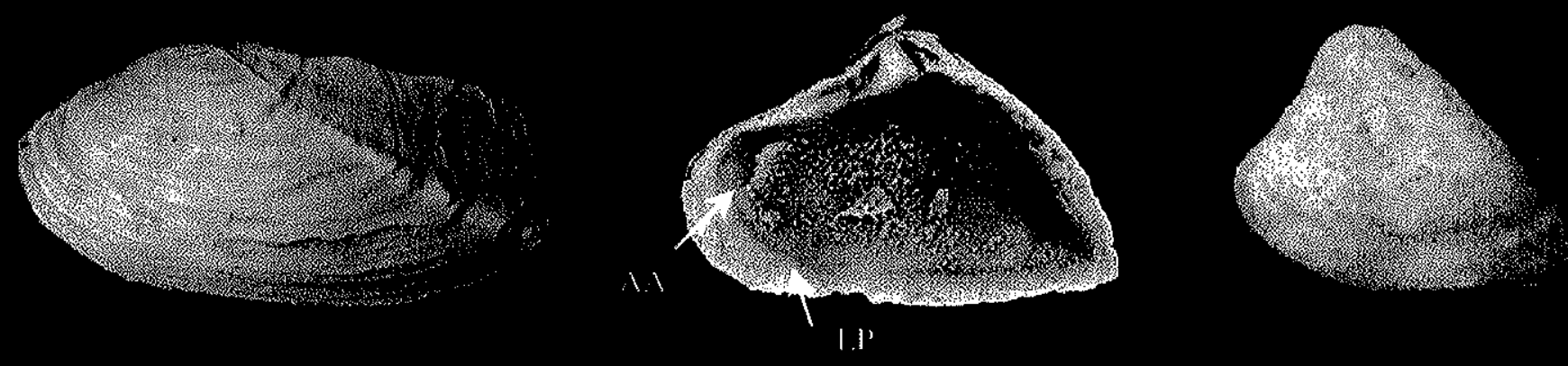

4

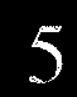

6
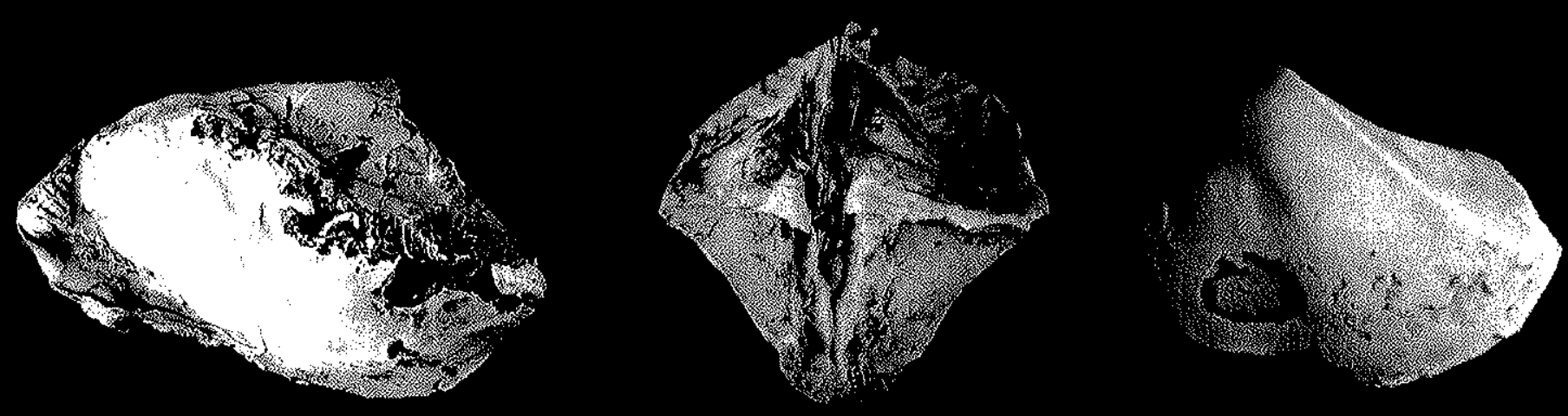

7

8

9
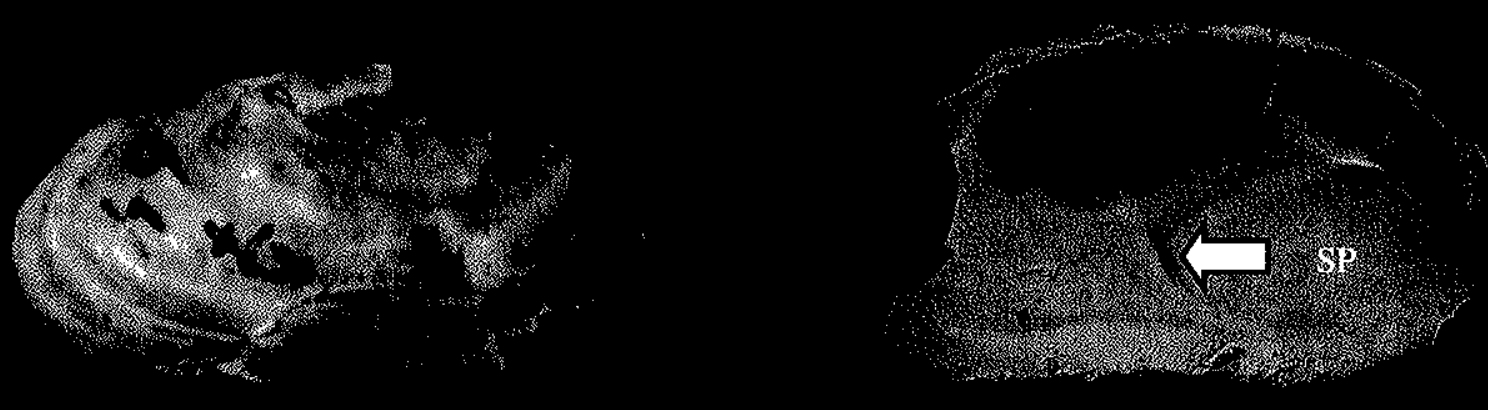